\title{
IUCN
}

\section{National Red data book of mammals in Jordan}

Ehab Eid, Mohammad Abu Baker and Zuhair Amr 


\section{National Red data book of mammals in Jordan}

Ehab Eid, Mohammad Abu Baker and Zuhair Amr 
The designation of geographical entities in this book, and the presentation of the material, do not imply the expression of any opinion whatsoever on the part of IUCN concerning the legal status of any country, territory, or area, or of its authorities, or concerning the delimitation of its frontiers or boundaries.

The views expressed in this publication do not necessarily reflect those of IUCN.

IUCN is pleased to acknowledge the support of its Framework Partners who provide core funding: Ministry for Foreign Affairs of Finland; Government of France and the French Development Agency (AFD); the Ministry of Environment, Republic of Korea; the Norwegian Agency for Development Cooperation (Norad); the Swedish International Development Cooperation Agency (Sida); the Swiss Agency for Development and Cooperation (SDC) and the United States Department of State.

Published by:

Copyright:

Citation:

Revised by:

ISBN:

DOI:

Maps prepared by:

Cover photo:

Back cover photo:

Layout by:

Available from:
IUCN Regional Office for West Asia, Amman, Jordan

(C) 2020 IUCN, International Union for Conservation of Nature and Natural Resources

Reproduction of this publication for educational or other noncommercial purposes is authorised without prior written permission from the copyright holder provided the source is fully acknowledged.

Reproduction of this publication for resale or other commercial purposes is prohibited without prior written permission of the copyright holder.

Eid, E., Abu Baker, M., and Amr, Z. (2020). National Red data book of mammals in Jordan. Amman, Jordan: IUCN Regional Office for West Asia Amman.

Dr. Hany El Shaer, Regional Director

Eng. Natalia Boulad, Protected Areas, World Heritage and Biodiversity Programme Manager

Eng. Hanna Haddad: Programme Assistant -Protected Areas, World Heritage and Business Programme

978-2-8317-2076-0 (PDF)

https://doi.org/10.2305/IUCN.CH.2020.12.en

Eng. Hanna Haddad

Sand cat; Felis margarita @ Shutterstock

Stone marten; Martes foina (C) Ehab Eid

Muhammad Abutarboush

IUCN, International Union for Conservation of Nature IUCN Regional Office for West Asia

Sweifiyeh, Abdel Latif Salah Street, \#29 Amman, Jordan

Tel +962 (6) 554 6912/3/4

Fax +962 (6) 5546915

Email: westasia@iucn.org

www.iucn.org/resources/publications 


\section{Table of Contents}

\section{Executive summary}

Acknowledgements

1. Background

1.1 Jordan's context

1.2 Mammals of Jordan

1.3 Extinct species of mammals

2. The national Red List assessment

2.1 Application of the IUCN Red List Categories and Criteria at the regional level 6

2.2 Assessment procedure $\quad 8$

2.3 Assessment results $\quad 8$

3. Species accounts $\quad 15$

$\begin{array}{ll}3.1 \text { Eulipotyphla } & 16\end{array}$

$\begin{array}{ll}3.2 \text { Chiroptera } & 22\end{array}$

$\begin{array}{ll}3.3 \text { Rodentia } & 50\end{array}$

$\begin{array}{ll}\text { 3.4 Carnivora } & 76\end{array}$

$\begin{array}{ll}3.5 \text { Lagomorpha } & 94\end{array}$

$\begin{array}{ll}3.6 \text { Hyracoida } & 96\end{array}$

$\begin{array}{lc}3.7 \text { Artiodactyla } & 98\end{array}$

$\begin{array}{lr}\text { 4. Threats } & 109\end{array}$

4.1 Illegal hunting and persecution $\quad 110$

$\begin{array}{ll}4.2 \text { Habitat loss and degradation } & 110\end{array}$

5. Conservation measures $\quad 113$

$\begin{array}{ll}5.1 \text { In situ conservation measures } & 114\end{array}$

5.1.1 Legal framework $\quad 114$

$\begin{array}{ll}\text { 5.1.2 Protected areas } & 115\end{array}$

$\begin{array}{ll}\text { 5.1.3 Special conservation areas } & 115\end{array}$

5.2 Ex situ conservation measures 116

5.2.1 Al Mawa for Nature and Wildlife $\quad 116$

5.2.2 Captive breeding and re-introduction programmes $\quad 116$

5.3 Public awareness 116

$\begin{array}{ll}\text { Recommendations } & 119\end{array}$

$\begin{array}{ll}\text { References } & 121\end{array}$ 



\section{Executive summary}

This is the first national Red List assessment of the 85 mammalian species, reported from Jordan. The aim was to assess the national conservation status of the terrestrial mammals in Jordan. The information provided in this text will help to put local conservation priorities into a national context, thus maximizing the effectiveness of conservation measures, and facilitating the development of integrated national conservation strategies. This Red List publication summarizes results for terrestrial mammals, and provides the first overview of the conservation status of these species to follow IUCN Regional Red Listing guidelines. It identifies species that are threatened with extinction at the regional level in order that appropriate conservation action can be taken to improve their status.

A national workshop was conducted and supported by the Regional Office for West Asia of the International Union for Conservation of Nature (IUCN ROWA) where all mammalian species have been assessed according to the IUCN categories and criteria (IUCN, 2001) and the guidelines for application of IUCN Red List Criteria at Regional Level (IUCN, 2003). A taxon data sheet was compiled for each species, as well as a detailed distribution map.

A total of 33 species (39\%) out of the 85 assessed species are considered threatened, of which, ten are Critically Endangered, 20 are Endangered, and three are Vulnerable. In addition, five (6\%) were considered to be Near Threatened, three (3\%) are Data Deficient, 38 are Least Concern and six Regionally Extinct representing 7\% of the assessed species.

According to the assessment results, the majority of species are in danger. The main threat to all mammalian species is indiscriminate and sustained persecution through hunting, trapping and poisoning. Other threats include habitat destruction and degradation through overgrazing, expansion of roads and settlements and commercial and industrial development. The main conservation efforts highlighted in the establishment of several conserved areas including protected areas and special conservation areas, and mammals are surviving within.

Effective law enforcement is needed where more staff should be allocated and trained. A sustained public awareness campaign is also required across Jordan to highlight the ecological importance of mammals and to counter the prevailing negative attitude towards them. Research on the ecology, population and conservation status of mammals is needed and should be encouraged through academic institutions. Establishing a natural history museum and a zoological garden is a tool to enhance the cooperation and documentation of records, as well as increase public awareness. 


\section{Acknowledgements}

We are grateful to our host organizations, IUCN (International Union for Conservation of Nature) and IUCN's Regional Office for West Asia (IUCN ROWA), for their support and encouragement to have this publication inhand. Special thanks extended to Dr. Hany El Shaer; Regional Office Director who welcomed this publication and made it available. Thanks are also extended to Mrs. Natalia Boulad; Protected Areas and Biodiversity Programme Manager for her constant support, and advise. We would like to extend our appreciation to Eng. Hanna Haddad; Protected Areas, World Heritage and Business Programme Assistant who is extremely appreciated for preparing all maps, and for his kind follow-up to the whole process of issuing this book. Appreciation goes to Mrs. Anwar Abu Sakkeih and Mrs. Ola Mallah for their kind support.

Special thanks go to the assessment reviewers represented by Dr. Nashat Hamidan from the Royal Society for the Conservation of Nature and Dr. Zafar Islam from the Saudi Wildlife Authority. Their comments, feedback and notes helped to shape the content of this document. Thanks is also extended to Ms. Sandra Habib for her efforts in editing and proof reading the document.

The production of this book would not have been possible without the support and commitment of a large community of scholars and experts on Jordanian mammals.

The mammals of Jordan assessment was entirely dependent on experts and contributors from Jordan, who generously gave their time and knowledge. Their enthusiasm and commitment to species conservation has enabled us to generate a comprehensive and detailed picture of the mammalian status and trends in Jordan. Authors acknowledge Mr. Thabit Al Share and Mr. Omar Abed from the Royal Society for the Conservation of Nature (RSCN) as well as Mr. Laith El Moghrabi; external expert for their contribution and participation during the assessment workshop.

Authors acknowledge and appreciate the valuable support provided by Mr. Craig HILTON-TAYLOR; Head, Red List Unit, Species Cambridge Unit, and Mr. David ALLEN; Regional Biodiversity Assessment Officer, Species Cambridge Unit especially in revising the document and providing their inputs and advices.

Finally, we acknowledge all efforts made in Jordan to conserve species and habitats. To that end, we extend our appreciation to the Ministry of Environment, and its nature conservation department for their fundamental role in issuing national policies and legal framework, which guide the nature conservation field in Jordan. In addition, we acknowledge the extraordinary role of the Royal Society for the Conservation of Nature in establishing and managing the protected areas network in Jordan. The role of other entities such as Al Ma'wa for Nature and Wildlife / Princess Alia Foundation, which provide shelters and sanctuary for rescued animals, is gratefully acknowledged. We appreciate also the valuable and vital efforts performed by the Royal Department for Nature Protection in law enforcement, and providing the legal mechanism to protect species and habitats. We take this opportunity to offer our apologies to any entity whose contribution in conserving mammalian species we may have unwittingly unacknowledged. 



\subsection{Jordan's context}

Jordan lies at the center of the Eastern Mediterranean region, also known as the Levant. It sits strategically at the crossroads of three continents: Asia, Africa and Europe, with a total area of 89,341 $\mathrm{km}^{2}$ (Amr, 2012). Mountains run along Jordan's entire western side bordering the east bank of the upper Rift Valley in the Jordan River and Wadi Araba. The eastern and southern boundaries are difficult to define ecologically, as the habitats merge gradually into the Syrian and the Arabian deserts.

The Highlands in the northwest above the Jordan Valley are dominated arable land that surround fragmented patches of Mediterranean evergreen forests that drop suddenly into the Jordan Rift Valley. At the center, east of the Dead Sea (the lowest point in the country at $-420 \mathrm{~m}$ below sea level), the Mediterranean mountains run south to the Ras Al-Naqab where steep wadis containing species of Ficus, Cordia, and Tamarindus and patches of juniper forests remain (Al Eisawi, 1996). Further south, the composition of the mountains converts totally into sandstone and granite as far south as Jabal Umm al Dami, the highest peak in the country at 1,854 $\mathrm{m}$ above sea level. The climate in Jordan varies greatly between the cool Mediterranean inland into the arid, warm deserts in the east and southeast (Al Eisawi, 1996).

\subsection{Mammals of Jordan}

Our knowledge on the diversity and species richness of mammals in Jordan is a result of continuous efforts over the past 50 years (Atallah, 1977, 1978; Harrison \& Bates, 1991; Qumsiyeh, 1996; Amr, 2000; Benda et al., 2010; Amr, 2012). So far, 83 species of mammals have been recorded in Jordan, belonging to seven orders (Eulipotyphla, Chiroptera, Carnivora, Hyracoidea, Artiodactyla, Lagomorpha and Rodentia). Chiropterans and rodents represent the highest diversity of known species, while lagomorphs and hyracoids are each represented by a single species. The bats of Jordan have been recently reviewed extensively based on new and previous records, echolocation and molecular data (Benda et al., 2010). Amr (2012) represents the most comprehensive and recent review of the mammals of Jordan based on their systematics, distribution, and ecology.

Jordan's location at the junction point of three different faunal elements, which are the African, Oriental and Palearctic has supported the presence of remarkable diversity of mammalian species of different zoogeographical affinities (Amr, 2012). In addition, the location represents biogeographic boundaries for the extreme distribution limit of several Afrotropical species that penetrate north through the Rift Valley such as rock hyrax (Procavia capensis) and Egyptian fruit bat (Rousettus aegyptiacus). Also Palearctic mammals that extend south into the Mediterranean mountains in Tafila and Petra including the European hedgehog (Erinaceus concolor); Persian squirrel (Sciurus anomalus); broad-toothed field mouse (Apodemus mystacinus); and the common badger (Meles meles) exists in Jordan as well as Oriental species such as Blanford's fox Nulpes cana) and Cheesman's gerbil (Gerbillus cheesmani) (Amr, 2000). The diversity of mammals is also supplemented by the occurrence of several wide-ranging species such as the Arabian wolf (Canis lupus) (Amr, 2000; Amr, 2012).

Many forms exemplify biome-restricted and habitat-restricted species, where wood mice, (Apodemus sp.); stone marten (Martes foina) and some horseshoe bats (Rhinolophus sp.) are found only in the wooded areas of the Mediterranean mountains. Other species such as Cheesman's gerbil (Gerbillus cheesmani) is an inhabitant of the sand dunes islands that are scattered across the deserts, whereas spiny mice (Acomys sp.) and the Nubian ibex (Capra nubiana) are confined to the rocky habitats (Amr, 2012). Earlier geological periods have created relict populations of some species, where the arboreal Asian garden dormouse (Eliomys melanurus) can still be found in the rocky habitats of Wadi Rum and the eastern desert and a wide ranging population of golden spiny mouse (Acomys russatus) in a melanistic form as the black spiny mouse (A. russatus lewisi) is found in black lava desert east of Jordan. 


\subsection{Extinct species of mammals}

Several species of mammals have become extinct from in Jordan. The historical records of the aurochs (Bos primigenius), were reported from ancient strata (about 7000 B.C.E) from Jericho (Qumsiyeh et al., 1996). The Pleistocene presence of the Addax (Addax nasomaculatus) and the bubale (Alcelaphus buselaphus) is documented (Bate, 1937). The exact time when these species became extirpated in the eastern Mediterranean region is unknown; the remaining small populations may have existed during the Roman period with the bubale perhaps surviving to the 19th century (Bodenheimer, 1958). Remains of the red deer (Cervus elaphus) were excavated at Tel Hesbon in layers from the $12^{\text {th }}$ to the $15^{\text {th }}$ century C.E. (Boessneck \& Von Den Driesch, 1978). The roe deer (Capreolus capreolus) and fallow deer (Dama mesopotamica) were common in late Paleolithic caves in Palestine (Bate, 1937 ) and through the $7^{\text {th }}$ to $6^{\text {th }}$ century B.C.E. in Jordan (Boessneck \& Von Den Driesch, 1978), whereas both species disappeared perhaps in the $19^{\text {th }}$ or $20^{\text {th }}$ century. The wild ass (Equus hemionus hemippus) and fallow deer (Dama mesopotamica) became extinct by the early 1920's, while the Syrian bear (Ursus arctos syriacus) also become extinct by 1941. The last Arabian oryx (Oryx leucoryx) was shot in the 1940's. The cheetah (Acinonyx jubatus) and perhaps the Arabian leopard (Panthera pardus nimr) appear to have survived in very small numbers, and Nubian ibex (Capra nubiana) are said to be numerous in the more inaccessible mountains (Fitter, 1967; Amr, 2012).

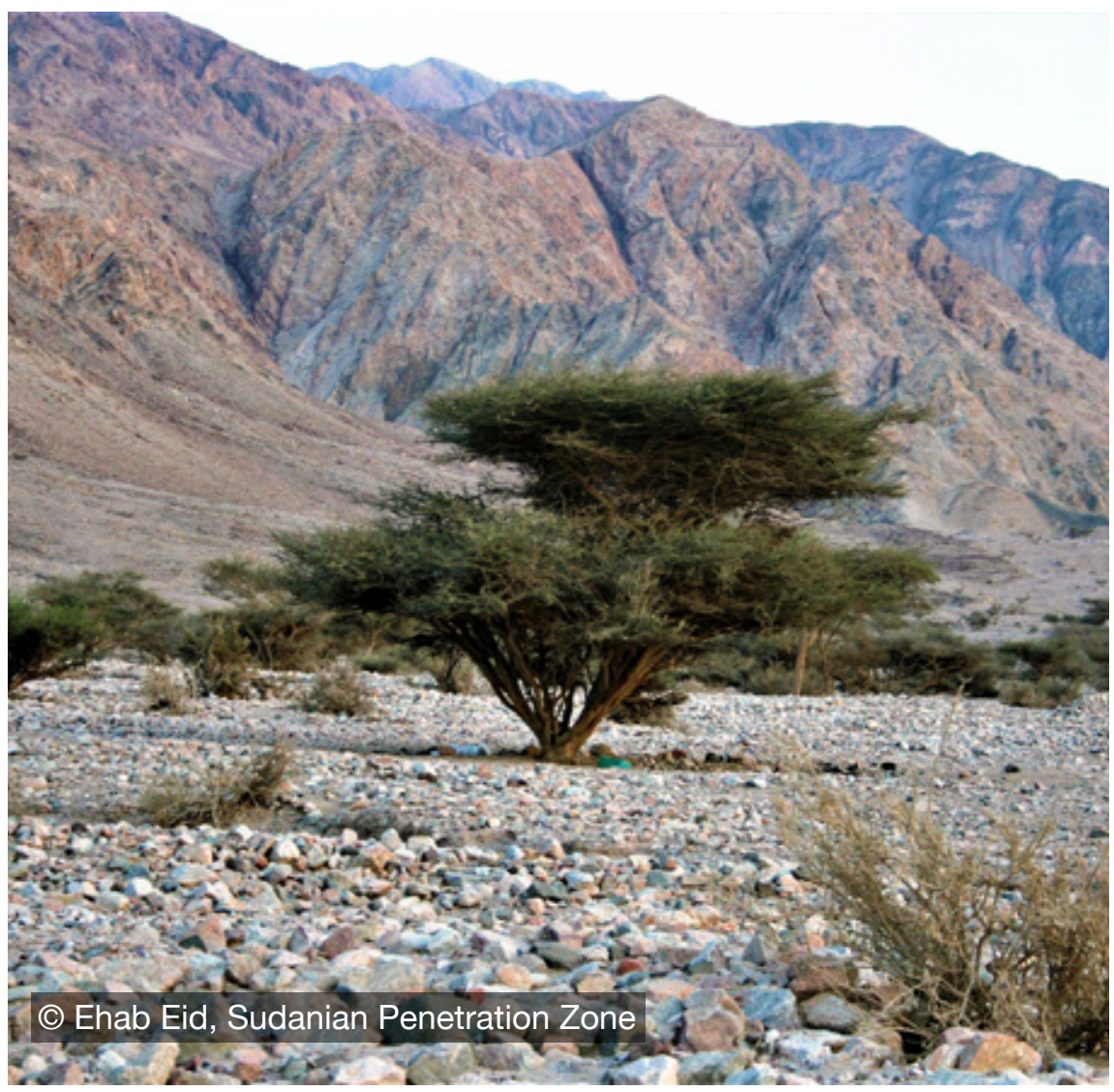




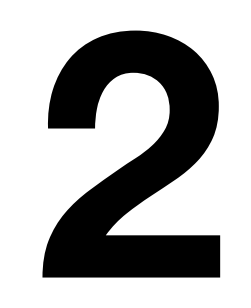

\section{The national Red List assessment}




\subsection{Application of the IUCN Red List Categories and Criteria at the regional level}

Red Lists have been in existence for nearly 60 years (Baillie and Groombridge, 1996). They are often considered the first step in setting priorities for conservation actions and focusing attention on threatened species (Lamoreux et al., 2003). The 'IUCN Red List Categories and Criteria' (IUCN, 2001) are now recognised as an international standard, and used by many countries and organisations worldwide.

The Guidelines for Application of IUCN Red List Criteria at Regional and National Levels: Version 4.0 was applied in conjunction with guidelines for Application of IUCN Red List Criteria at Regional Levels: Version 3.1 (IUCN, 2001, 2012) and the latest version of the Guidelines for Using the IUCN Red List Categories and Criteria. These guidelines assess the risk of regional extinction, and therefore address a number of issues not encountered when conducting assessments on a global scale. Figure 1 and Table 1 (below) illustrate the criteria used in the Red List.

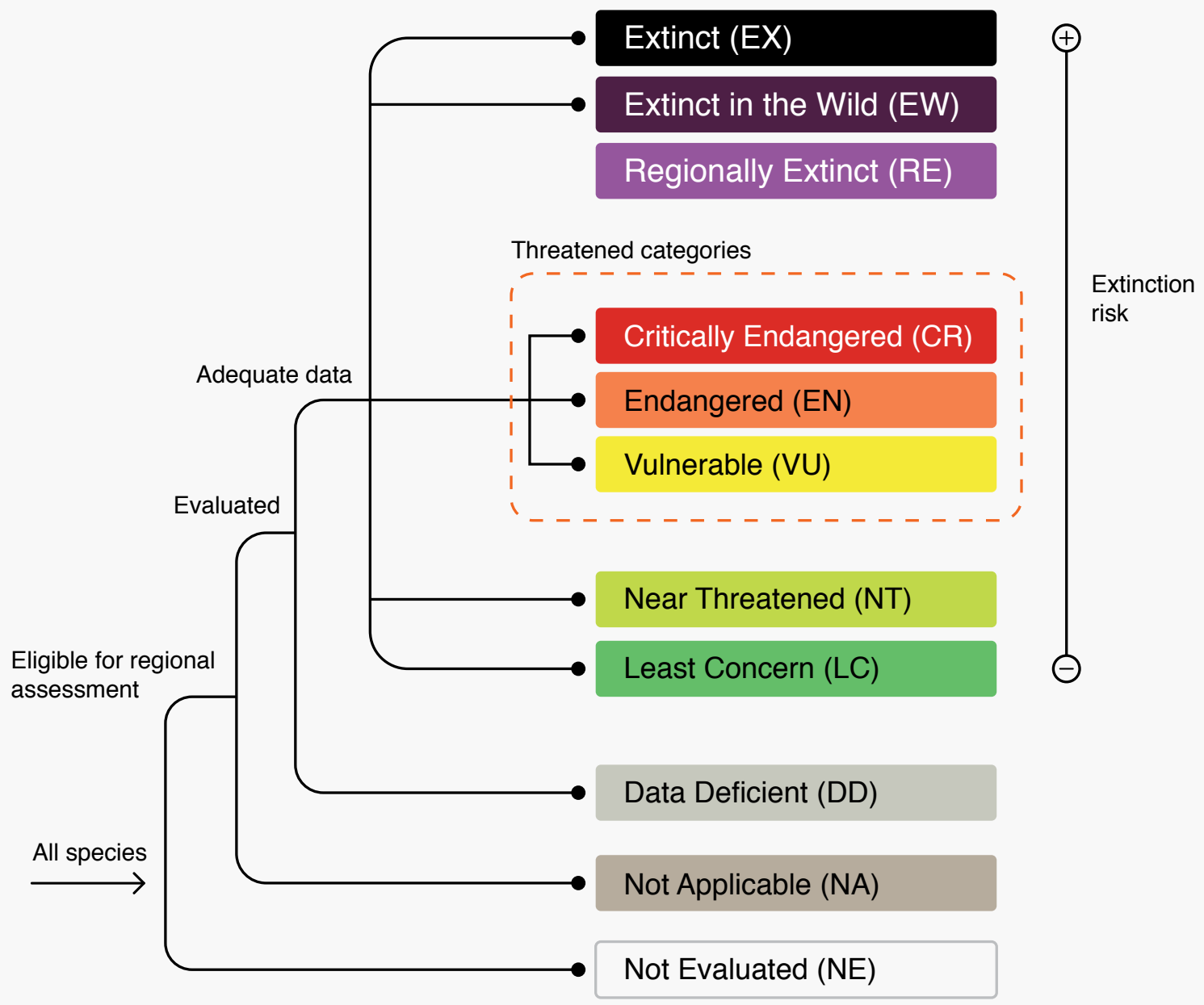

Figure 1: IUCN Red List Categories at the regional level (IUCN, 2003) 
Table 1. Definition of the categories used in the Red List (IUCN 2001; 2003).
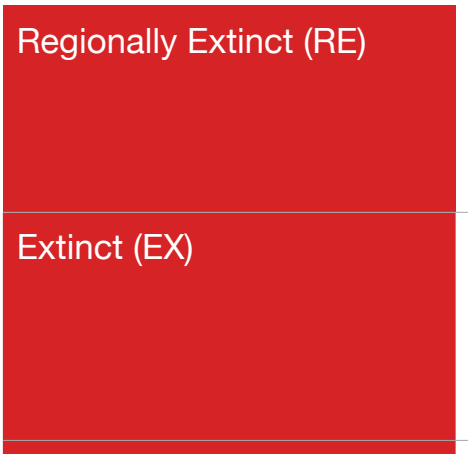

Extinct in the Wild (EW)

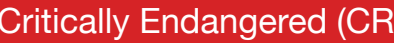

Endangered (EN)

Vulnerable (VU)

Near Threatened (NT)

Least Concern (LC)

Data Deficient (DD)

A taxon is RE when there is no reasonable doubt that the last individual potentially capable of reproduction within the region has died or disappeared from the region or, in the case of a former visiting taxon, individuals no longer visit the region.

A taxon is Extinct when there is no reasonable doubt that the last individual has died. A taxon is presumed Extinct when exhaustive surveys in known and/or expected habitat, at appropriate times (diurnal, seasonal, annual), and throughout its historic range have failed to record an individual. Surveys should be over a time frame appropriate to the taxon's life cycle and life form.

A taxon is Extinct in the Wild when it is known only to survive in cultivation, in captivity or as a naturalised population (or populations) well outside the past range. A taxon is presumed Extinct in the Wild when exhaustive surveys in known and/or expected habitat, at appropriate times (diurnal, seasonal, annual), and throughout its historic range have failed to record an individual. Surveys should be over a time frame appropriate to the taxon's life cycle and life form.

A taxon is Critically Endangered when the best available evidence indicates that it meets any of the criteria A to $E$ for Critically Endangered, and it is therefore considered to be facing an extremely high risk of extinction in the wild.

A taxon is Endangered when the best available evidence indicates that it meets any of the criteria $\mathrm{A}$ to $\mathrm{E}$ for Endangered and it is therefore considered to be facing a very high risk of extinction in the wild.

A taxon is Vulnerable when the best available evidence indicates that it meets any of the criteria A to $E$ for Vulnerable and it is therefore considered to be facing a high risk of extinction in the wild.

A taxon is Near Threatened when it has been evaluated against the criteria but does not qualify for Critically Endangered, Endangered or Vulnerable now, but is close to qualifying for or is likely to qualify for a threatened category in the near future.

A taxon is Least Concern when it has been evaluated against the criteria and does not qualify for Critically Endangered, Endangered, Vulnerable or Near Threatened. Widespread and abundant taxa are included in this category.

A taxon is Data Deficient when there is inadequate information to make a direct, or indirect, assessment of its risk of extinction based on its distribution and/or population status. A taxon in this category may be well studied, and its biology well known, but appropriate data on abundance and/or distribution are lacking. Data Deficient is therefore not a category of threat. Listing of taxa in this category indicates that more information is required and acknowledges the possibility that future research will show that threatened classification is appropriate. It is important to make positive use of whatever data are available. In many cases great care should be exercised in choosing between DD and a threatened status. If the range of a taxon is suspected to be relatively circumscribed, and a considerable period of time has elapsed since the last record of the taxon, threatened status may well be justified. 


\subsection{Assessment procedure}

This is the first national Red List assessment for the mammals of Jordan. A workshop was held at IUCN's Regional Office for West Asia / Regional Office for West Asia (IUCN ROWA) to assess the status of all mammalian species of Jordan according to the IUCN categories and criteria (IUCN, 2001) and the guidelines for application of IUCN Red List Criteria (Figure 1) at Regional Level (IUCN, 2003). Fauna experts representing the academia, NGOs and experts in Red Listing have participated in the assessment process. A taxon data sheet was compiled for each species, as well as a detailed distribution map.

The first step entailed reviewing the list of Jordan's mammals using the Guidelines for Application of IUCN Red List Criteria at Regional Levels (IUCN, 2003) (Figure 1). 80 species were applicable for assessment and assessed during the workshops (Table 1, Figure 1). Five species were identified as Not Applicable for the national assessment, four of which were considered as introduced species including house mouse; Mus musculus, brown rat; Rattus norvegicus; black rat; Rattus rattus and the coypu, Myocastor coypus. In addition, The Melanistic or Lewis's spiny mouse; Acomys russatus lewisi was not assessed as it is a sub-species according to the latest assessment (Amr, 2000), and it was instead assessed at the species level.

Information available on species' distributions and populations is generally very limited. There are no systematic long-term monitoring programmes in Jordan to generate accurate estimates of rates of population decline. Current maps are mainly based on available knowledge or extrapolations from a relatively small number of known sites. Consequently, Red List assessments frequently relied on trends that were inferred suspected or estimated (IUCN 2008).

\subsection{Assessment results}

A total of 33 species (39\%) out of the 85 assessed species are considered threatened, of which, ten are Critically Endangered, 20 are Endangered, and three are Vulnerable. In addition, five (6\%) were considered to be Near Threatened, three (3\%) are Data Deficient, 38 are Least Concern (45\%), and six Regionally Extinct representing $7 \%$ of the assessed species. (Figure 2; Table 2).

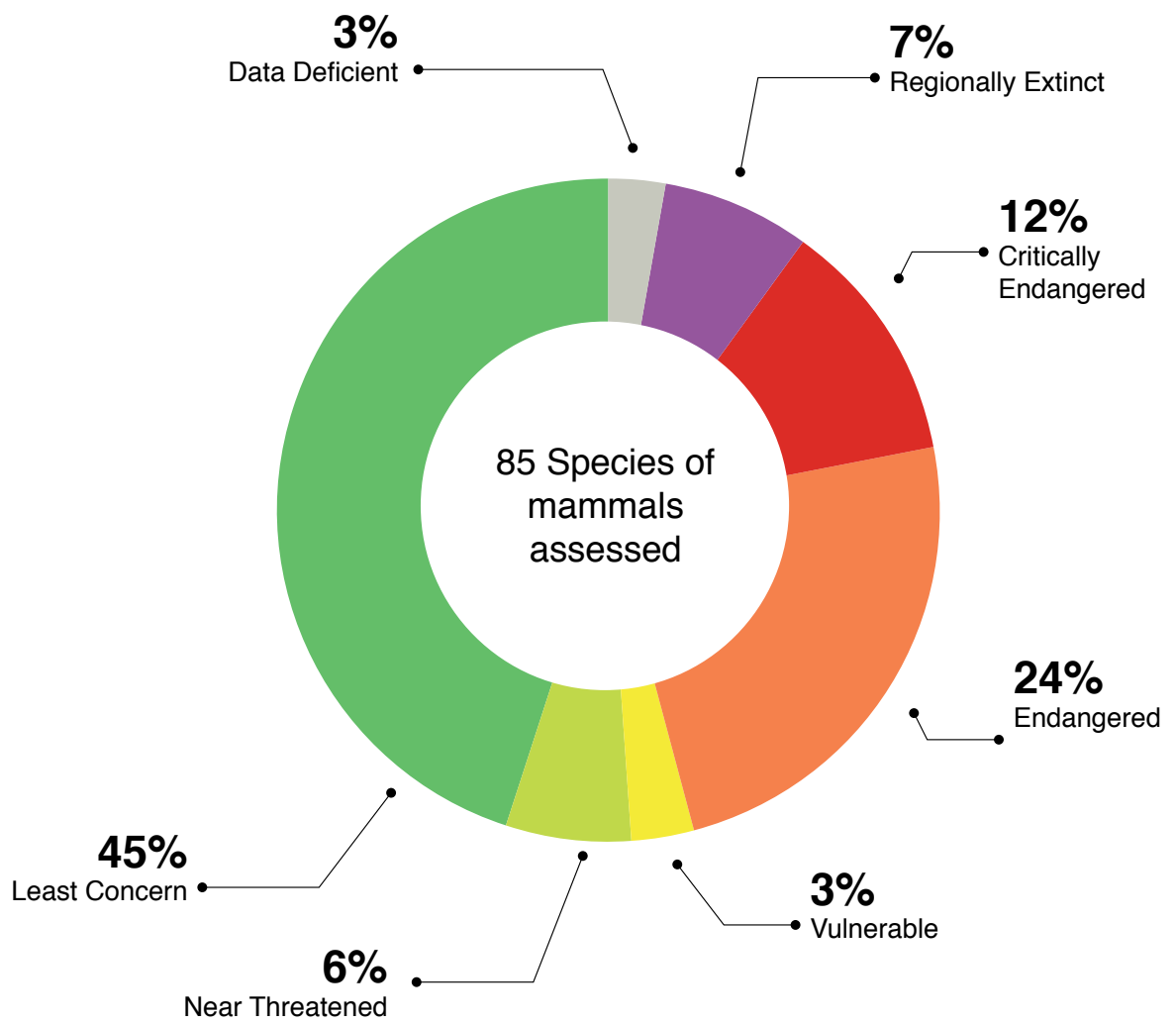

Figure 2. Red List status of the mammals in Jordan. 
Almost $40 \%$ of the species assessed are threatened at the national level, if compared to only $10 \%$ threatened globally (Table 2). This is due to the limited scale of Jordan total area, and the level of impact imposed on species at the national level. The Artiodactyla and Carnivora group recorded the highest number of threatened species (Table 2).

Table 2. National Red List status of mammals in Jordan, 2020. (Note: ${ }^{\circ}$ refer to species with status downlisted)

\begin{tabular}{|c|c|c|c|c|c|}
\hline$\#$ & Species & Common Name & $\begin{array}{l}\text { National } \\
\text { Status }\end{array}$ & $\begin{array}{l}\text { Global } \\
\text { Status, } 2020\end{array}$ & $\begin{array}{l}\text { Population Trend } \\
\text { in Jordan }\end{array}$ \\
\hline 1 & Oryx leucoryx & Arabian oryx & RE & VU & \\
\hline 2 & Dama mesopotamica & Fallow deer & RE & EN & \\
\hline 3 & Equus hemionus hemippus & Wild ass & RE & NT & \\
\hline 4 & Ursus arctos syriacus & Syrian bear & $\mathrm{RE}$ & LC & \\
\hline 5 & Acinonyx jubatus & Cheetah & RE & VU & \\
\hline 6 & Panthera pardus nimr & Arabian leopard & RE & VU & \\
\hline 7 & Rhinolophus mehelyi & Mehely's horseshoe bat & CR & VU & Decreasing \\
\hline 8 & Gerbillus andersoni & Anderson's gerbil & $\mathrm{CR}$ & LC & Decreasing \\
\hline 9 & Caracal caracal & Caracal & $\mathrm{CR}$ & LC & Decreasing \\
\hline 10 & Felis chaus & Jungle cat & CR & LC & Decreasing \\
\hline 11 & Felis margarita & Sand cat & $\mathrm{CR}$ & LC & Decreasing \\
\hline 12 & Lutra lutra & Eurasian otter & $\mathrm{CR}$ & NT & Decreasing \\
\hline 13 & Gazella dorcas & Dorcas gazelle & CR & VU & Decreasing \\
\hline 14 & Gazella gazella & Mountain gazelle & $\mathrm{CR}^{\circ}$ & EN & Decreasing \\
\hline 15 & Gazella marica & Goitered gazelle & $\mathrm{CR}$ & VU & Decreasing \\
\hline 16 & Capreolus capreolus & Roe deer & $\mathrm{CR}$ & LC & Decreasing \\
\hline 17 & Rhinolophus ferrumequinum & Greater horseshoe bat & EN & LC & Decreasing \\
\hline 18 & Rhinopoma microphyllum & Greater mouse-tailed bat & EN & LC & Decreasing \\
\hline 19 & Taphozous perforatus & Egyptian tomb bat & EN & LC & Decreasing \\
\hline 20 & Taphozous nudiventris & Naked-rumped tomb bat & EN & LC & Decreasing \\
\hline
\end{tabular}




\begin{tabular}{|c|c|c|c|c|c|}
\hline 21 & Nycteris thebaica & Egyptian slit-faced bat & EN & LC & Decreasing \\
\hline 22 & Miniopterus pallidus & Schreibers's long-fingered bat & EN & LC & Decreasing \\
\hline 23 & Myotis blythii & Lesser mouse-eared bat & EN & LC & Decreasing \\
\hline 24 & Myotis emarginatus & Geoffroy's bat & EN & LC & Decreasing \\
\hline 25 & Sciurus anomalus & Persian squirrel & EN & LC & Decreasing \\
\hline 26 & Allactaga euphratica & Euphrates jerboa & EN & LC & Decreasing \\
\hline 27 & Apodemus flavicollis & Yellow-necked mouse & EN & LC & Decreasing \\
\hline 28 & Canis lupus & Arabian wolf & EN & LC & Decreasing \\
\hline 29 & Vulpes cana & Blanford's fox & EN & LC & Decreasing \\
\hline 30 & Herpestes ichneumon & Egyptian mongoose & EN & LC & Decreasing \\
\hline 31 & Hyaena hyaena & Striped hyaena & EN & NT & Decreasing \\
\hline 32 & Martes foina & Stone marten & EN & LC & Decreasing \\
\hline 33 & Lepus capensis & Cape hare & EN & LC & Decreasing \\
\hline 34 & Procavia capensis & Rock hyrax & EN & LC & Decreasing \\
\hline 35 & Capra nubiana & Nubian ibex & EN & VU & Decreasing \\
\hline 36 & Rhinolophus euryale & Mediterranean horseshoe bat & EN & NT & Stable \\
\hline 37 & Asellia tridens & Trident leaf-nosed bat & $V U^{\circ}$ & LC & Decreasing \\
\hline 38 & Hystrix indica & Indian crested porcupine & VU & LC & Decreasing \\
\hline 39 & Meles meles & Common badger & VU & LC & Decreasing \\
\hline 40 & Rousettus aegyptiacus & Egyptian fruit bat & $N T^{\circ}$ & LC & Decreasing \\
\hline 41 & Rhinolophus hipposideros & Lesser horseshoe bat & NT & LC & Unknown \\
\hline 42 & Barbastella leucomelas & Asian barbastelle & NT & LC & Unknown \\
\hline
\end{tabular}




\begin{tabular}{|c|c|c|c|c|c|}
\hline 43 & Eliomys melanurus & Asian garden dormouse & NT & LC & Decreasing \\
\hline 44 & Vulpes rueppelli & Sand fox & NT & LC & Unknown \\
\hline 45 & Myotis capaccinii & Long-fingered bat & $\mathrm{DD}$ & VU & Unknown \\
\hline 46 & Nesokia indica & Short-tailed bandicoot rat & $\mathrm{DD}$ & LC & Unknown \\
\hline 47 & Mellivora capensis & Honey badger & $\mathrm{DD}$ & LC & Unknown \\
\hline 48 & Crocidura suaveolens & Lesser white-toothed shrew & LC & LC & Stable \\
\hline 49 & Suncus etruscus & Etruscan shrew & LC & LC & Stable \\
\hline 50 & Erinaceus concolor & Southern white-breasted hedgehog & LC & LC & Stable \\
\hline 51 & Hemiechinus auritus & Long-eared hedgehog & LC & LC & Increasing \\
\hline 52 & Paraechinus aethiopicus & Desert hedgehog & LC & LC & Stable \\
\hline 53 & Rhinolophus blasii & Blasius's horseshoe bat & LC & LC & Stable \\
\hline 54 & Rhinolophus clivosus & Geoffroy's horseshoe bat & LC & LC & Stable \\
\hline 55 & Rhinopoma cystops & Egyptian mouse-tailed bat & LC & LC & Stable \\
\hline 56 & Tadarida teniotis & European free-tailed bat & LC & LC & Increasing \\
\hline 57 & Eptesicus bottae & Botta's serotine & LC & LC & Increasing \\
\hline 58 & Hypsugo ariel & Desert pipistrelle & LC & $\mathrm{DD}$ & Stable \\
\hline 59 & Myotis nattereri & Natterer's bat & LC & LC & Stable \\
\hline 60 & Otonycteris hemprichi & Desert long-eared bat & LC & LC & Increasing \\
\hline 61 & Pipistrellus kuhli & Kuhl's pipistrelle & LC & LC & Increasing \\
\hline 62 & Pipistrellus pipistrellus & Common pipistrelle & LC & LC & Increasing \\
\hline 63 & Plecotus christii & Christie's big-eared bat & LC & DD & Unknown \\
\hline 64 & Jaculus jaculus & Lesser Egyptian jerboa & LC & LC & Stable \\
\hline 65 & Cricetulus migratorius & Gray dwarf hamster & LC & LC & Increasing \\
\hline 66 & Microtus guentheri & Günther's vole & LC & LC & Increasing \\
\hline 67 & Acomys dimidiatus & Arabian spiny mouse & LC & LC & Increasing \\
\hline
\end{tabular}




\begin{tabular}{|c|c|c|c|c|c|}
\hline 68 & Acomys russatus & Golden spiny mouse & LC & LC & Decreasing \\
\hline 69 & Dipodillus dasyurus & Wagner's gerbil & LC & LC & Increasing \\
\hline 70 & Gerbillus cheesmani & Cheesman's gerbils & LC & LC & Increasing \\
\hline 71 & Gerbillus gerbillus & Lesser Egyptian gerbil & LC & LC & Stable \\
\hline 72 & Gerbillus henleyi & Pygmy gerbil & LC & $\mathrm{LC}$ & Stable \\
\hline 73 & Gerbillus nanus & Baluchistan gerbil & LC & LC & Increasing \\
\hline 74 & Meriones crassus & Sundevall's jird & LC & LC & Increasing \\
\hline 75 & Meriones libycus & Libyan jird & LC & LC & Increasing \\
\hline 76 & Meriones tristrami & Tristram's jird & LC & LC & Increasing \\
\hline 77 & Psammomys obesus & Fat sand rat & LC & LC & Increasing \\
\hline 78 & Sekeetamys calurus & Bushy-tailed jird & LC & LC & Stable \\
\hline 79 & Apodemus mystacinus & Broad-toothed field mouse & LC & LC & Increasing \\
\hline 80 & Spalax ehrenbergi & Palestine mole rat & LC & LC & Increasing \\
\hline 81 & Canis aureus & golden jackal & LC & LC & Increasing \\
\hline 82 & Vulpes vulpes & Red fox & LC & LC & Increasing \\
\hline 83 & Felis silvestris & Wild cat & LC & LC & Stable \\
\hline & Vormela peregusna & Marbled polecat & LC & VU & Stable \\
\hline & Sus scrofa & Wild boar & LC & LC & Increasing \\
\hline
\end{tabular}


The majority (5/9 or 56\%) of ungulate (Artiodactyla) in Jordan are categotrized as threatened according to the assessment results. In addition, three species have been found as Regionally Extinct and a single unguate was assessed as a Least Concern species (wild boar). The carnivores contain 10 threatened species, one Data Defeicient, one Near Threatened, and three Regionally Extinct species, where the remaining carnivores are Least Concern. Bats contain 11 species assessed as threatened animals, three Near Threatened, one Data Defeicient and the enduring are Least Concern. Rodents of Jordan encompass five threatened animals, one Data Defeicient, one Near Threatened and the remaining species of rodents are assessed as Least Concern. The assessment has showed that both the cape hare (Lagomorpha) and the rock hyrax (Procavidae) are threatened with extinction, where all Eulipotyphla species are Least Concern (Figure 3).

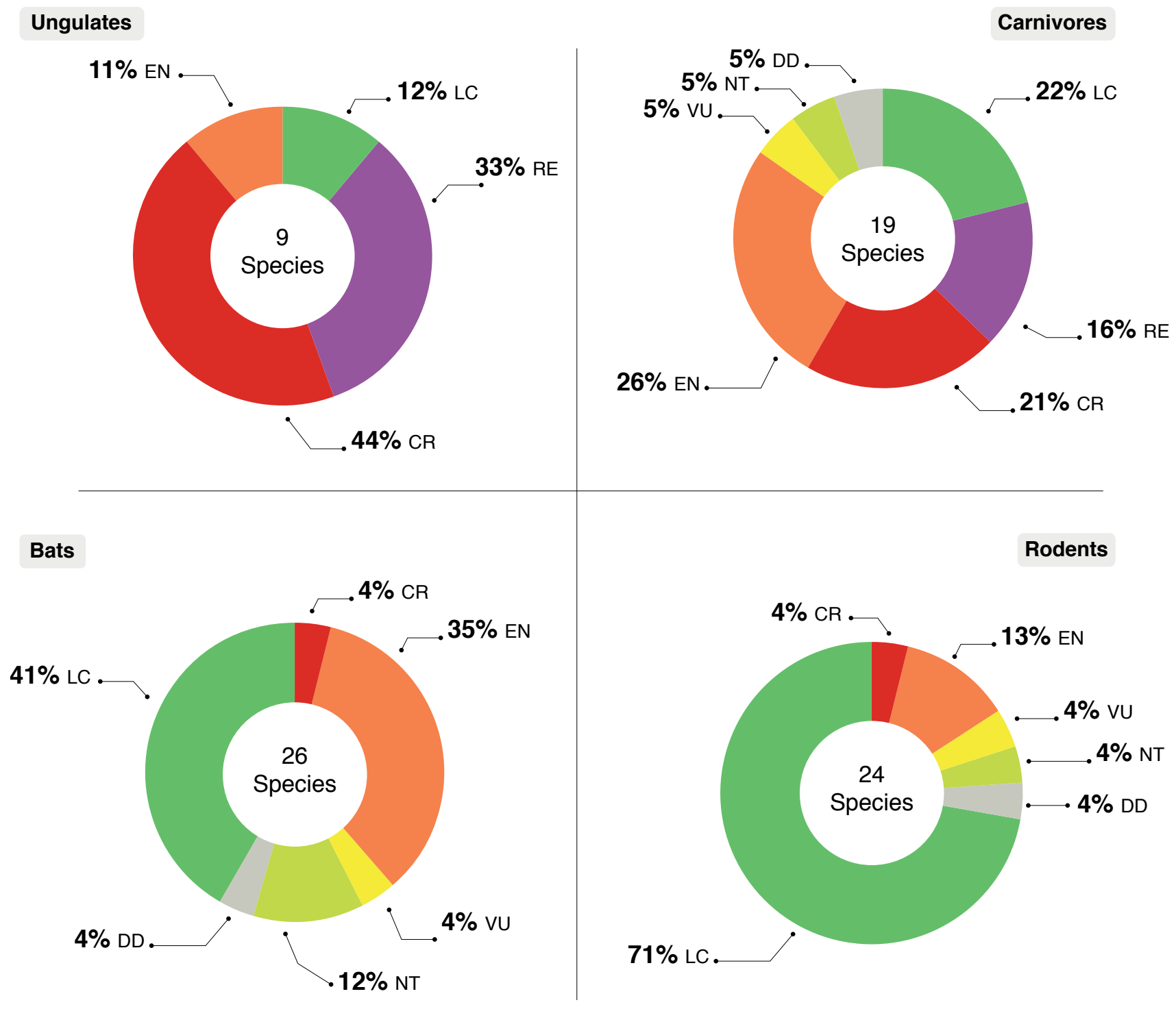

Figure 3: Comparison of the conservation status of four Jordanian mammal groups. RE = Regionally Extinct, CR $=$ Critically Endangered, EN $=$ Endangered, $\mathrm{VU}=$ Vulnerable, $\mathrm{NT}=$ Near Threatened, $\mathrm{LC}=$ Least Concern, $\mathrm{DD}=$ Data Deficient. 



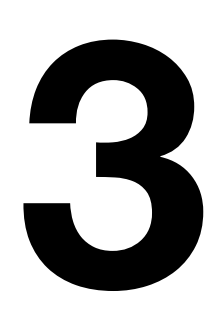

Species accounts 


\subsection{Eulipotyphla}

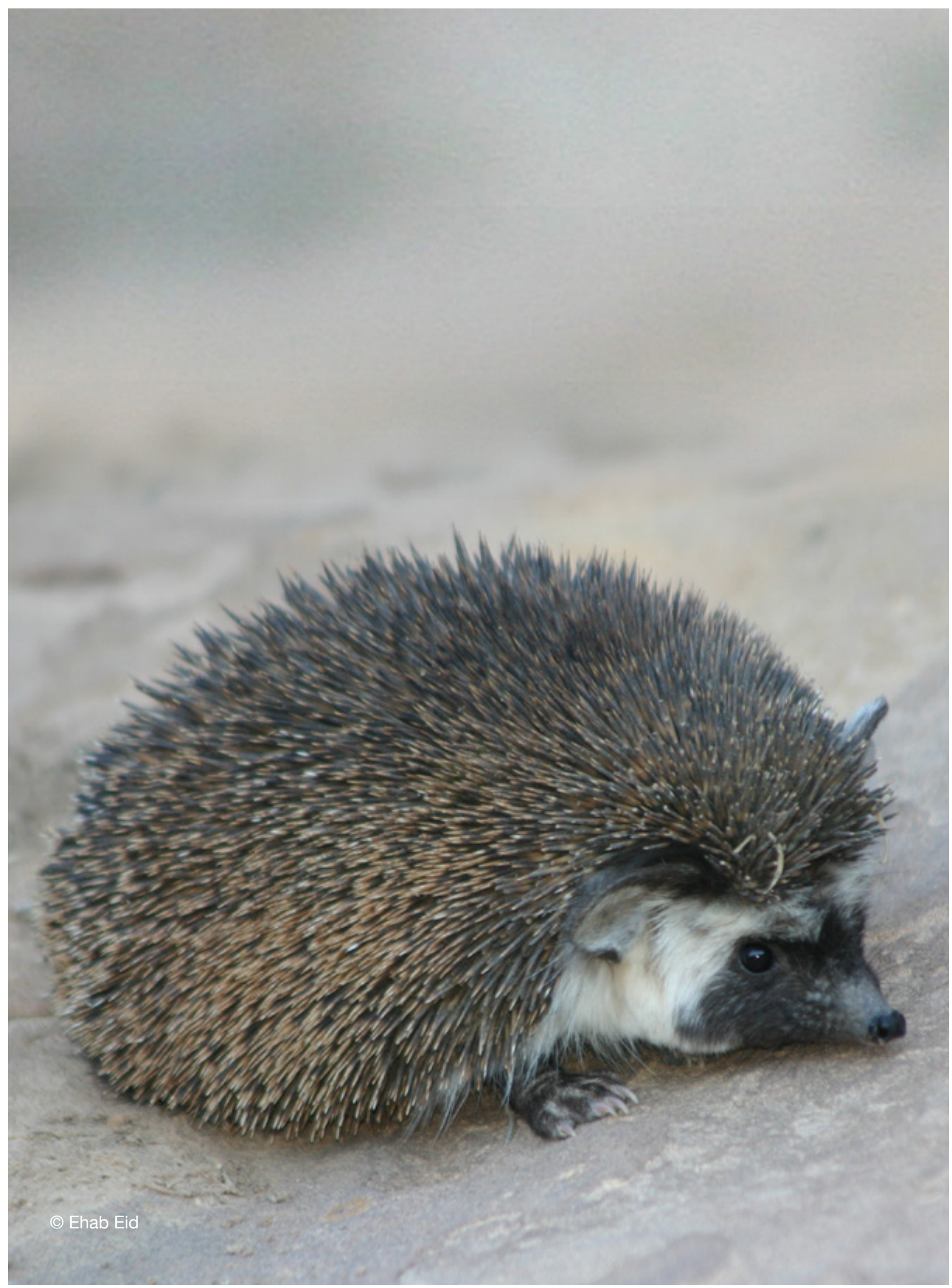




\section{Crocidura suaveolens (Pallas, 1811)}

Animalia - Chordata - Mammalia - Eulipotyphla - Soricidae

Common name(s): Lesser shrew, Lesser white-toothed shrew.

Red List status: Least Concern.

Justification: This species is widespread and common throughout its range of distribution in Jordan, with presumed stable population, and no significant threats known at present.

Geographical range: Atlantic coast of Spain and probably Portugal extending eastwards through Europe and Asia to Siberia. The southernmost edge of its distribution reaches Sinai in Egypt, Asia Minor, Palestine, Jordan, Saudi Arabia, Iran and China. In Jordan, this species is recorded from various localities including Azraq Shishan, Ajloun, Al Karak, Sakib, Wadi Zarqa, Azraq Wetland Reserve, Al-Sareeh, Shaumari Wildlife Reserve, Iraq Al Wahaj, Marj Hammam, Abdoun, and Al Hamme.

Population: The population size in Jordan is unknown

\section{Area of occupancy}

48

\section{Extent of occurrence}

5269

Biogeographical realms: Palearctic.

General use and trade information: No trade or use in this species is known.

Threats: No threats are known. However, pesticides and herbicides in agricultural habitats might be considered as potential threats.

Conservation actions: This species is protected in situ at Ajloun Forest Reserve, Azraq Wetland Reserve and Shaumari Wildlife Reserve. In addition, it is Listed in Appendix III for wildlife protection of the Agricultural Law Number 13 for the year 2015 based on regulation Number 43 for the year 2008. No other conservation measures are recommended at present.

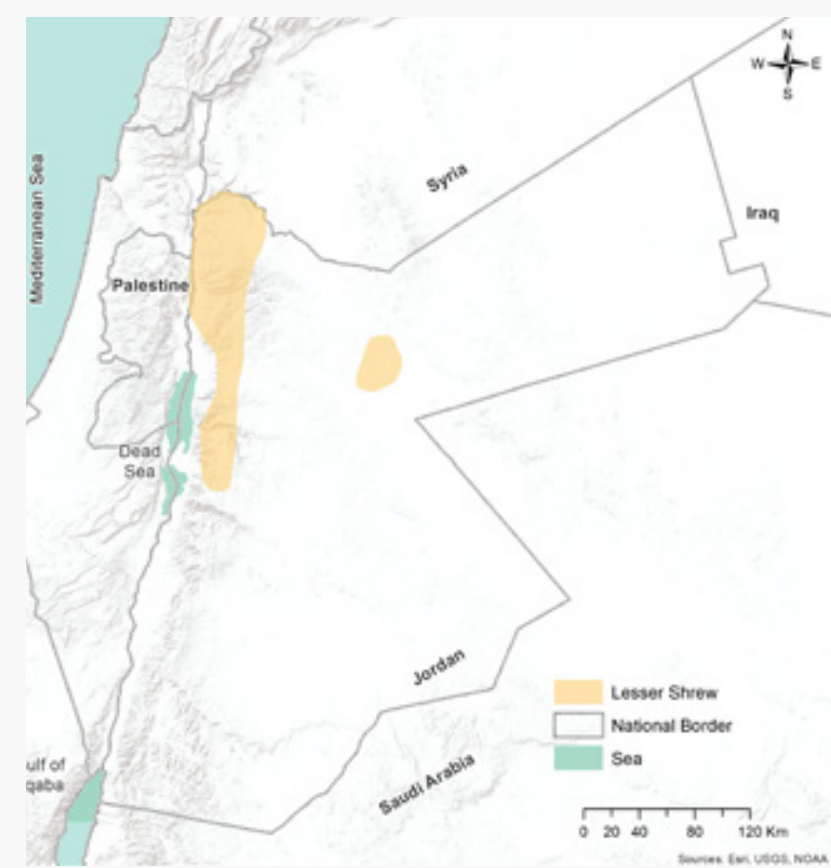

Map 1: Distribution of Crocidura suaveolens in Jordan.

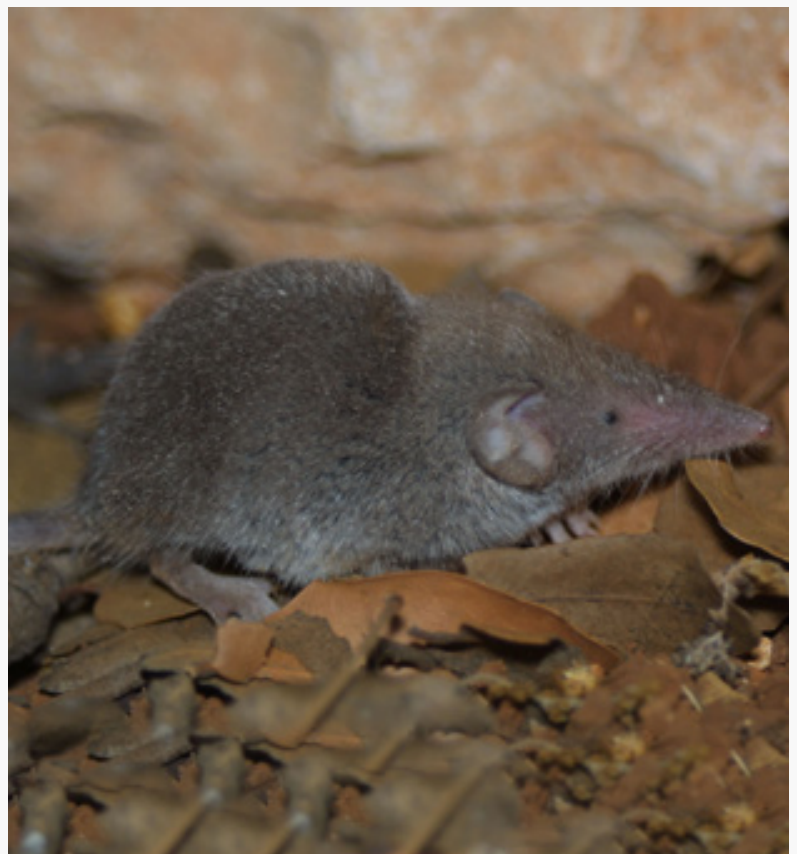

Figure 4: Crocidura suaveolens (C) Mohammad Abu Baker) 


\section{Suncus etruscus (Savi, 1822)}

Animalia - Chordata - Mammalia - Eulipotyphla - Soricidae

Common name(s): Etruscan shrew, Pygmy white-toothed shrew, Savi's pygmy shrew, White-toothed pygmy shrew.

Red List status: Least Concern.

Justification: Listed as Least Concern in view of its wide distribution, presumed stable population due to the tolerance of a degree of habitat modification.

Geographical range: This species is widespread from Southern Europe and North Africa, through parts of the Near East and Arabian Peninsula, Central Asia, South and central Asia, Europe and mainland Southeast Asia, to the island of Borneo in the east. In Jordan, it is recorded from Azraq ash Shishan, Jarash, 3km north of Ajloun, $5 \mathrm{~km}$ West of Al Karak, $2 \mathrm{~km}$ west of Sakeb, Shaumari Wildlife Reserve, Amman National Park, Dana Biosphere Reserve and Wadi Zarqa Ma'in.

Population: The population size in Jordan is unknown.

\section{Area of occupancy}

36

\section{Extent of occurrence}

5064

Biogeographical realms: Palearctic.

General use and trade information: No trade or use in this species is known.

Threats: No threats are known at present in Jordan.

Conservation actions: This species is protected in situ in several protected areas including Ajloun and Dibeen Forest Reserves, Azraq Wetland Reserve, Shaumari Wildlife Reserve, and Dana Biosphere Reserve.

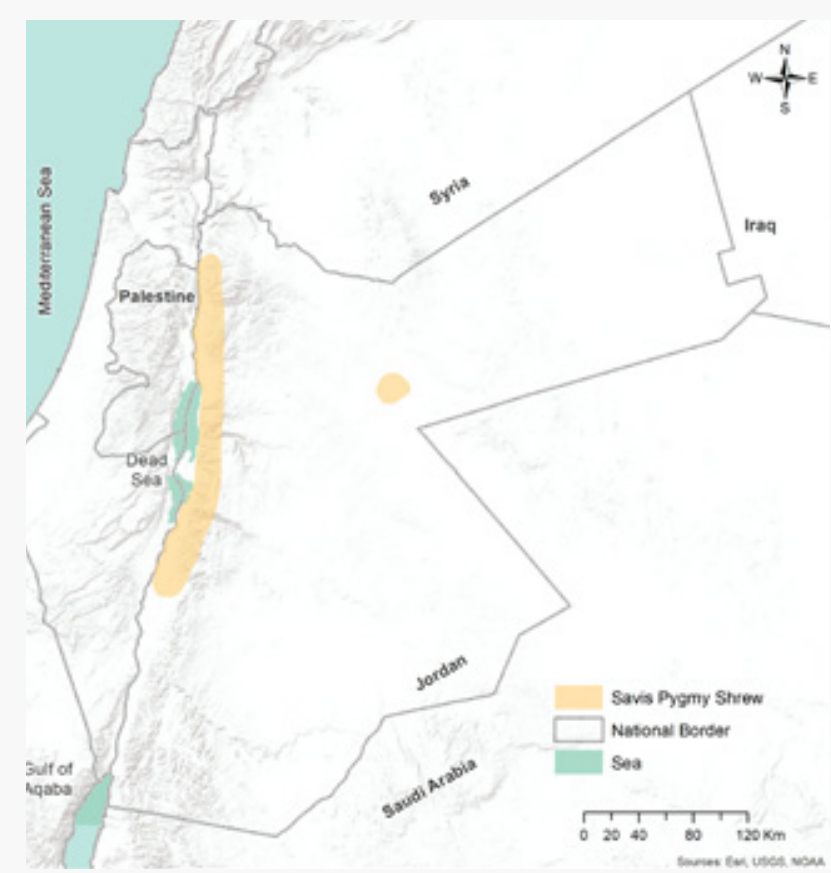

Map 2: Distribution of Suncus etruscus in Jordan.

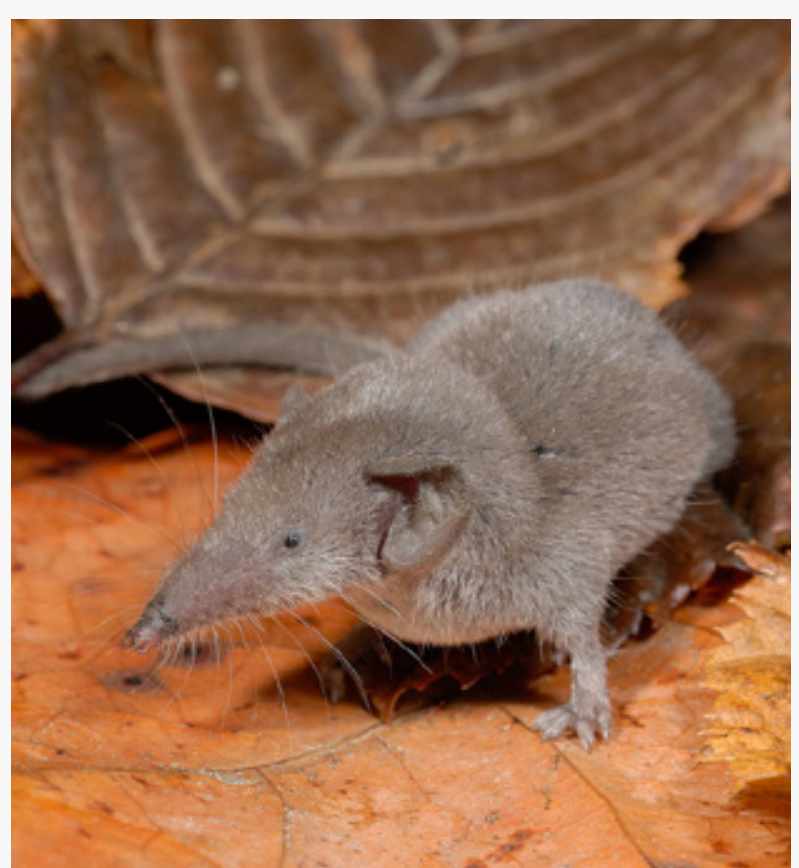

Figure 5: Suncus etruscus (○ Roberto Sindaco) 


\section{Erinaceus concolor (Martin, 1838)}

Animalia - Chordata - Mammalia - Eulipotyphla - Erinaceidae

Common name(s): Southern white-breasted hedgehog, Eastern European hedgehog.

Red List status: Least Concern.

Justification: This species is widespread, common in Jordan and appears to have a stable population at present.

Geographical range: Its global range is Asia Minor to Palestine, Syria, Jordan, Lebanon, northern Iraq and northwestern Iran, and the southern Caucasus (Wilson and Reeder, 2005). In the Mediterranean region, it is recorded in Greece (Rhodes), Anatolian Turkey, Palestine, Syria and Lebanon. In Jordan, this species is recorded from Al Hummar, At Tafilah, Irbid, Jarash, Jubayhah, Mahis, Ramtha, Marj Al Hammam, Petra, Wadi Zarqa Ma'in, Dibeen Forest Reserve, Fuhis, Jabal Masuda, and Madaba.

Population: The population size in Jordan is unknown.

Area of occupancy

84

\section{Extent of occurrence}

7476

Biogeographical realms: Palearctic.

General use and trade information: Eid et al, (2011) reported this species in trade from the Animal public market in Amman where specimens were exhibited as pets. In addition, its flesh is cooked and used to treat nocturnal enuresis in some pocket areas in Jordan (Aloufi and Eid, 2016).

Threats: No threats are known to be seriously affecting the species at present. However, road killing, collection and trade are likely to represent potential threats in the future as well as using pesticides which can lead to prey composition decline.

Conservation actions: This species is protected in situ in Dibeen Forest Reserve and Mujib Biosphere Reserve. In addition, it is Listed in Appendix III for wildlife protection of the Agricultural Law Number 13 for the year 2015 based on regulation Number 43 for the year 2008.

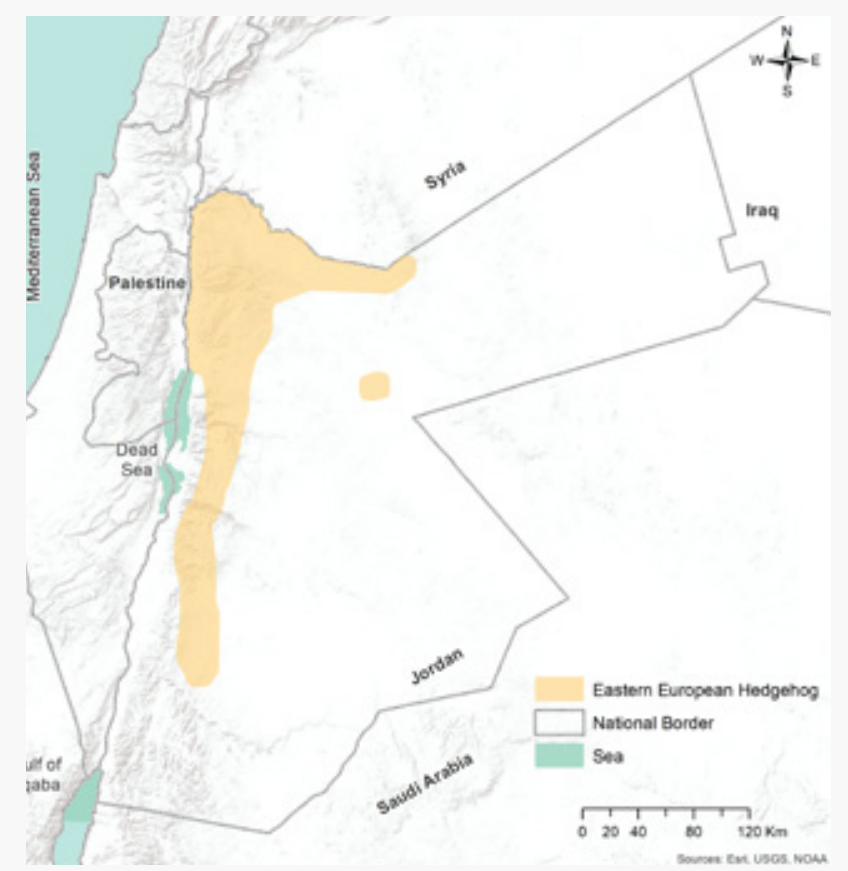

Map 3: Distribution of Erinaceus concolor in Jordan.

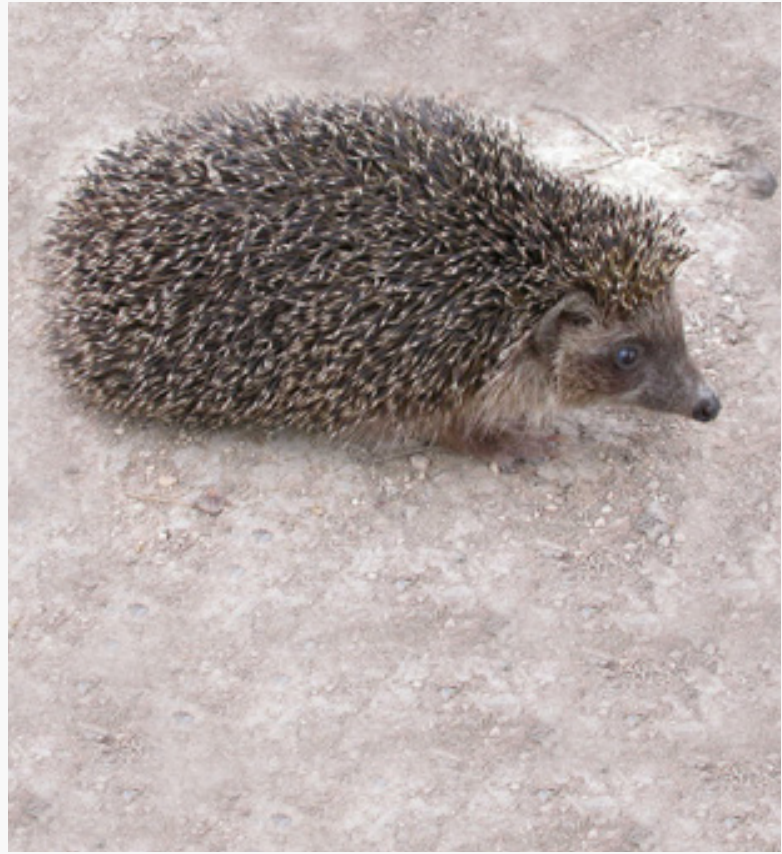

Figure 6: Erinaceus concolor (@ Zuhair Amr) 


\section{Hemiechinus auritus (Gmelin, 1770)}

Animalia - Chordata - Mammalia - Eulipotyphla - Erinaceidae

Common name(s): Long-eared hedgehog.

Red List status: Least Concern.

Justification: A common and widespread species in Jordan, with a suspected increase in its population in Jordan. In addition, there are no documented threats at present along the absence of documented threats.

Geographical range: It extends from the Eastern Mediterranean region, through southwest Asia to western Pakistan in the south; and from eastern Ukraine through Mongolia (Gobi desert), to China (Xinjiang). In Jordan, this species is recorded from Amman, Jarash, Zarqa, between Safawi and Ruwayshid, Deheibe el Gharbiye, Wadi Zarqa, Al Karak, Azraq, Dana, Irbid, Qasr Burqu', and Um al Qittaun.

Population: The population size in Jordan is unknown.

Area of occupancy

48

\section{Extent of occurrence}

29635

\section{Biogeographical realms: Oriental.}

General use and trade information: Eid et al., (2011) reported this species in trade from the Animal public market in Amman where specimens were exhibited as pets. In addition, its flesh is cooked and used to treat nocturnal enuresis in some pocket areas in Jordan (Aloufi and Eid, 2016).

Threats: No threats are known to be seriously affecting the species at present. However, road killing, collection and trade are likely to represent potential threats in the future as well as using pesticides which can lead to prey composition decline.

Conservation actions: This species is protected in situ in Dana Biosphere Reserve, Dibeen Forest Reserve and Shubak Proposed protected area. In addition, it is Listed in Appendix III for wildlife protection of the Agricultural Law Number 13 for the year 2015 of the regulation Number 43 for the year 2008.

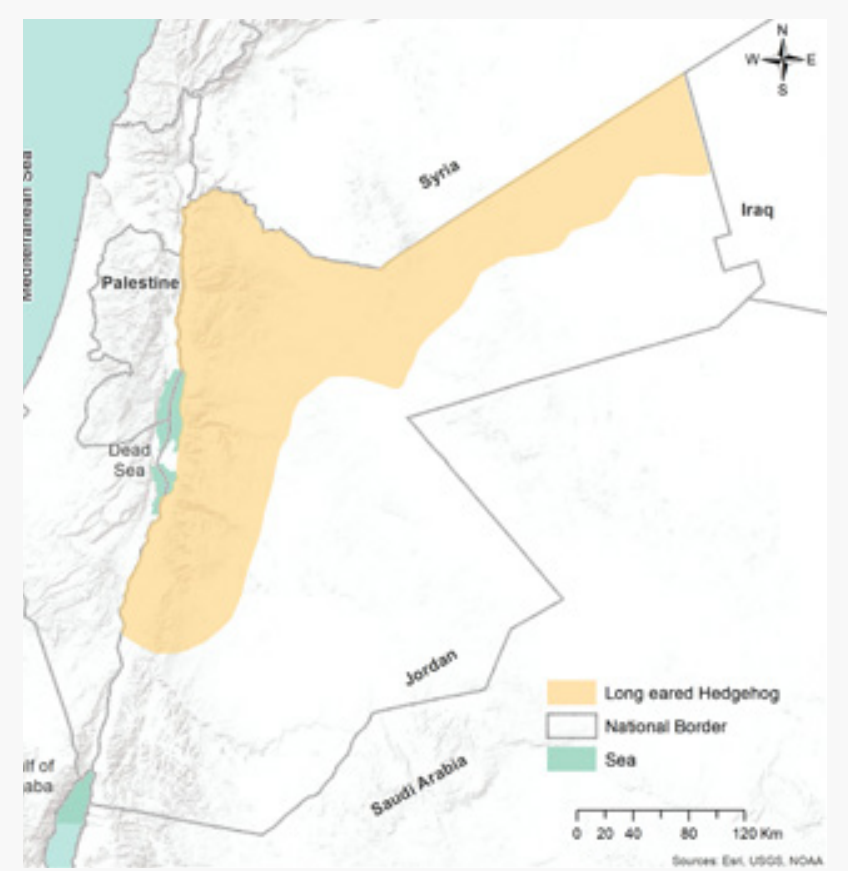

Map 4: Distribution of Hemiechinus auritus in Jordan.

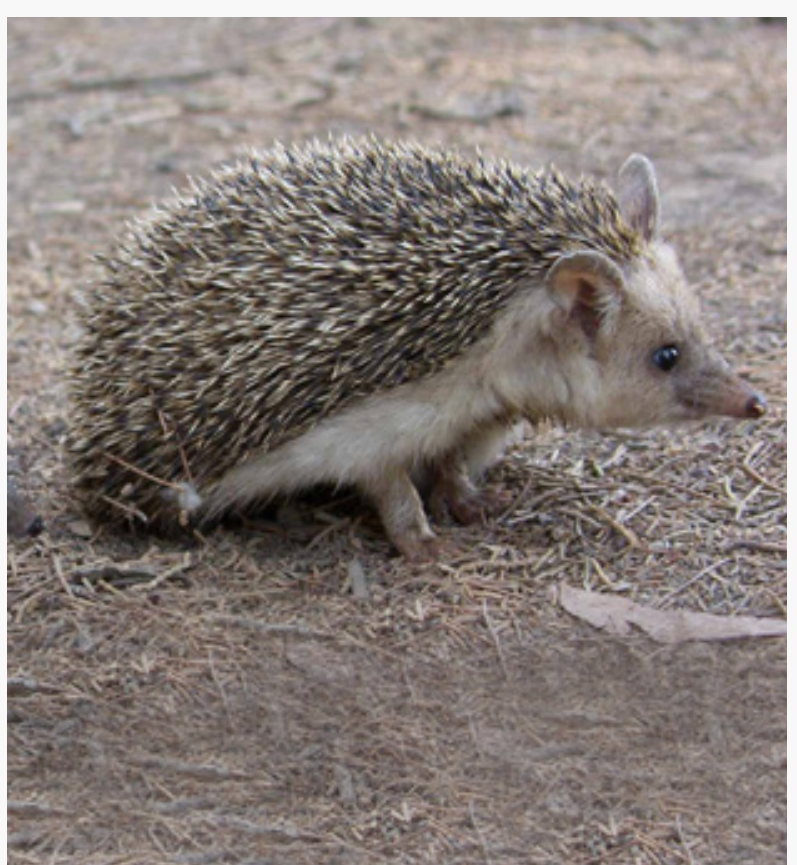

Figure 7: Hemiechinus auritus (๑) Zuhair Amr) 


\section{Paraechinus aethiopicus (Ehrenberg, 1832)}

Animalia - Chordata - Mammalia - Eulipotyphla - Erinaceidae

Common name(s): Desert hedgehog.

Red List status: Least Concern.

Justification: Listed as Least Concern in view of its wide distribution, presumed stable population, it occurs in a number of protected areas, and has a tolerance of a degree of habitat modification.

Geographical range: It is distributed from Mauritania, Western Sahara and Morocco in the west, to Egypt, Sudan, Eritrea and Ethiopia in the east, where it has been recorded from Syria, Palestine, Jordan, Iraq and marginally in Iran, and from most of the Arabian Peninsula. Insular populations occur on Djerba (Tunisia), Bahrain and Tanb (Arabian Gulf). In Jordan, this species is reported from Wadi Araba, Al Jafr, Azraq ash Shishan, Qasr Al Hallabat, Wadi ad Dulayl, Wadi Rum, Azraq ad Druze, Azraq Wetland Reserve, Al Mafraq, Al Hazim, Dana Biosphere Reserve, Faydat ad Dahikiyah, Jabal Masuda, Jawa, Petra, and Qasr Burqu'.

Population: The population size in Jordan is unknown.

\section{Area of occupancy}

84

\section{Extent of occurrence}

46479

Biogeographical realms: Afrotropical.

General use and trade information: Its flesh is cooked and used to treat nocturnal enuresis in some pocket areas in Jordan (Aloufi and Eid, 2016).

Threats: No threats are known to be seriously affecting the species at present. However, road killing, collection and trade are likely to represent potential threats in the future as well as using pesticides which can lead to prey composition decline.

Conservation actions: This species is protected in situ in Dana and Mujib Biosphere Reserves, Wadi Rum World Heritage Area and Burqu protected area. In addition, it is Listed in Appendix III for wildlife protection of the Agricultural Law Number 13 for the year 2015 of the regulation Number 43 for the year 2008.

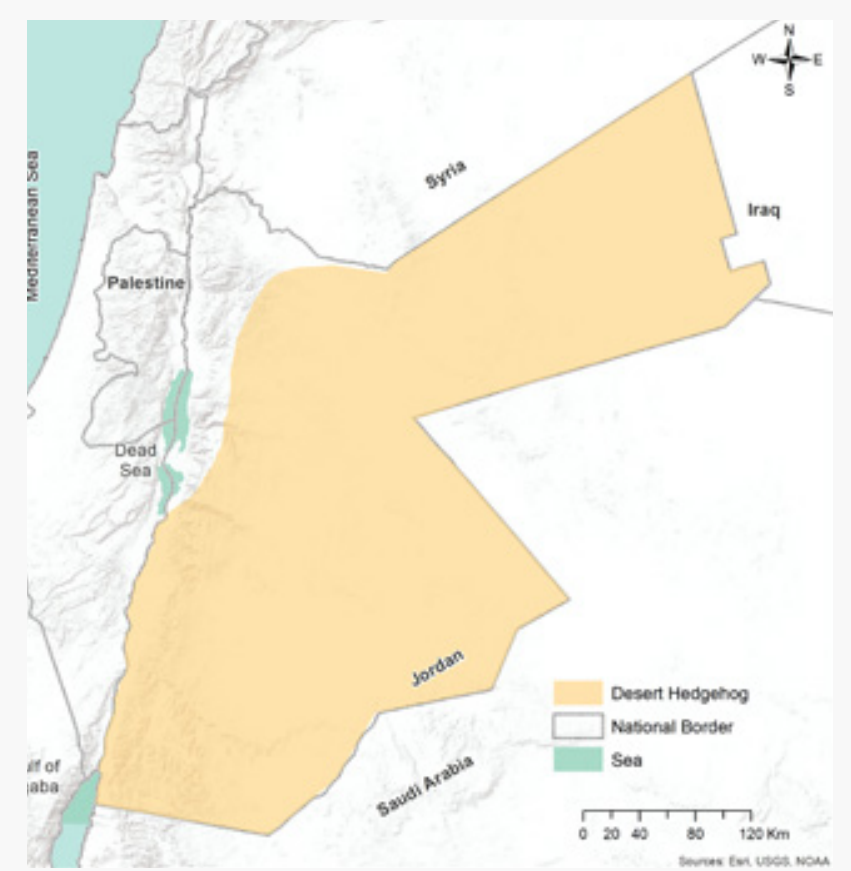

Map 5: Distribution of Paraechinus aethiopicus in Jordan.

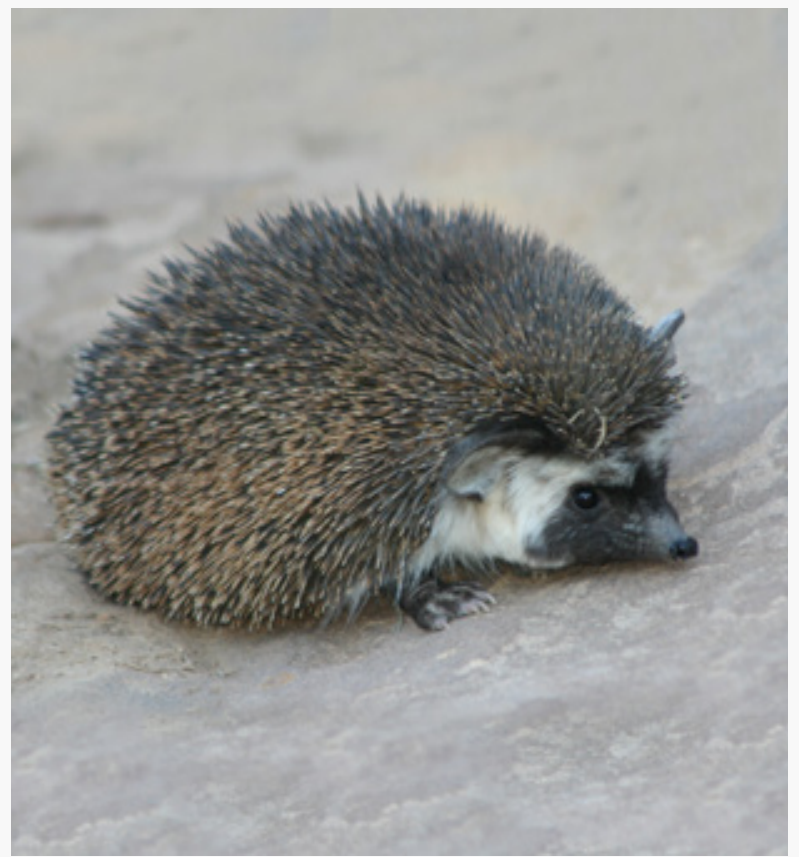

Figure 8: Paraechinus aethiopicus (C) Ehab Eid) 


\subsection{Chiroptera}

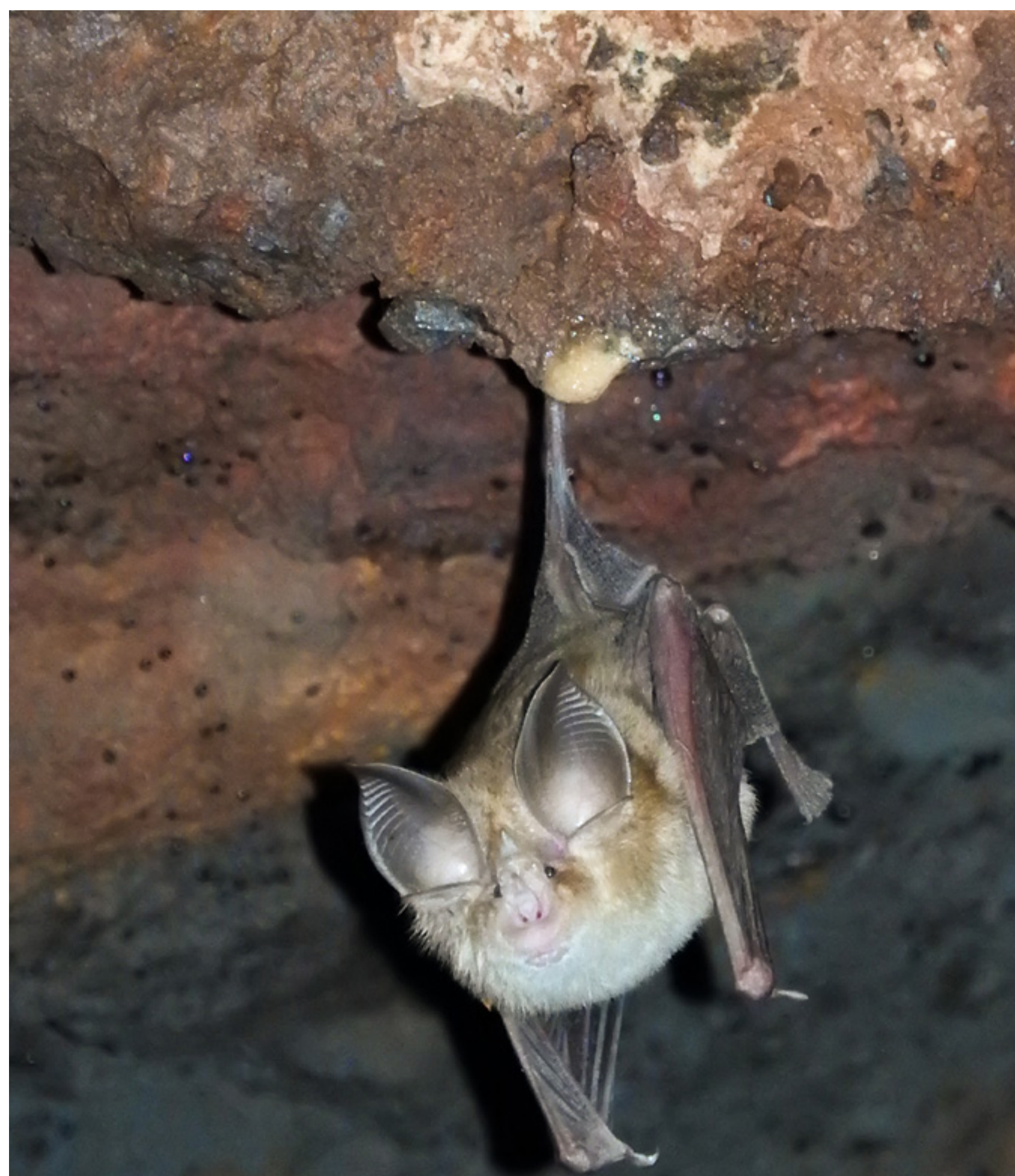




\section{Rousettus aegyptiacus (Savi, 1822)}

Animalia - Chordata - Mammalia - Chiroptera - Pteropodidae

Common name(s): Egyptian fruit bat, Egyptian rousette.

Red List status: Near Threatened ${ }^{\circ}$.

Justification: A clear population decline was observed over the past 40 years, and several colonies have been extinct from various localities along the Dead Sea area of Jordan. This species was assessed as Vulnerable species (A2a), but it was downlisted to Near Threatened due to potential migration from Palestine, which could support the existing population in Jordan.

Geographical range: Patchily distributed across sub-Saharan Africa and North Africa; also ranges outside of Africa through south-west Asia to Iran and Pakistan; also on Cyprus. In Jordan, this species is recorded from Zarqa' River, Amman, Al Hemma, Ghawr es Safi, Wadi Fidan, Wadi Ibn Hamad, Wadi Faynan, Tabaqat Fahl, Ar Raddass, Al Qafrayn, Al Qunayya, Aqaba, Ar Raddass, Az Zara Springs, Dana, Iraq Al Amir, Iraq Al Wahaj, Jufat Al Qafrayn, Kufranja, Nahla, Tabaqat Fahl, Wadi Al Wala, Wadi Abu Khushabeh, and Zarqa' River valley.

Population: The population size in Jordan is unknown. However, records on some population have been obtained by Amr et. al., (1987) who reported more than a thousand bats in a cave near Al Hamma during May 1983. Another large colony was observed at Wadi Ibn Hammad, where thousands of bats were active in a cave along the streamsides. In 2005, a colony with more than 90 individuals was observed in Wadi Zarqa Mai'n, but no longer exist (E. Eid. personal communication)

Area of occupancy

80

\section{Extent of occurrence}

Biogeographical realms: Afrotropical.

General use and trade information: No trade in this species is known. However, all bats are collected to a lesser extent for their blood, which is used for medicinal purposes to stop hair growth for newborn girls (Aloufi and Eid, 2016).

Threats: This species faces a number of threats, including access of farmers and visitors to their nesting areas, which causes disturbance (Amr et al. 2006a). In addition, persecution by farmers is a serious threat since they consider this species as a pest.

Conservation actions: This species is protected in situ in a number of protected areas such as Ajloun and Dibeen Forest Reserves, Dana and Mujib Biosphere Reserves. In addition, it is Listed in Appendix III for wildlife protection of the Agricultural Law Number 13 for the year 2015 of the regulation Number 43 for the year 2008.

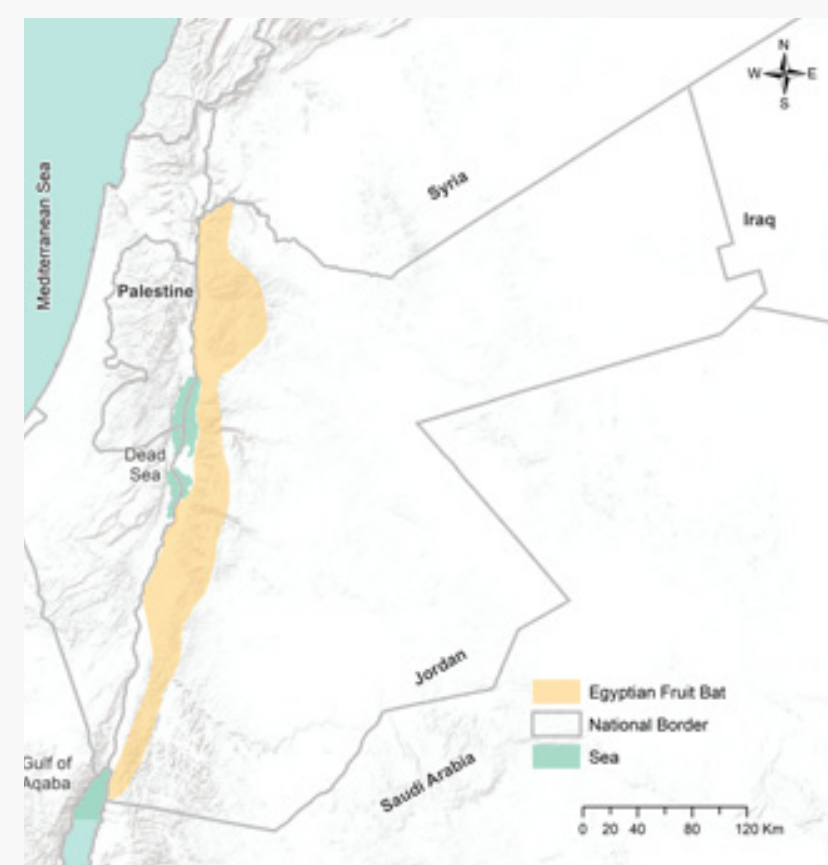

Map 6: Distribution of Rousettus aegyptiacus in Jordan.

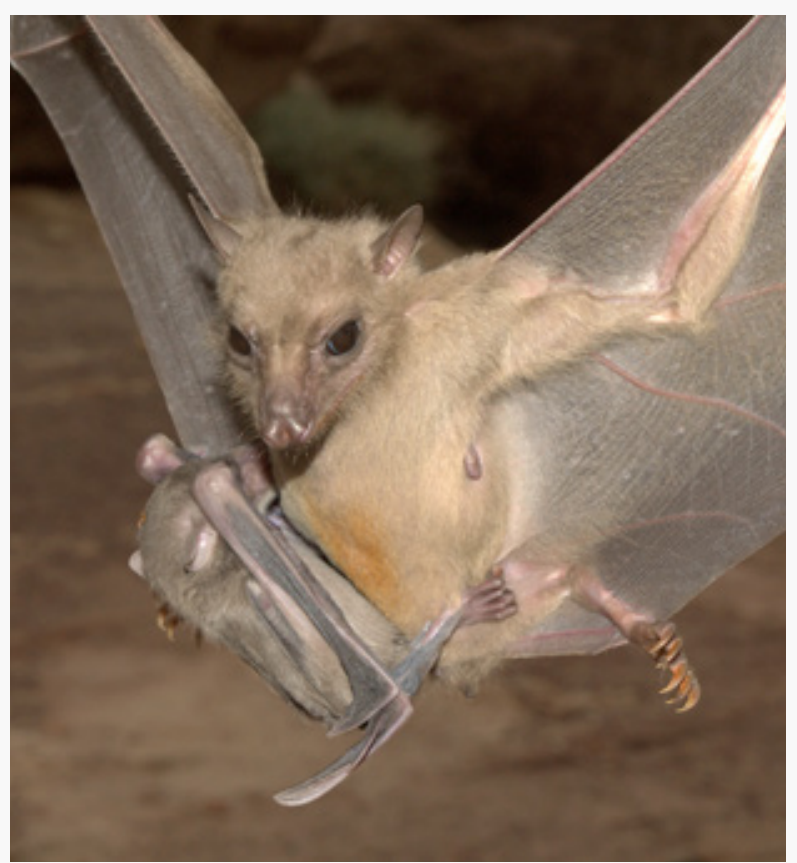

Figure 9: Rousettus aegyptiacus (C Antonin Reiter) 


\section{Rhinolophus blasii (Blasius, 1853)}

Animalia - Chordata - Mammalia - Chiroptera - Rhinolophidae

Common name(s): Blasius's horseshoe bat, Peak-saddle horseshoe bat, Peters's horseshoe bat.

Red List status: Least Concern.

Justification: Widespread and common species, with presumed stable population and no significant threats to its population at present.

Geographical range: It occurs from northeastern South Africa and the Democratic Republic of Congo, through south Malawi, to East African, Ethiopia and Somalia, and it is only present in Morocco and Algeria in North Africa. In addition, it has a patchy distribution extending from Turkey in the west to Pakistan in the east and from the Caucasus in the north to Yemen in the south (Wilson and Reeder 2005). In Europe, it was recorded from western Anatolia and from the Levant (Syria, Lebanon, Jordan, and Palestine). In Jordan, it is recorded from Jarash, Amman, Tabqat Fahl, Wadi Finan, Madaba, Zubiya, Wadi Khanzaireh, Ash Shawbak, Karak, Ash Shawbak, Iraq Al Amir, Iraq Al Wahaj, Khashibah, Malka, Qurayqira, and Zubiya.

Population: The population size in Jordan is unknown. However, a population of 30-40 individuals was found near Jarash forest in October 1976 (Qumsiyeh, 1980). Another small population was located in Wadi Finan (Benda et al., 2010).

\section{Area of occupancy}

48

\section{Extent of occurrence}

6484

Biogeographical realms: Palaearctic, Afrotropical.

General use and trade information: No trade or use in this species is known.

Threats: No direct threats, but disturbance and loss of habitats could be a potential threat to this species (Amr et al. 2006a).

Conservation actions: This species is protected in situ in Ajloun and Dibeen Forest Reserves.
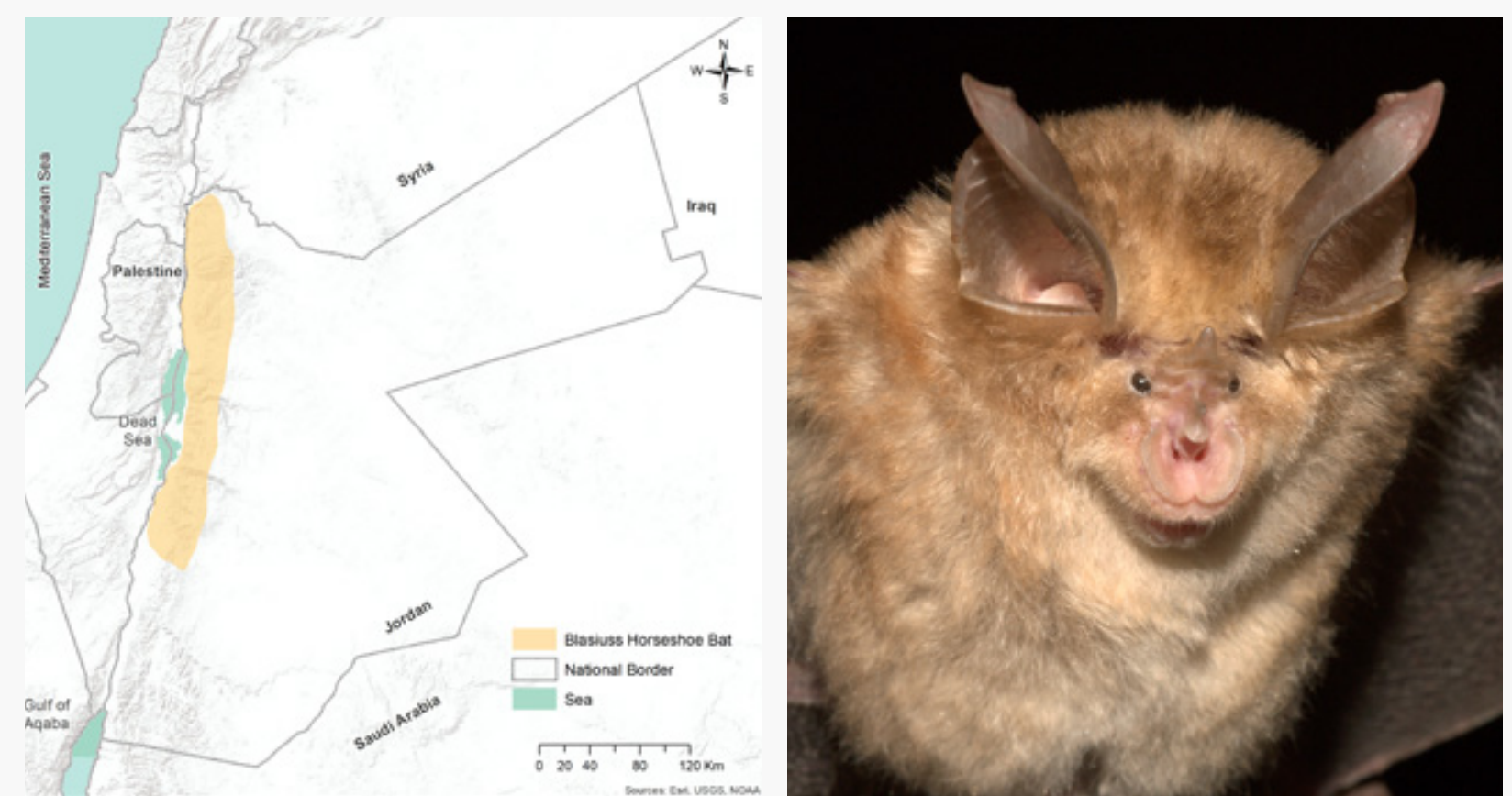

Map 7: Distribution of Rhinolophus blasii in Jordan. 


\section{Rhinolophus clivosus (Cretzschmar, 1828)}

Animalia - Chordata - Mammalia - Chiroptera - Rhinolophidae

Common name(s): Arabian horseshoe bat, Cretzschmar's horseshoe bat, Geoffroy's horseshoe bat.

Red List status: Least Concern.

Justification: Wide distribution, common and presumed stable population. No significant threats have been documented at present and it occupies a wide extent of occurrence in Jordan.

Geographical range: Turkmenistan to Afghanistan; Arabia to Algeria; sub- Saharan Africa to Liberia, Cameroon and South Africa. In Jordan, this species is recorded from Disah, Wadi Fidan, Petra, Al Ghal, Dana, Jabal Al Bayda, Jebel Masuda, Khirbet Finan, and Wadi Dharih.

Population: The population size in Jordan is unknown.

\section{Area of occupancy}

36

\section{Extent of occurrence}

5311

Biogeographical realms: Afrotropical.

General use and trade information: No trade or use in this species is known.

Threats: No major threats are known, although disturbance of roosting sites, and indirect poisoning resulting from the use of pesticides could be considered threats (Amr et al. 2006a).

Conservation actions: This species is protected in situ in Dana Biosphere Reserve, and Wadi Rum World Heritage Area.

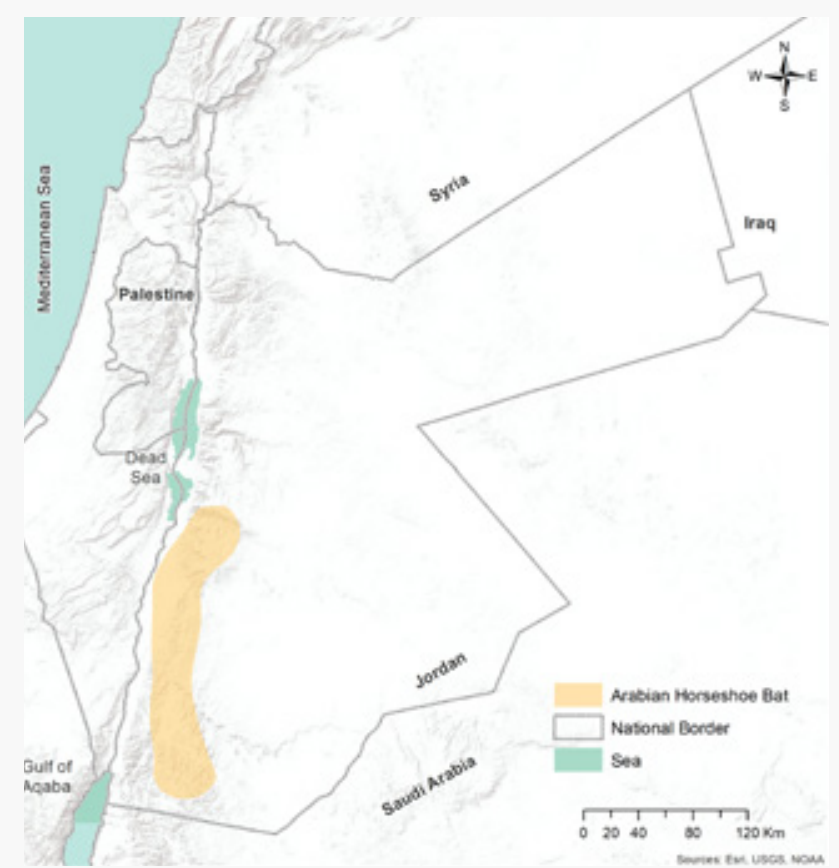

Map 8: Distribution of Rhinolophus clivosus in Jordan

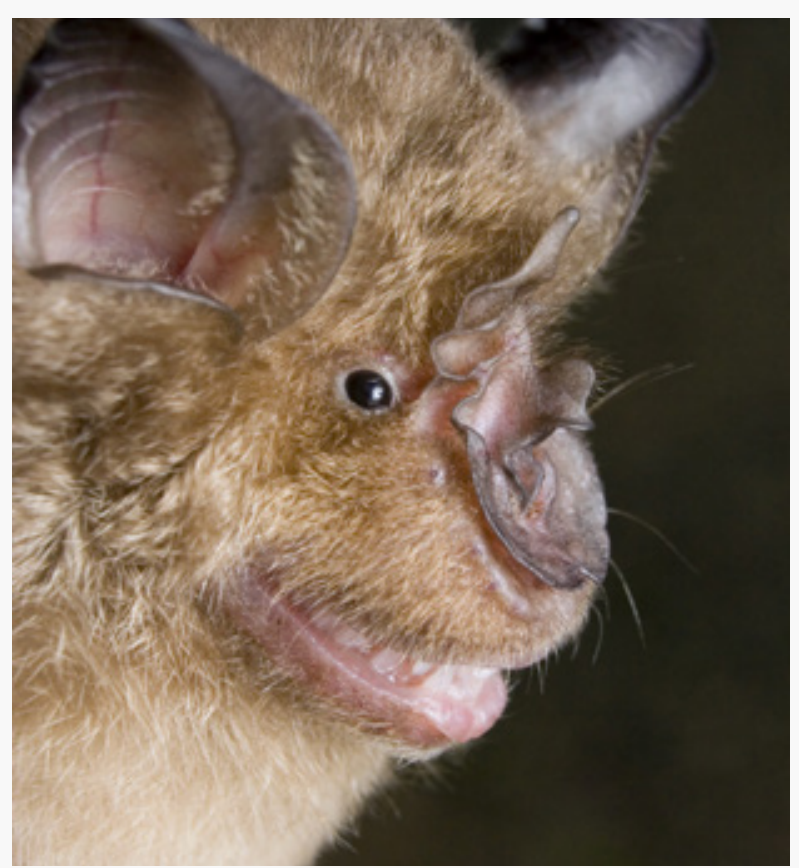

Figure 11: Rhinolophus clivosus (@ Shutterstock) 


\section{Rhinolophus euryale (Blasius, 1853)}

Animalia - Chordata - Mammalia - Chiroptera - Rhinolophidae

Common name(s): Mediterranean horseshoe bat.

Red List status: Endangered A1a; B1, B2ab (i, iii).

Justification: Despite the absence of information on populations size in Jordan, but a sharp decline in number of colonies have been observed, and many other colonies disappeared since early nineteen century. In addition, the extent of occurrence is below $500 \mathrm{~km}^{2}$ which qualify this species as an Endangered species.

Geographical range: Occurs in southern Europe, north-west Africa with known range extending across northern Morocco, Algeria, and Tunisia. In Jordan, this species is found in Dibbin Forest Park, Jarash, Zubiya, Dibbin, Iraq Al Wahaj, and Khashibah.

Population: The population size in Jordan is unknown.

Area of occupancy

20

\section{Extent of occurrence}

845

Biogeographical realms: Palearctic.

General use and trade information: No trade or use in this species is known.

Threats: Major threats are represented by deforestation, development and fragmentation within its suitable habitats (Amr et al. 2006a). The species' strong dependence on caves for roosting makes it particularly sensitive to cave disturbance.

Conservation actions: This species is protected in situ in Ajloun and Dibeen Forest Reserves. However, sharp decline has been observed and few individuals are still observed at present.

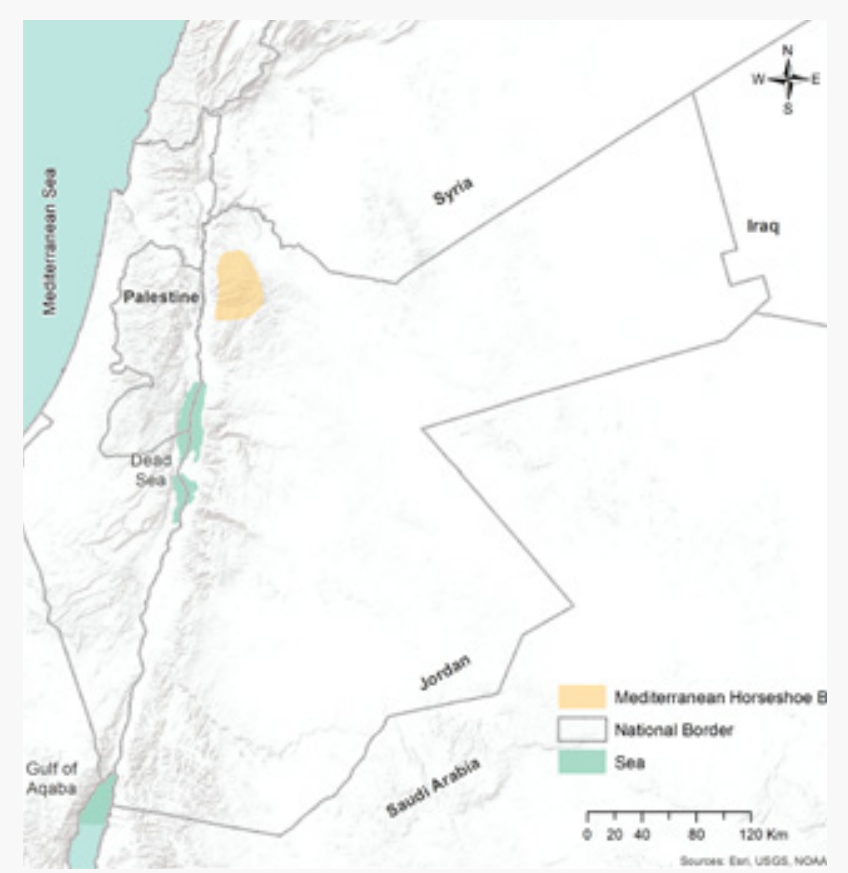

Map 9: Distribution of Rhinolophus euryale in Jordan.

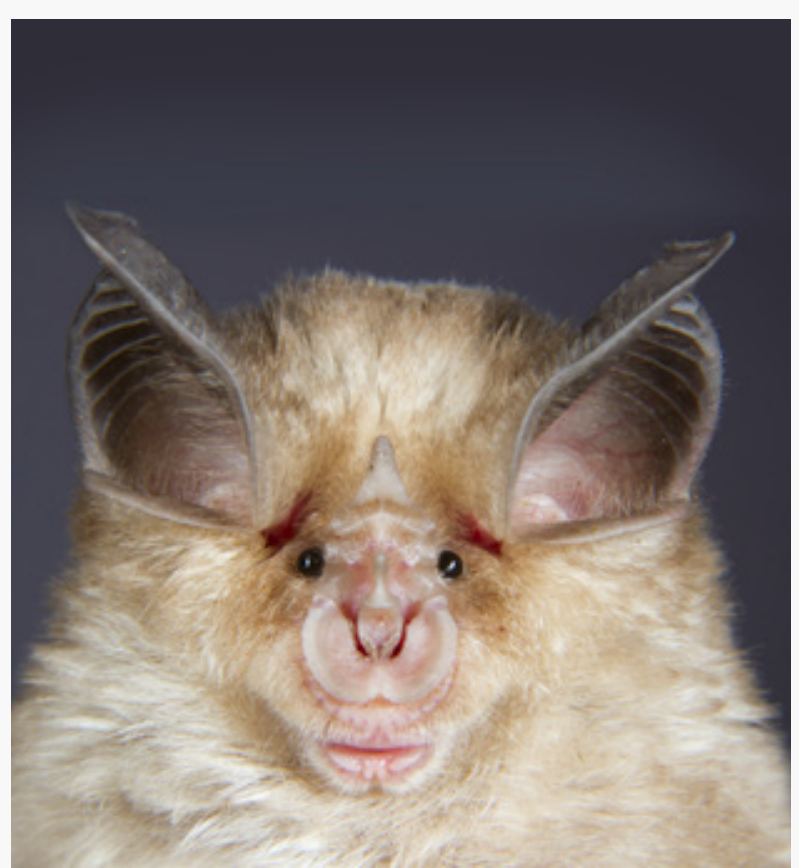

Figure 12: Rhinolophus euryale (@ Shutterstock) 


\section{Rhinolophus hipposideros (Bechstein, 1800)}

Animalia - Chordata - Mammalia - Chiroptera - Rhinolophidae

Common name(s): Lesser horseshoe bat.

Red List status: Near Threatened.

Justification: This species was assessed as Near Threatened as more knowledge is still required on its population, and distribution, in spite of the existing threats on its population, which might qualify it to the threatened category in the future.

Geographical range: It is found in all the European countries (including the islands) of the Mediterranean region. In North Africa it is recorded from Morocco, Algeria, Tunisia and the eastern part of the Sinai (to Egypt), and occurs in eastern Africa. Also recorded from Anatolia and the countries of the Levant. In Jordan, this species is recorded in Dibeen Forest Reserve, Zubiya, Bait Idis, Marj Al Hammam and Wadi Rum.

Population: The population size in Jordan is unknown.

Area of occupancy

20

\section{Extent of occurrence}

1781

Biogeographical realms: Palearctic.

General use and trade information: No trade or use in this species is known.

Threats: Disturbance of caves and loss of habitats due to deforestation especially in the northern parts of Jordan.

Conservation actions: This species is protected in situ in Dibeen and Ajloun Forest Reserves. However, serious decline in its population have been noticed from Dibeen Forest Reserve and few specimens are still exist at present.

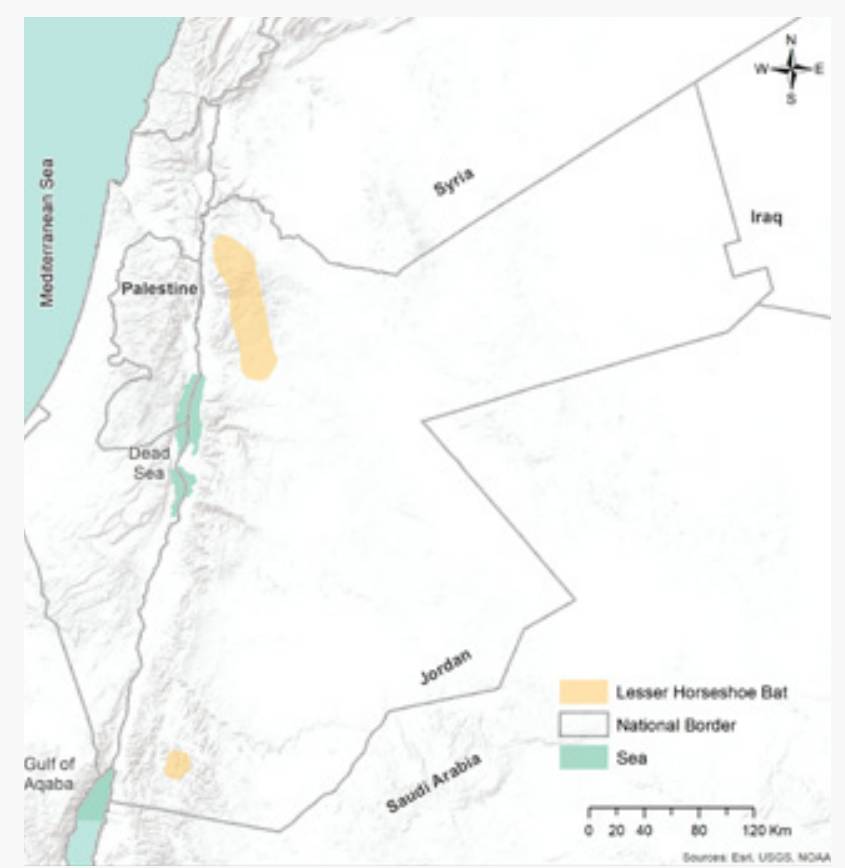

Map 10: Distribution of Rhinolophus hipposideros in Jordan.

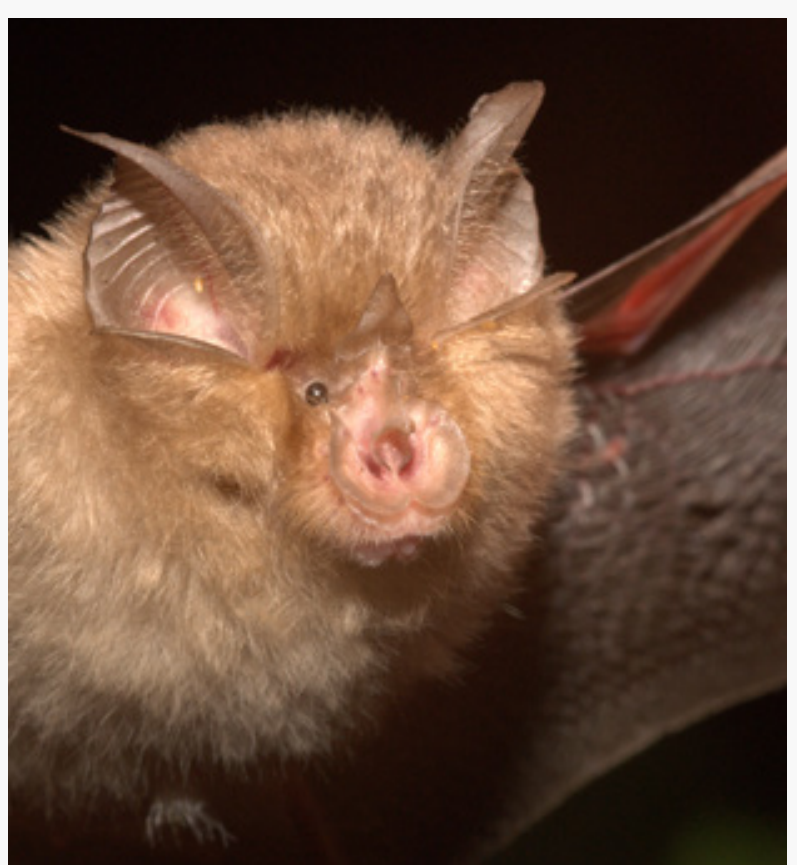

Figure 13: Rhinolophus hipposideros (C Antonin Reiter) 


\section{Rhinolophus ferrumequinum (Schreber, 1774)}

Animalia - Chordata - Mammalia - Chiroptera - Rhinolophidae

Common name(s): Greater horseshoe bat.

Red List status: Endangered A1a; B1, B2ab (i, ii, iii).

Justification: The population of this species is seriously declining in Jordan due to continuous forests degradation, destruction and severe fragmentations. An observed decline in its population was confirmed from Dibeen Forest Reserve where few specimens still exist at present.

Geographical range: This species has a wide range in the Palaearctic, occurring from North Africa and southern Europe through south west Asia, the Caucasus, Iran, Afghanistan, Pakistan and the Himalayas to south-eastern China, Korea, and Japan. In Jordan, this species is recorded in Jarash, Khirbat Sa'ad, Suwaylih, Zarqa River, Dibeen Forest Park, Tabqat Fahl, Zubiya, Quwaylibah, Arjan, Iraq Al Wahaj, Mahna, and Malka.

Population: The population size in Jordan is unknown.

Area of occupancy

36

\section{Extent of occurrence}

2162

Biogeographical realms: Palearctic.

General use and trade information: No trade or use in this species is known.

Threats: Caves disturbance, in addition to deforestation, development and fragmentation within its suitable habitats (Amr et al., 2006a).

Conservation actions: This species is protected in situ at Ajloun, Dibeen and Yarmouk Forest Reserves.

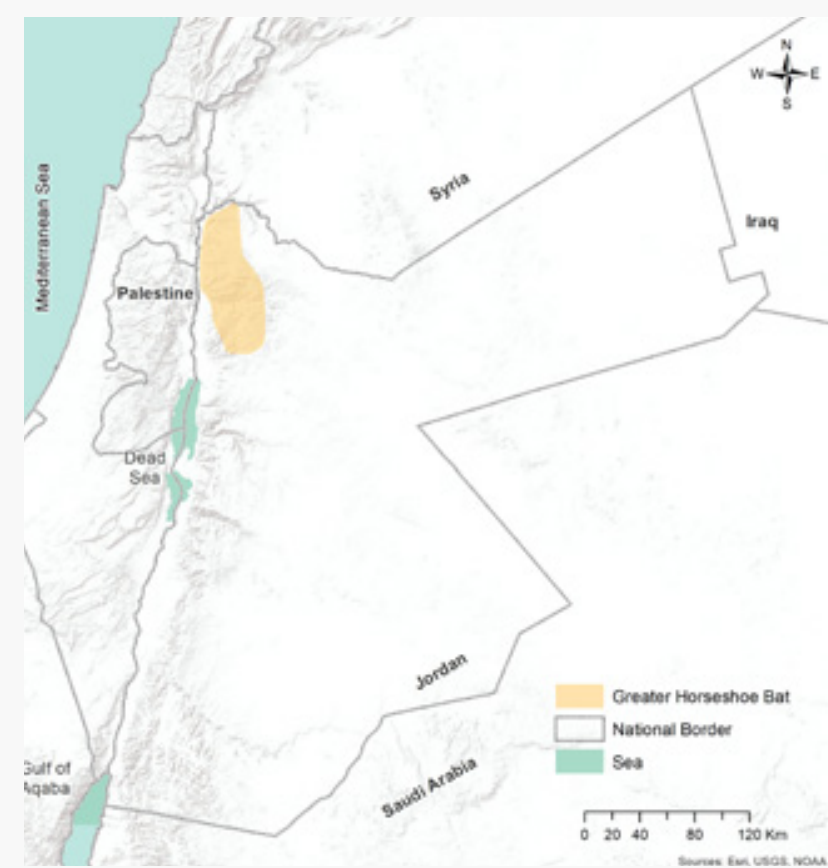

Map 11: Distribution of Rhinolophus ferrumequinum in Jordan.

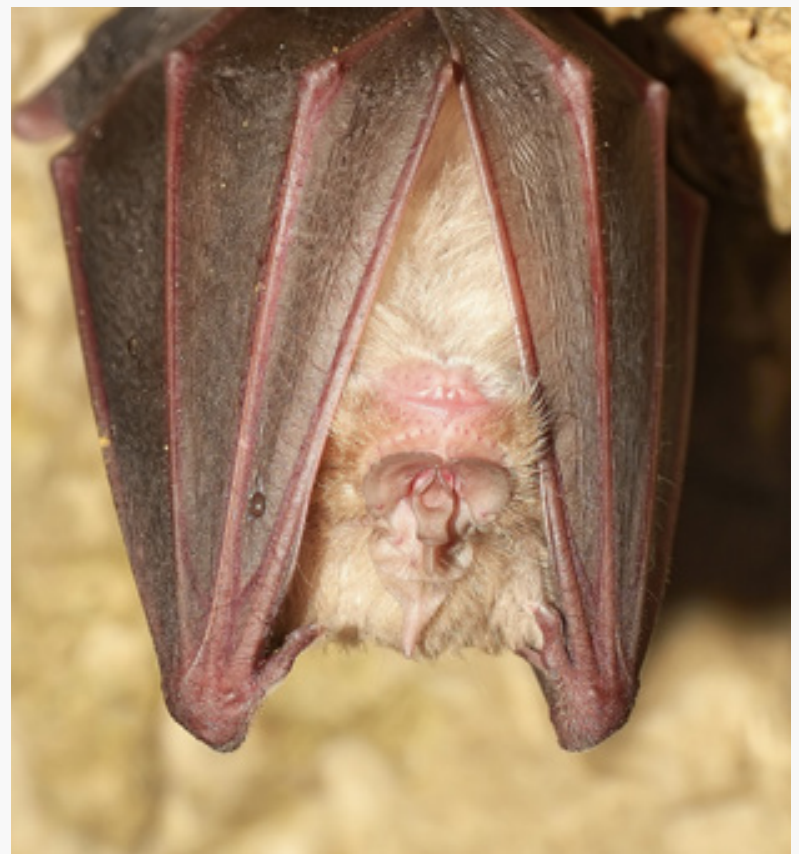

Figure 14: Rhinolophus ferrumequinum (@ Zuhair Amr) 


\section{Rhinolophus mehelyi (Matschie, 1901)}

Animalia - Chordata - Mammalia - Chiroptera - Rhinolophidae

Common name(s): Mehely's horseshoe bat.

Red List status: Critically Endangered B1ab (i, ii, iii).

Justification: The population of this species is severely declining in Jordan and it has a strictly confined area of occupancy and extent of occurrence. It was assessed as a vulnerable species at the global level.

Geographical range: It has a discontinuous distribution from North Africa (Morocco, Algeria, Tunisia and Egypt) and southern Europe (southern Portugal and Spain, possibly one occurrence in France, a few places in Italy and the Balkans) through Asia Minor, Anatolia, to Transcaucasia, Iran and Afghanistan. In Jordan, this species was recorded in a single locality in An Naqeh.

Population: The population size in Jordan is unknown.

Area of occupancy

4

\section{Extent of occurrence}

71

Biogeographical realms: Palearctic.

General use and trade information: No trade or use in this species is known.

Threats: The species is affected by the disturbance and destruction of caves as they are used by locals for livestock shelters and fodder storage (Amr et al., 2006a).

Conservation actions: No conservation measures have been applied to protect this species in Jordan.

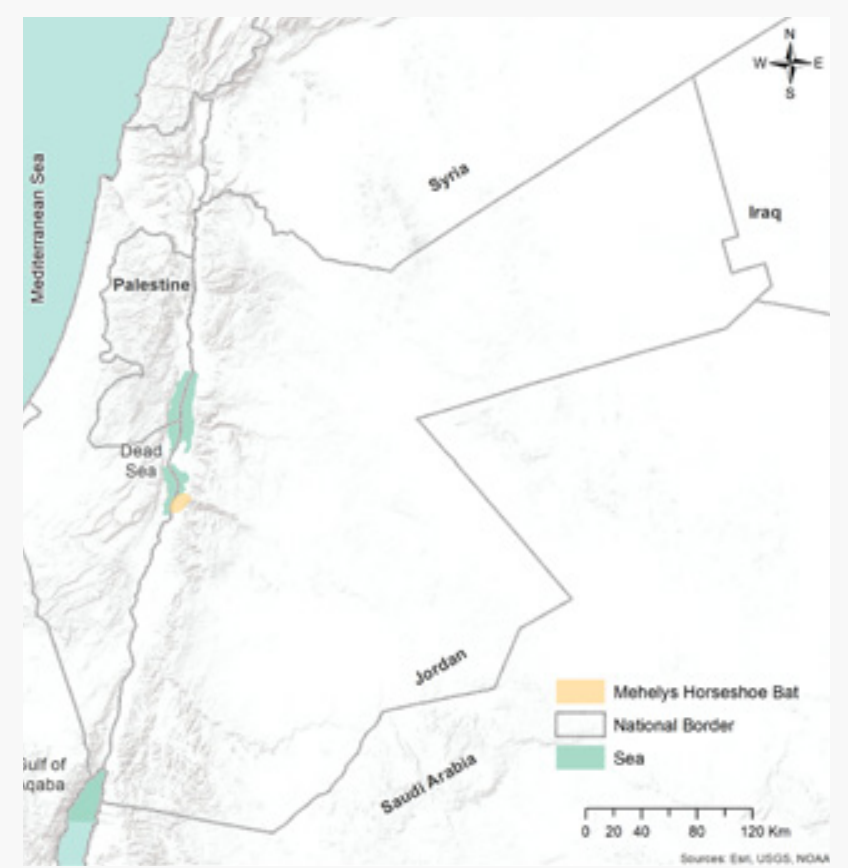

Map 12: Distribution of Rhinolophus mehelyi in Jordan.

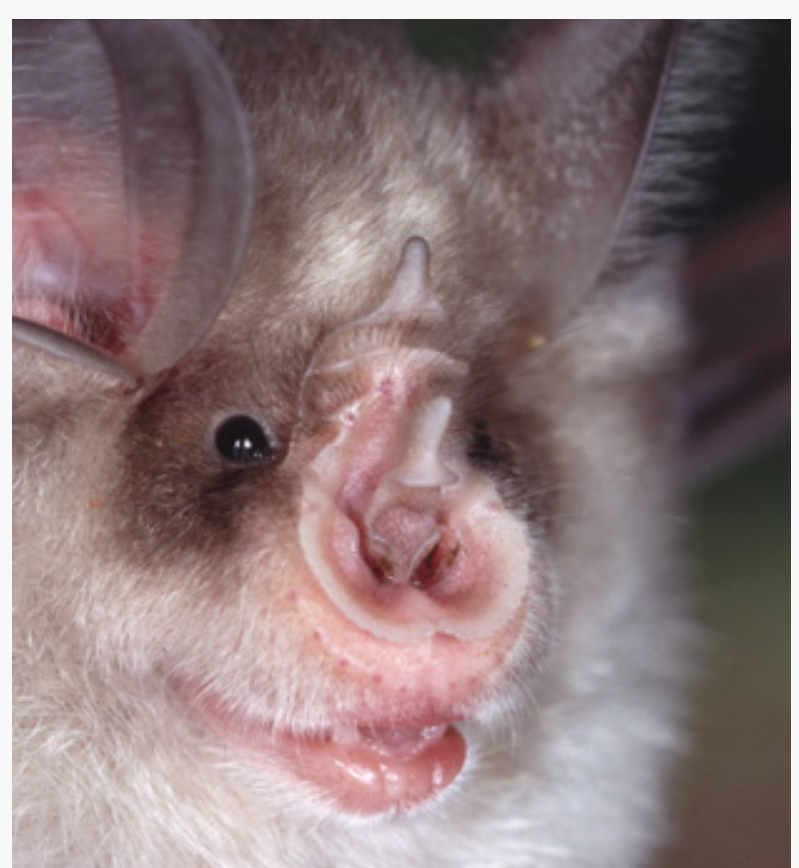

Figure 15: Rhinolophus mehelyi (@ Antonin Reiter) 


\section{Asellia tridens (E. Geoffroy, 1813)}

Animalia - Chordata - Mammalia - Chiroptera - Hipposideridae

Common name(s): Geoffroy's trident leaf-nosed bat, Trident bat, Trident leaf-nosed bat.

Red List status: Vulnerable ${ }^{\circ} \mathrm{B} 1, \mathrm{~B} 2 \mathrm{ab}(\mathrm{i}, \mathrm{ii}, \mathrm{iii})$.

Justification: This species has a confined distribution, presumed small population, but further studies are required to enhance our knowledge on reasons of decline, population size and its areas of occurrence. Although, this species qualifies for the Endangered category due to the regional migration patterns, which are not likely to be decline, it was downlisted as Vulnerable species

Geographical range: Pakistan to Arabia, Sinai Peninsula and Palestine, Syria; Egypt to Morocco, Senegal, Chad, Sudan and S Somalia; Socotra. In Jordan, this species is found in An Naqah, Petra and Qurayqira.

Population: Migratory species, restricted to few areas along Wadi Araba.

\section{Area of occupancy}

12

\section{Extent of occurrence}

1440

Biogeographical realms: Palearctic, Afrotropical.

General use and trade information: No trade or use in this species is known.

Threats: The main threat is destruction of roosting areas and human disturbance through fire and use of caves as sheep enclosures. In addition, the use of pesticides especially in Ghor Safi area is a major threat (Amr et al., 2006a).

Conservation actions: This species is protected in situ in Dana Biosphere Reserve.

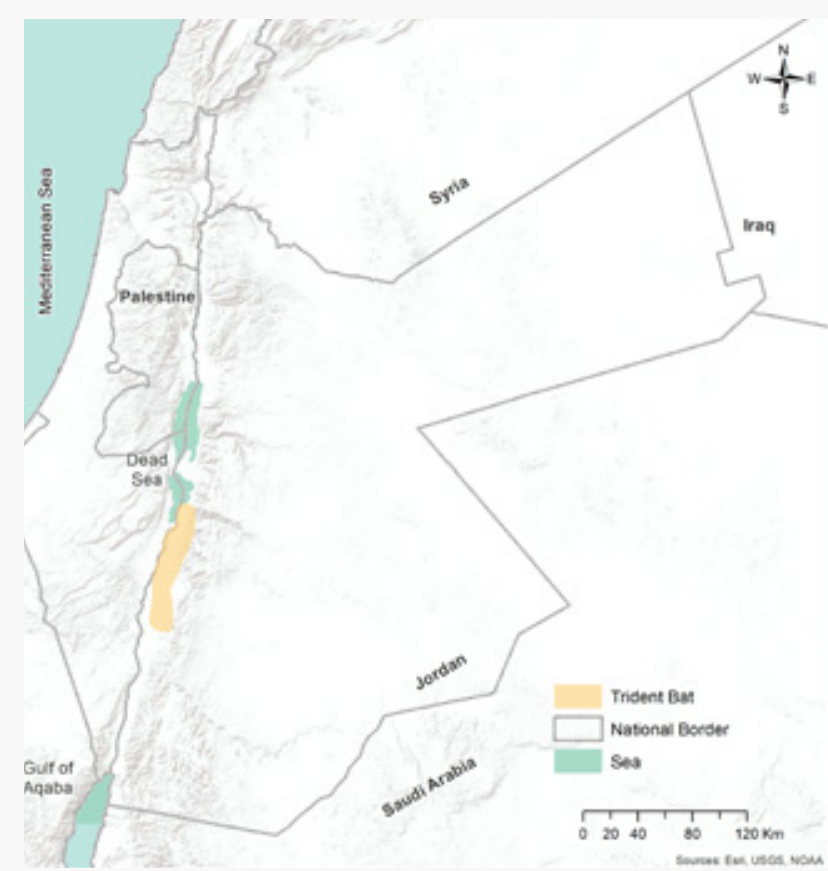

Map 13: Distribution of Asellia tridens in Jordan

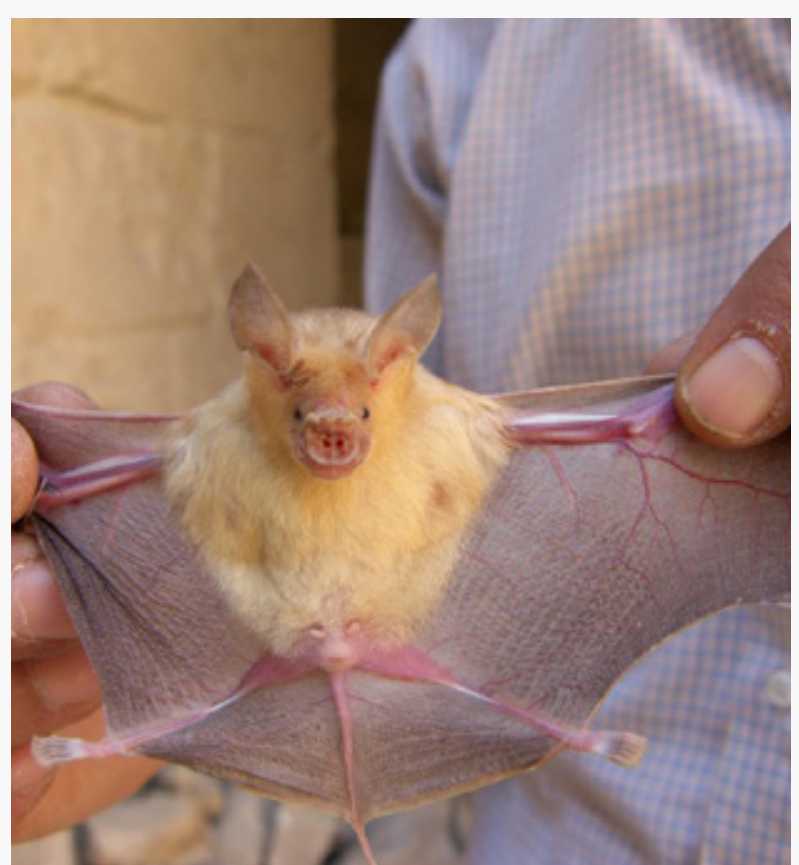

Figure 16: Asellia tridens (C Zuhair Amr) 


\section{Rhinopoma cystops (Gray, 1831)}

Animalia - Chordata- Mammalia- Chiroptera- Rhinopomatidae

Common name(s): Lesser mouse-tailed bat.

Red List status: Least Concern.

Justification: A widespread and common species and no threats known to affect its population at present.

Geographical range: Occurs across central and northern Africa through Arabia and southern Asia; from Morocco to India north to Palestine, Jordan Iraq and Afghanistan and south to Kenya. In Jordan, this species is recorded from Wadi Fidan, Al Majdal, Jarash, Tabaqat Fahl, An Naqah, Petra, Aqaba, Az Zara, Baptism Site, Bethania, Ghawr es Safi, Iraq Al Amir, Jufat Al Qafrayn, Karak Castle, Khirbet Finan, Qurayqira, Umm Qais, Wadi Al Hasa, Wadi Al Wala, Wadi Dana, Wadi Ibn Hammad, Wadi Shu'ayb, Wadi Weida'a and Al Jubyha.

Population: Species' population data is not available from Jordan, but appears to be particularly abundant based on observations.

\section{Area of occupancy}

68

\section{Extent of occurrence}

6548

Biogeographical realms: Palearctic, Afrotropical.

General use and trade information: No trade or use in this species is known.

Threats: No major threats reported, but human disturbance in roost sites and pesticide might be considered potential threats (Amr et al., 2006a).

Conservation actions: This species is protected in situ in Yarmouk Protected Area, Dana and Mujib Biosphere Reserves, and Fifa Protected Area.

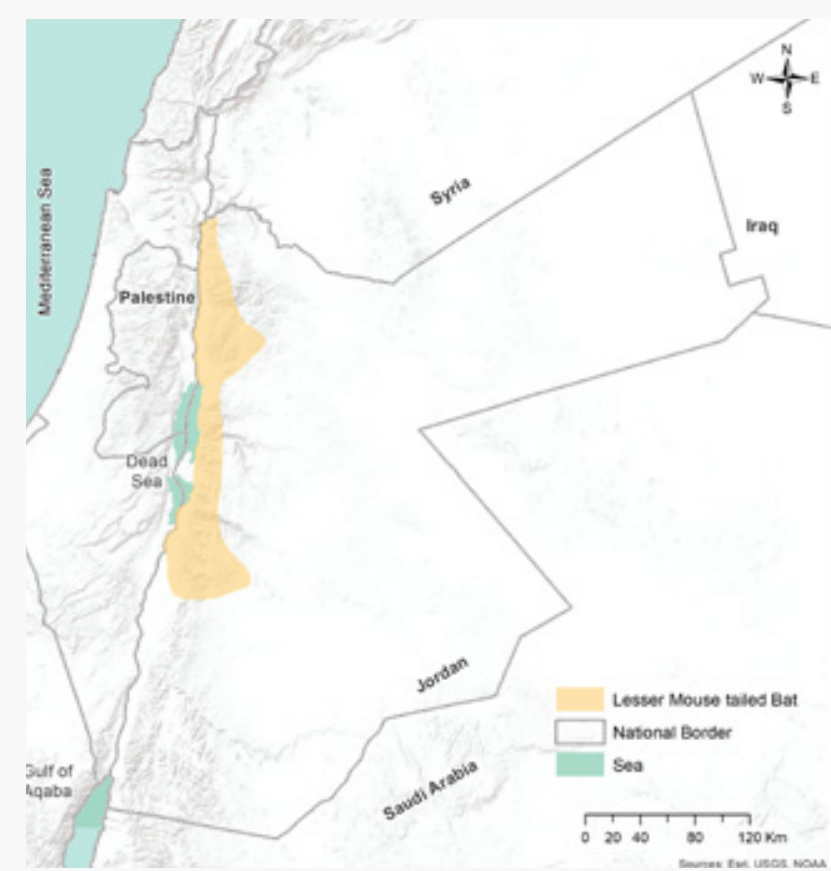

Map 14: Distribution of Rhinopoma cystops in Jordan.

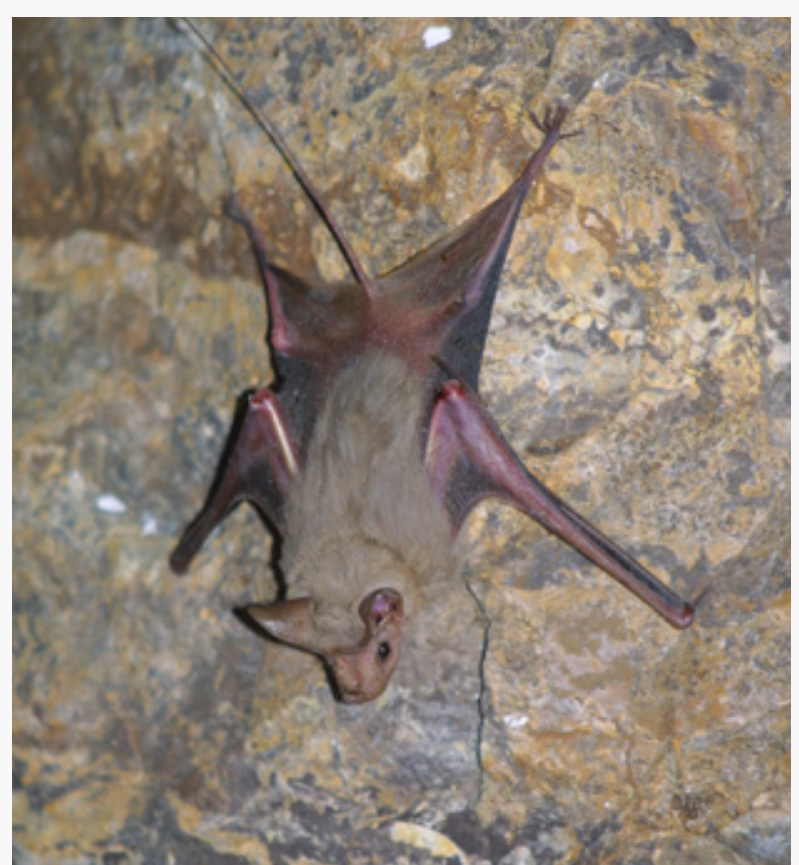

Figure 17: Rhinopoma cystops (C Mohammad Abu Baker) 


\section{Rhinopoma microphyllum (Brünnich, 1782)}

Animalia - Chordata - Mammalia - Chiroptera - Rhinopomatidae

Common name(s): Greater mouse-tailed bat.

Red List status: Endangered A1a; B1, B2ab (iii).

Justification: The population of this species is declining in Jordan, and several threats are affecting the existing population especially from the agricultural expansion in their areas of occurrence and the intensive use of pesticides.

Geographical range: Distribution range extends from northern Africa through southwest Asia to Afghanistan, Pakistan and India. In Southeast Asia, there are single old records from Thailand, Sumatra, Egypt, Jordan, and Morocco. In Jordan, this species is recorded from Al Majdal, Tabqat Fahl, Petra, Arjan, and Jufat Al Qafrayn.

Population: No estimates of the population size is available from Jordan.

\section{Area of occupancy}

28

\section{Extent of occurrence}

Biogeographical realms: Palearctic, Afrotropical, Oriental.

General use and trade information: No trade or use in this species is known.

Threats: Human disturbance in roost sites and use of pesticides are considered major threats at present (Amr et al., 2006a).

Conservation actions: This species is protected in situ in Mujib Biosphere Reserve.

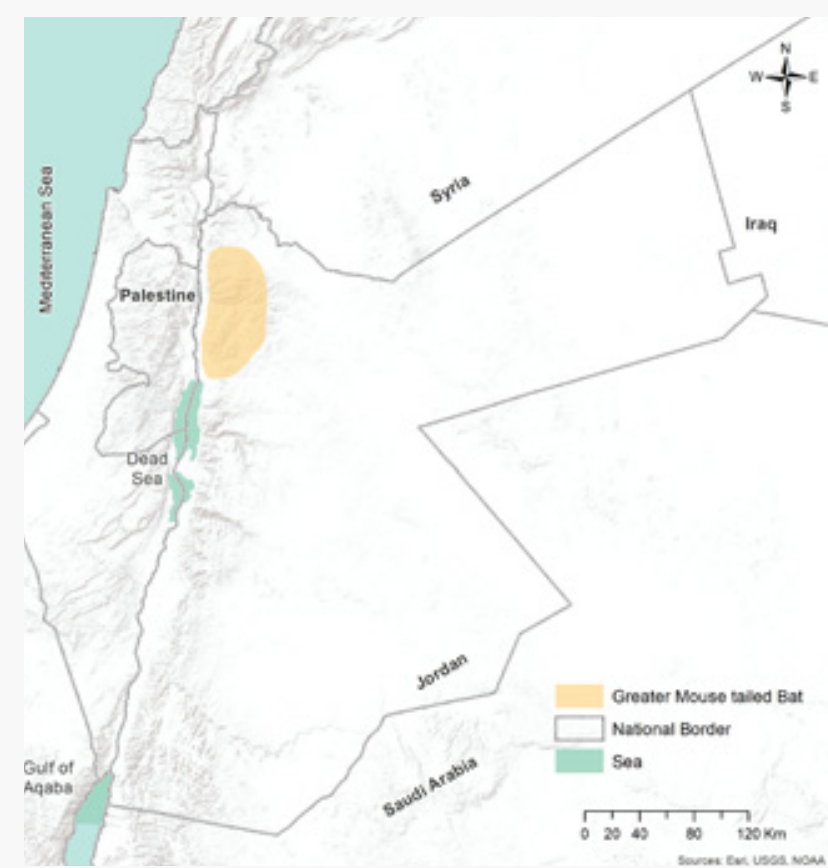

Map 15: Distribution of Rhinopoma microphyllum in Jordan.

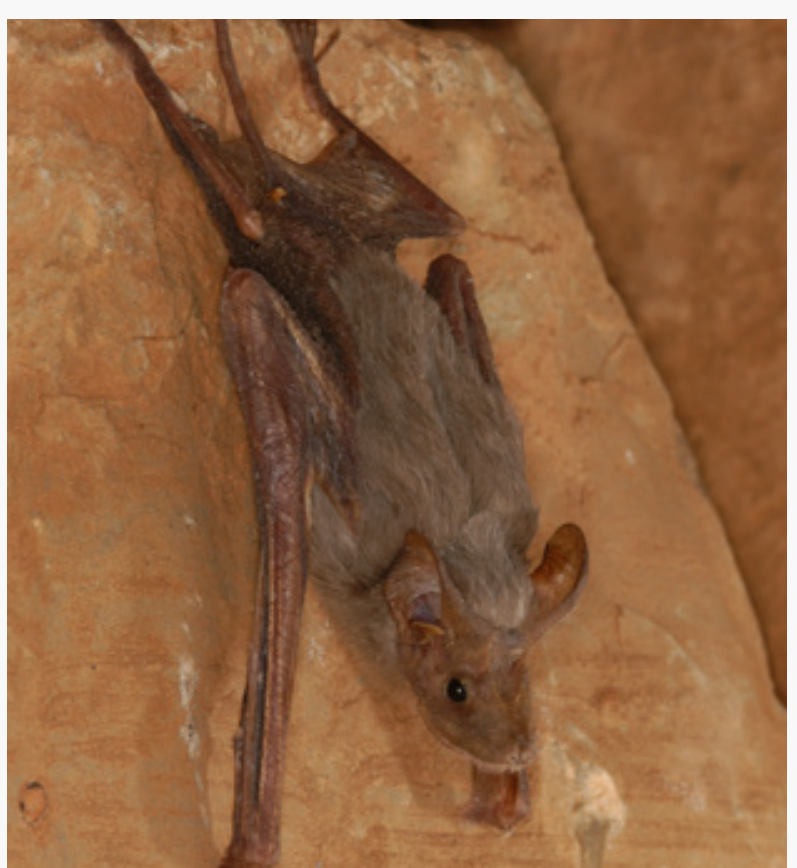

Figure 18: Rhinopoma microphyllum (@ Antonin Reiter) 


\section{Taphozous perforatus (E. Geoffroy, 1818)}

Animalia - Chordata - Mammalia - Chiroptera - Emballonuridae

Common name(s): Egyptian tomb bat, Geoffroy's tomb bat, African taphozous, Perforated taphozous bat, Tomb bat.

Red List status: Endangered B1, B2ab (iii).

Justification: This species is considered a rare species in Jordan. There is a continuous decline in its population, where threats affecting its areas of occurrence are still ongoing.

Geographical range: Senegal to Botswana, Mozambique, Somalia and Egypt, Jordan, Palestine, S Arabia, S Iran, Pakistan, NW India. In Jordan, this species is recorded 2 km East Ghawr es Safi, Az Zara, Al Mujib Nature Reserve, Hammamat Borbatah, Jufat Al Qafrayn and Wadi Ibn Hammad.

Population: Very rare species, and the population is declining in Jordan.

Area of occupancy

28

\section{Extent of occurrence}

Biogeographical realms: Afrotropical, Oriental.

General use and trade information: No trade or use in this species is known.

Threats: Disturbance of caves from visitors is a major threat.

Conservation actions: This species is protected in situ in Mujib Biosphere Reserve.

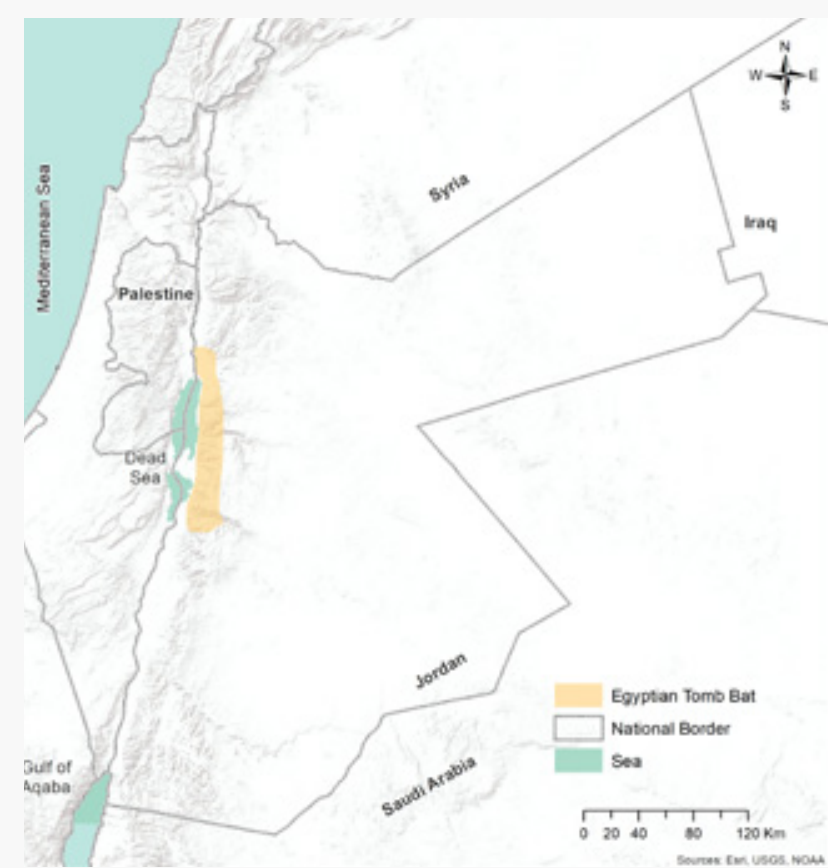

Map 16: Distribution of Taphozous perforatus in Jordan

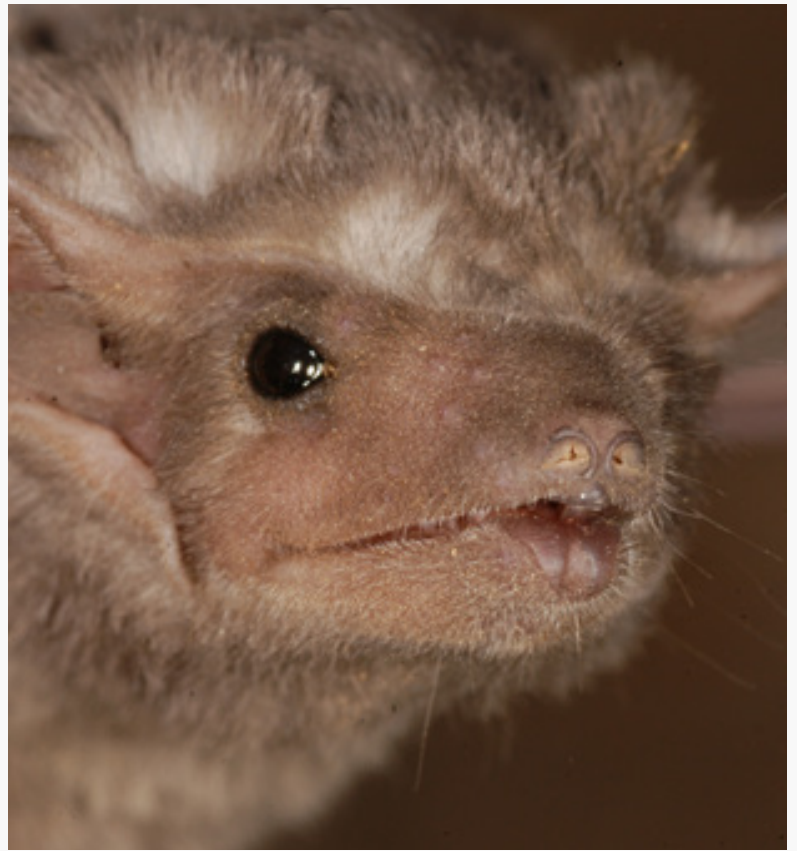

Figure 19: Taphozous perforatus (C Antonin Reiter) 


\section{Taphozous nudiventris (Cretzschmar, 1830)}

Animalia - Chordata - Mammalia - Chiroptera - Emballonuridae

Common name(s): Naked-rumped tomb bat.

Red List status: Endangered B1, B2ab (iii).

Justification: Listed as Endangered for its limited distribution, presumed small population, and because it is likely to be declining fast enough to be qualified for Listing in a threatened category.

Geographical range: It has been recorded throughout the southern desert and sub-desert belt of western and central Palaearctic, from Morocco, through the Saharan region across northern Africa to Egypt and north through the Middle East to southern Turkey, and the more arid areas of the Indian subcontinent. The most southerly record is from northern Tanzania. In South Asia this species is presently known from Afghanistan (Kabul, Kandahar and Nangarhar provinces), Bangladesh, India (Andhra Pradesh, Bihar, Delhi, Gujarat, Karnataka, Madhya Pradesh, Maharashtra, Rajasthan, Sikkim, Tamil Nadu, Uttar Pradesh and West Bengal) and Pakistan (Punjab and Sind). In Jordan, this species is recorded between South Shunah and Suwaymah, Ar Raddass, Az Zara Springs, Hammamat Borbatah, and Jufat Al Qafrayn.

Population: Population is declining in Jordan

\section{Area of occupancy}

\section{Extent of occurrence}

Biogeographical realms: Afrotropical, Oriental.

General use and trade information: No trade or use in this species is known.

Threats: Human disturbance, loss of roosts and use of pesticides impact populations negatively (Amr et al., 2006).

Conservation actions: This species is protected in situ in Mujib Biosphere Reserve.

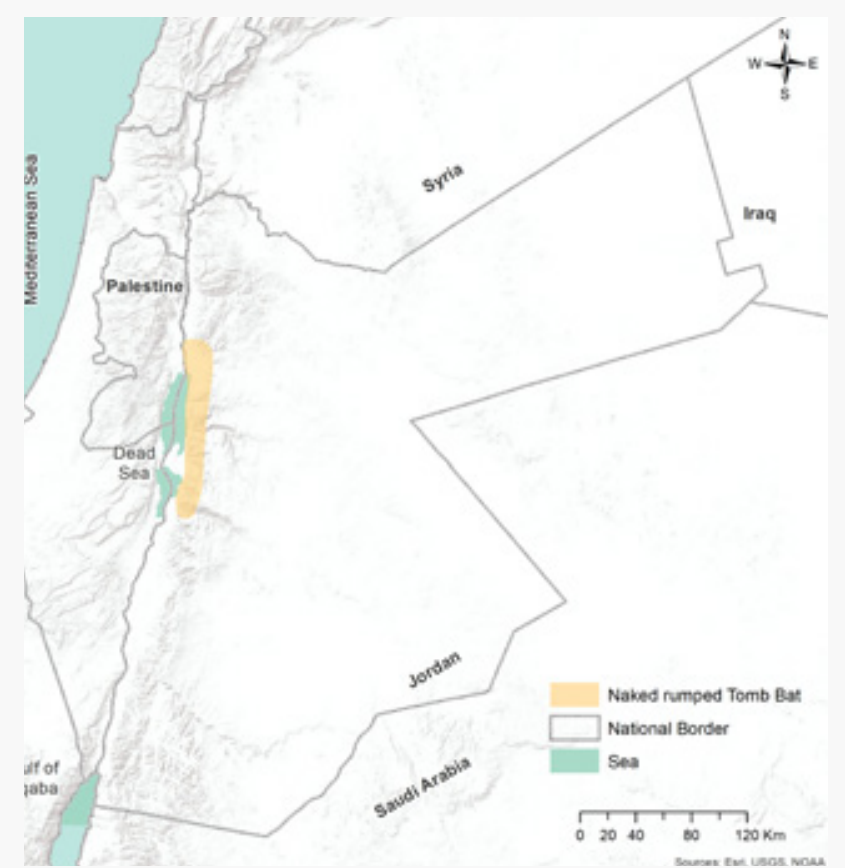

Map 17: Distribution of Taphozous nudiventris in Jordan.

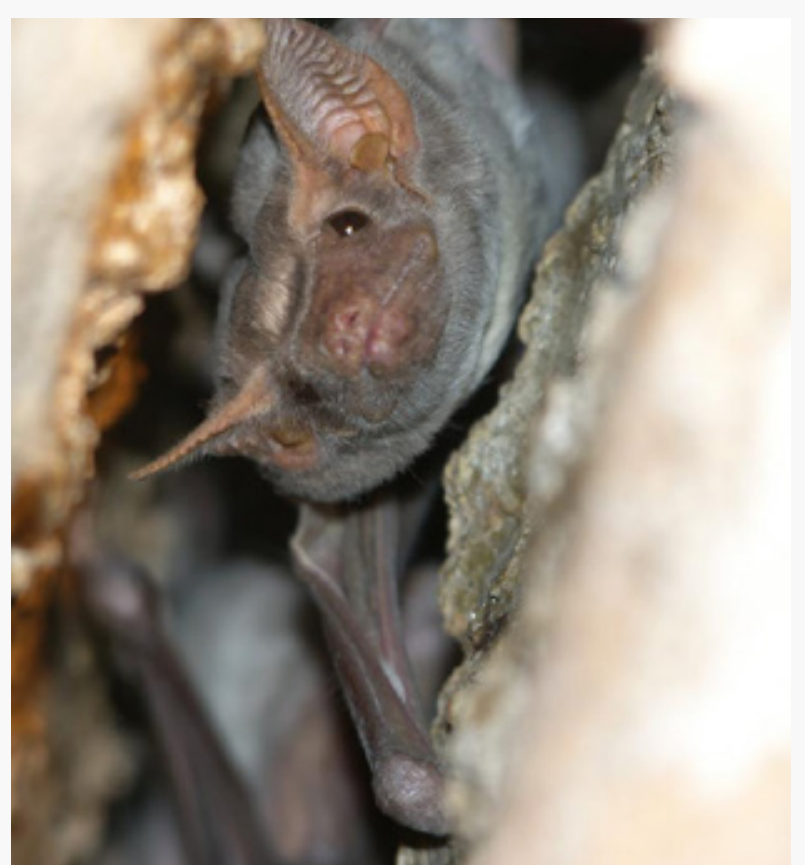

Figure 20: Taphozous nudiventris (@ Adwan Shehab) 


\section{Nycteris thebaica (E. Geoffroy, 1818)}

Animalia - Chordata- Mammalia- Chiroptera- Emballonuridae

Common name(s): Cape long-eared bat, Common slit-faced bat, Egyptian slit-faced bat, Geoffroy's nycteris.

Red List status: Endangered B1, B2ab (i, ii).

Justification: A rare species in Jordan, with few records. Threats on its population is ongoing and accelerated in its areas of occurrence.

Geographical range: Central Arabia; Palestine; Sinai; Egypt to Morocco, Senegal, Benin, Somalia and Kenya, then south to South Africa in open country; Zanzibar and Pemba. In Jordan, this species is recorded in Ar Raddass, Qurayqira, and Wadi Al Hasa.

Population: Rare and uncommon species with few specimens recorded in Jordan.

\section{Area of occupancy}

\section{Extent of occurrence}

Biogeographical realms: Afrotropical.

General use and trade information: No trade or use in this species is known.

Threats: Roost disturbance and degradation are the main threats.

Conservation actions: This species is protected in situ in Dana and Mujib Biosphere Reserves.

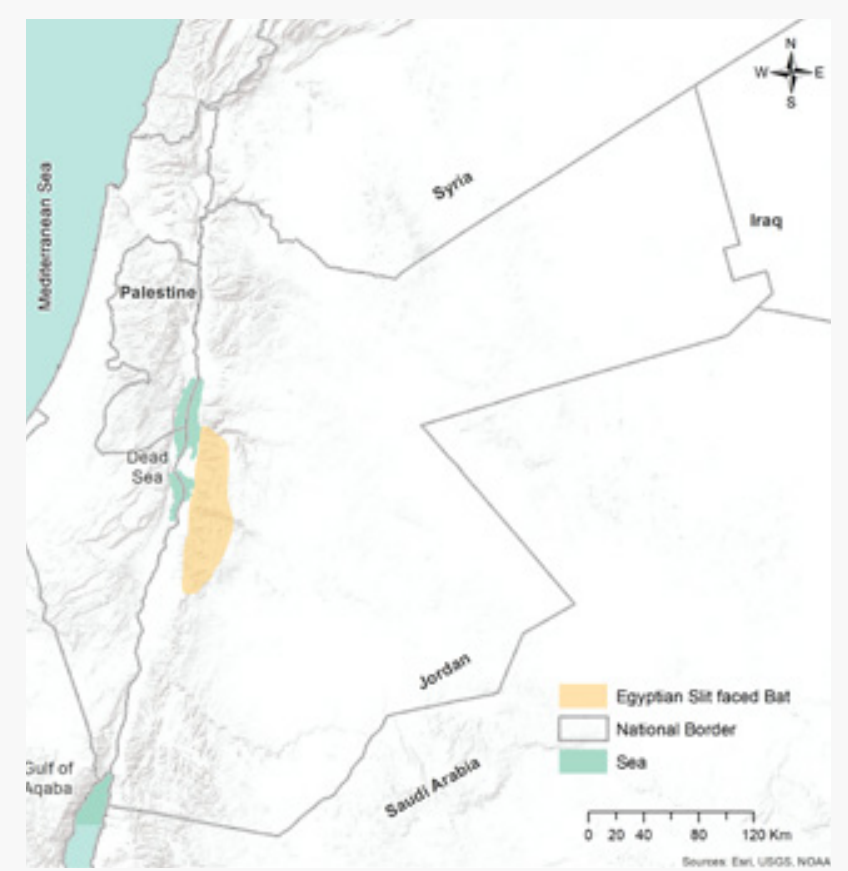

Map 18: Distribution of Nycteris thebaica in Jordan.

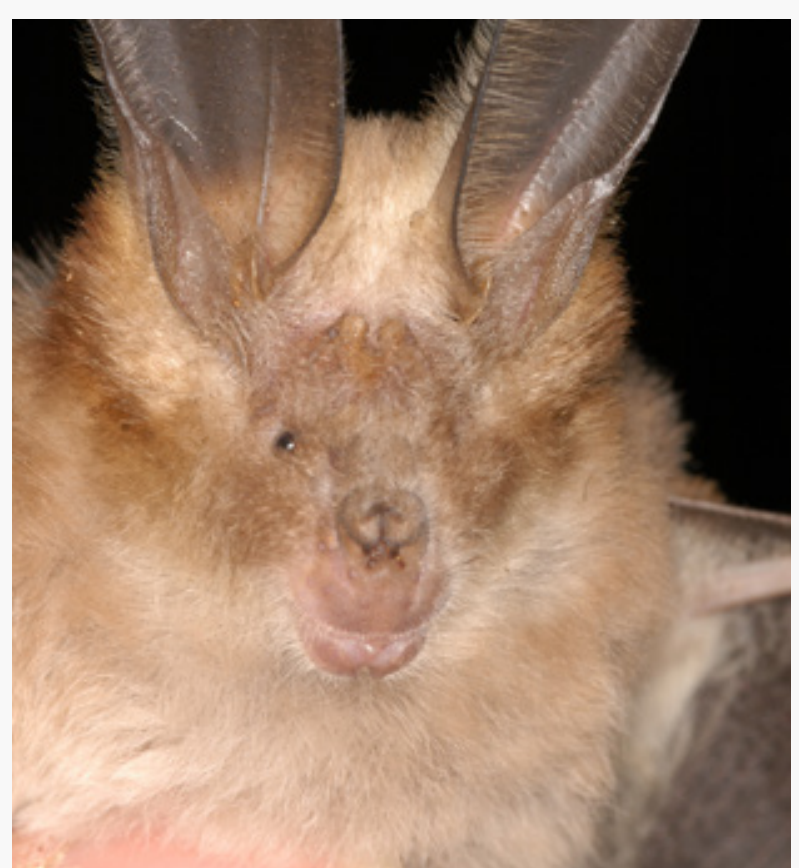

Figure 21: Nycteris thebaica (@ Antonin Reiter) 


\section{Tadarida teniotis (Rafinesque, 1814)}

Animalia - Chordata - Mammalia - Chiroptera - Molossidae

Common name(s): European free-tailed bat.

\section{Red List status: Least Concern.}

Justification: The species is widely distributed over a large extent of occurrence. In addition no threats are known to affect its population at present.

Geographical range: It is well known in the Mediterranean basin, occurring from Portugal, Spain eastwards through southern Europe to the Balkans, Turkey, Palestine and Jordan. In North Africa it has been recorded from Morocco, Algeria, Tunisia, Libya and Egypt. It is possibly present on Madeira (to Portugal) as there was a supposed old record, but it has not been recorded from there again. It occurs on all the Canary Islands (to Spain) except for Fuerteventura and Lanzarote. In Jordan, this species is recorded from Faidhat edh Dhahikiya, Wadi Sirhan, Jubyha, Disah, Ghawr es Safi, Jarash, Amman, Ar Raddass, Petra, Al Mujib Biosphere Reserve, Al Mustaba, Aqaba, Azraq wetland, Az Zara, Dana, Dilagha, Duqra, Iraq Al Amir, Ma'an, Qaser Amra, Qasr Burqu, Qurayqira, Rashah, South Shunah, Tall Numiera, Umm Qais, Wadi Al Wala, Wadi Ghuweir, Wadi Rum, Wadi Shu'ayb, Wadi Weida'a, Wadi Zarqa Ma'in, Zarqa, and Wadi Al Hasa.

Population: It is a common species with a wide distribution.

\section{Area of occupancy}

\section{Extent of occurrence}

15890

Biogeographical realms: Palearctic.

General use and trade information: No trade or use in this species is known.

Threats: It is negatively affected by disturbance, loss of roosts in buildings, and use of pesticides. Deforestation affects the species in some parts of its range (Amr et al., 2006a).

Conservation actions: This species is protected in situ in Dibeen and Ajloun Forest Reserves, Dana and Mujib Biosphere Reserves, and Wadi Rum World Heritage Area.

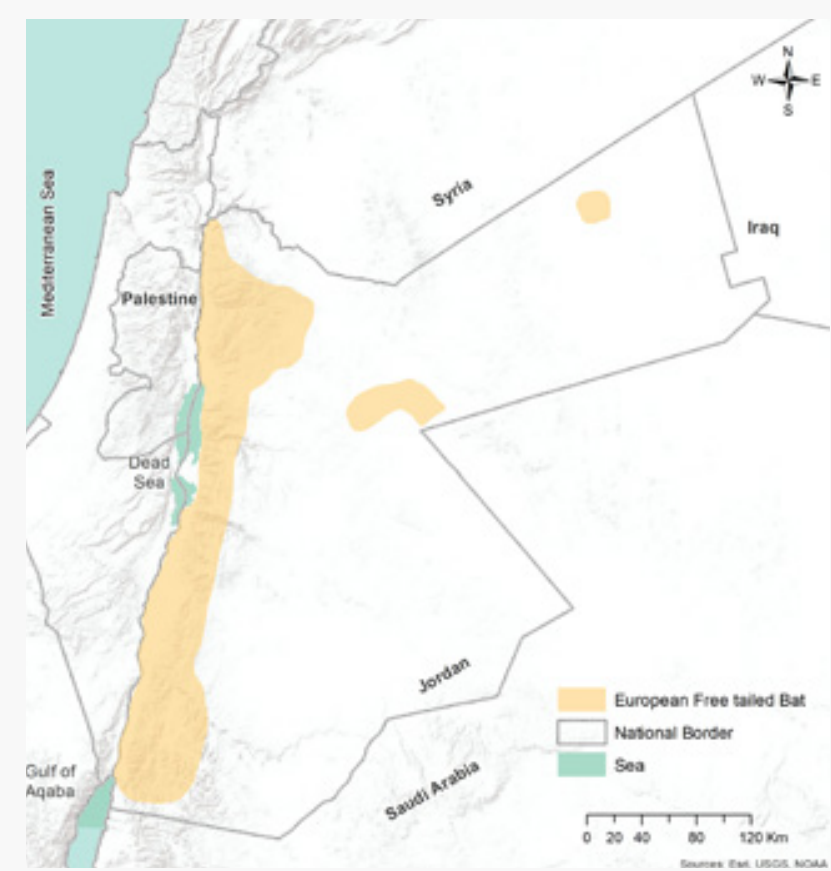

Map 19: Distribution of Tadarida teniotis in Jordan.

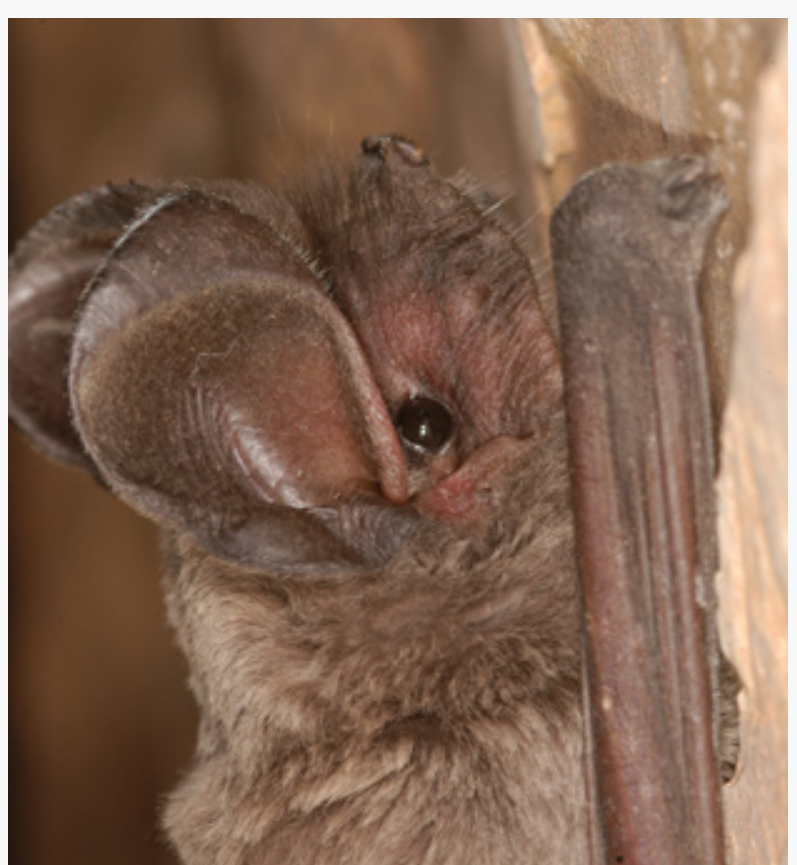

Figure 22: Tadarida teniotis (C Antonin Reiter) 


\section{Miniopterus pallidus (Tomes, 1857)}

Animalia - Chordata - Mammalia - Chiroptera - Vespertilionidae

Common name(s): Not assigned.

Red List status: Endangered B1, B2ab.

Justification: This species has a confined distribution in Jordan and is under continuous decline due to the continued threats that are affecting its population. This species was known previously as Miniopterus scherbersii.

Geographical range: S Europe, north to Netherlands and S Poland, Crimea, Caucasus, east to Uzbekistan and E Iran; Palestine; Morocco; Algeria; Tunisia; Lebanon; Afghanistan. In Jordan, this species is recorded from Dibbin, Jarash, Ramtha, and Khashibah.

Population: No estimates of the population size is available from Jordan.

\section{Area of occupancy}

\section{Extent of occurrence}

660

Biogeographical realms: Palearctic.

General use and trade information: No trade or use in this species is known.

Threats: Changes in land management, especially agricultural activities, can affect populations of this species. Disturbance to roosts in caves and buildings and using caves by herders and their livestock may also be a problem (Amr et al., 2006a).

Conservation actions: This species is not protected by any means in Jordan.

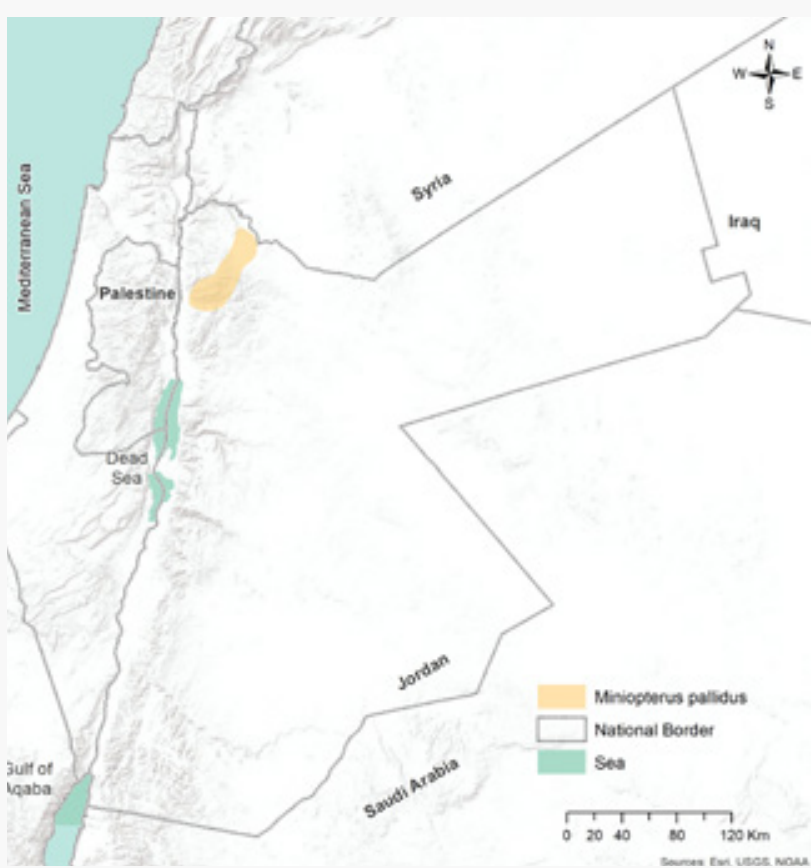

Map 20: Distribution of Miniopterus pallidus in Jordan

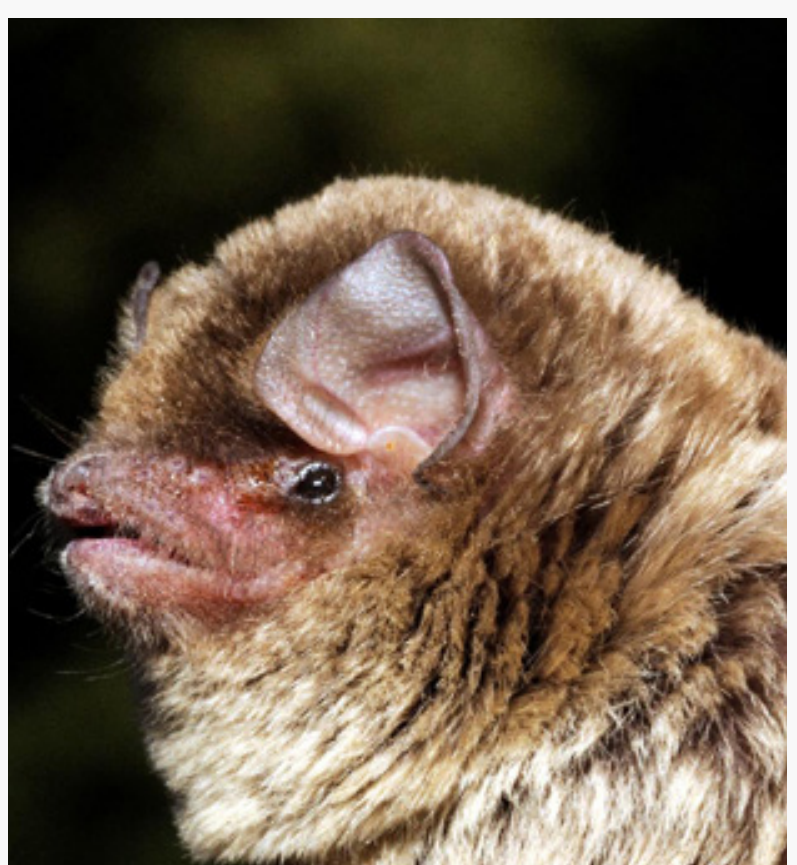

Figure 23: Miniopterus pallidus (@ Antonin Reiter) 


\section{Barbastella leucomelas (Cretzschmar, 1826)}

Animalia - Chordata - Mammalia - Chiroptera - Vespertilionidae

Common name(s): Eastern barbastelle, Asian barbastelle.

Red List status: Near Threatened.

Justification: Uncommon species, and its records are recent in Jordan (Benda et al., 2009). It is considered endemic to the desert regions surroundings the northern edge of the Red Sea. It was assessed as a Near Threatened species since limited knowledge is available on its presumable small population in Jordan. Therefore, more research is needed to identify its population status and to document the threats, which are affecting its population.

Geographical range: Afghanistan, Armenia, Azerbaijan; Bhutan, China, Sinai, Eritrea, Georgia, India, Iran, Palestine, Jordan, Japan, Kyrgyzstan, Nepal, Pakistan, Russian Federation, Saudi Arabia, Taiwan, China, Tajikistan, Turkmenistan, Uzbekistan. In Jordan, this species is recorded from Al Ghal, As Salihiyyah, Jebel Masuda, and Dana Biosphere Reserve.

Population: Rare or uncommon species, where only individuals were recorded but no colonies.

\section{Area of occupancy}

16

\section{Extent of occurrence}

4138

Biogeographical realms: Oriental.

General use and trade information: No trade or use in this species is known.

Threats: The main threat is destruction of roosting areas and human disturbance through fire and using caves as sheep enclosures. In addition, use of pesticides in the Jordan Valley, especially in Ghor Safi area (Amr et al., 2006).

Conservation actions: This species is protected in situ in Dana Biosphere Reserve and Wadi Rum World Heritage Area.

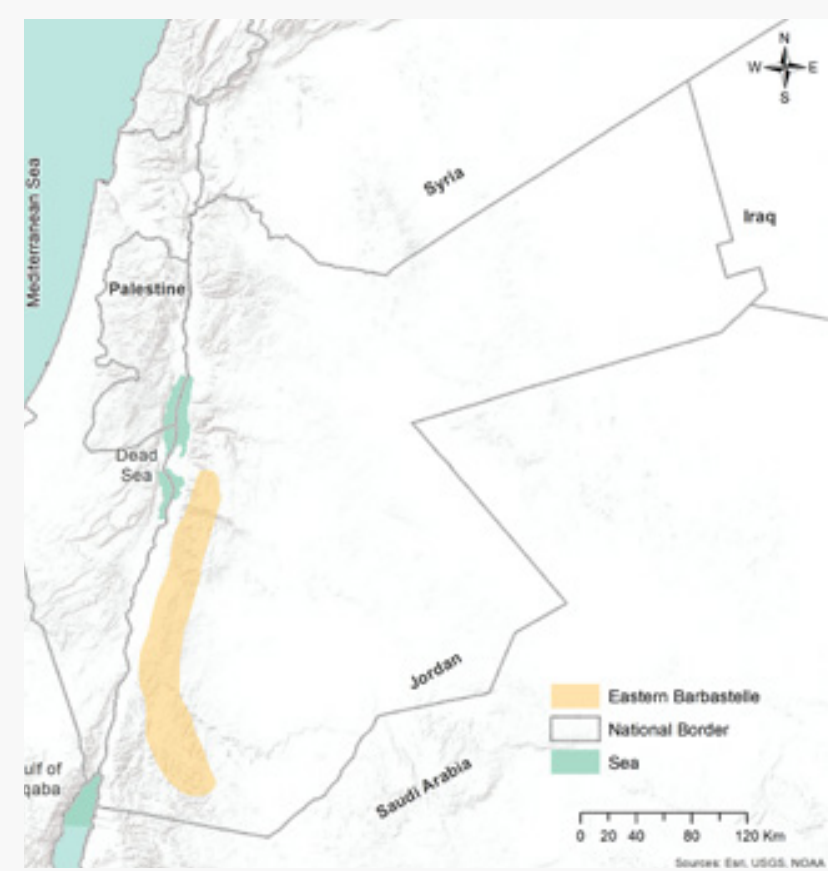

Map 21: Distribution of Barbastella leucomelas in Jordan

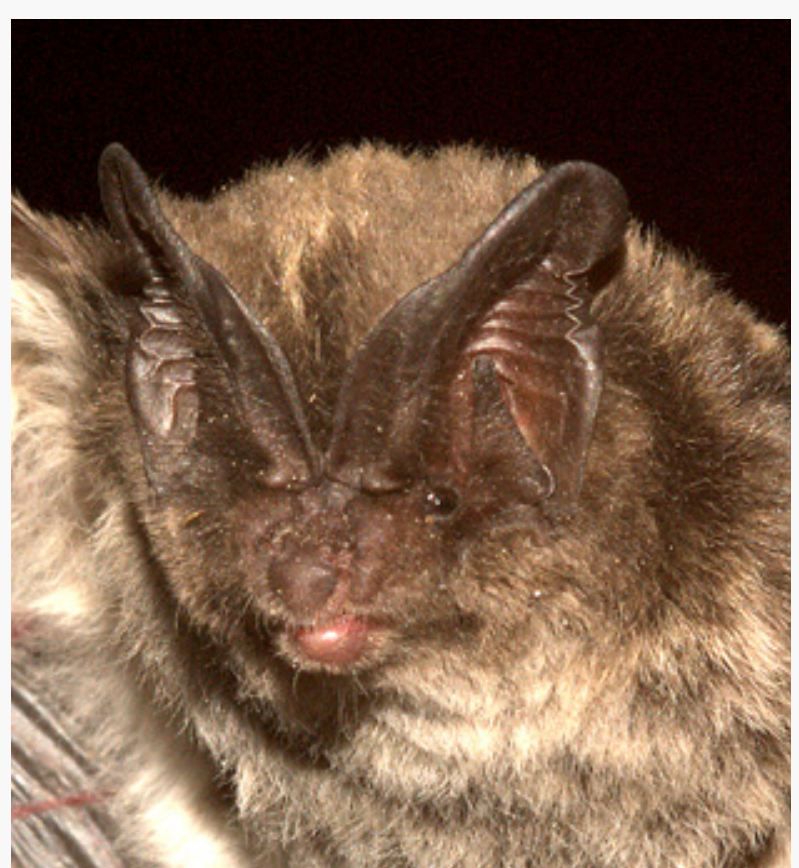

Figure 24: Barbastella leucomelas (@ Antonin Reiter) 


\section{Eptesicus bottae (Peters, 1869)}

Animalia - Chordata - Mammalia - Chiroptera - Vespertilionidae

Common name(s): Botta's serotine.

Red List status: Least Concern.

Justification: The species has a relatively wide range of distribution in Jordan along the Jordan Rift Valley and is considered common. In addition, no major threats are known. Hence it is Listed as Least Concern.

Geographical range: Occurs from the eastern Mediterranean around margins of Arabian Peninsula to Iraq, Iran and southern Caucasus states; also from central Asia to India, northwestern China and possibly Mongolia. In Jordan, this species is recorded from Wadi Rum, Disah, Petra, Ar Raddass, Ras Al Naqab, Al Ghal, Al Maqar'iyya, As Salihiyyah, Dana, Hammamat Borbatah, Jabal Al Bayda, Jebel Masuda, Jufat Al Qafrayn, Mu'ta, Mujib Reserve, Qurayqira, Wadi AI Wala, Wadi Rum, and Wadi Weida'a.

Population: It is considered common species in Jordan.

Area of occupancy

72

\section{Extent of occurrence}

8550

Biogeographical realms: Palaearctic.

General use and trade information: No trade or use in this species is known.

Threats: Destruction of caves and disturbance by visitors are the main threats for this species.

Conservation actions: This species is protected in situ in Dana and Mujib Biosphere Reserves as well as Wadi Rum World Heritage Area.

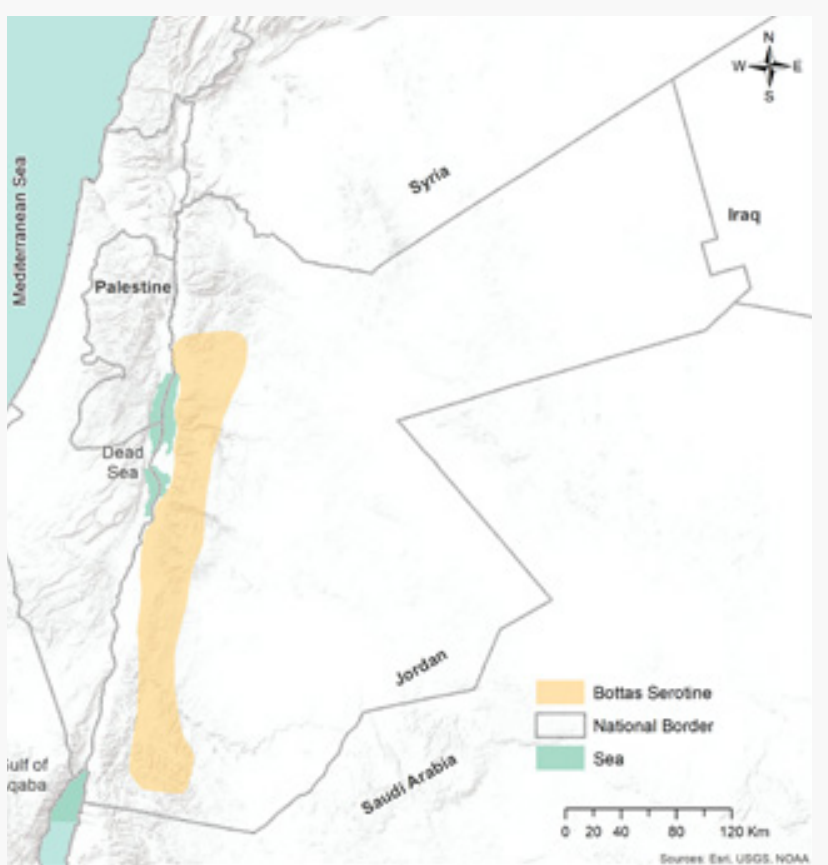

Map 22: Distribution of Eptesicus bottae in Jordan

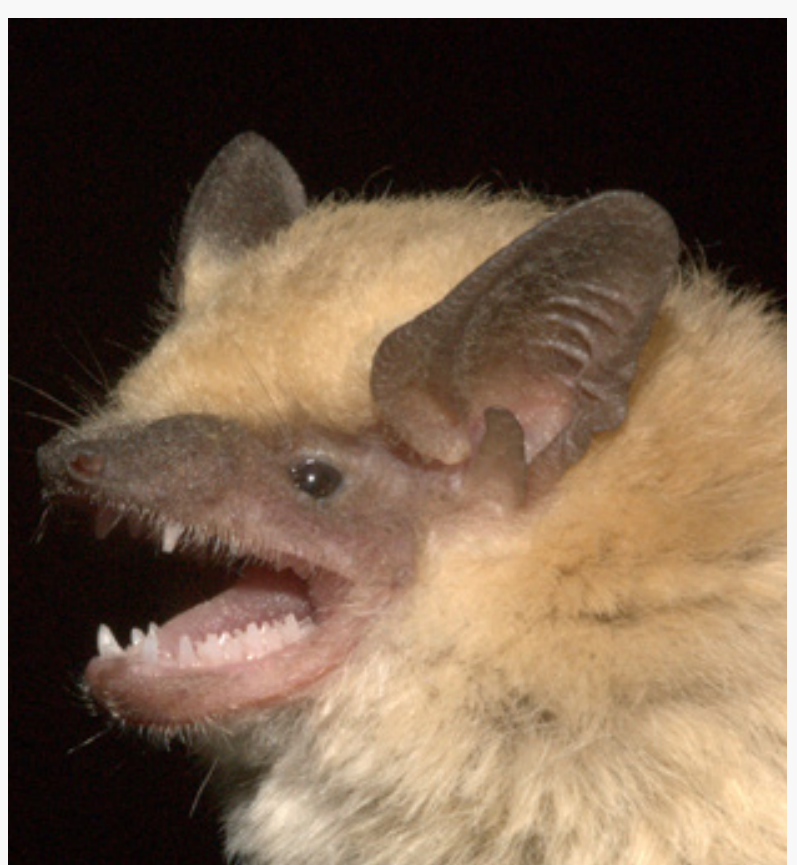

Figure 25: Eptesicus bottae ( Antonin Reiter) 


\section{Hypsugo ariel (Thomas, 1904)}

Animalia - Chordata - Mammalia - Chiroptera - Vespertilionidae

Common name(s): Desert pipistrelle.

Red List status: Least Concern.

Justification: common and distributed in arid and dry regions of the Jordanian deserts along Wadi Araba and Wadi Rum. Previous records for Pipistrellus bodenheimeri and Pipistrellus ariel from Jordan are considered now as Hypsugo ariel.

Geographical range: Recorded from Palestine, Jordan, Egypt, Saudi Arabia, and Sudan. In Jordan, this species is recorded in Disah, Ghawr es Safi, Petra, Al Ghal, Dana, Hammamat Borbatah, Tall Numiera, Wadi Abu Al 'Asal, Wadi lbn Hammat, Wadi Rum and Wadi Weida'a.

Population: The population is apparently small but is probably stable

\section{Area of occupancy}

\section{Extent of occurrence}

Biogeographical realms: Afrotropical.

General use and trade information: No trade or use in this species is known.

Threats: Destruction of caves and disturbance by visitors are the main threats for this species. Loss of natural habitat because of agricultural intensification and use of pesticides is another threat but to a lesser extent (Amr et al., 2006a).

Conservation actions: This species is protected in situ in Mujib and Dana Biosphere Reserves, and Wadi Rum World Heritage Area.

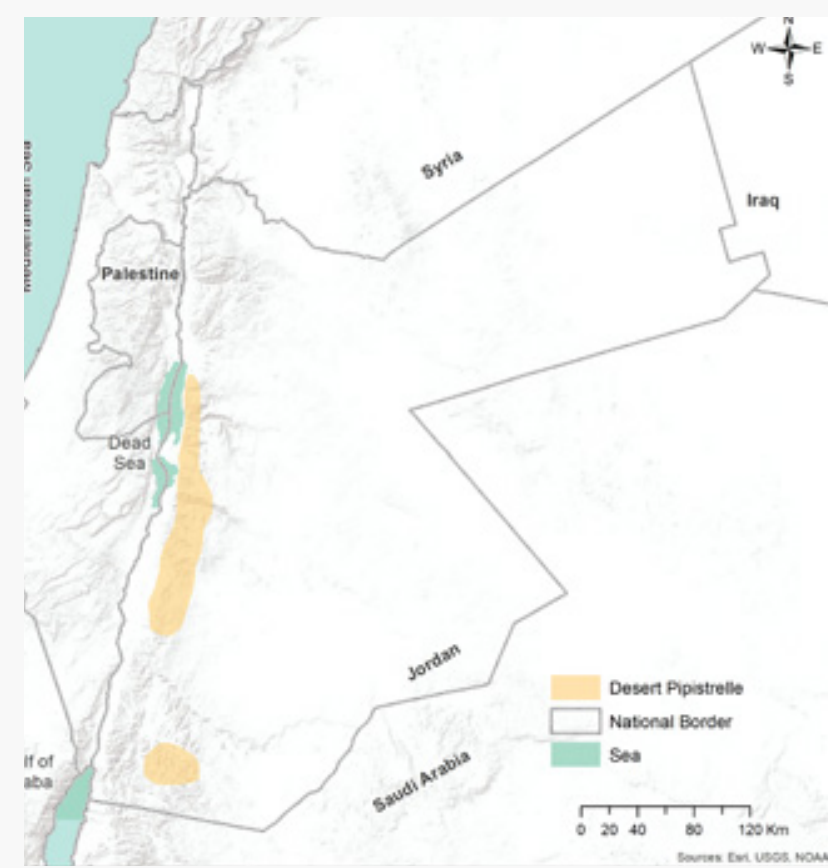

Map 23: Distribution of Hypsugo ariel in Jordan.

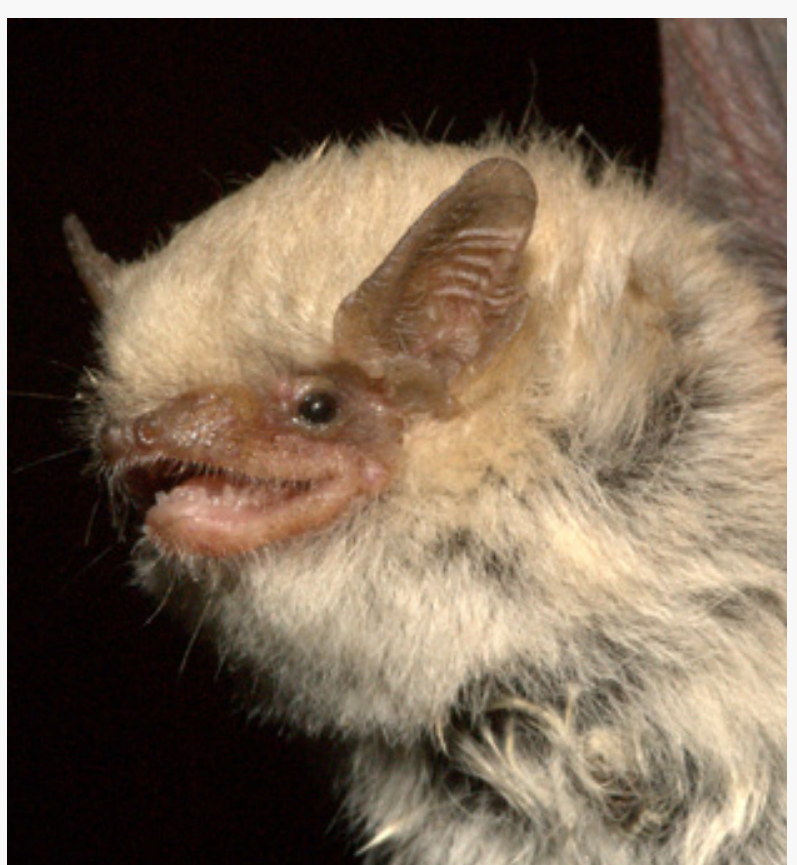

Figure 26: Hypsugo ariel (@ Antonin Reiter) 


\section{Myotis blythii (Tomes, 1857)}

Animalia - Chordata - Mammalia - Chiroptera - Vespertilionidae

Common name(s): Lesser mouse-eared myotis, Lesser mouse-eared bat.

Red List status: Endangered B1, B2ab (i, ii, iii).

Justification: A rare species, with a confined distribution limited to the forested region in the northern parts of Jordan. The species is experiencing serious threats due to heavy pressures on the limited forest areas which represents less than $1 \%$ of Jordan area.

Geographical range: Southern Europe, southern parts of central Europe, and non-arid parts of southwestern Asia from Asia Minor. In Jordan, this species is recorded in Khashibah and Iraq Al Wahaj.

Population: Population is under sever threat in Jordan.

\section{Area of occupancy}

\section{Extent of occurrence}

28

170

Biogeographical realms: Palearctic.

General use and trade information: No trade or use in this species is known.

Threats: Changes in land use patterns, especially forest degradation and other agricultural activities encroachments. Disturbance to roosts in caves and buildings. Use of caves by herders and their livestock may also be a problem.

Conservation actions: This species is not protected in Jordan.

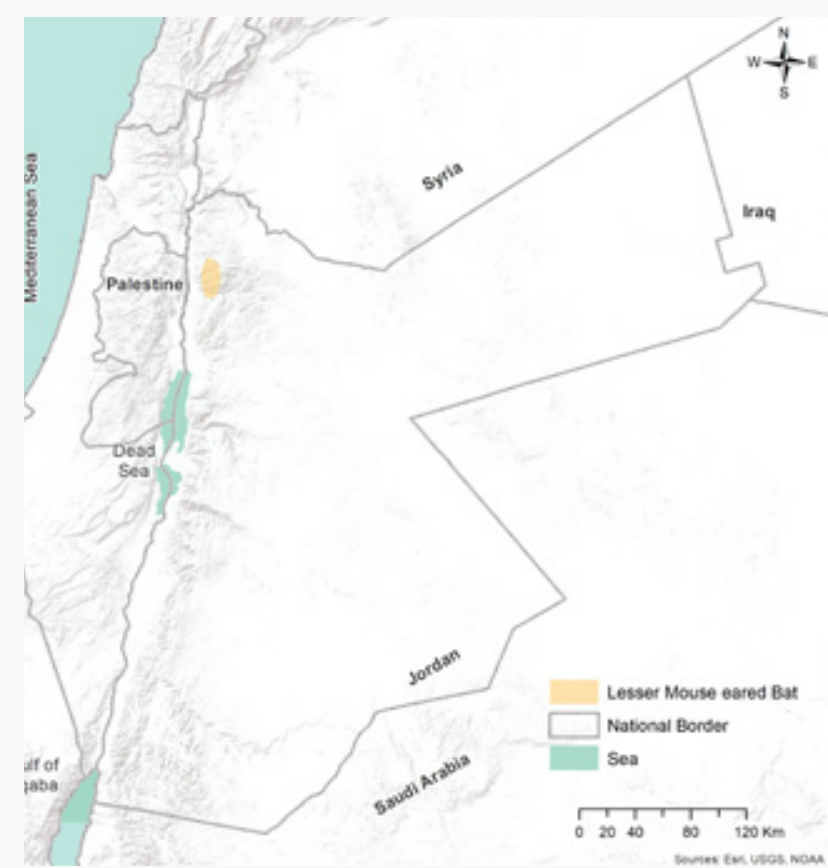

Map 24: Distribution of Myotis blythii in Jordan.

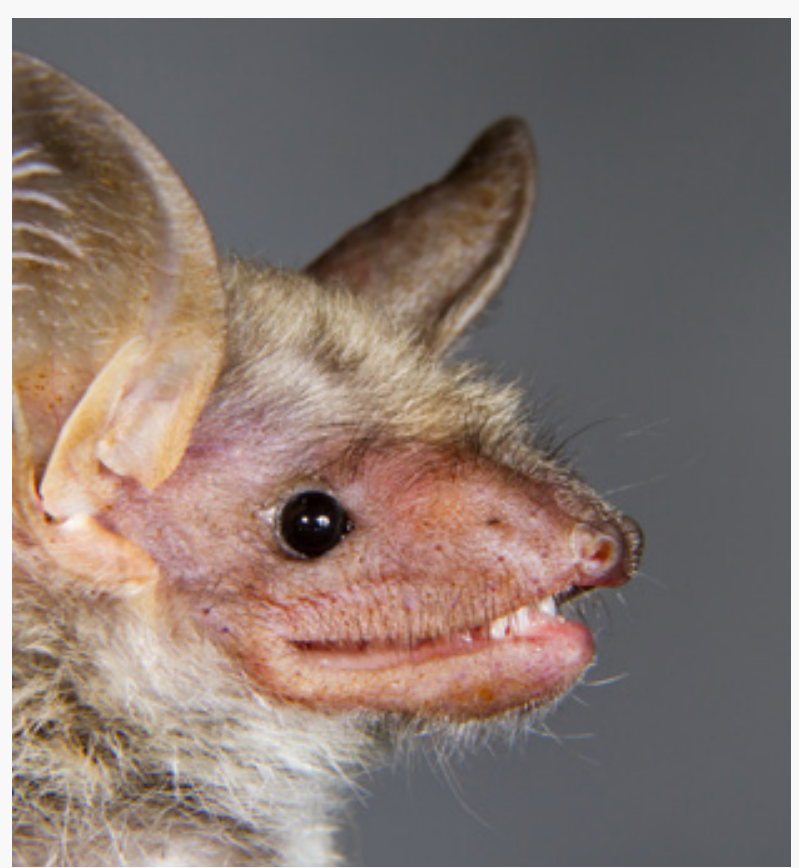

Figure 27: Myotis blythii (C Antonin Reiter) 


\section{Myotis capaccinii (Bonaparte, 1837)}

Animalia - Chordata - Mammalia - Chiroptera - Vespertilionidae

Common name(s): Long-fingered bat.

Red List status: Data Deficient.

Justification: A single record of this species was confirmed from Jordan, and represents the most southern extreme distribution in the region (Penda et al., 2010). More research is required on this species, detailing aspects such as habitat preferences, population size, threats and extent of occurrence.

Geographical range: Mediterranean zone and islands of Europe and NW Africa; Turkey; Palestine; Iraq; Iran; Uzbekistan. In Jordan, this species was only recorded in Tabqat Fahl.

Population: The population is thought to be declining due to habitat degradation.

Area of occupancy

4

\section{Extent of occurrence}

69

Biogeographical realms: Palearctic.

General use and trade information: No trade or use in this species is known.

Threats: Threats include changes in water quality due to pollution and dam construction, and loss of water bodies and watercourses. Damage or disturbance to caves used as roosts may also be a problem as the species is very dependent on caves.

Conservation actions: This species is Listed in Appendix III for wildlife protection of the Agricultural Law Number 13 for the year 2015 based on regulation Number 43 for the year 2008.

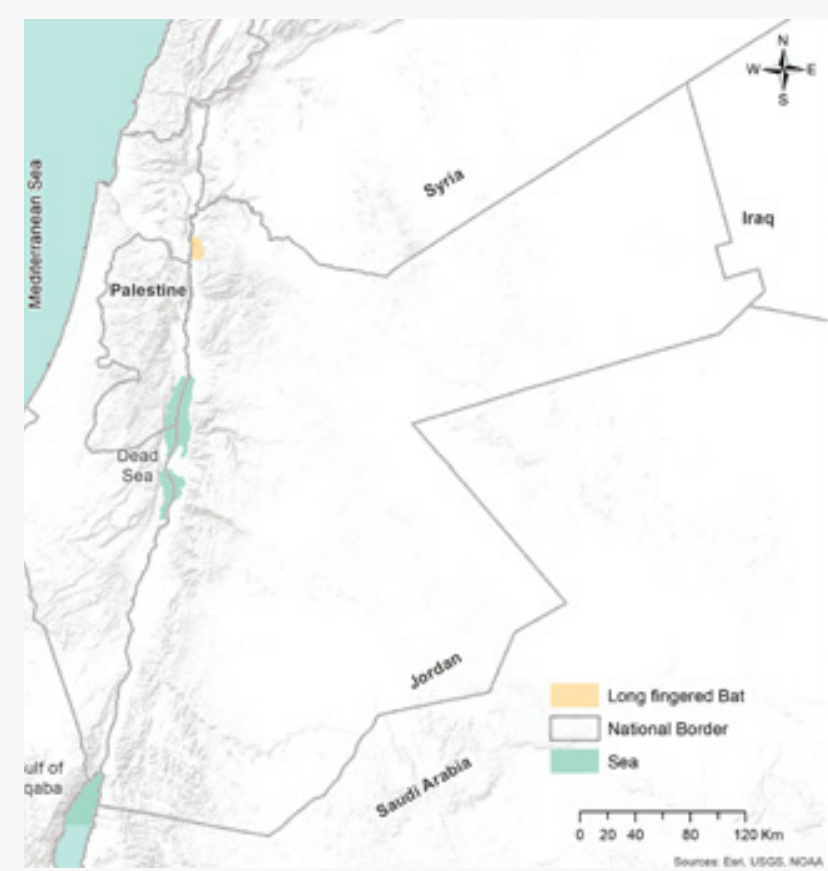

Map 25: Distribution of Myotis capaccinii in Jordan.

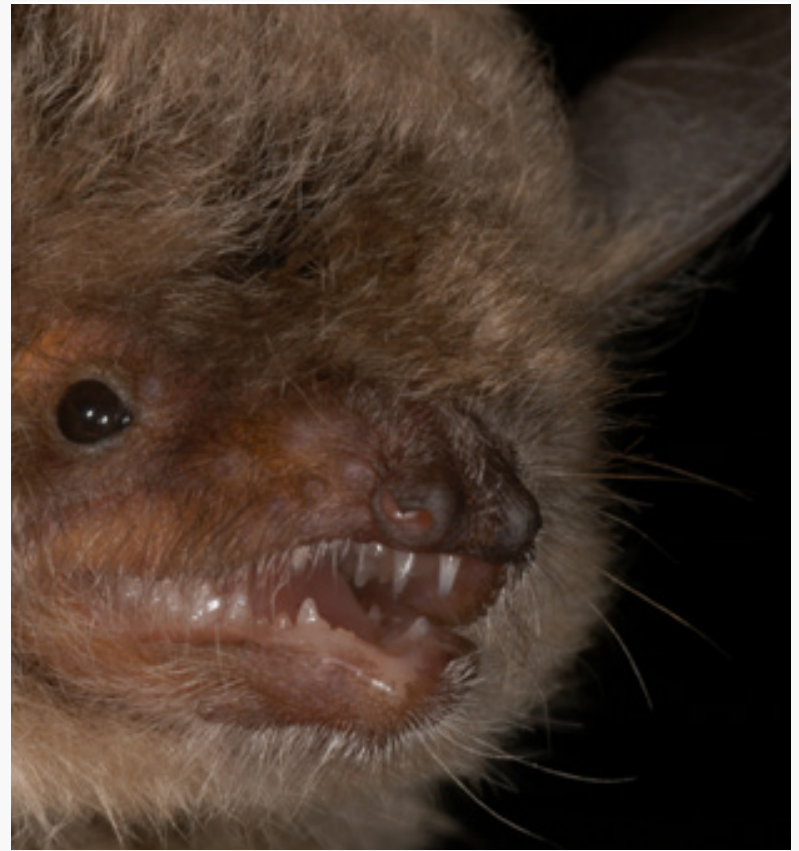

Figure 28: Myotis capaccinii (C Antonin Reiter) 


\section{Myotis emarginatus (E. Geoffroy, 1806)}

Animalia - Chordata - Mammalia - Chiroptera - Vespertilionidae

Common name(s): Geoffroy's bat, Geoffroy's myotis.

Red List status: Endangered B1, B2ab (i, ii, iii).

Justification: The species experienced a significant decline in most areas where it was recorded and it is restricted to forested areas at the northern areas of Jordan, which experienced heavy pressures of logging and forest degradation.

Geographical range: S Europe, north to Netherlands and S Poland, Crimea, Caucasus, east to Uzbekistan and E Iran; Palestine; Morocco; Algeria; Tunisia; Lebanon; Afghanistan. In Jordan, this species is found in Dibbin Forest Park, Arjan, Iraq Al Wahaj, Khashibah, and Zubiya.

Population: It may be rare as a sharp decline was recorded.

Area of occupancy

28

\section{Extent of occurrence}

705

Biogeographical realms: Palearctic.

General use and trade information: No trade or use in this species is known.

Threats: This species is mainly associated with forest habitats, therefore all deforestation and degradation activities can affect its population (Amr et al., 2006a). Destruction of caves, use of pesticides and disturbance by visitors are the main threats for this species.

Conservation actions: This species is protected in situ in Dibeen and Ajloun Forest Reserves.

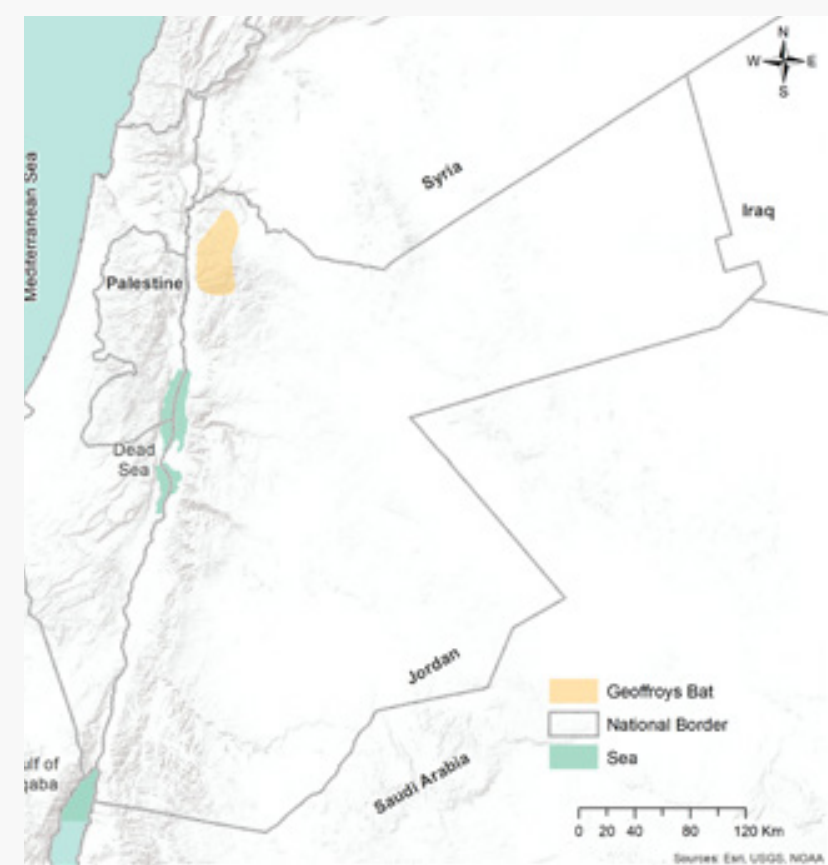

Map 26: Distribution of Myotis emarginatus in Jordan.

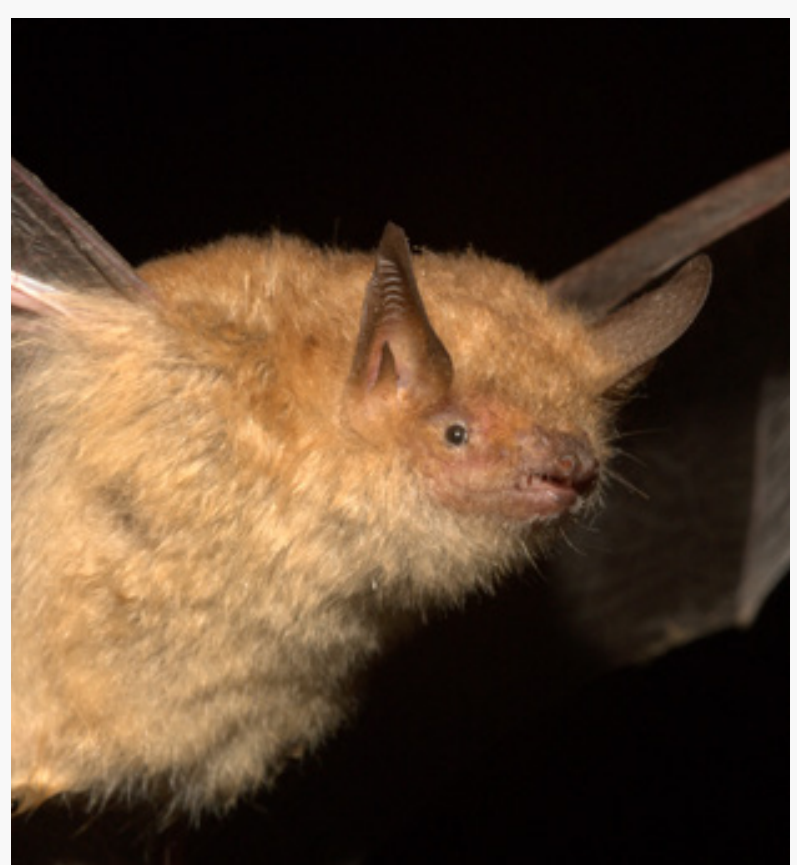

Figure 29: Myotis emarginatus (C Antonin Reiter) 


\section{Myotis nattereri (Kuhl, 1817)}

Animalia - Chordata - Mammalia - Chiroptera - Vespertilionidae

Common name(s): Natterer's bat.

\section{Red List status: Least Concern.}

Justification: This species occupies a wide range distribution, and is considered common with limited threats on its population.

Geographical range: Europe (except Scandinavia); NW Africa; Turkey; Palestine; Iraq; Crimea and Caucasus to Turkmenistan. In Jordan, this species is recorded in Dibbin Forest Park, Arjan, Ash Shawbak, Dana, Iraq Al Wahaj, and Zubiya.

Population: Population is stable in Jordan.

\section{Area of occupancy}

\section{Extent of occurrence}

28

1362

Biogeographical realms: Palaearctic.

General use and trade information: No trade or use in this species is known.

Threats: No major threats. However, the species is affected by loss of woodlands and other changes in land management and development (Amr et al., 2006a). Loss of or damage to roost sites may also be a problem.

Conservation actions: This species is protected in situ in Ajloun Forest Reserve and Dana Biosphere Reserve. In addition, it is Listed in Appendix III for wildlife protection based on Agricultural Law Number 13 for the year 2015 based on regulation Number 43 for the year 2008.

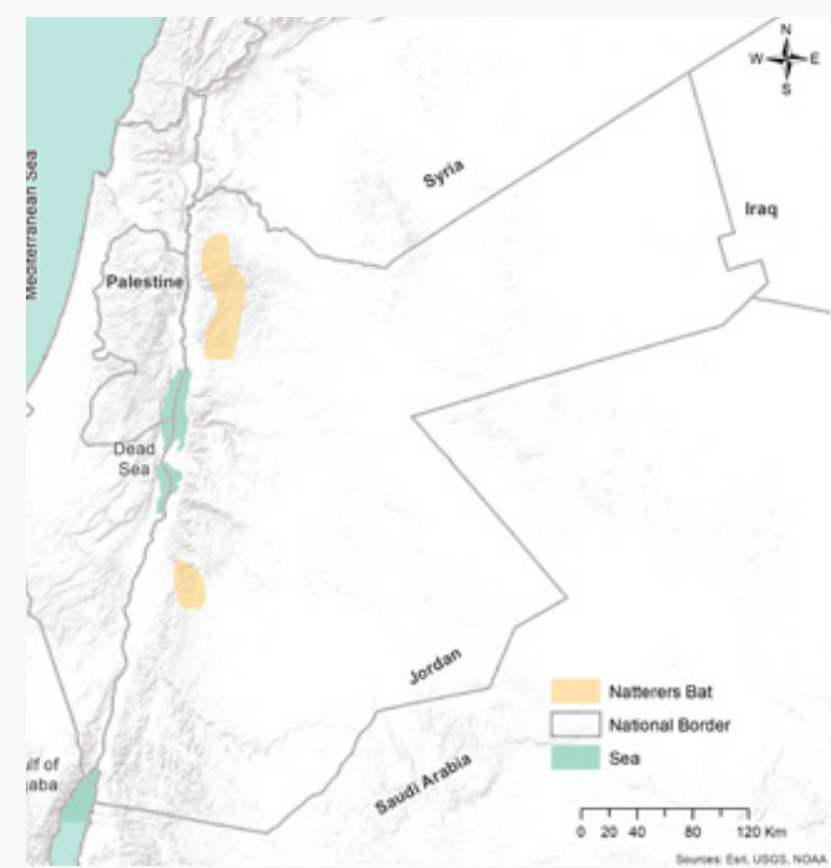

Map 27: Distribution of Myotis nattereri in Jordan.

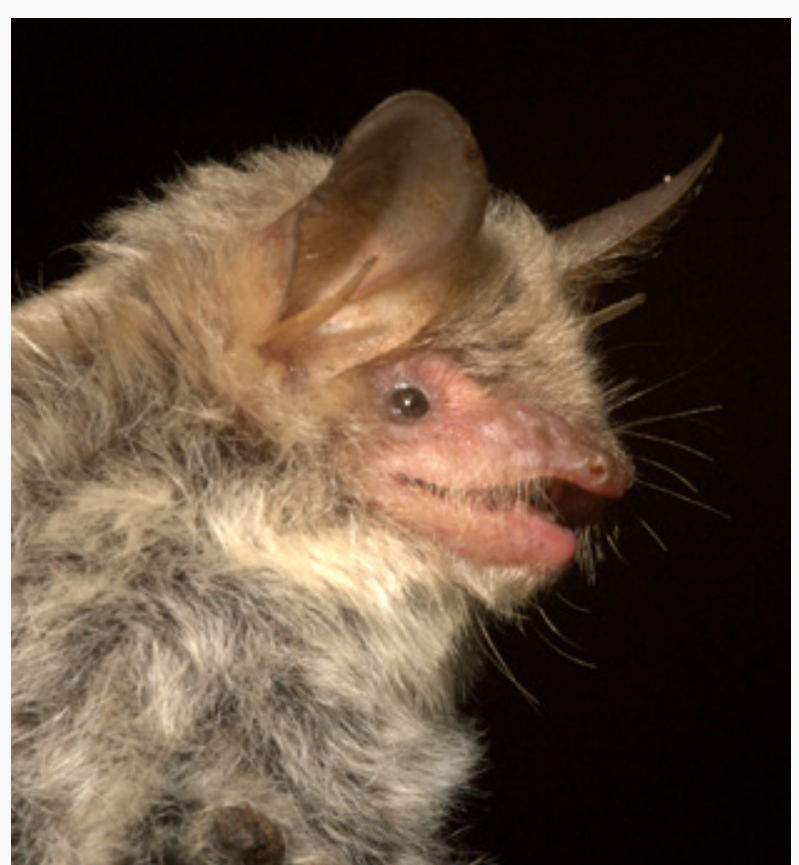

Figure 30: Myotis nattereri (C Antonin Reiter) 


\section{Otonycteris hemprichii (Peters, 1859)}

Animalia - Chordata - Mammalia - Chiroptera - Vespertilionidae

Common name(s): Desert long-eared bat.

Red List status: Least Concern.

Justification: The species is widespread, there is no evidence of current significant population decline.

Geographical range: The desert zone from Morocco and Niger through Egypt and Arabia to Tadzhikistan, Afghanistan, and Kashmir. In Jordan, this species is recorded from Azraq Ash Shishan, Azraq ed Druz, Wadi Rum, Disah, Quraiqira, Burqa', Ghadir Al-Qatawneh, Ar Raddass, Al Bishriyya, Al Hazim, Al Mujib Reserve, Al Shawmari Wildlife Reserve, Dana, Jabal Masuda, Petra, Qasr Burqu', Qasr Kharana, Quraiqira, Quseir Amra, Wadi Abu Al 'Asa'l and Wadi Rum.

Population: Thought to have a stable population, and is common in several desert areas in Jordan.

Area of occupancy

72

\section{Extent of occurrence}

31856

Biogeographical realms: Saharo-Arabian, Oriental.

General use and trade information: No trade or use in this species is known.

Threats: No major threats. However, the use of pesticides is believed to be affecting this species (Amr et al., 2006a).

Conservation actions: This species is protected in situ in Mujib and Dana Biosphere Reserves, and Wadi Rum World Heritage Area.

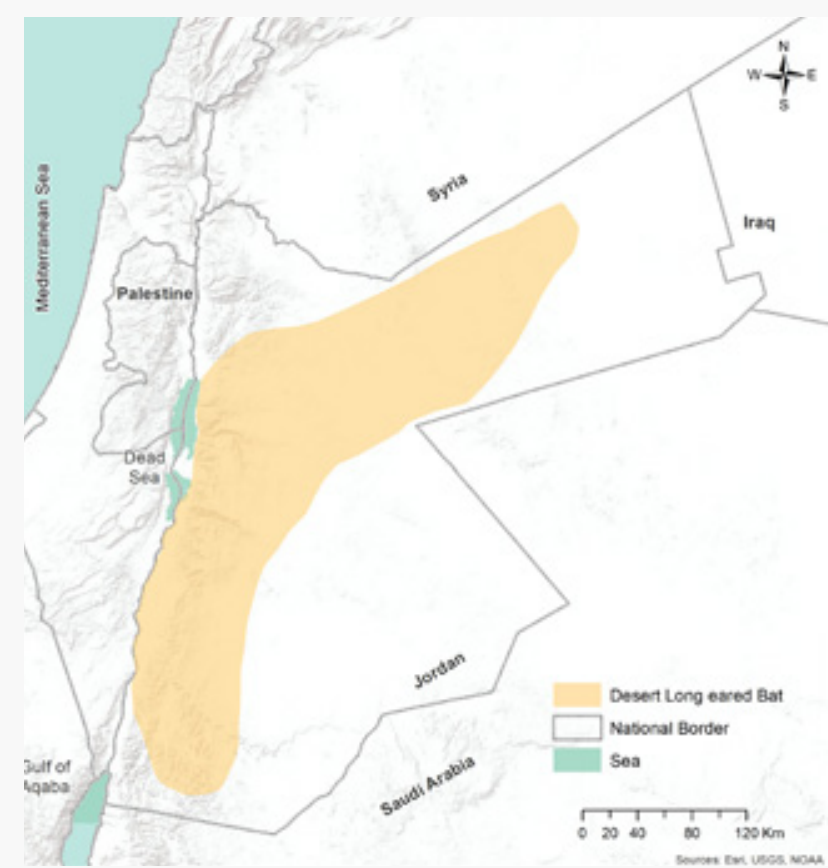

Map 28: Distribution of Otonycteris hemprichi in Jordan.

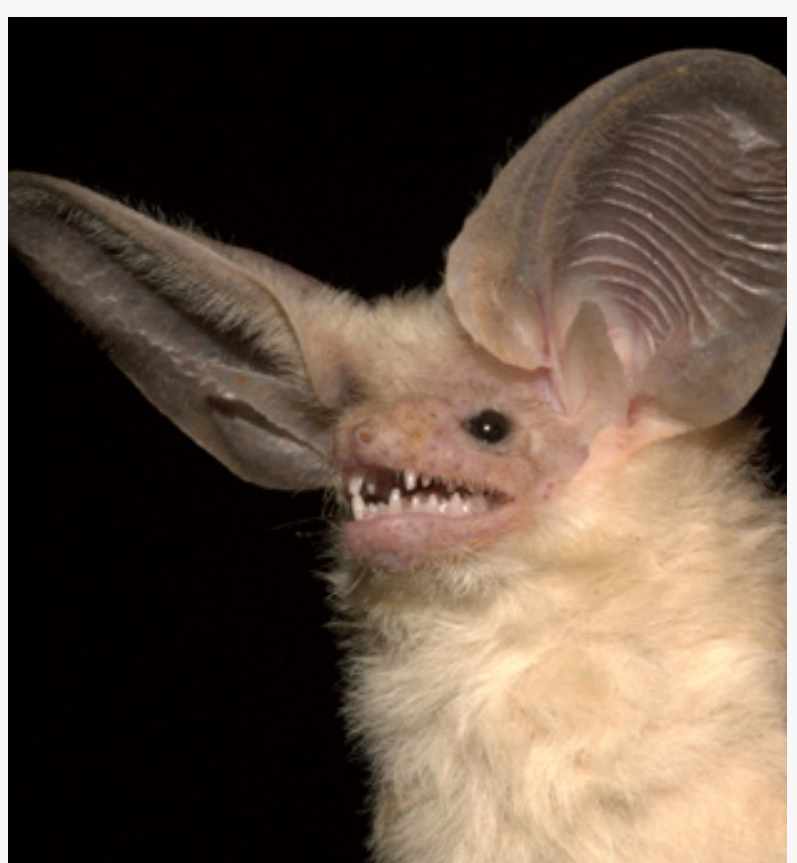

Figure 31: Otonycteris hemprichii (C) Antonin Reiter) 


\section{Pipistrellus kuhli (Kuhl, 1817)}

Animalia - Chordata- Mammalia- Chiroptera- Vespertilionidae

Common name(s): Kuhl's pipistrelle.

Red List status: Least Concern.

Justification: The species is widespread with stable populations, there is no evidence of current significant population decline.

Geographical range: Kuhl's pipistrelle has a wide distribution, occurring across North Africa, southern Europe, the Middle East and Arabian Peninsula, and into southwest Asia, as far east as Pakistan and India, and north to Kazakhstan. In Jordan, this species is recorded from Suwaylih, between South Shounah and Swymah, Aqraba, Ramtha, Wadi Musa, Al Hazim, Azraq ed Druz, Azraq ash Sheishan, Qasr Azraq, Al Dhahek, Al Halabat Al Sharkiyah, Al Khrba, Aqaba, Arjan, As Salihiyyah, Az Zarqa' River Valley, Dayr 'Alla, Dir Deglah, Duqra, Ghawr es Safi, Iraq Al Amir, Jerash, Jufat Al Qafrayn, Malka, Nahla, Qasr Kharana, Quseir Amra, Ramtha and Wadi Shu'ayb.

Population: Kuhl's pipistrelle is a widespread and abundant species, and populations are increasing in parts of its range. Considered as one of the most common bats in Jordan

\section{Area of occupancy}

96

Biogeographical realms: Palearctic

General use and trade information: No trade or use in this species is known.

Threats: Agricultural expansion and the use of pesticides to eradicate mosquitoes, particularly in urban areas, may reduce its food supply in these areas (Amr et al., 2006a).

Conservation actions: This species is protected in situ in Dibeen and Ajloun Forest Reserves, and Dana Biosphere Reserve.

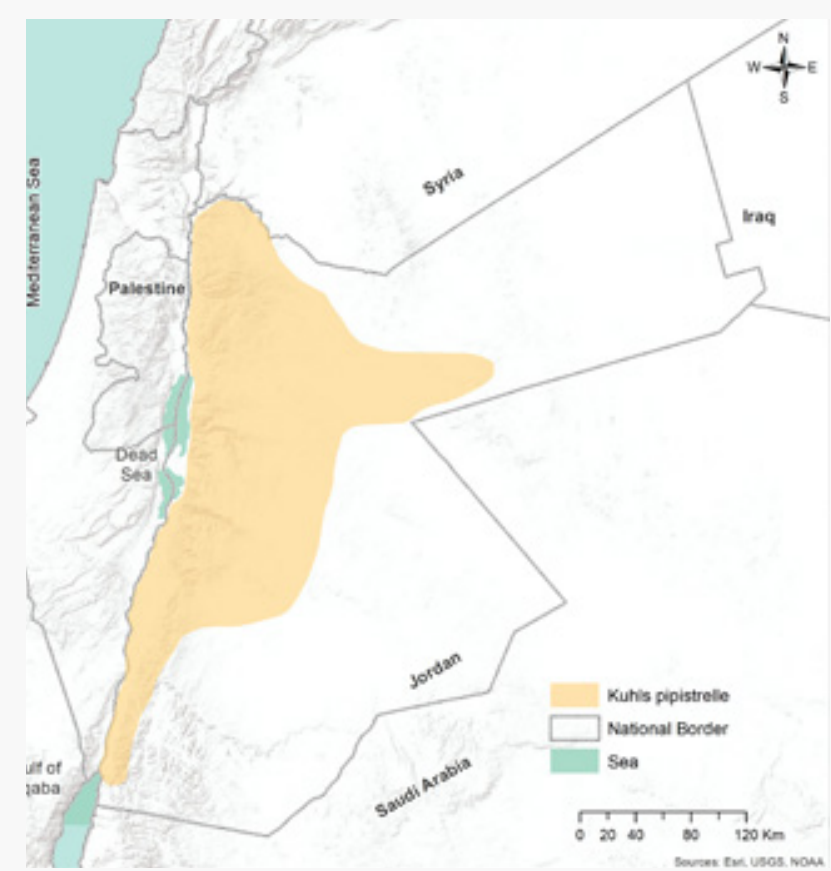

Map 29: Distribution of Pipistrellus kuhli in Jordan.

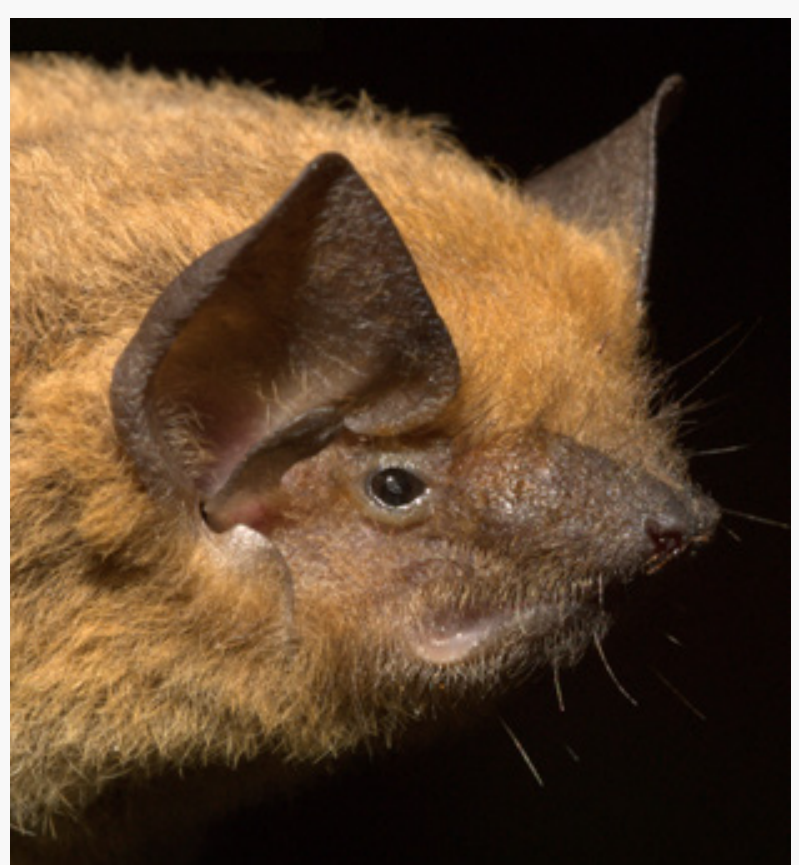

Figure 32: Pipistrellus kuhli (C Antonin Reiter) 


\section{Pipistrellus pipistrellus (Harrison, 1960)}

Animalia - Chordata - Mammalia - Chiroptera - Vespertilionidae

Common name(s): Common pipistrelle.

\section{Red List status: Least Concern.}

Justification: The species is widespread with stable populations, there is no evidence of current significant population decline.

Geographical range: Range extending from the British Isles through southern Scandinavia, much of Europe (including all the Mediterranean countries, but with the exception of northern Fennoscandia) to the Volga and Caucasus; and through parts of north-western Africa (mountainous areas of Morocco, Algeria and Tunisia, also in Cyrenaica in Libya) and south-west Asia to central and eastern Asia (China, India, Myanmar). In Jordan, this species is recorded from Northern Jordan, Al Maqar'iyya, Arjan, As Salihiyyah, Dana, Jebel Masuda, Nahla, Petra, Qurayqira, Tall Numiera, Wadi Al Hasa and Wadi Al Wala.

Population: A widespread and abundant species, and one of the most common bats in Jordan.

\section{Area of occupancy}

44

\section{Extent of occurrence}

3601

Biogeographical realms: Palearctic, Oriental.

General use and trade information: No trade or use in this species is known.

Threats: No major threats were reported, disturbance could be considered as a threat to this species.

Conservation actions: This species is protected in situ in Dibeen and Ajloun Forest Reserves, and Dana Biosphere Reserve.

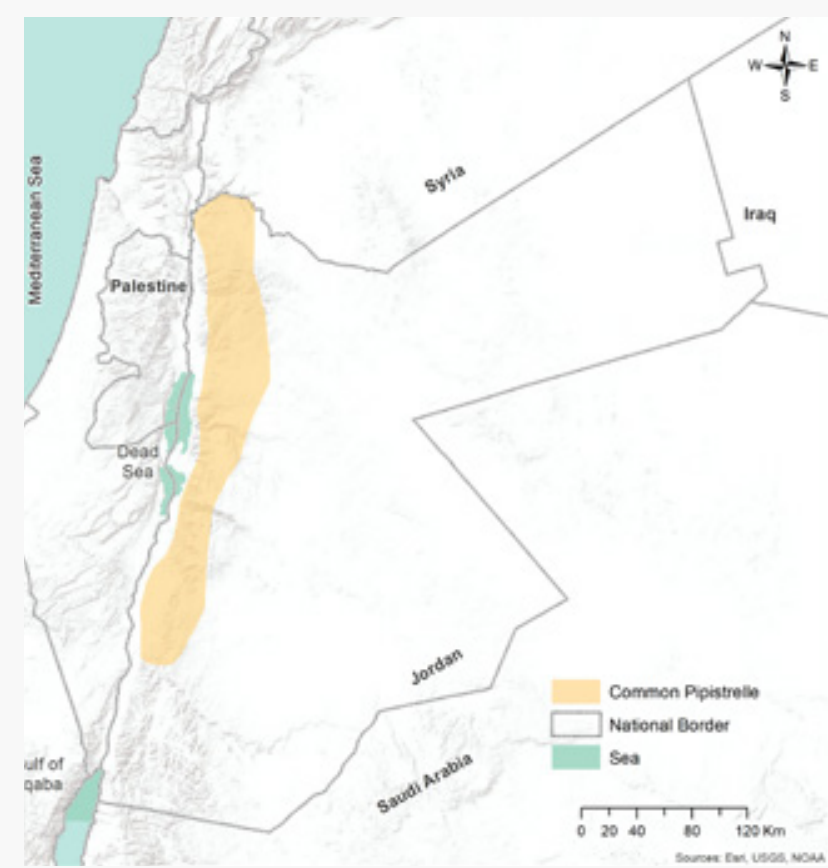

Map 30: Distribution of Pipistrellus pipistrellus in Jordan

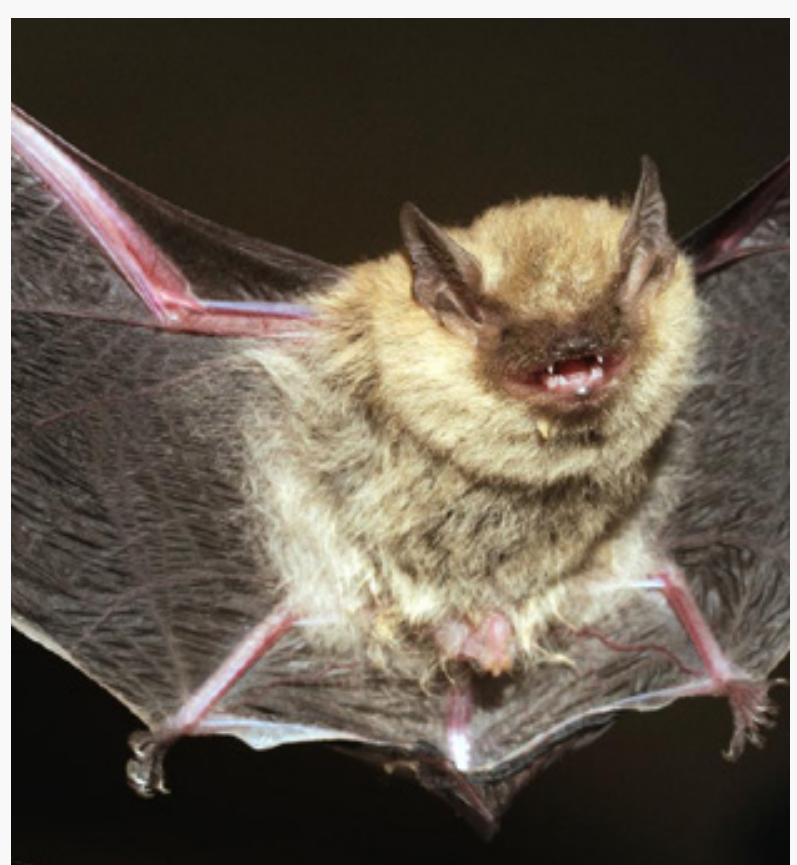

Figure 33: Pipistrellus pipistrellus (๑ Antonin Reiter) 


\section{Plecotus christii (Gray, 1838)}

Animalia - Chordata - Mammalia - Chiroptera - Vespertilionidae

Common name(s): Christi's big-eared bat.

Red List status: Least Concern.

Justification: Although small population are identified from Jordan so far, but this species is located in remote areas with no knowns threats on its population at present.

Geographical range: Known only from a few localities in NE Africa, including eastern Libya, Egypt including Sinai, Palestine, Jordan and Sudan. In Jordan, this species is recorded from Disah, Gharandal, Ras Al Naqab, Petra, Al Ghal, Ash Shawbak, Dana, Jabal Al Bayda, Jebel Masuda, Mukawir, Qurayqira and Wadi Rum.

Population: Probably very small population only scattered and isolated records

\section{Area of occupancy}

\section{Extent of occurrence}

52

6578

Biogeographical realms: Palearctic

General use and trade information: No trade or use in this species is known.

Threats: No major threats were reported, though it might be affected by human disturbance.

Conservation actions: This species is protected in situ in Dana Biosphere Reserve and Wadi Rum World Heritage Area.

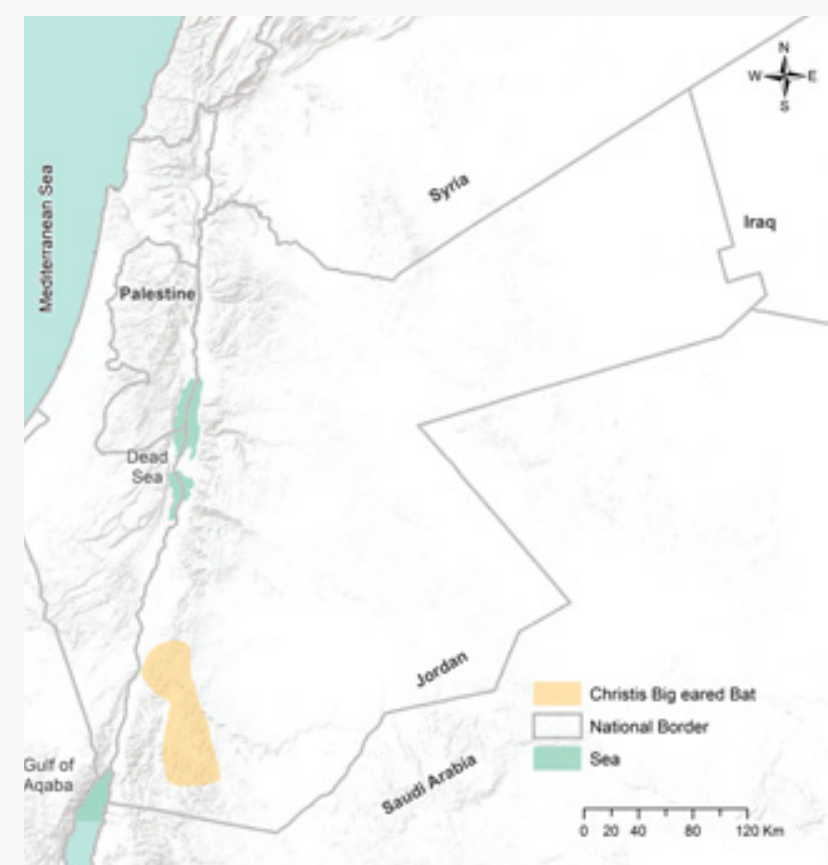

Map 31: Distribution of Plecotus christii in Jordan.

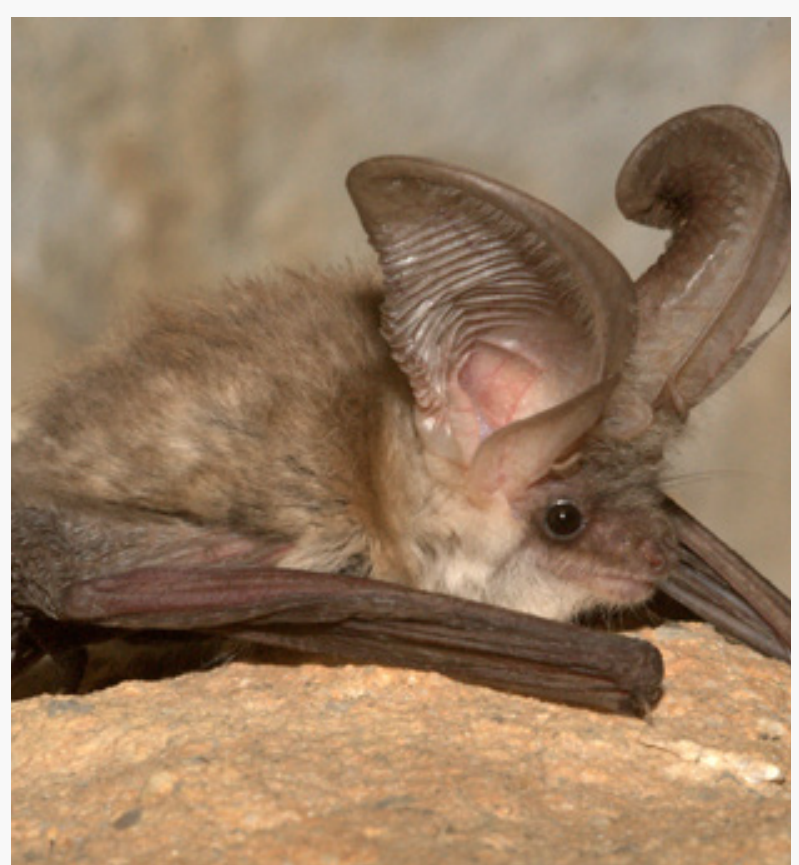

Figure 34: Plecotus christii (@ Antonin Reiter) 



\subsection{Rodentia}

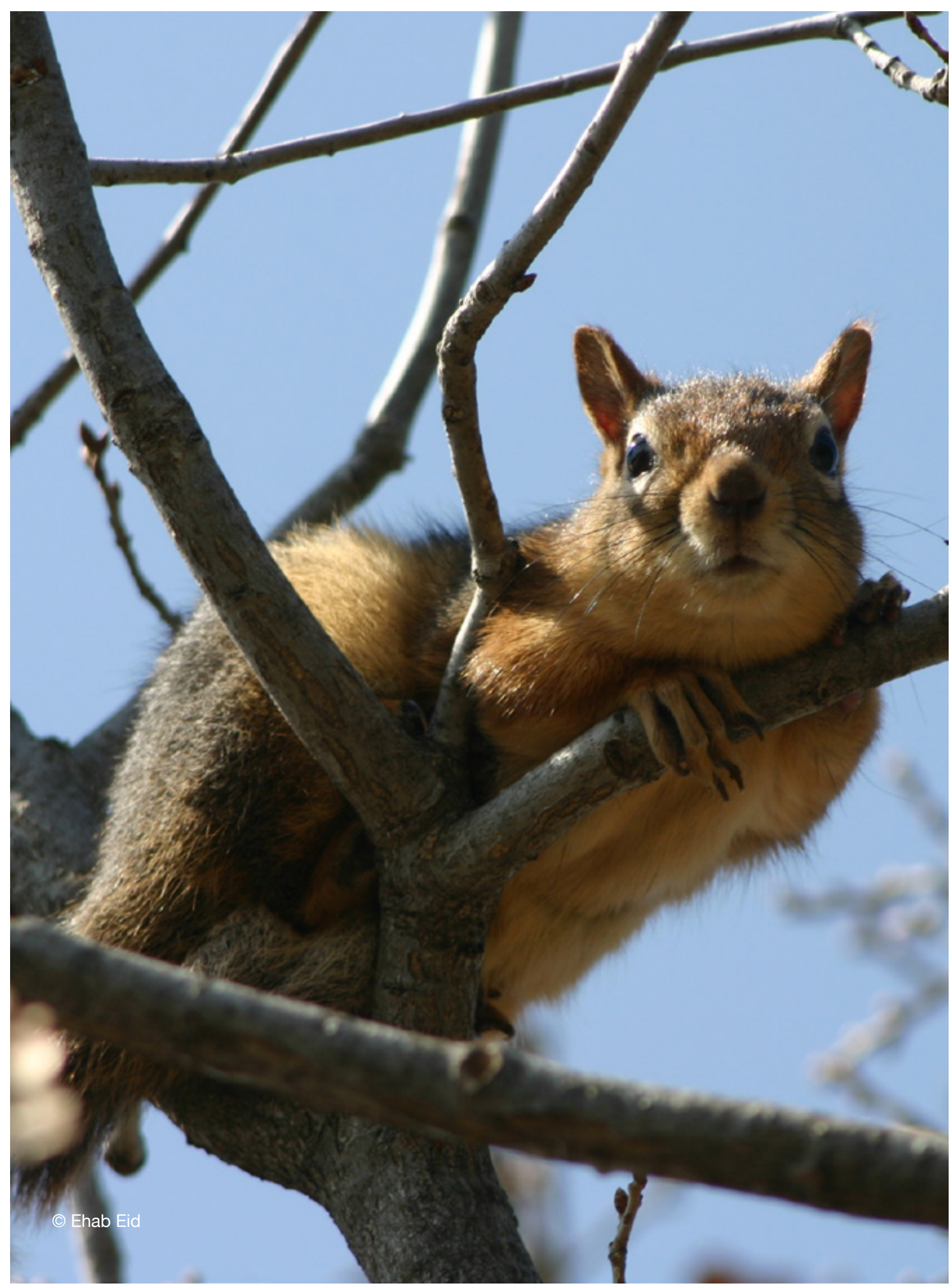




\section{Sciurus anomalus (Güldenstaedt, 1785)}

Animalia - Chordata - Mammalia - Rodentia - Sciuridae

Common name(s): Caucasian squirrel, Persian squirrel.

Red List status: Endangered B1, B2ab (i, ii, iii).

Justification: The population of this species is restricted to the forested areas of Jordan, which represents less than $1 \%$ of Jordan's area and is under severe and continued threats.

Geographical range: occurs in southeastern Europe and southwest Asia. In the Mediterranean region it occurs in Turkey (introduced to the area around Istanbul in 1964), the islands of Lesbos (Greece) and Gökçeada (Turkey) (Mitchell-Jones et al., 1999), Syria, Lebanon, Palestine and Jordan (Wilson and Reeder, 2005). Also occurs in Transcaucasia (Armenia, Azerbaijan, and Georgia), northern and western Iran, and Iraq. A significant part of its range is within the Asiatic part of Turkey. In Jordan, this species is recorded from Kufranja, Burma, Ajluon Forest Reserve, Dibeen Forest Reserve, Raimoon, between Sakeb and Anjara and Tabakat Fahal (Amr et al., 2018).

Population: Declines have been reported in parts of its distribution.

\section{Area of occupancy}

32

\section{Extent of occurrence}

577

Biogeographical realms: Palearctic.

General use and trade information: This species was recorded in trade in Animal Public market in Amman city exhibited as pet species (Eid et al., 2011).

Threats: Forest degradation, deforestation, forest fire and trapped for trading are major threats. Habitat fragmentation is a serious threat (Amr et al., 2006a). In addition, this species is collected for market trade, and is under various threats of nest destruction and the widespread threat of the feral cat a potential predator.

Conservation actions: This species is protected in situ in Dibeen and Ajloun Forest Reserves (Amr et al., 2006). In addition, it is Listed in Appendix III for wildlife protection of the Agricultural Law Number 13 for the year 2015 based on regulation Number 43 for the year 2008.

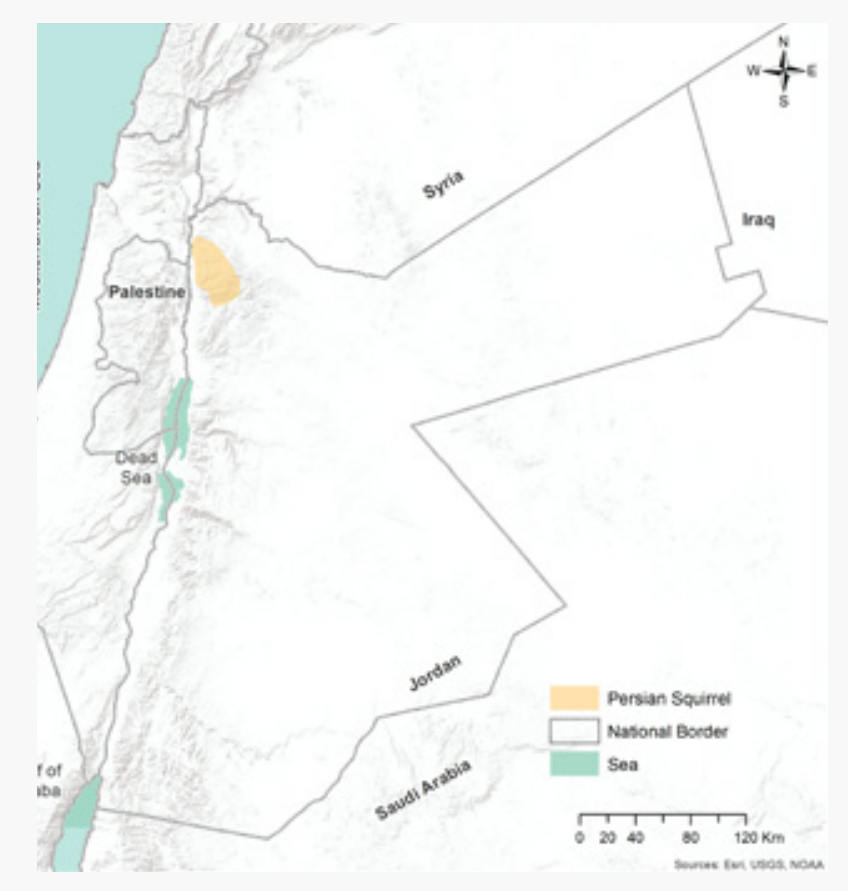

Map 32: Distribution of Sciurus anomalus in Jordan.

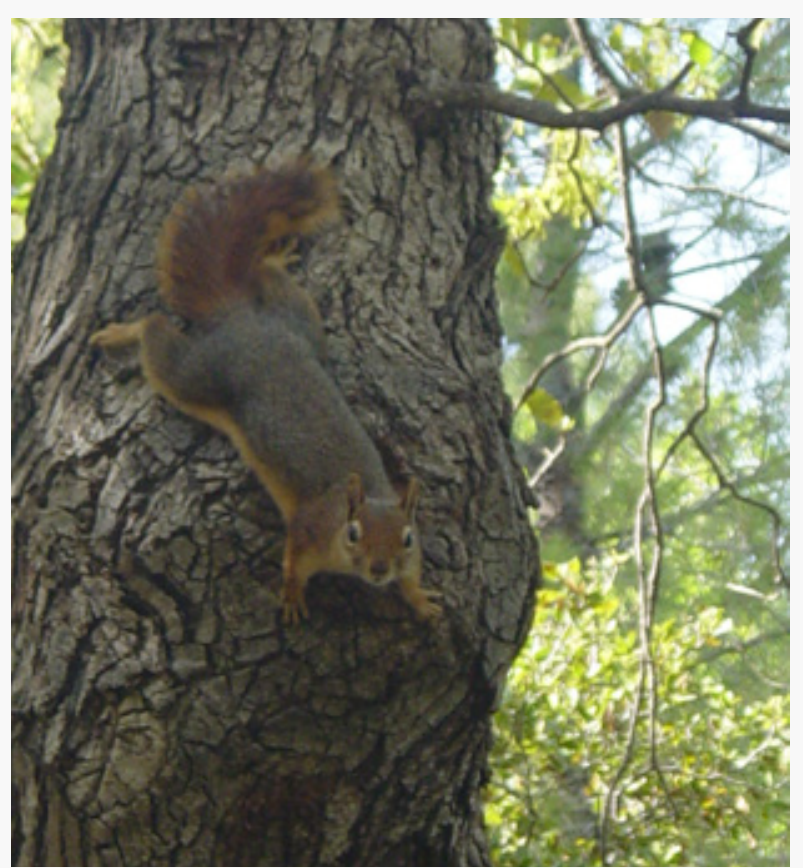

Figure 35: Sciurus anomalus (@ Sami Alatoom) 


\section{Eliomys melanurus (Wagner, 1839)}

Animalia - Chordata - Mammalia - Rodentia - Gliridae

Common name(s): Asian garden dormouse.

Red List status: Near Threatened.

Justification: This species has patchy distribution with some populations considered relicts. Threats are occurring consistently and documented.

Geographical range: Widespread species, occurring from the Middle East and the Arabian Peninsula westwards to Egypt. In Jordan, this species is recorded in Jiza, Um Al Rasas, Moab and Edom, Azraq Ad Druz, Wadi Rajil, Azraq Druz, Daba'ah, Al Wisad, Wadi Rum, Dana Biosphere Reserve, Wadi Al Barra at Dana reserve, Marj Al Hammam, Burqu', and Dibeen Forest Reserve (Amr et al., 2018).

Population: No information about this species population was recorded.

Area of occupancy

48

\section{Extent of occurrence}

4662

\section{Biogeographical realms: Palearctic.}

General use and trade information: This species was not recorded in trade or use from Jordan.

Threats: Habitat degradation, tree cutting and woodcutting are major threats.

Conservation actions: This species is protected in situ in Dibeen Forest Reserve, Dana Biosphere Reserve, Wadi Rum World Heritage Area, Azraq Wetland Reserve, and Burqu' Protected Area. In addition, it is Listed in Appendix III for wildlife protection of the Agricultural Law Number 13 for the year 2015 based on regulation Number 43 for the year 2008.

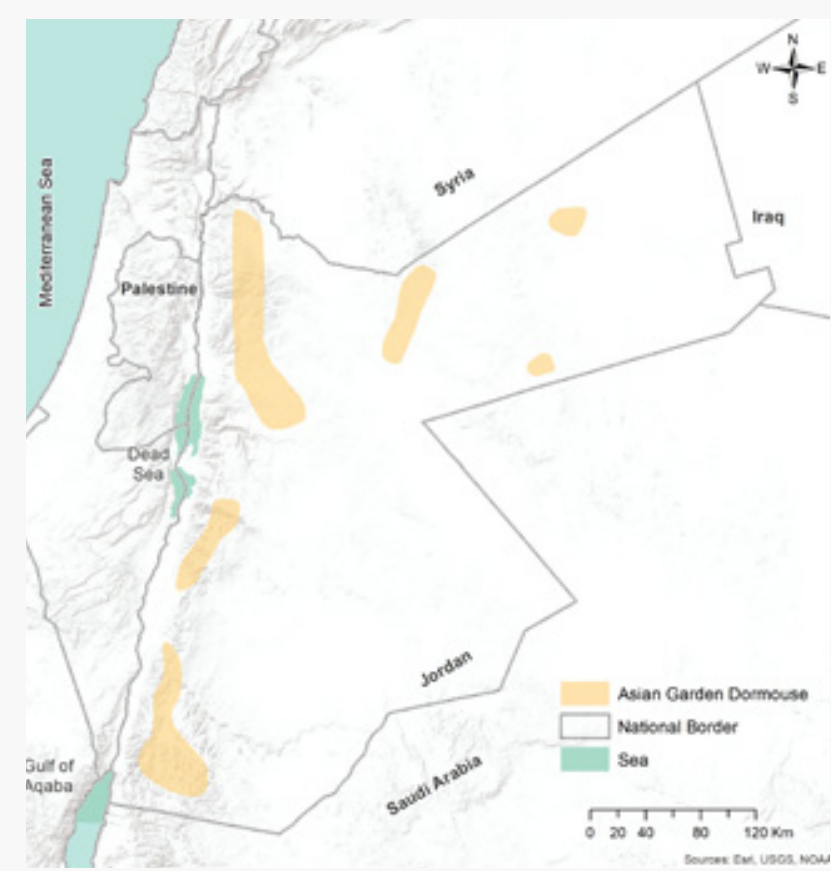

Map 33: Distribution of Eliomys melanurus in Jordan.

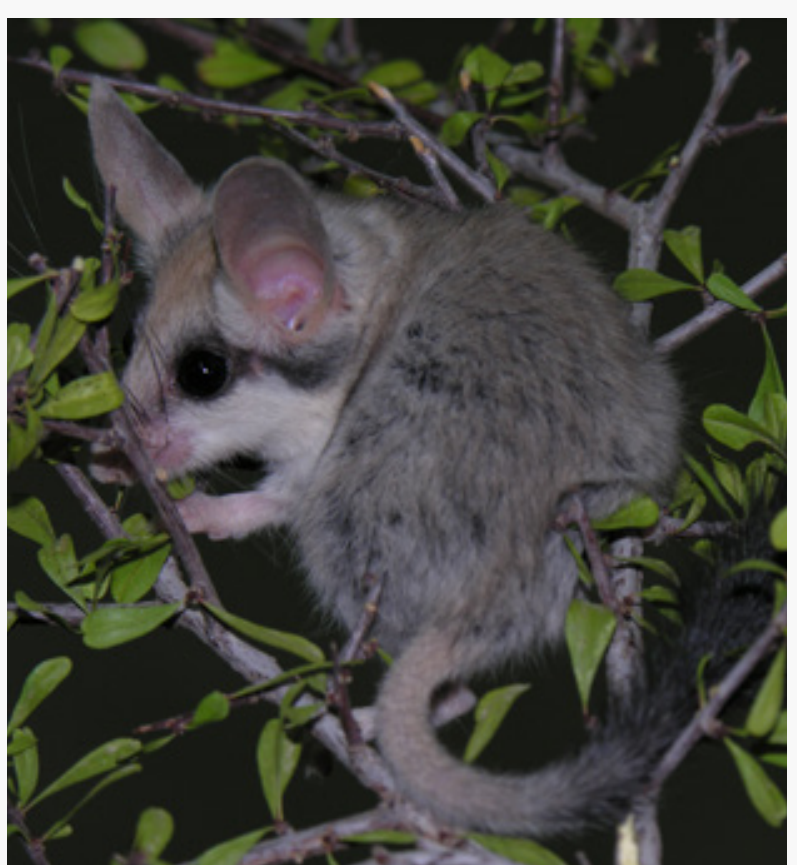

Figure 36: Eliomys melanurus (@ Mohammad Abu Baker) 


\section{Allactaga euphratica (Thomas, 1881)}

Animalia - Chordata - Mammalia - Rodentia - Dipodidae

Common name(s): Euphrates jerboa, five-toed jerboa.

Red List status: Endangered A2ac.

Justification: Severe decline has been observed in its habitats due to the intensive agricultural expansion, habitats degradation and deterioration.

Geographical range: Allactaga euphratica is recorded from Turkey, Syria, and eastern Jordan, through northern Saudi Arabia and Iraq to Kuwait and Iran. It has recently been recorded in Lebanon (Abi-Said 2004). The southern and eastern limits of the range are poorly defined. In Jordan, this species is recorded from Amman, $50 \mathrm{~km}$ W Al Jafr, Qasr Amra, 30 km east of Al Mafraq, 45 km N Ma'an, Jawa, Al Shawmari, Um Al Quttain, Qasr Al Halabat, Qasr Al Kharanah, Burqu' and Ernbeh (Amr et al., 2018).

Population: The populations have declined by approximately 50\% over the past 20 years owing to agricultural expansion.

\section{Area of occupancy}

44

Biogeographical realms: Palearctic.

General use and trade information: This species was recorded in trade in Jordan's animal market (Eid et al., 2011). In addition, this species is considered edible by several tribes of Bedouin in Jordan (Qumsiyeh, 1996; Amr, 2012; Amr et al, 2018).

Threats: The species has declined by approximately 50\% over the past 20 years owing to agricultural expansion, which is considered a major threat. In addition, this species is hunted as a food source in the eastern desert but to a limited extent.

Conservation actions: This species is protected in situ in Azraq Wetland Reserve, Shaumari Wildlife Reserve and Burqu' Protected Area. In addition, it is Listed in Appendix III for wildlife protection of the Agricultural Law Number 13 for the year 2015 based on regulation Number 43 for the year 2008.

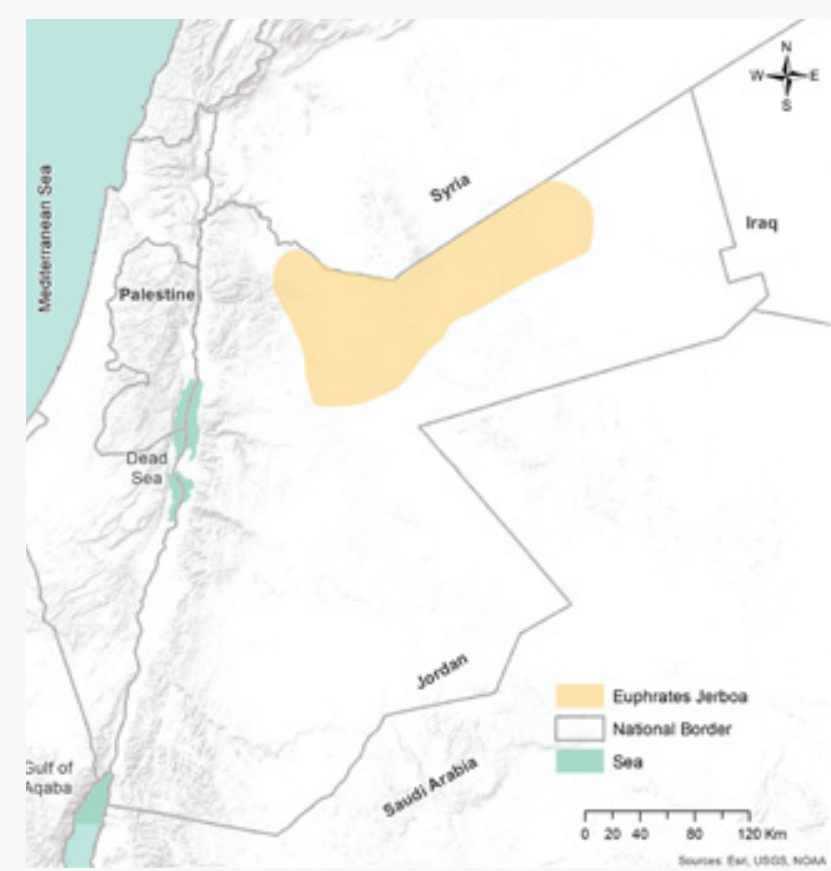

Map 34: Distribution of Allactaga euphratica in Jordan.

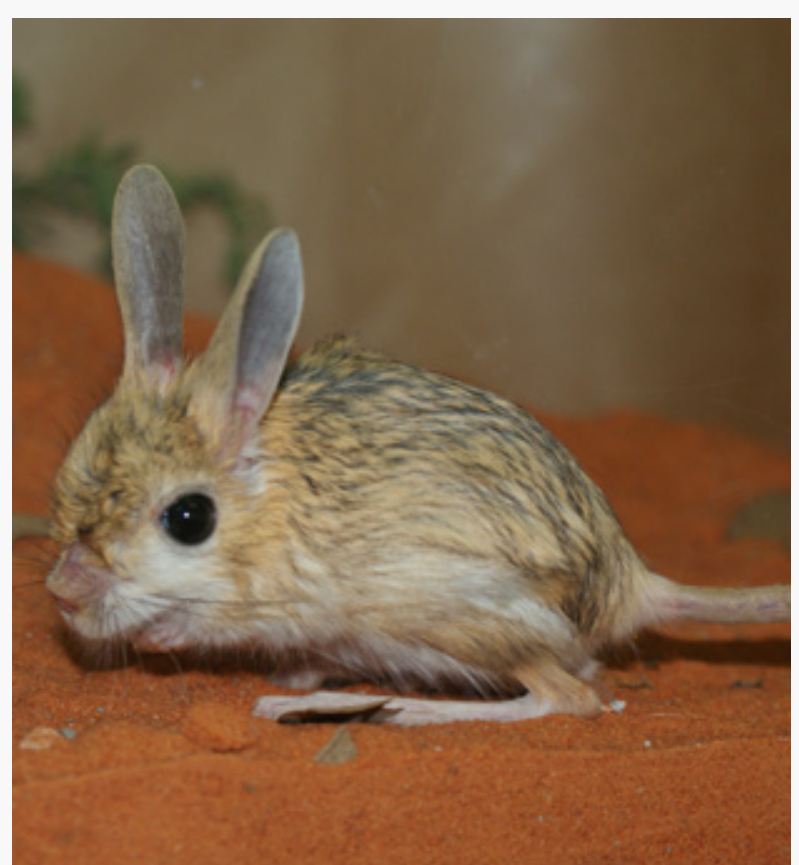

Figure 37: Allactaga euphratica (@ Adwan Shehab) 


\section{Jaculus jaculus (Linnaeus, 1758)}

Animalia - Chordata - Mammalia - Rodentia - Dipodidae

Common name(s): Lesser Egyptian jerboa.

\section{Red List status: Least Concern.}

Justification: Listed as Least Concern because this species is a widespread in open desert with a presumed large population.

Geographical range: This species is found throughout North Africa and the Arabian Peninsula as far east as southwestern Iran. It is found in desert and semi-desert with patchy records from Senegal and Mali through Mauritania and Morocco to Algeria, Tunisia, Libya, Egypt, Eritrea and Somalia (though absent from the Nile Delta). In Jordan, this species is recorded from Al Jafr, Azraq Ash Shishan, Qaser Amra, Jawa, Wadi Finan, Al Shawmari Wildlife Reserve, Al Hazim, Al Wisad, Buqay'awiyah, Qasr Burqu', Ruwayshid, Safawi, Wadi Al Hashad, Wadi Rum, Faydat ad Dahikiyah, Azraq Nature Reserve, Qasr Al Kharanah, Petra, Jawa, Qatar, Rahmeh, Reishah and Wadi Finan (Amr et al., 2018).

Population: A widespread species, although somewhat patchily distributed in parts of its range.

\section{Area of occupancy}

48

\section{Extent of occurrence}

36513

\section{Biogeographical realms: Afrotropical.}

General use and trade information: This species is hunted for its meat in parts of the eastern desert of Jordan. Aloufi and Eid, (2016) stated that the flesh of this species is cooked and eaten to treat vitiligo.

Threats: In some areas in Jordan, the species is spotlighted and hunted for food and bait for falconry but to a lesser extent. Locally eaten by humans, since they are easily excavated from their burrow systems. Habitats alteration is another threat.

Conservation actions: This species is protected in situ in Wadi Rum World Heritage Area, Qatar protected area and Burqu' Protected Area.

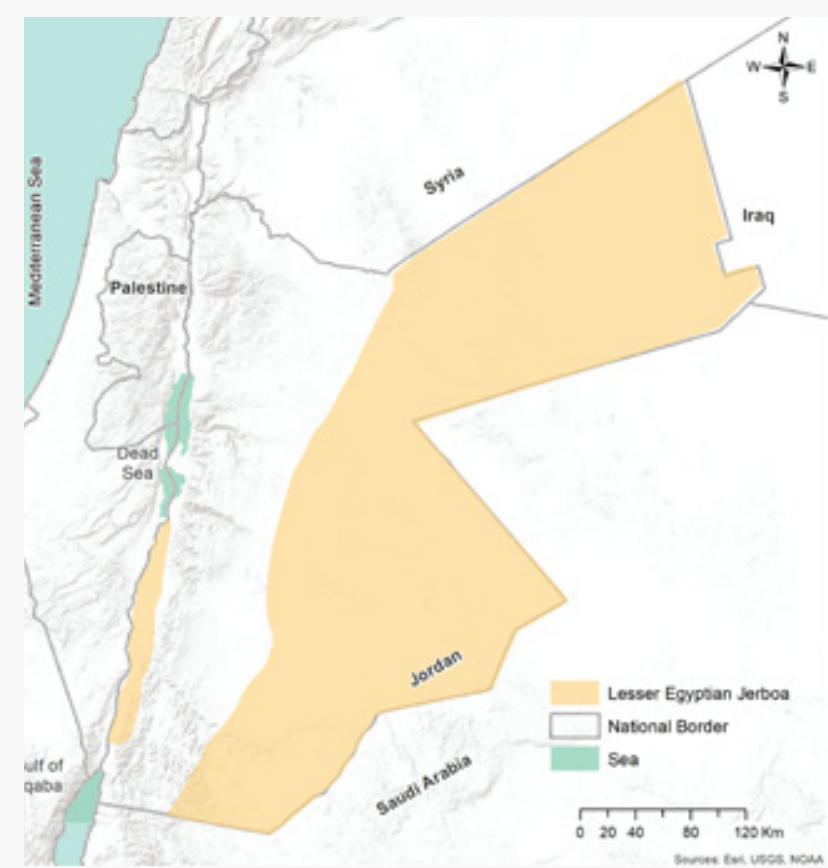

Map 35: Distribution of Jaculus jaculus in Jordan.

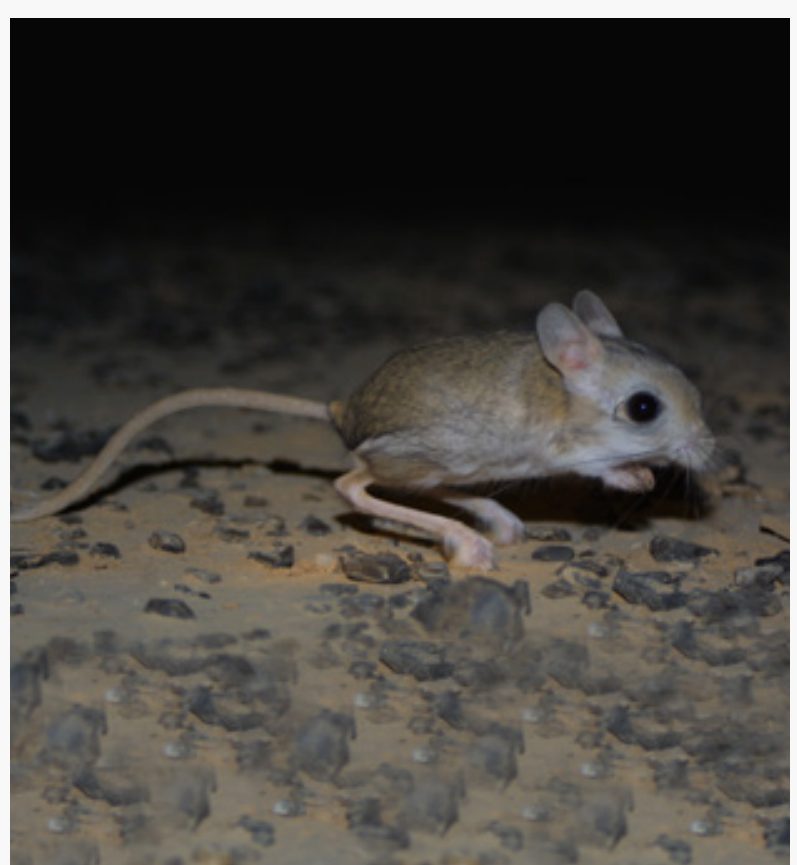

Figure 38: Jaculus jaculus (@ Mohammad Abu Baker) 


\section{Cricetulus migratorius (Pallas, 1773)}

Animalia - Chordata - Mammalia - Rodentia - Cricetidae

Common name(s): Gray dwarf hamster, gray hamster.

Red List status: Least Concern.

Justification: Although it has a confined distribution no known threats on its population exists at present and it is presumed that it has a stable population.

Geographical range: Extends from Eastern Europe through Russia and central Asia to Mongolia and western China. The southernmost edge of its range extends through Palestine, Iraq, Iran, Afghanistan, Pakistan and northern India (Jammu and Kashmir), where Jordan represents its southernmost distribution. It has also been recorded from Greece, Turkish Thrace, and Bulgaria. In Jordan, this species is recorded in Al Muwaqqar, Jawa, Wadi Zarqa, S Jarash, Al-Sareeh, Faydat ad Dahikiyah, Qasr al Hallabat, Marj Al Hammam, Wadi Al Barra in Dana reserve, Wadi Zarqa Ma'in and Suf (Amr et al., 2018).

Population: No information is available on this species.

\section{Area of occupancy}

40

\section{Extent of occurrence}

11586

Biogeographical realms: Palearctic, Oriental.

General use and trade information: This species was not recorded in trade or use from Jordan.

Threats: urbanization and agricultural expansion represent the major threats.

Conservation actions: This species is protected in situ in Ajloun Forest Reserve, Dana and Mujib Biosphere Reserves.

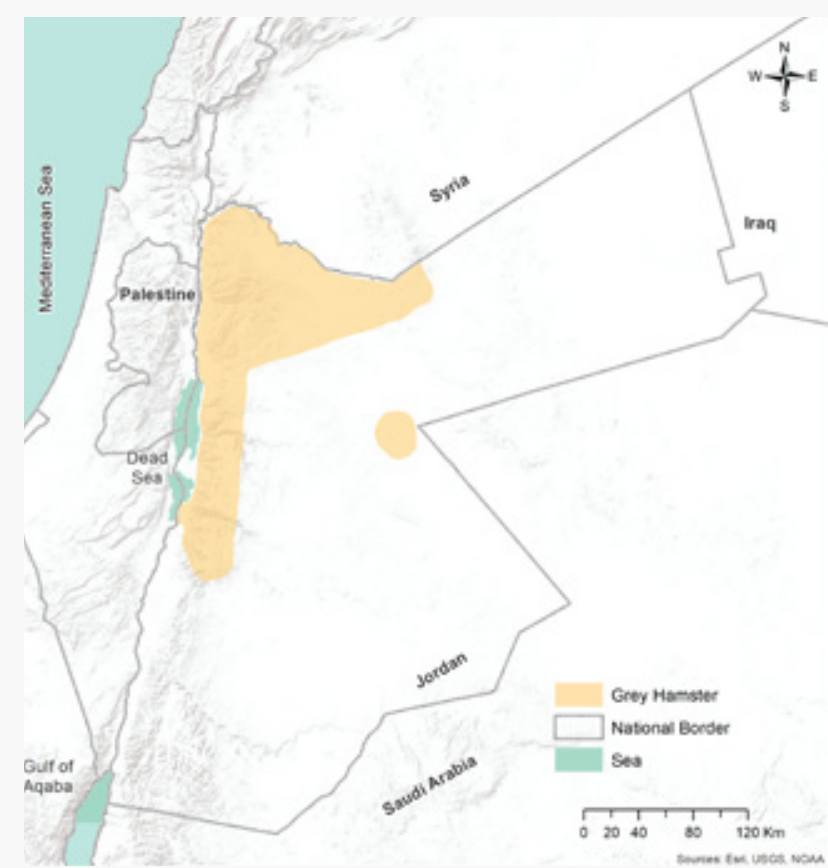

Map 36: Distribution of Cricetulus migratorius in Jordan.

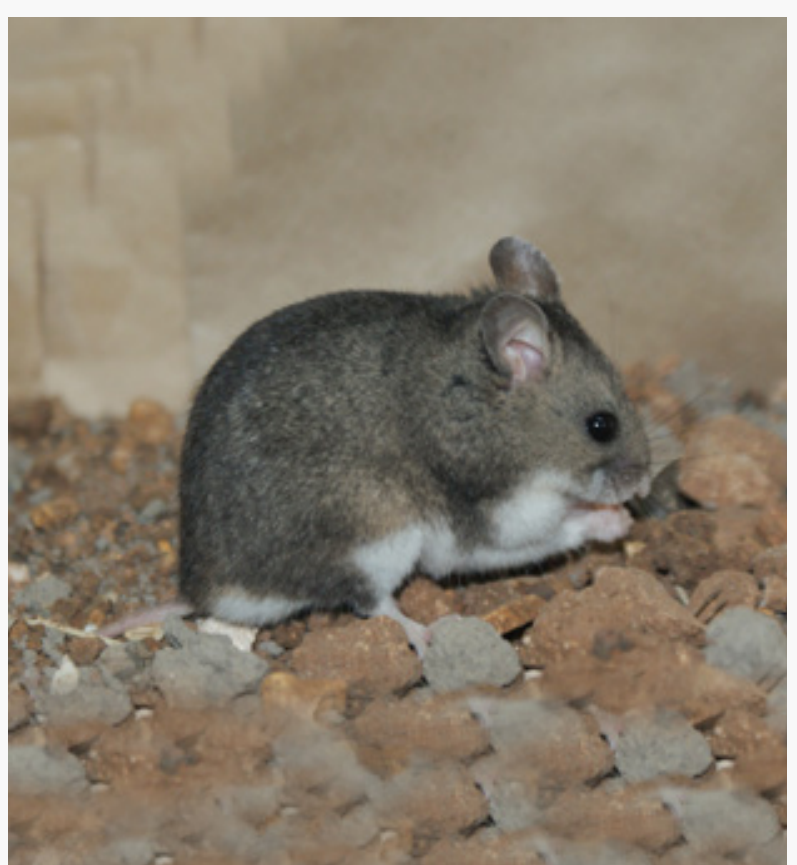

Figure 39: Cricetulus migratorius (@ Adwan Shehab) 


\section{Microtus guentheri (Danford and Alston, 1880)}

Animalia - Chordata - Mammalia - Rodentia - Microtinae

Common name(s): Günther's vole.

Red List status: Least Concern.

Justification: A widespread and common species with no major threats. It is tolerant of a range of habitat types, both natural and man-made and is hence Listed as Least Concern. In addition it is considered as a pest species and Jordan represents southernmost range of distribution.

Geographical range: Microtus guentheri occurs from the south-east Balkans and Turkey through Syria, Lebanon, and Palestine, with an isolated range segment in northern Libya. Within Europe, it has a discontinuous range in southern Serbia (Serbia and Montenegro), F. Y. R. Macedonia, parts of southern and eastern Greece, southern Bulgaria, and Turkish Thrace, and has been recorded from $150 \mathrm{~m}$ to $500 \mathrm{~m}$ above sea level). In Jordan, this species is recorded from Ibbin, Al-Sareeh, Marj Al Hammam, Amman National Park, Wadi Zarqa Ma'in and Ajlun Forest Reserve (Amr et al., 2018).

Population: A common species.

\section{Area of occupancy}

20

\section{Extent of occurrence}

4449

Biogeographical realms: Palearctic.

General use and trade information: No use or trade data was collected from Jordan.

Threats: This species was considered as a pest species in Jordan and a control of its population was performed. However, this does not affect its population, and no major threats are known to occur.

Conservation actions: This species is protected in situ in Ajloun Forest Reserve.

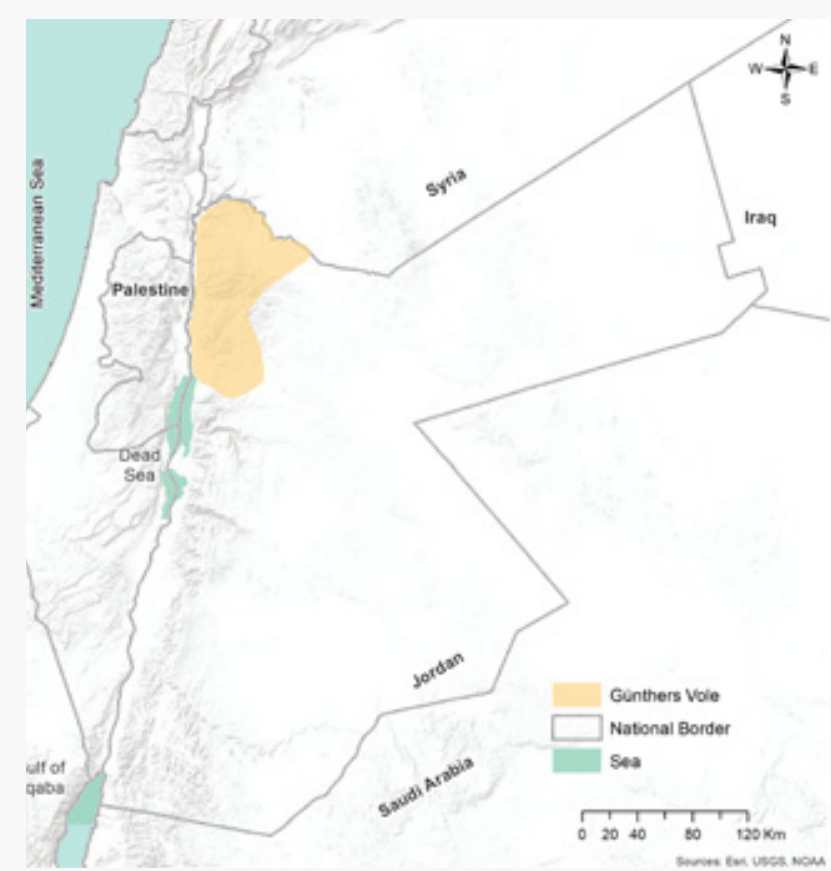

Map 37: Distribution of Microtus guentheri in Jordan

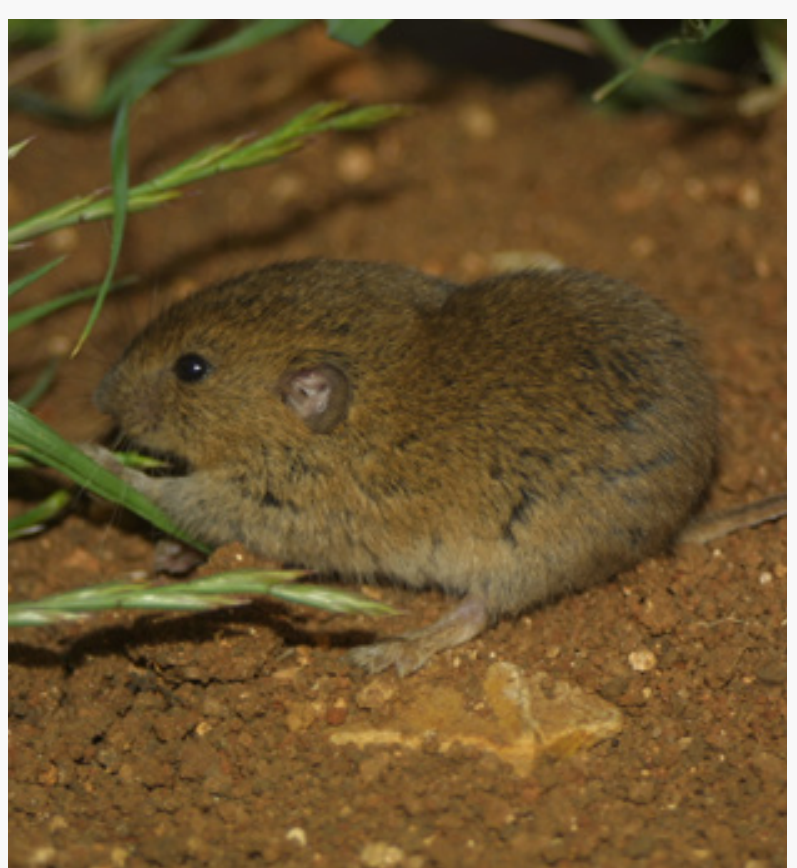

Figure 40: Microtus guentheri (C Mohammad Abu Baker) 


\section{Acomys dimidiatus (Cretzschmar, 1826)}

Animalia - Chordata - Mammalia - Rodentia - Muridae

Common name(s): Arabian spiny mouse, Eastern spiny mouse.

Red List status: Least Concern.

Justification: Listed as Least Concern as it is a common species, spreading over a wide area along the upper Rift Valley in Jordan.

Geographical range: This species is widely distributed along the Jordan Rift Valley extending from northern parts of Jordan until its most southern edges. Worldwide, it extends from the Sinai Peninsula of Egypt, Lebanon, Syria, Jordan and Palestine, through much of the Arabian Peninsula, southern Iraq and Iran to southern Pakistan. In Jordan, this species is recorded from Aqaba, At Tafilah, Petra, Wadi Al Karak, Moab and Ghawr es Safi, Wadi Zarqa Ma'in, Aqaba, Gharandal, S Jarash, Wadi Al Hidan, 20 km N Quweirah, Wadi Rum, Dana Biosphere Reserve, Petra, Wadi Musa, Marj Al Hammam, Iraq al Wahaj, Wadi lbn Hammad, Rajif, Wadi Suweid, Al Hemmah, Dahal, Fifa, Humrat Ma'in, Jabal Masuda, Jarash, Malka, Qatar PA, Rahmeh, Wadi Al Mujib, Wadi Tlah (Amr et al., 2018).

Population: This species is common in Jordan.

\section{Area of occupancy}

104

\section{Extent of occurrence}

12276

Biogeographical realms: Palearctic.

General use and trade information: This species was not recorded in use or trade from Jordan.

Threats: There are presumably no major threats to this widespread and adaptable species.

Conservation actions: This species is well protected in situ since it was recorded in several protected areas and special conservation sites in Jordan including Dibeen and Ajloun Forest Reserves, Dana and Mujib Biosphere Reserves, Wadi World Heitage Site, Fifa Protected Area, Rahma, Wadi Ibn Hammad and Khayouf Special Conservation areas, and Burqu' Protected Area.

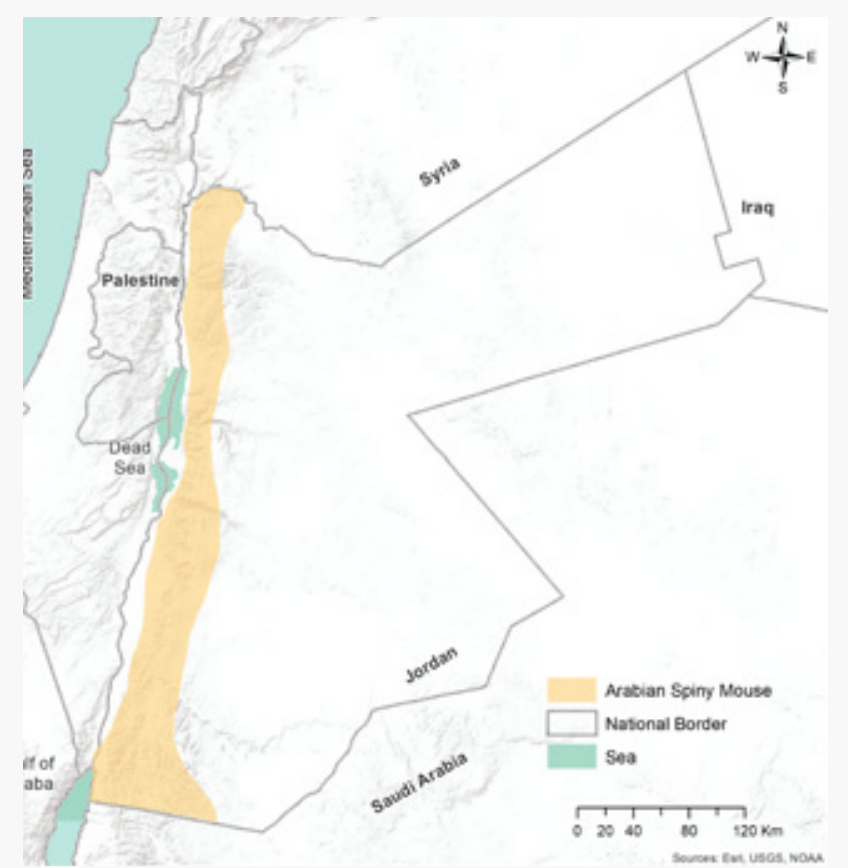

Map 38: Distribution of Acomys dimidiatus in Jordan

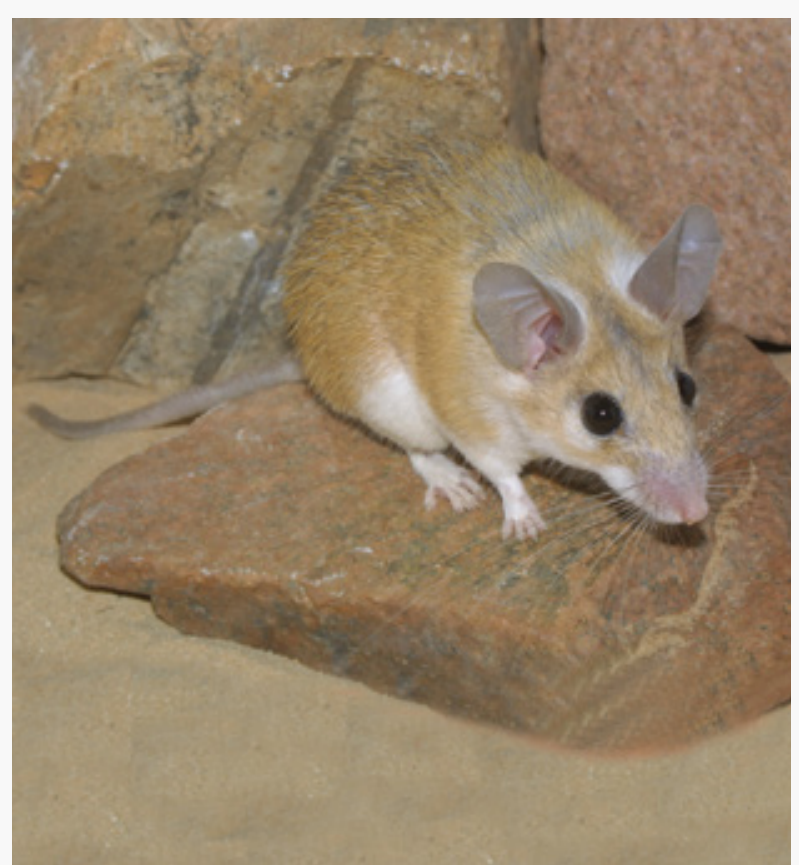

Figure 41: Acomys dimidiatus ( Mohammad Abu Baker) 


\section{Acomys russatus (Wagner, 1840)}

Animalia - Chordata - Mammalia - Rodentia - Muridae

Common name(s): Golden spiny mouse.

Red List status: Least Concern.

Justification: The species is widespread within the desert rocky habitats in Jordan and no known threats on its population exist at present.

Geographical range: This species was recorded from the Middle East (Jordan, Palestine, Saudi Arabia, northern Yemen, Oman, Egypt, and the Sinai Peninsula. In Jordan, the Golden Spiny Mice inhabits the southwestern sandstone mountain range from Ghawr es Safi, King Hussein Bridge, Swymeh, Wadi Zarqa Ma'in, Wadi Karak, Wadi Fidan, Wadi Al Mujib, At Tafilah, Gharandal, Madaba, Petra, Rahmeh, Reishah, Wadi Rum and Aqaba Mountains. A separate population in a melanistic form that is considered a subspecies of Acomys russatus (A. russatus lewisi) can be found in the northeastern black lava desert (e.g. Azraq ad Duruz, Safawi, Jawa, Burqu' Protected Area) (Amr et al., 2018).

Population: No data on population size is available, presumed stable based on available records in Jordan.

\section{Area of occupancy}

\section{Extent of occurrence}

Biogeographical realms: Palearctic.

General use and trade information: No trade or use information were reported.

Threats: No threats were recorded on this widespread and common species.

Conservation actions: This species is protected in situ in Dana and Mujib Biosphere Reserves, Wadi Rum World Heritage Area and Burqu' Protected Area.

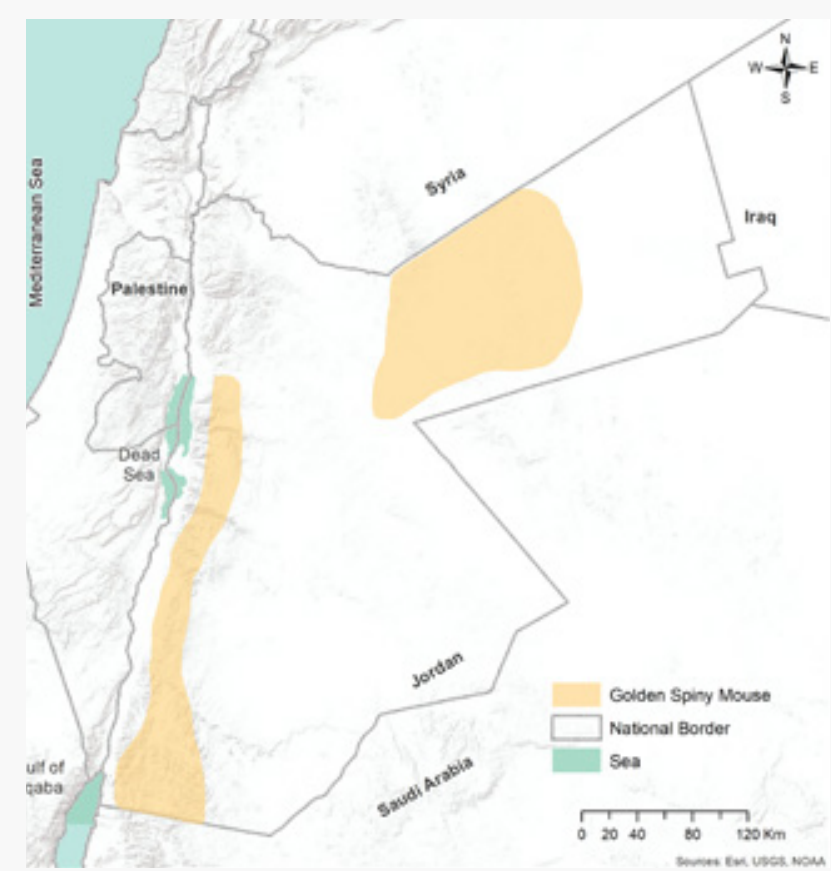

Map 39: Distribution of Acomys russatus in Jordan.

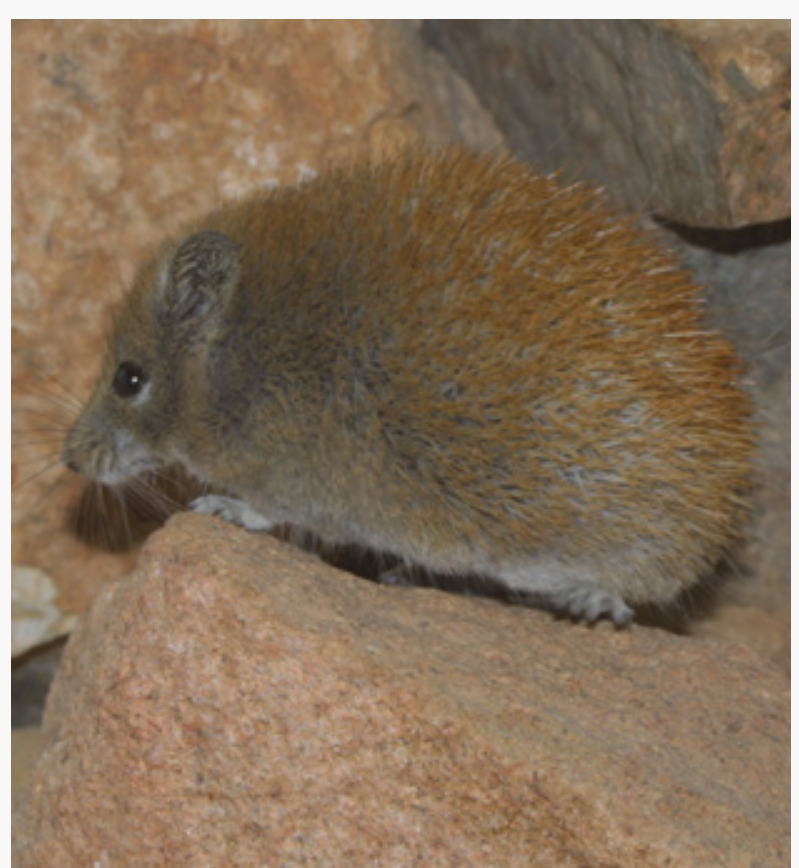

Figure 42: Acomys russatus (C Mohammad Abu Baker) 


\section{Dipodillus (Petteromys) dasyurus (Wagner, 1842)}

Animalia - Chordata - Mammalia - Rodentia - Gerbillinae

Common name(s): Wagner's gerbil.

Red List status: Least Concern.

Justification: Is widespread and common species, and there are no major threats at present, hence is Listed as Least Concern.

Geographical range: Middle East, Arabian Peninsula and marginally into eastern desert of Egypt. In the Mediterranean, it occurs in Egypt, Palestine, Jordan, Lebanon, Syria, and Turkey. In Jordan, it is widly distributed where it was recorded from Ain Musa, Bir ed-Doleh, Petra, Wadi Al Hassa, Al-Jafr, N Aqaba, Azraq, Jarash, Petra, Ras Al Naqab, Wadi Musa, Al Muwaqqar, Al Shawmari, Aqaba, Ghawr Nimrin, Wadi Rajil, King Hussein Bridge, Prince Mohammed Bridge, Burqu', Al Lajjun, Al Wisad, Azraq ad Duruz, Buqay'awiyah, Jawa, Ruwayshid, Wadi Salma, Al Quweirah, Disah, Mudawwarah, Dana Biosphere Reserve, Wadi Al Hashad, Faydat ad Dahikiyah, Qasr Al Kharanah, Qasr Al Halabat, Marj Al Hammam, Iraq al Wahaj, Wadi am Numayr, Wadi Khariobsa, Wadi Rum, Wadi Ibn Hammad, Rajif, Wadi Suweid, Ernebeh, Fifa, Jabal Masuda, Marab Omish, Qatar, Rahmeh and Wadi Al Mujib (Amr et al., 2018).

Population: A common species.

\section{Area of occupancy}

180

\section{Extent of occurrence}

87810

Biogeographical realms: Palearctic.

General use and trade information: No trade or use was recorded for this species.

Threats: No major threats.

Conservation actions: This species is well-protected in situ where it is reported from Dibeen, Ajloun Yarmouk and Forest Reserves, Dana and Mujib Biosphere Reserves, Fifa Protected Area, Wadi Rum World Heritage Area, Qatar Protected Area, Azraq Wetland Reserve, and Burqu' Protected Area.

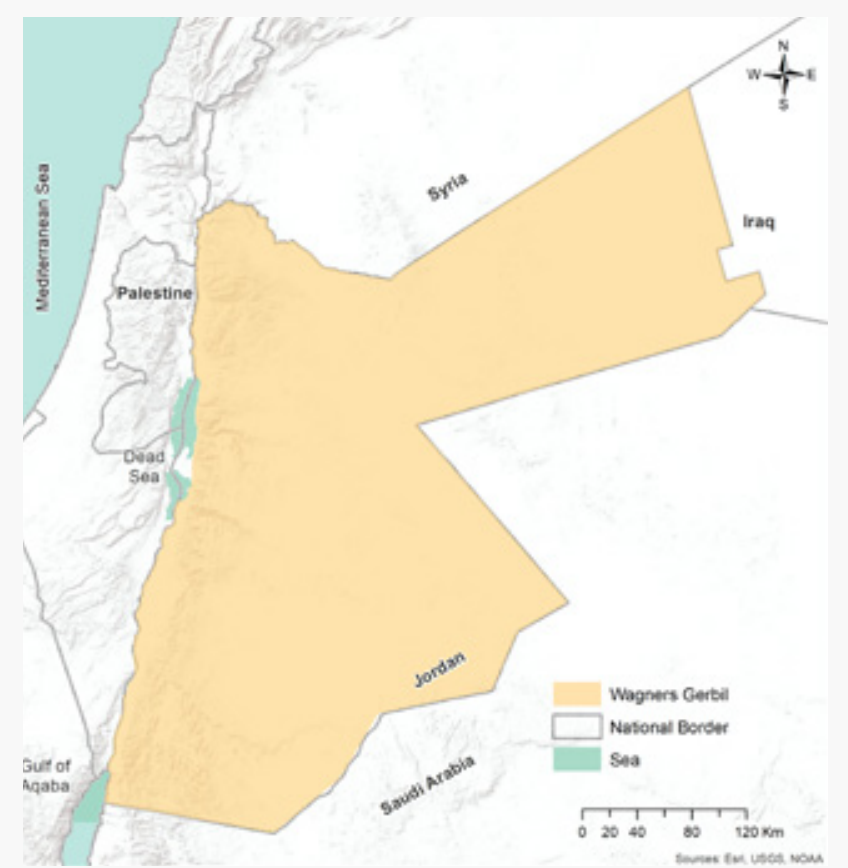

Map 40: Distribution of Gerbillus dasyurus in Jordan.

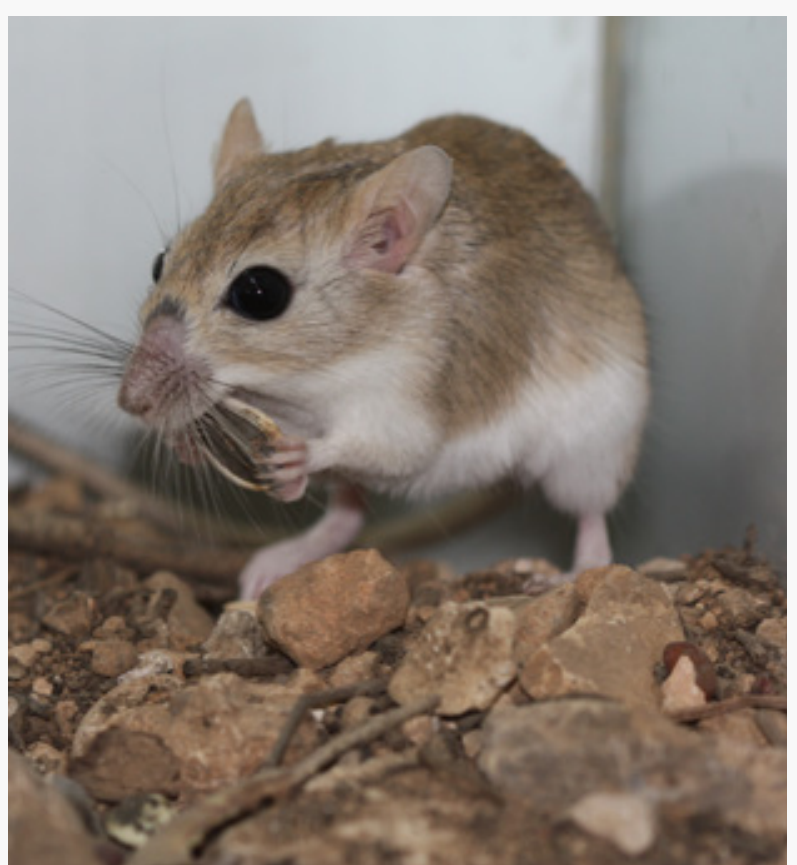

Figure 43: Dipodillus (Petteromys) dasyurus (C Zuhair Amr) 


\section{Gerbilus andersoni (De Winton, 1902)}

Animalia - Chordata - Mammalia - Rodentia - Gerbillinae

Common name(s): Andersons gerbil.

Red List status: Critically Endangered B2ab (ii, iii).

Justification: This species has been recorded in a single locality in Jordan, which is considered the last eastern distribution worldwide. It is considered rare and is under serious threats from quarrying, which is causing habitats destruction. Therefore it was assessed as a Critically Endangered species.

Geographical range: From Tunisia and Libya eastwards to Egypt, Palestine and Jordan. In Jordan, it is found in Al Quweirah, 22 km N Al Quweirah and 5 Km S Ras Al Naqab (Amr et al., 2018).

Population: No data on population size, presumed very rare based on the available records.

\section{Area of occupancy}

4

Biogeographical realms: Palearctic.

General use and trade information: No trade or use was recorded for this species.

Threats: quarrying activities is considered a major threat. In addition, the gas pipeline extended from Egypt to Amman is crossing the species habitats.

Conservation actions: This species is not protected in Jordan.

\section{Extent of occurrence}

182

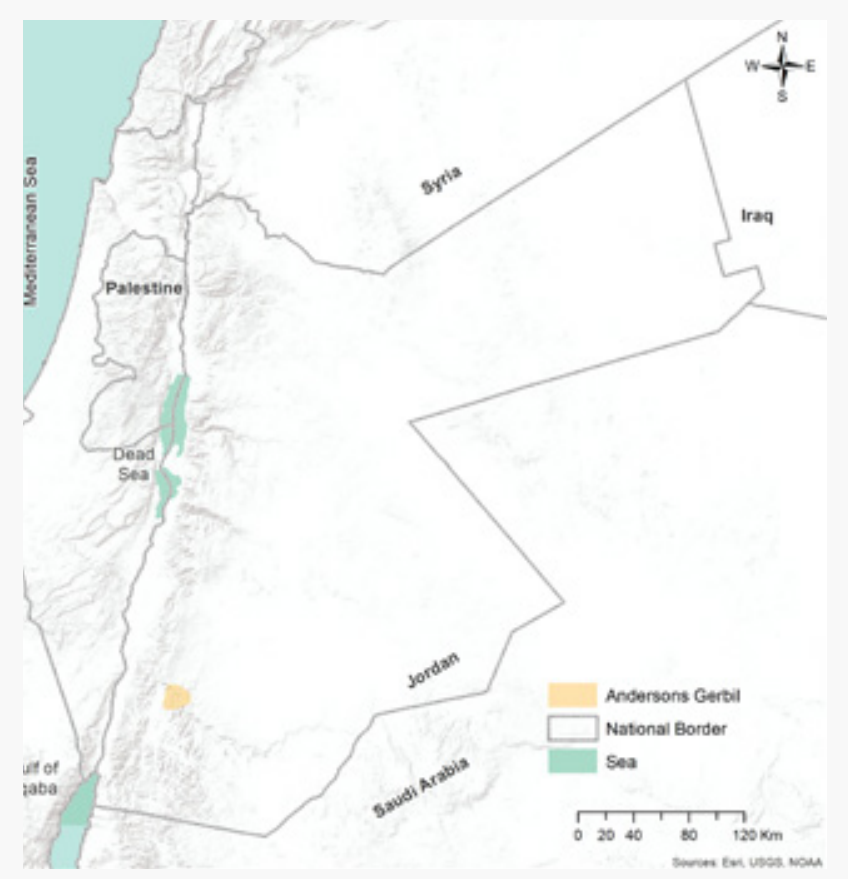

Map 41: Distribution of Gerbilus andersoni in Jordan.

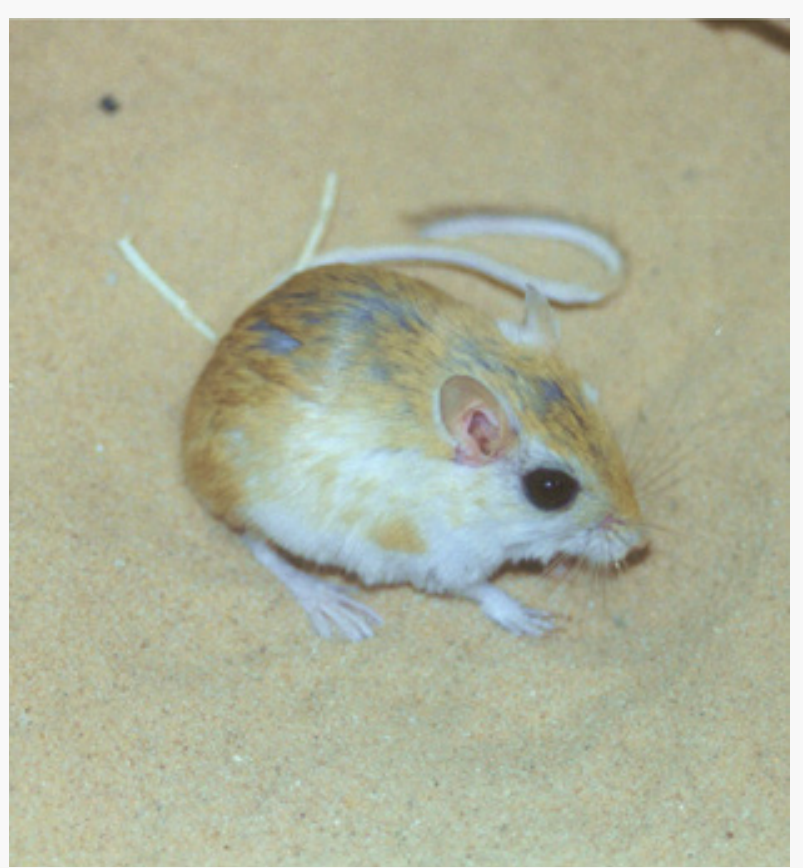

Figure 44: Gerbilus andersoni (@ Mohammad Abu Baker) 


\section{Gerbillus cheesmani (Thomas, 1919)}

Animalia - Chordata - Mammalia - Rodentia - Gerbillinae

Common name(s): Cheesman's gerbil.

Red List status: Least Concern.

Justification: Locally common species confined to sand dunes habitats with no major threats at present.

Geographical range: Arabian Peninsula, Iraq, Iran and Jordan. In Jordan, it is recorded from Al Ghamr, Al Jafr, Dumaythat, Al Quweirah, Al Wisad, Qattafi, S Ruwayshid, Disah, Mudawwarah, Wadi Rum (Amr et al., 2018).

Population: A common and widespread species in areas with sand dunes.

\section{Area of occupancy}

32

\section{Extent of occurrence}

6717

Biogeographical realms: Oriental.

General use and trade information: This species was not recorded in use or trade from Jordan.

Threats: No major threats, but habitat degradation from off-roads driving are localized threats in Wadi Rum.

Conservation actions: This species is protected in situ in Wadi Rum World Heritage Area, and Qatar protected area.

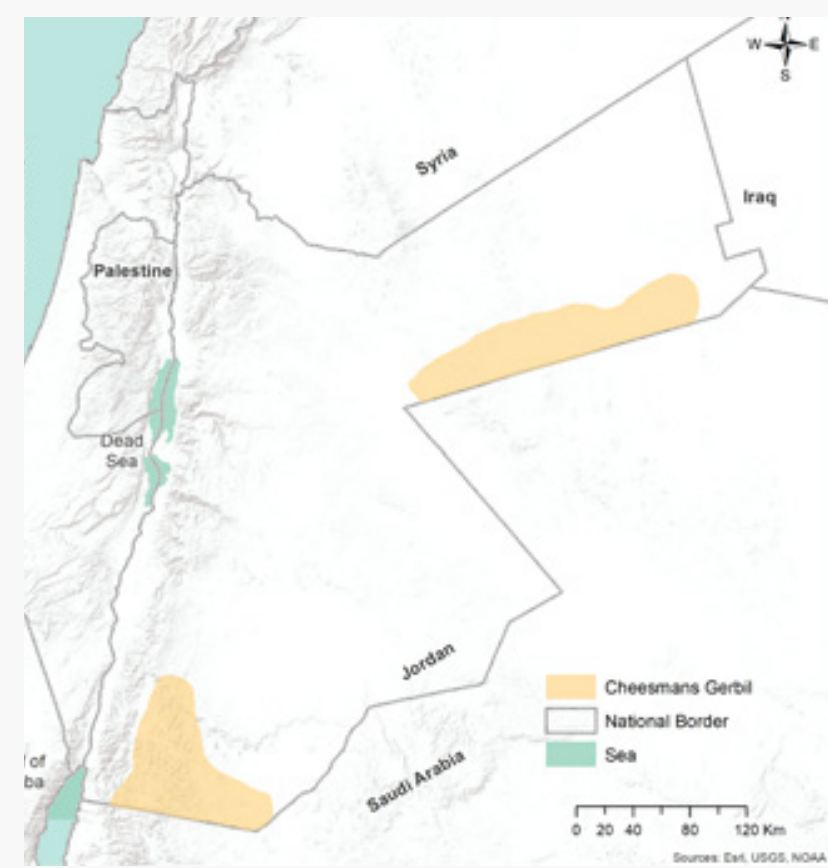

Map 42: Distribution of Gerbilus cheesmani in Jordan.

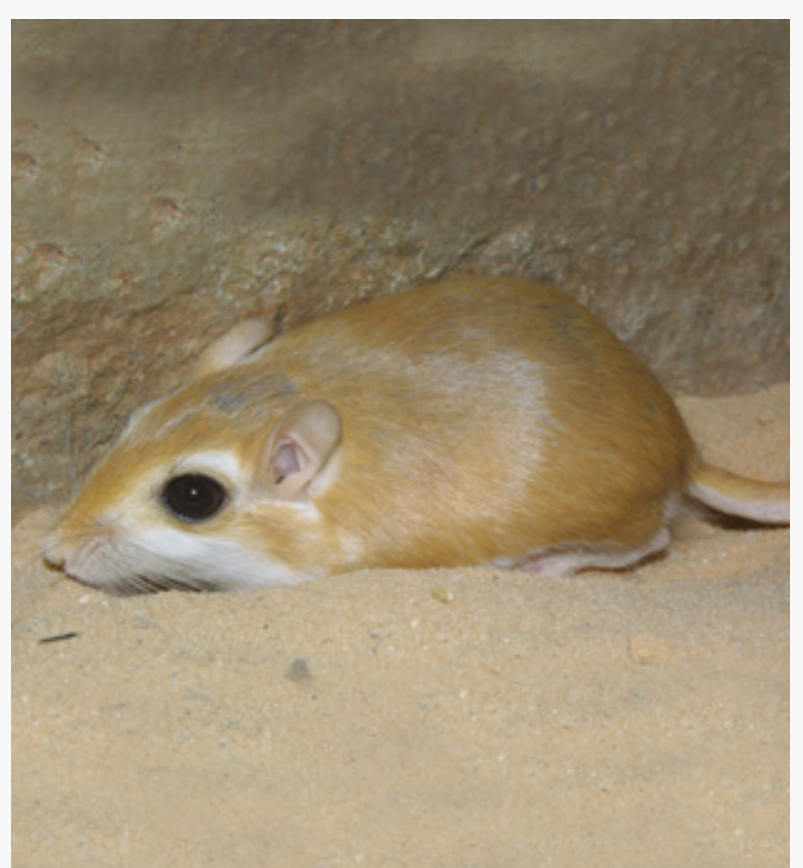

Figure 45: Gerbillus cheesmani (@ Mohammad Abu Baker) 


\section{Gerbillus gerbillus (Olivier, 1801)}

Animalia - Chordata - Mammalia - Rodentia - Gerbillinae

Common name(s): Lesser Egyptian gerbil.

Red List status: Least Concern.

Justification: Listed as Least Concern in view of its distribution, presumed stable population and because it is unlikely to be declining fast enough to qualify for Listing in a more threatened category.

Geographical range: This species is found throughout the desert and semi-desert regions of northern Africa. It also occurs marginally in Palestine and Jordan. In Jordan, it is recorded in N Aqaba, Quraiqira, Rishah, Gharandal and Rahmeh (Amr et al., 2018).

Population: It is a common species.

\section{Area of occupancy}

20

\section{Extent of occurrence}

3220

Biogeographical realms: Afrotropical.

General use and trade information: No trade or use was recorded for this species.

Threats: There are no major threats to this species, but farming projects (land transformation) represent localized threats in Wadi Araba.

Conservation actions: This species is proteted in situ in Dana Biosphere Reserve.

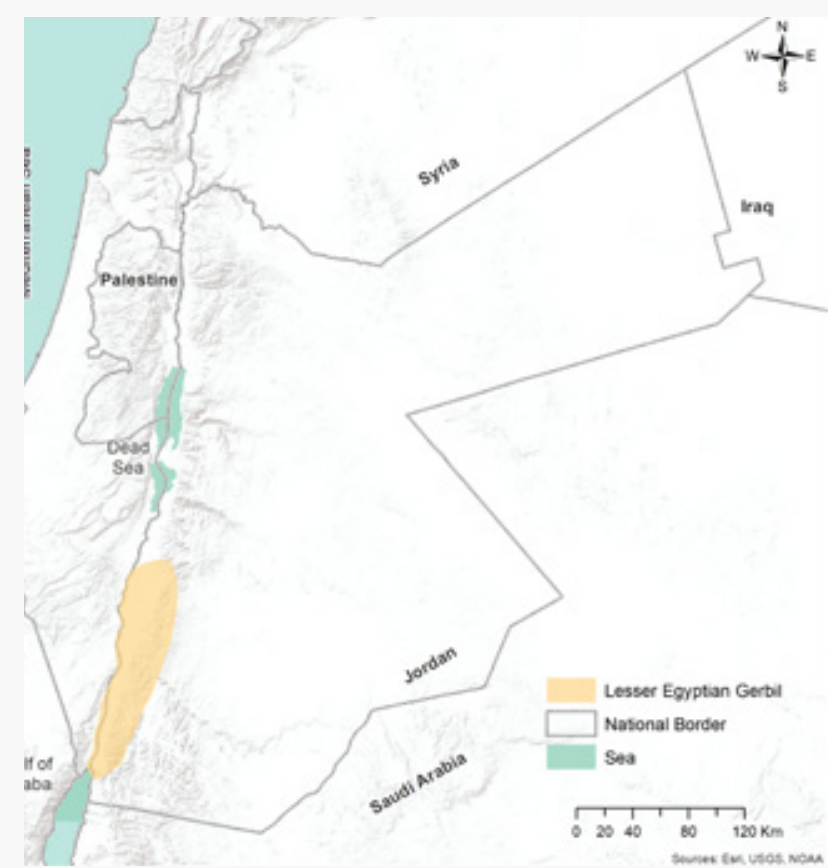

Map 43: Distribution of Gerbilus gerbillus in Jordan.

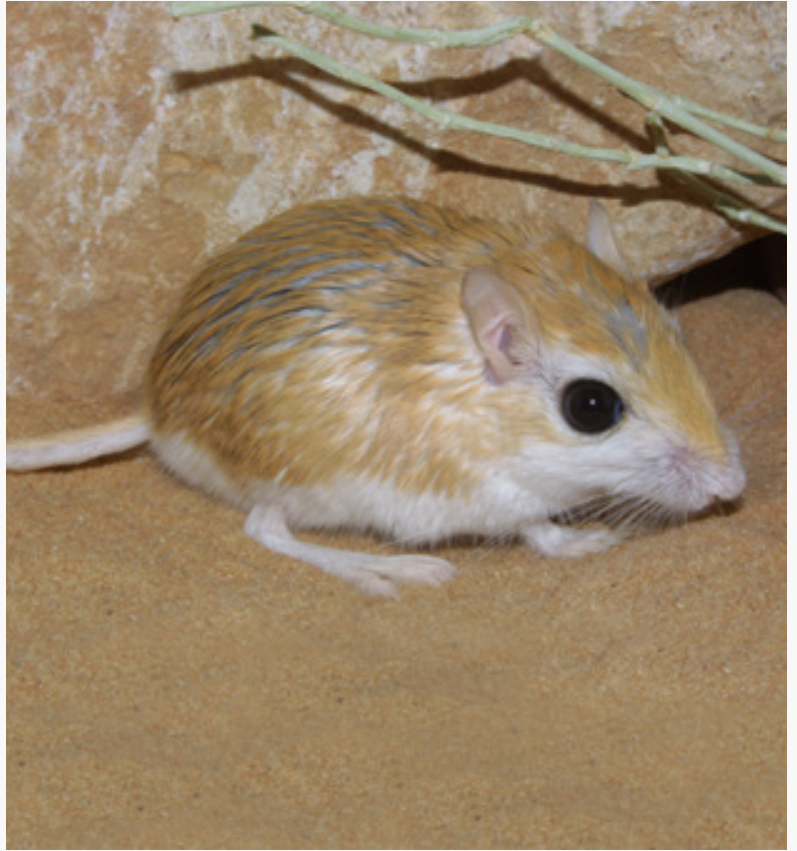

Figure 46: Gerbillus gerbillus (@) Mohammad Abu Baker) 


\section{Gerbillus henleyi (De Winton, 1903)}

Animalia - Chordata - Mammalia - Rodentia - Gerbillinae

Common name(s): Pygmy gerbil.

Red List status: Least Concern.

Justification: Despite limited number of localities and patchy distribution, this species is widely distributed along its range in Jordan.

Geographical range: This species occurs in arid and semi-desert areas surrounding the Sahara Desert. It has been recorded in central Morocco, northern Algeria, Tunisia, northern Libya, northern Egypt, Sudan, central Chad, central Niger, Mali, Burkina Faso, south Mauritania and northern Senegal. Outside Africa there are records from Palestine, Jordan and the western Arabian Peninsula. In Jordan, this species is recorded from Al Jafr, Faidat Al Dhahikiya, Al Hazim, Al Jafr, Al Shawmari, Mudawwarah, and Burqu' (Amr et al., 2018).

Population: This species is relatively abundant in suitable habitat.

\section{Area of occupancy}

20

\section{Extent of occurrence}

4190

Biogeographical realms: Afrotropical.

General use and trade information: No trade or use was recorded for this species.

Threats: There are no major threats to this species.

Conservation actions: This species is protected in situ in Shaumari Wildlife Reserve and Burqu' Protected Area.

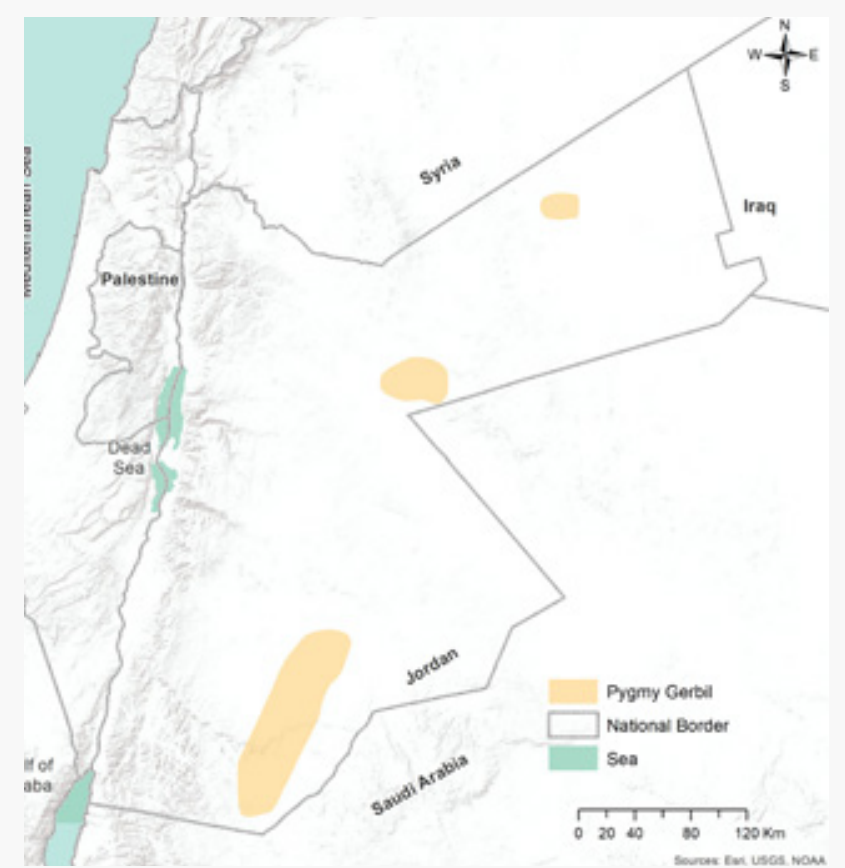

Map 44: Distribution of Gerbilus henleyi in Jordan.

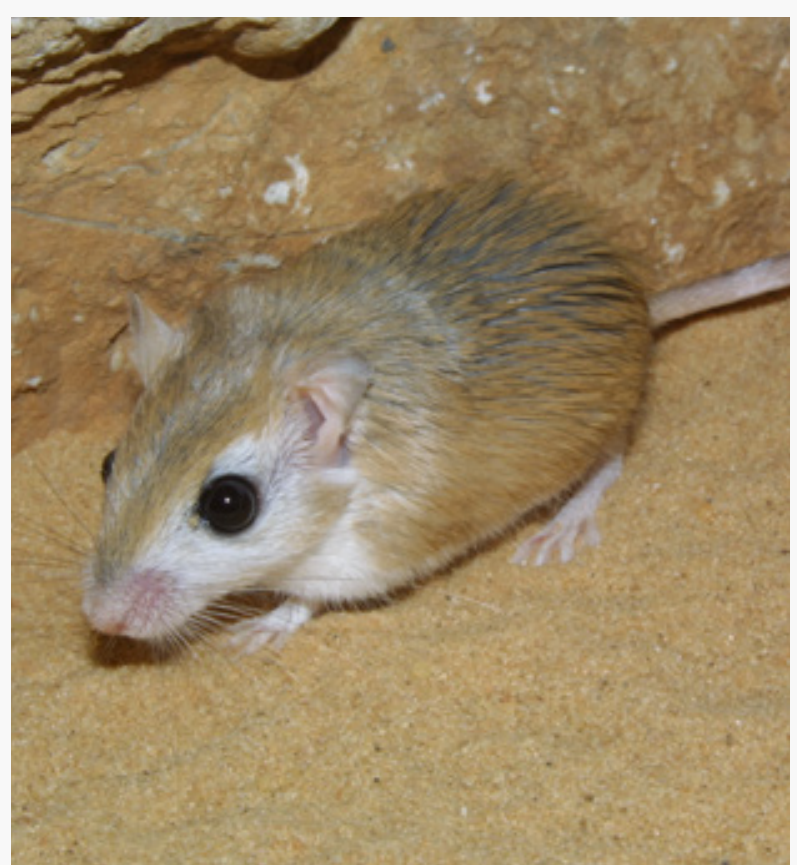

Figure 47: Gerbillus henleyi (@ Mohammad Abu Baker) 


\section{Gerbillus (Hendecapleura) nanus (Blanford, 1875)}

Animalia - Chordata- Mammalia- Rodentia- Gerbillinae

Common name(s): Arabian dwarf gerbil, Baluchistan gerbil.

Red List status: Least Concern.

Justification: A common and widespread species with no major threats, hence assessed as Least Concern.

Geographical range: Occurs in the western part of the Sahara and Sahel (from Morocco to Tunisia in the north and from Mauritania through northern Mali and Niger to Chad in the south). Also present in the Arabian Peninsula and the Middle East through Afghanistan and Pakistan to northwest India. In Jordan, this species is recorded from Aqaba, Amman, Ain Al Atmash, Wadi al Khanzair, Wadi Araba, Wadi Rum, Al Hazim, Al Ghamr, Al Shawmari, Azraq, Faydat Ad Dahikiyah, Wadi Araba, Disah, Mudawwarah, Ras Al Naqab, Azraq Wetland Reserve, Qatar, and Rahmeh (Amr et al., 2018).

Population: It is a locally common species within its localities.

Area of occupancy

56

\section{Extent of occurrence}

10487

Biogeographical realms: Afrotropical.

General use and trade information: No trade or use was recorded for this species.

Threats: There are no major threats to this species.

Conservation actions: This species is protected in situ in Fifa Protected Area, Qatar Protected Area, Wadi Rum World Heritage Area and Burqu' Protected Area.

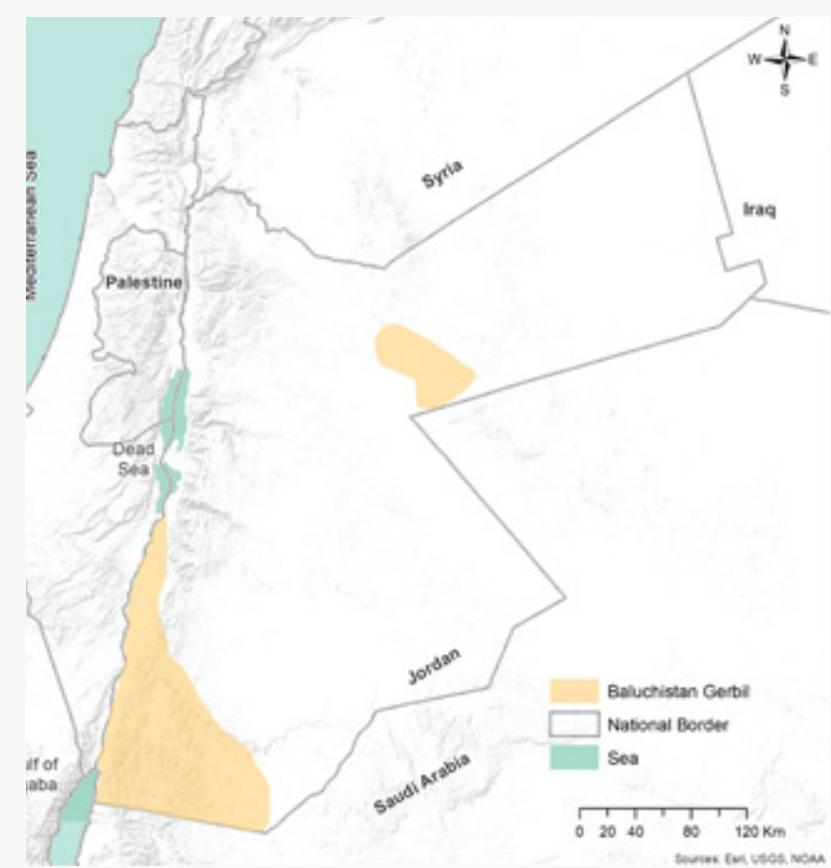

Map 45: Distribution of Gerbilus nanus in Jordan.

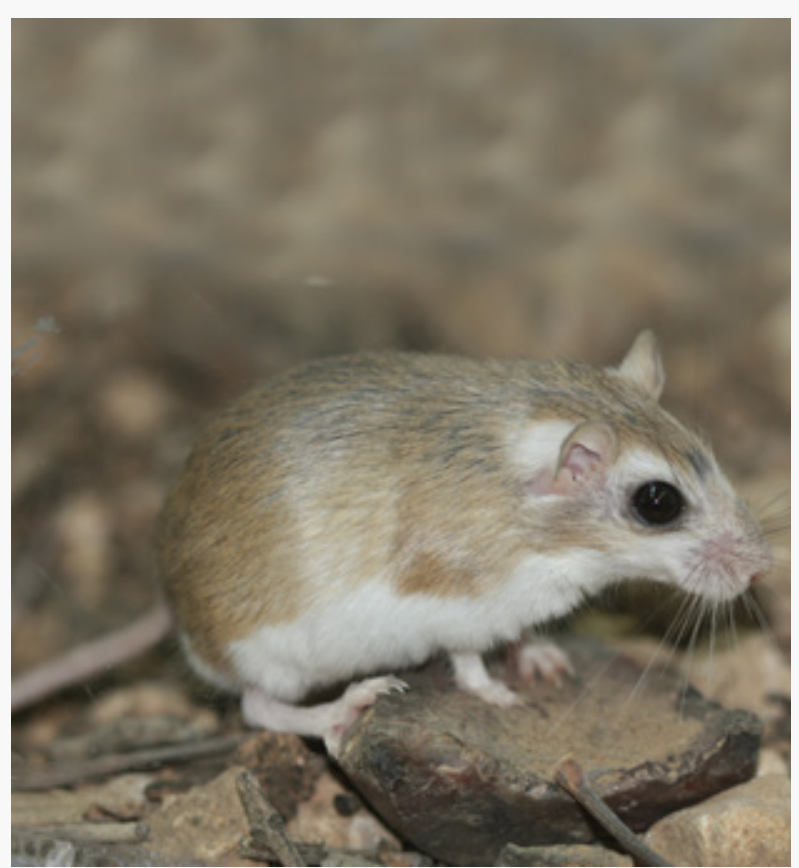

Figure 48: Gerbillus (Hendecapleura) nanus (@ Mohammad Abu Baker) 


\section{Meriones (Pallasiomys) crassus (Sundevall, 1842)}

Animalia - Chordata- Mammalia- Rodentia- Gerbillinae

Common name(s): Sundevall's jird.

Red List status: Least Concern.

Justification: $M$. crassus is common and widespread. With no known threats on its population in Jordan therefore assessed as Least Concern.

Geographical range: Meriones crassus occurs across north Africa from Morocco to Egypt south to Sudan; also in Asia through the Arabian Peninsula north to Turkey and east to western Pakistan. There are also records of this species from Niger and the headwaters of the Nile in Sudan. In Jordan, this species is recorded from Suwira, Al Jafr, Azraq, Amman, S Wadi Araba, Aqaba, Ghazaleh, Qatrana, Wadi Khanzairah, Wadi Al Hashad, Wadi Rum, Faydat ad Dahikiyah, Al Hazim, Buqay'awiyah, Qattafi, Al Shawmari Wildlife Reserve, Wadi Salma, Mudawwarah, Qasr Al Kharanah, Qasr Al Halabat, King Talal Dam and Qaser Amra (Amr et al., 2018).

Population: It is a locally common species within its range.

\section{Area of occupancy}

80

\section{Extent of occurrence}

44633

Biogeographical realms: Afrotropical.

General use and trade information: No use or trade data was collected from Jordan.

Threats: There are no major threats to this species.

Conservation actions: This species is protected in situ in Wadi Rum World Heritage Area, Azraq Wetland Reserve and Burqu' Protected Area.

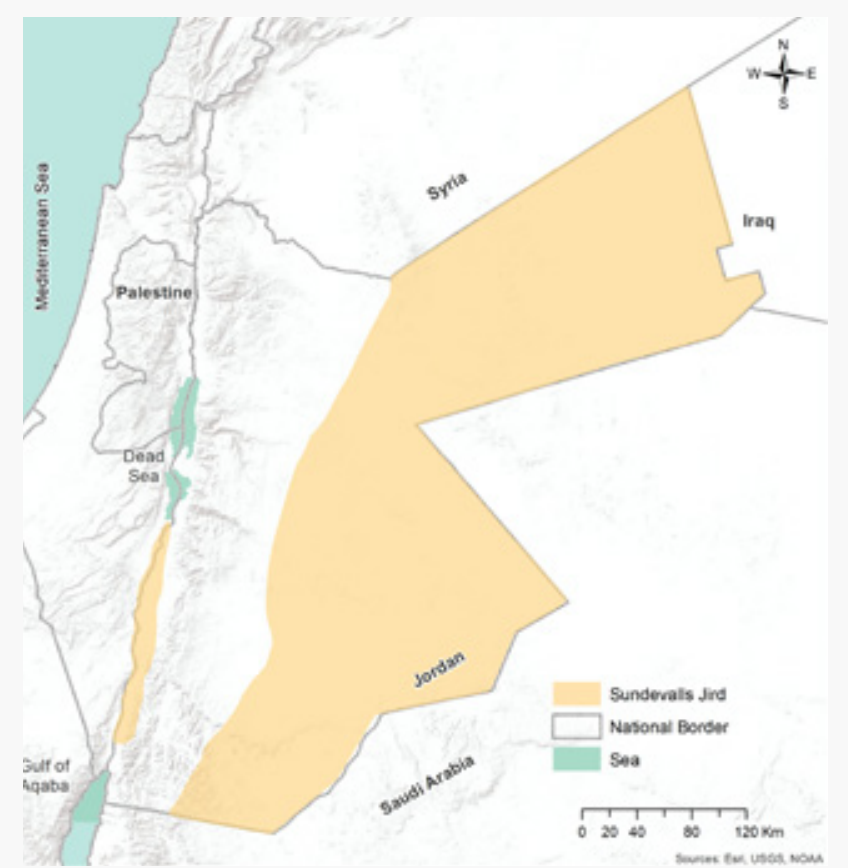

Map 46: Distribution of Meriones crassus in Jordan.

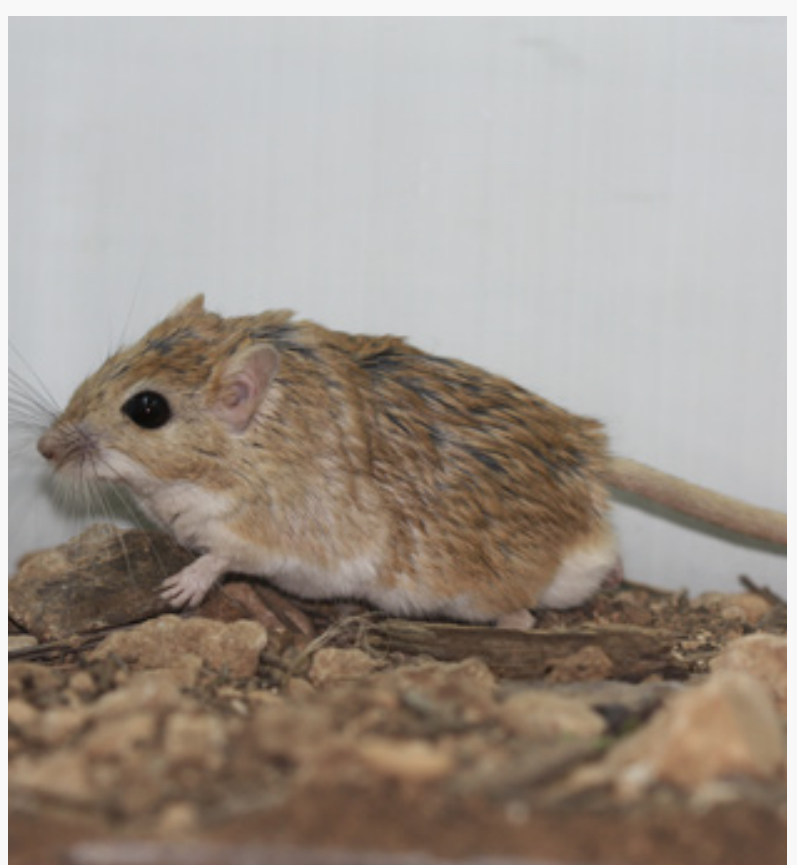

Figure 49: Meriones (Pallasiomys) crassus (@ Zuhair Amr) 


\section{Meriones (Pallasiomys) libycus (Lichtenstein, 1823)}

Animalia - Chordata - Mammalia - Rodentia - Gerbillinae

Common name(s): Libyan jird.

Red List status: Least Concern.

Justification: Listed as Least Concern in view of its wide distribution, presumed large population and because it is unlikely to be declining fast enough to qualify for Listing in a more threatened category.

Geographical range: Meriones libycus has a wide global range, occurring in North Africa (from Western Sahara and Mauritania to Egypt) and in Asia (from the Arabian Peninsula east to China). In Jordan, this species was recorded from Al-Jafr, Al-Mahammadia, Azraq, King Hussein Bridge, Qasr Al Halabat, Qatrana, Al Hazim, Azraq ash Shishan, Al Wisad, Disah, Al Shawmari Wildlife Reserve, Azraq Wetland Reserve, Qasr Al Kharanah, Qasr Al Halabat, Burqu', Bayer, Omish and Swaqa (Amr et al., 2018).

Population: It is a locally common species across its range.

\section{Area of occupancy}

48

\section{Extent of occurrence}

39183

Biogeographical realms: Palearctic, Oriental.

General use and trade information: No use or trade data was collected from Jordan.

Threats: There are no major threats to this species. It is considered a pest in some areas, as it may feed on crops.

Conservation actions: This species is protected in situ in Azraq and Shaumari Reserves, Wadi Rum World Heritage Area and Burqu' Protected Area.

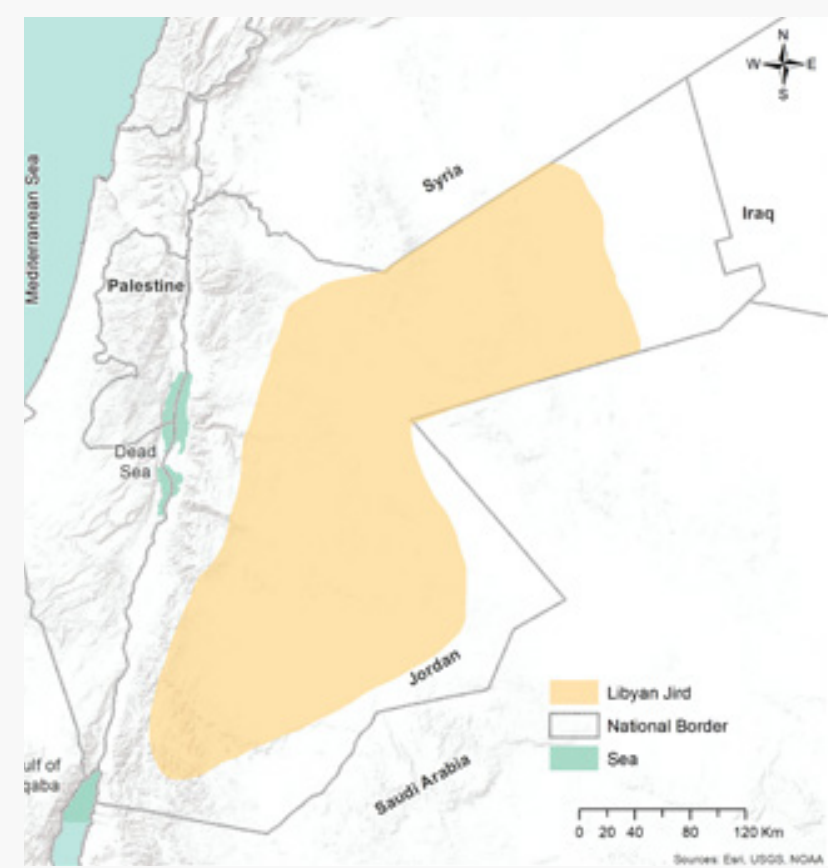

Map 47: Distribution of Meriones libycus in Jordan.

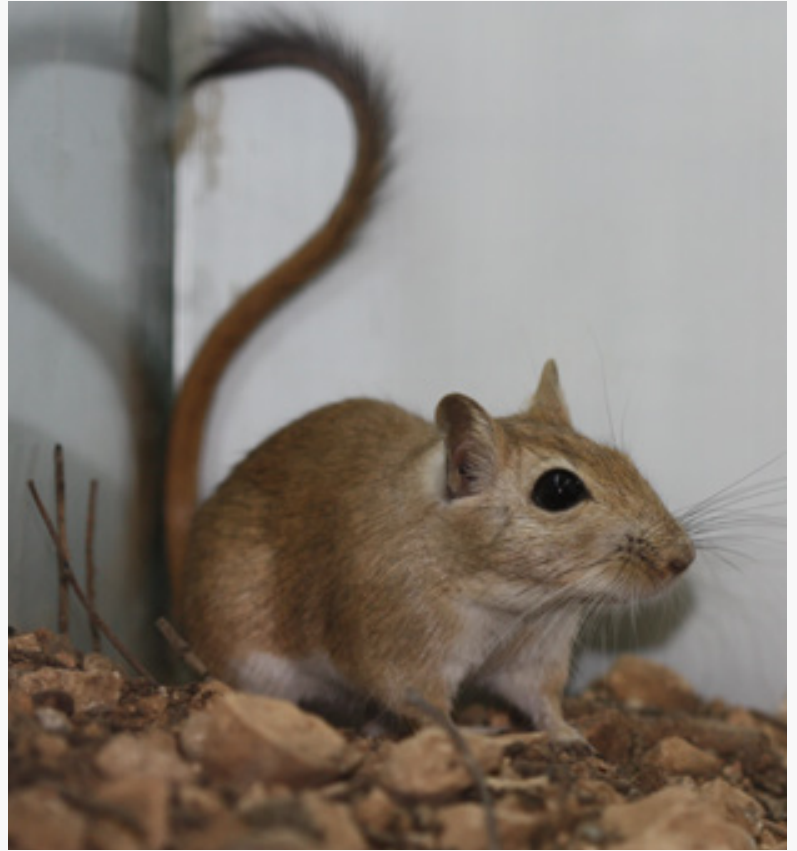

Figure 50: Meriones (Pallasiomys) libycus (@ Zuhair Amr) 


\section{Meriones tristrami (Thomas, 1892)}

Animalia - Chordata - Mammalia - Rodentia - Gerbillinae

Common name(s): Tristram's jird.

Red List status: Least Concern.

Justification: Meriones tristrami is a widespread and common species across its range. It is not threatened at present and is Listed as Least Concern.

Geographical range: Meriones tristrami has a global range that extends from Anatolia and the Caucasus south to Jordan, Syria, Palestine, northwest Iran and Iraq. In Jordan this species is recorded from Ash Shawbak, At Tafilah, Ain Gleidat, Amman, Ras Al Naqab, Jawa, Ghazaleh, Irbid, Jawa, King Hussein Bridge, Surra Reserve Station, Dana Biosphere Reserve, As Sareeh, Um Al Quttain, Wadi Zarka, S Jarash, Al Sareeh, Wadi Al Seer, Marj Al-hammam, Ajlun Forest Reserve, Amman National park, Amman University, Iraq al Wahaj, Rajif, Wadí Suweid, Wadi Zarqa Ma'in, Al Lajjoun, Ramtha, Wadi Al Mujib, Wadi Rattia in Dana (Amr et al., 2018).

Population: A common and widespread species in Jordan, and limited knowledge on its population exists from Jordan.

Area of occupancy 100

\section{Extent of occurrence}

14679

Biogeographical realms: Palearctic.

General use and trade information: No use or trade data was collected from Jordan.

Threats: There are no serious threats affecting this species at present.

Conservation actions: This species is protected in situ in Dibeen and Ajloun Forest Reserves, Mujib Biosphere Reserve.

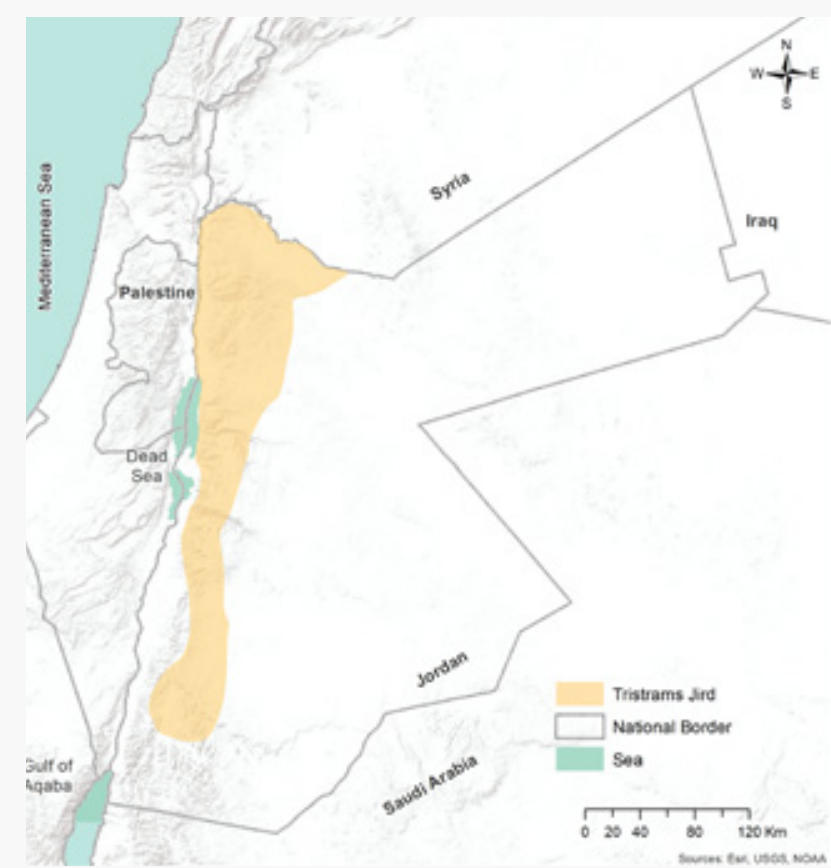

Map 48: Distribution of Meriones tristrami in Jordan.

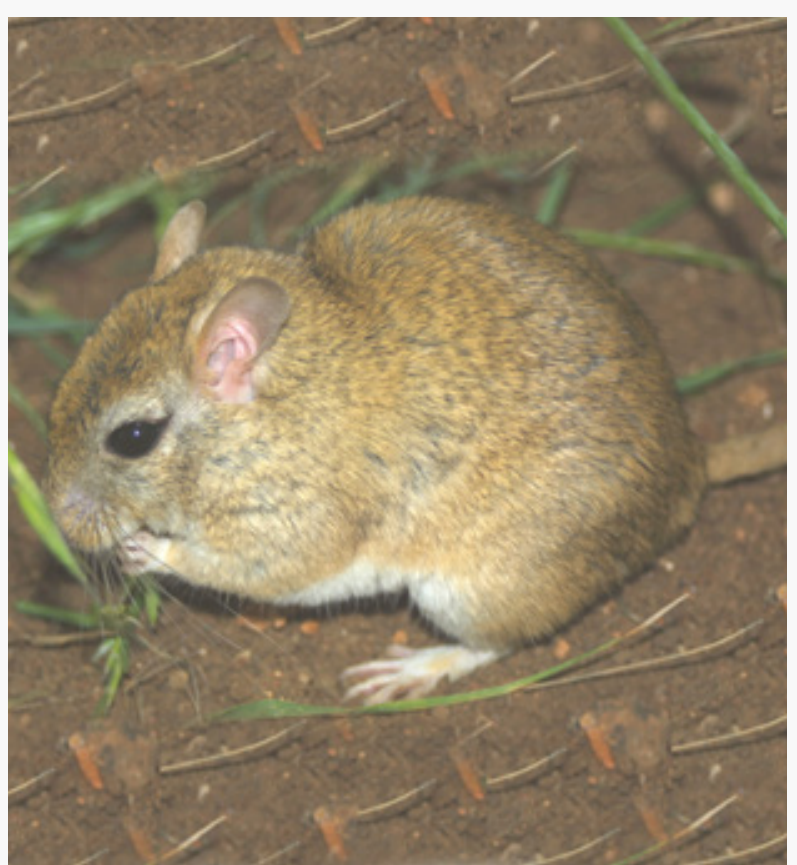

Figure 51: Meriones tristrami (@ Mohammad Abu Baker) 


\section{Psammomys obesus (Cretzschmar, 1828)}

Animalia - Chordata - Mammalia - Rodentia - Gerbillinae

Common name(s): Fat sand rat.

Red List status: Least Concern.

Justification: Listed as Least Concern in view of its wide distribution, presumed stable population and because it is unlikely to be declining fast enough to qualify for Listing in a more threatened category.

Geographical range: This species is found in North Africa from Mauritania and Western Sahara to Egypt and east through Sinai Peninsula into Saudi Arabia, Palestine, Jordan and Syria. In Jordan, this species is recorded from Al Muwaqqar, Qasr El Halabat, 60 km S Amman, 20 km NW Quweirah, Wadi Rum, Dana Biosphere Reserve, Al-Hassa, Al Lajjoon, Al Jafr, Al Qatranah, Aqaba, Daba'ah, Jabal Masuda, Ma'an, Swaqa, and Um Al Rasas (Amr et al., 2018).

Population: It is a locally common species within its range.

\section{Area of occupancy}

32

\section{Extent of occurrence}

26458

Biogeographical realms: Afrotropical.

General use and trade information: No trade but is hunted for its meat in the southern parts of Jordan.

Threats: No major threats. However, it is persecuted as a pest and is a reservoir for disease leishmaniasis.

Conservation actions: This species is protected in situ in Dana Biosphere Reserve, and Wadi Rum World Heritage Area.

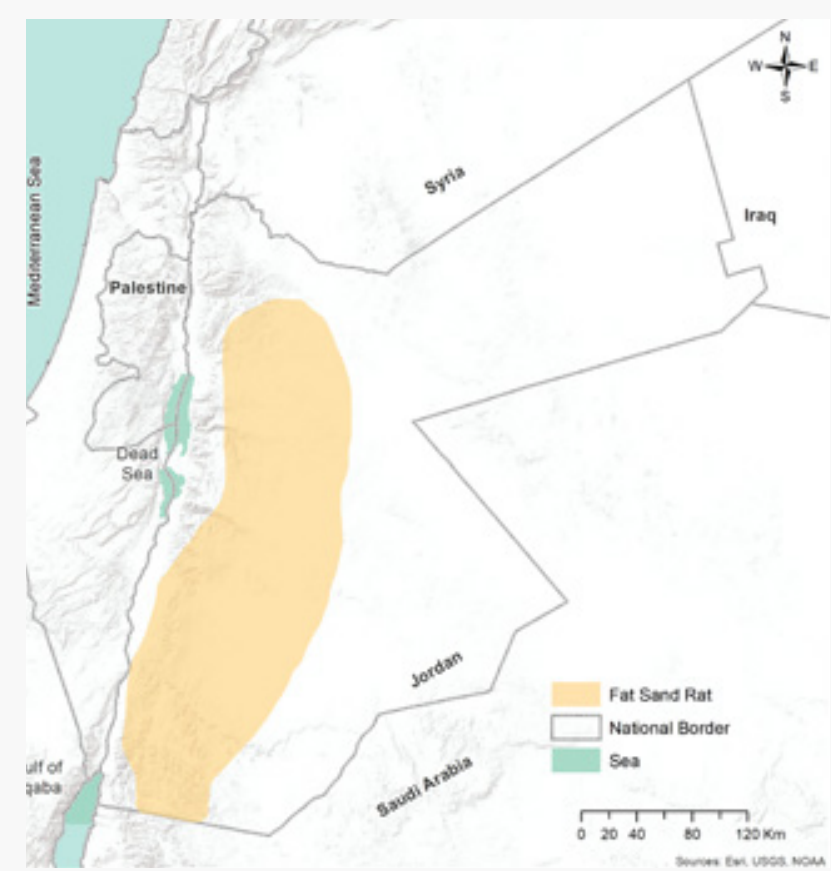

Map 49: Distribution of Psammomys obesus in Jordan.

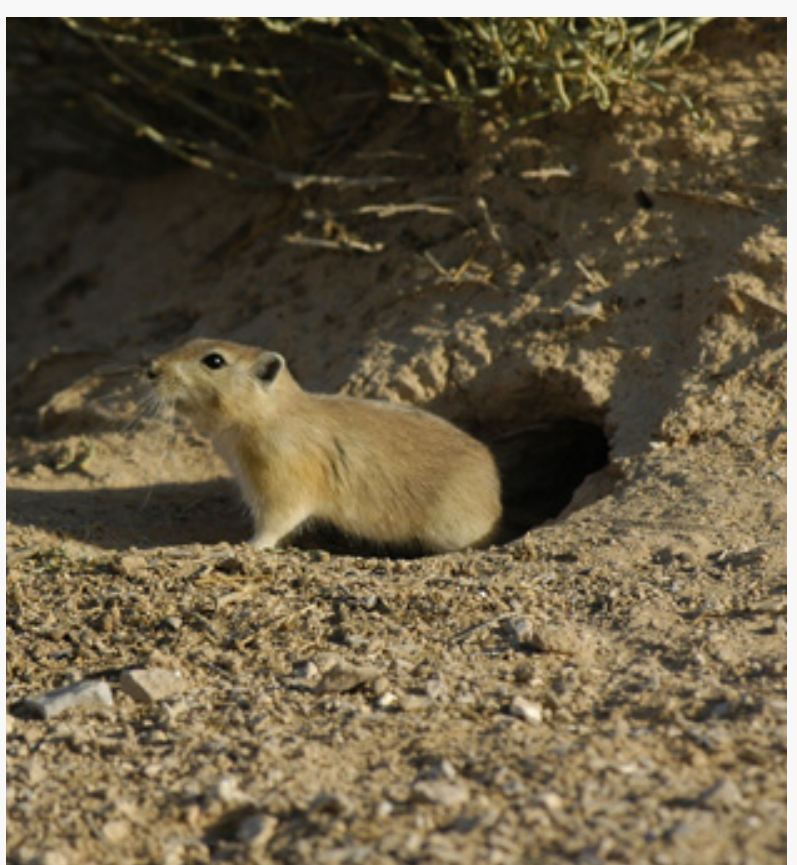

Figure 52: Psammomys obesus (๑ Shareef $\mathrm{Al}$ Jbour) 


\section{Sekeetamys calurus (Thomas, 1892)}

Animalia - Chordata - Mammalia - Rodentia - Gerbillinae

Common name(s): Bushy-tailed jird.

Red List status: Least Concern.

Justification: Rare species, but it is not under any serious threat at present, hence is assessed as Least Concern.

Geographical range: Nearly endemic to the Mediterranean region. It occurs in in northeast Sudan and eastern Egypt (Red Sea coastal areas of Egypt), Jordan and extends into Saudi Arabia (currently only know from an isolated record in Central Saudi Arabia, although likely occurs continuously from Jordan and north-western Saudi Arabia). In Jordan, this species is recorded 34 km N Aqaba, Wadi Rum, Jabal Masuda and Rahmeh (Amr et al., 2018).

Population: A rare species, occurring at relatively low densities.

Area of occupancy

16

\section{Extent of occurrence}

2150

Biogeographical realms: Afrotropical.

General use and trade information: No trade or use information was reported.

Threats: There are no major threats to this species.

Conservation actions: This species is protected in situ in Wadi Rum World Heritage Area, Dana Biosphere Reserve and Jabal Masuda Proposed Protected Area.

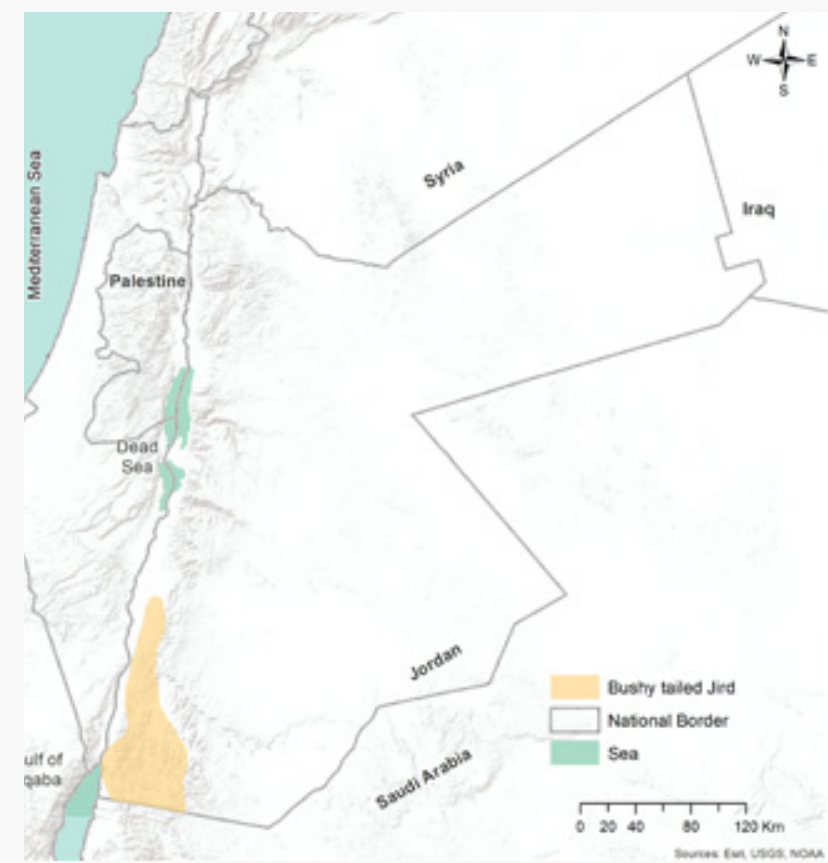

Map 50: Distribution of Sekeetamys calurus in Jordan.

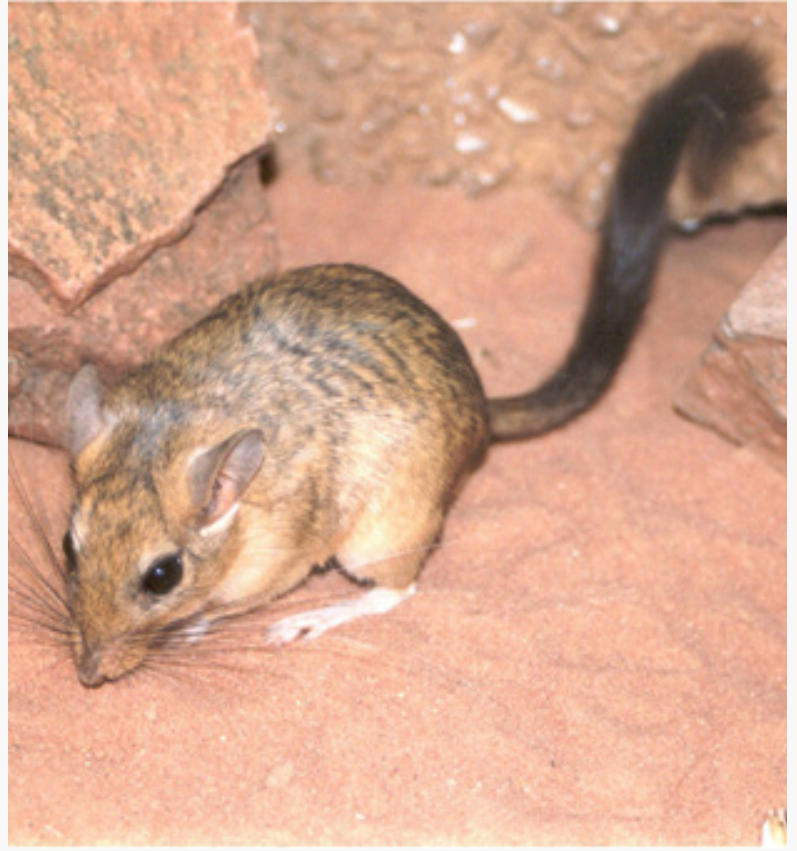

Figure 53: Sekeetamys calurus (C Mohammad Abu Baker) 


\section{Apodemus flavicollis (Melchior, 1834)}

Animalia - Chordata- Mammalia- Rodentia- Muridae

Common name(s): Yellow-necked field mouse.

Red List status: Endangered B1, B2ab (i, ii, iii).

Justification: This species is restricted to a few forested areas located in northern Jordan, which constitutes less than $1 \%$ of the total area of the Country. Jordan represents its southern limits worldwide.

Geographical range: This species extends from Great Britain across much of continental Europe to the Urals (Russian Federation). It is also found through Turkey east to W Armenia, the Zagros Mountains of Iran and south to Jordan, Syria, Lebanon and Palestine. In Europe, it is generally widespread, although it is absent from southern Iberia, western France, northern and central Fennoscandia, Russia and most islands (including Ireland). In Jordan, this species is recorded in Bergish and Kufr Khall (Abu Baker and Amr., 2008).

Population: population is presumed declining due to forests degradation in Jordan.

Area of occupancy

28

\section{Extent of occurrence}

409

Biogeographical realms: Palearctic.

General use and trade information: No use or trade information were documented regarding this species.

Threats: Forest degradation and continuous logging represents major threats on this species. In addition, habitat degradation due to agriculture may cause population declines.

Conservation actions: This species is protected in situ in Ajloun and Dibeen Forest Reserves.

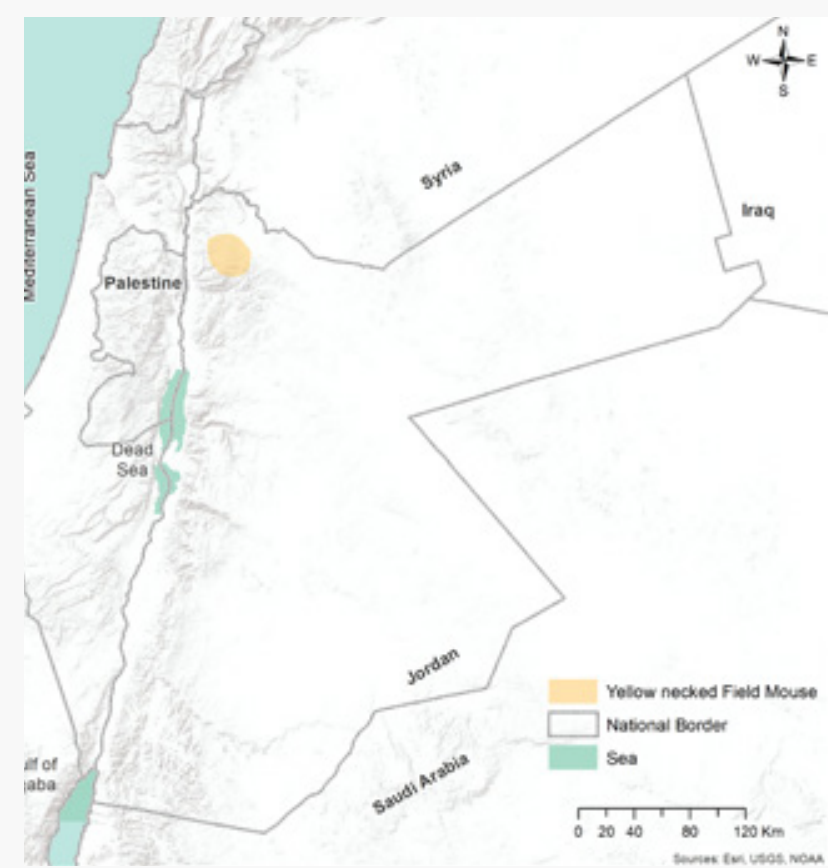

Map 51: Distribution of Apodemus flavicollis in Jordan.

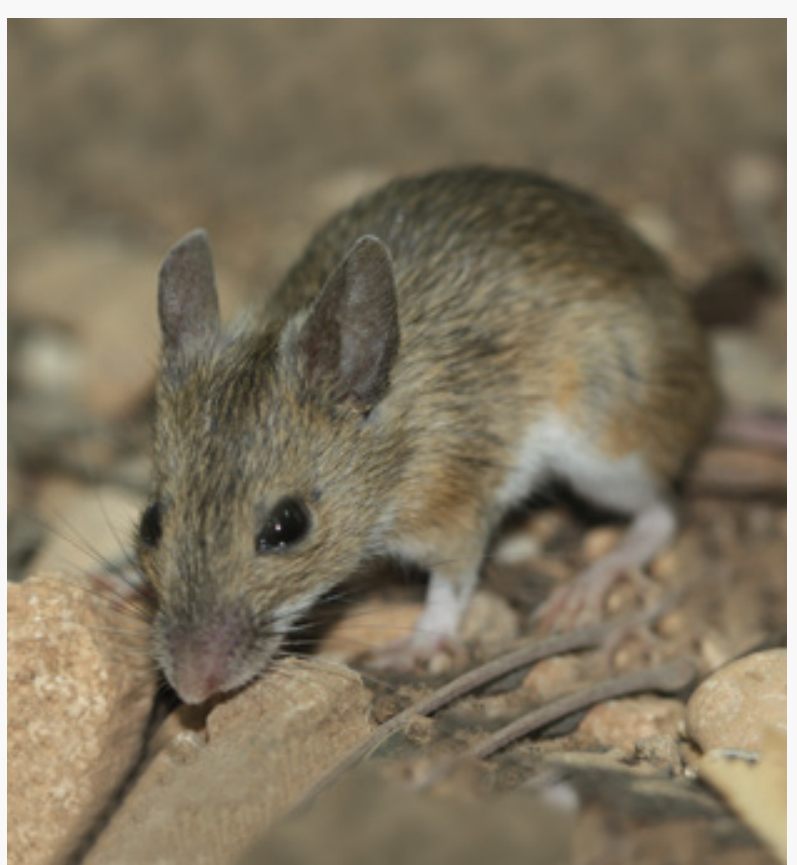

Figure 54: Apodemus flavicollis (○ Mohammad Abu Baker) 


\section{Apodemus mystacinus (Danford and Alston, 1877)}

Animalia - Chordata- Mammalia- Rodentia- Muridae

Common name(s): Eastern broad- toothed field mouse, broad- toothed field mouse.

Red List status: Least Concern.

Justification: Jordan represents the southernmost limit for this species. it is a widespread and abundant species in the forested areas within its distribution range in Jordan. It is common in suitable habitats, with no evidence of decline and no major threats.

Geographical range: It was recorded in some Aegean islands eastward through Turkey and Georgia to Palestine, Lebanon, Jordan, Syria, and northern Iraq. In Jordan, this species is recorded from Dibeen Forest Reserve, Ibbin, Ajlun Forest Reserve, Jarash, Petra, Wadi Musa, Al Hemma, Bergish, Kufr Khall, Zubya, Dana Biosphere Reserve, Wadi Al Seer, Amman National park, Iraq al Wahaj, Marj al-hammam, Wadi Al Barra in Dana reserve and Malka (Abu Baker and Amr., 2008).

Population: It is abundant in suitable habitats in Jordan.

\section{Area of occupancy}

48

\section{Extent of occurrence}

3597

Biogeographical realms: Palearctic.

General use and trade information: This species was not recorded in trade or use from Jordan.

Threats: It is negatively affected by forests degradation and use of pesticides. However, none of these are considered to be major threats at present.

Conservation actions: This species is protected in situ in Ajloun, Dibeen and Yarmouk forested areas, as well as Dana Biosphere Reserve.

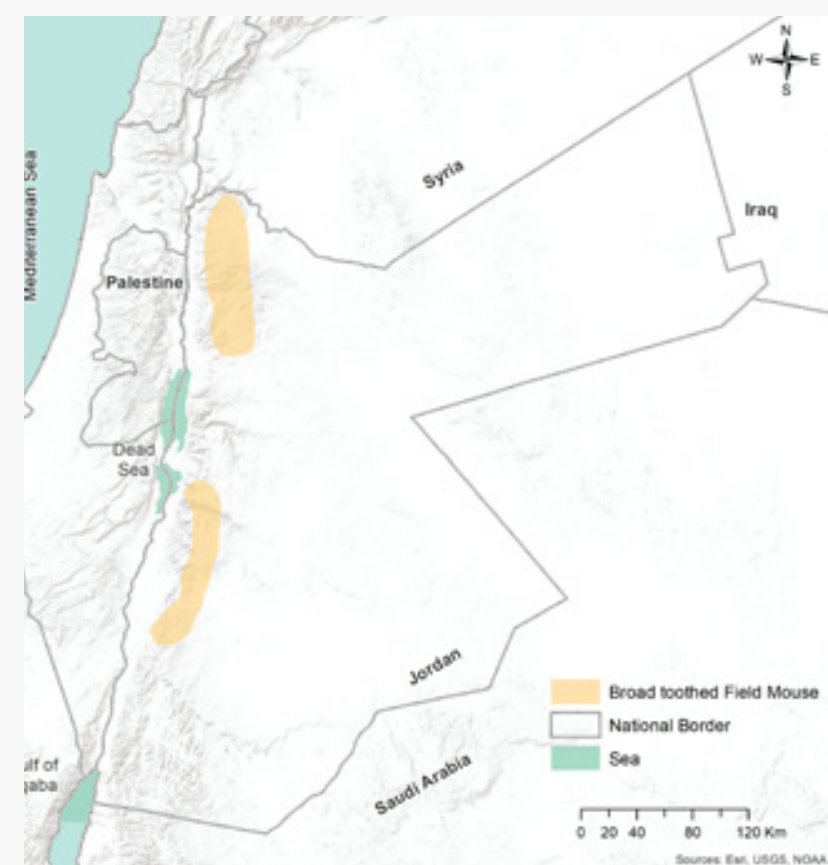

Map 52: Distribution of Apodemus mystacinus in Jordan

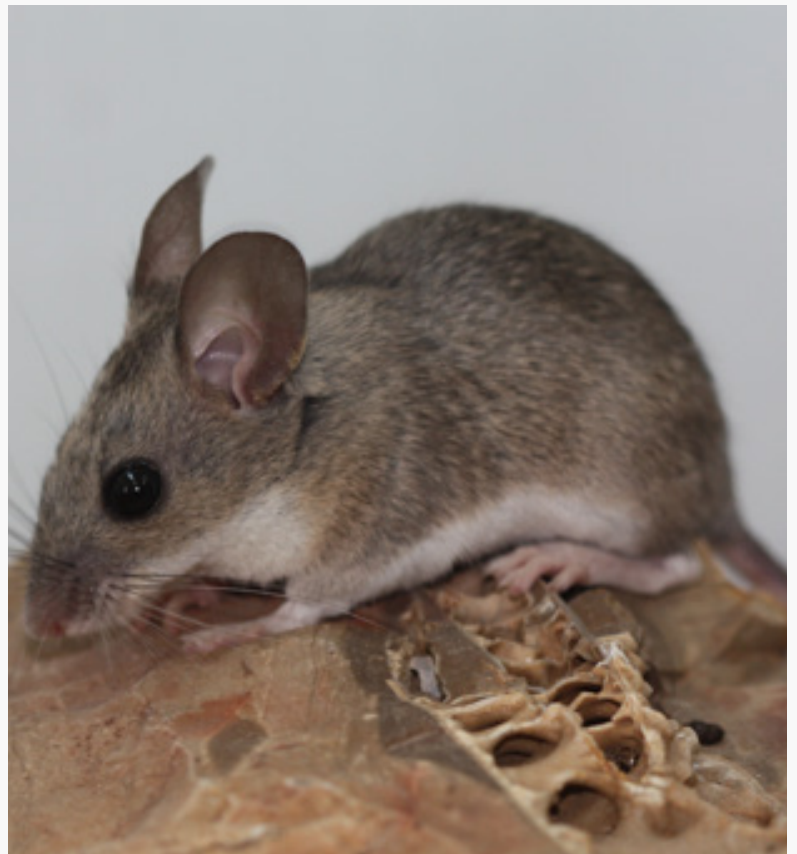

Figure 55: Apodemus mystacinus ( Mohammad Abu Baker) 


\section{Nesokia indica (Gray, 1830)}

Animalia - Chordata- Mammalia- Rodentia- Muridae

Common name(s): Short-tailed bandicoot rat.

Red List status: Data Deficient.

Justification: Listed as Data Deficient as recent studies yielded no further specimens, which justified the need of more research to verify its presence and to identify the existing threats on its population and habitats.

Geographical range: This very widespread species is present in North Africa, the Middle East, Central Asia, South Asia and China. In North Africa it has been recorded from Egypt, where it is largely confined to the western part of the Nile Delta (Hoath, 2003). In the Middle East it has been recorded from the Jordan Rift Valley, along the plains of the Tigris River in Syria, Iraq, Iran and possibly Turkey. It is present as an isolated population at Oqair and Saihat in eastern Saudi Arabia. It is very widespread over much of Iran. In Central Asia, it appears to be mostly associated with river plains, and appears to be distributed in Turkmenistan, Uzbekistan and Tajikistan. In South Asia, the species is distributed in Afghanistan, Bangladesh, northern India, Nepal and Pakistan. In China, the species has been recorded from Xinjiang. In Jordan this species is recorded from Ghor el Safie, Moab and Wadi Finan (Amr et al., 2018).

Population: Unknown.

\section{Area of occupancy}

28

\section{Extent of occurrence}

343

Biogeographical realms: Oriental.

General use and trade information: No trade or use information was reported from Jordan.

Threats: No information is available on threats.

Conservation actions: This species is protected in situ in Finan at the western parts of Dana Biosphere Reserve.

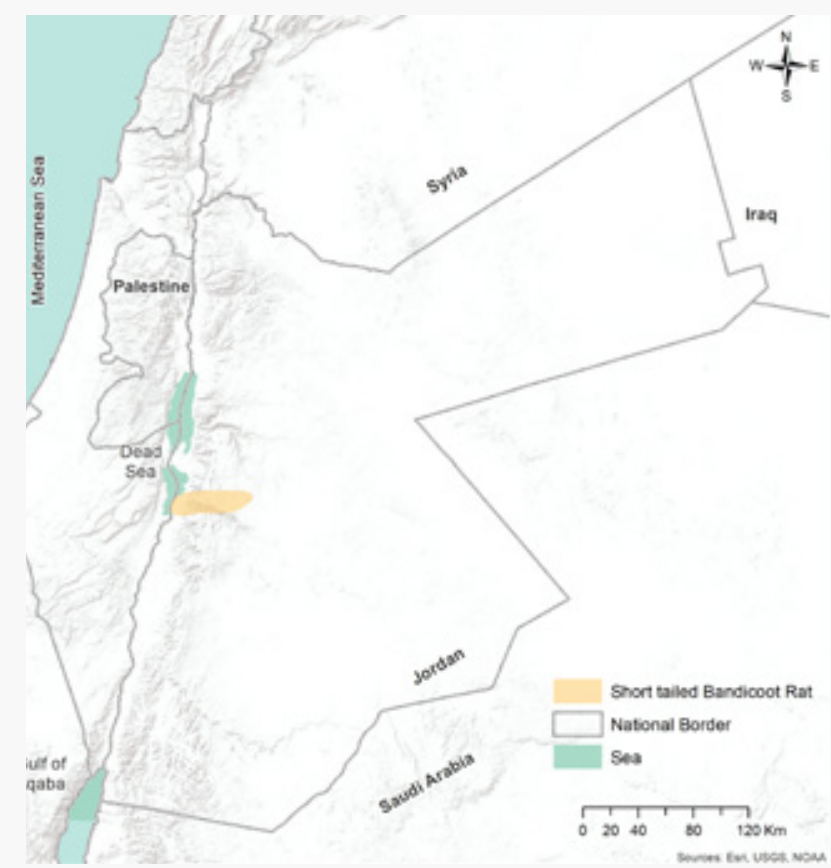

Map 53: Distribution of Nesokia indica in Jordan.

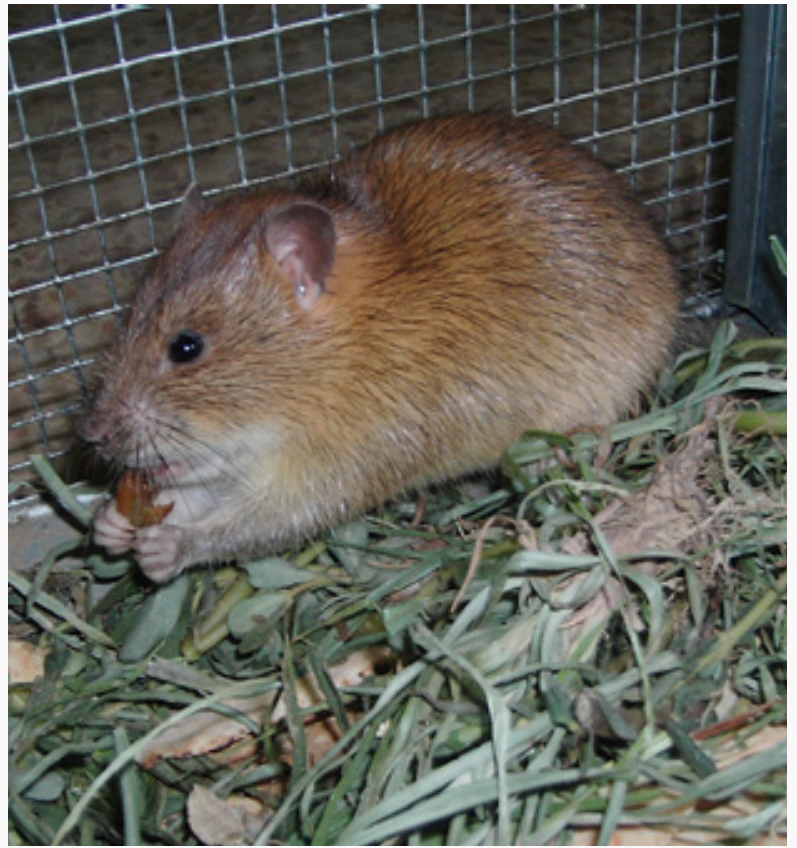

Figure 56: Nesokia indica (○ Adwan Shehab) 


\section{Hystrix indica (Kerr, 1792)}

Animalia - Chordata- Mammalia- Rodentia- Hystricidae

Common name(s): Indian crested porcupine.

Red List status: Vulnerable B1ab (i, ii, iii).

Justification: Despite its widespread distribution it is under severe threats, and the population is declining.

Geographical range: Recorded in Turkey and the eastern Mediterranean through southwest and central Asia (including Afghanistan and Turkmenistan) to Pakistan, India, Nepal, China and Sri Lanka. In Jordan, this species is recorded $4 \mathrm{Km}$ N Aqraba, Ain Lahzha, Fuhis, King Hussein Bridge, Wadi Fidan, Wadi Shoaib, Dana Biopshere Reserve, Bergish, Irbid, Jabal Masuda, Jawa, Jordan Valley, Malka, Petra, Wadi Araba, and Wadi Al Mujib (Amr et al., 2018).

Population: Its population is declined in Jordan.

Area of occupancy

40

\section{Extent of occurrence}

7685

\section{Biogeographical realms: Oriental.}

General use and trade information: This species is hunted for its meat and folk medicinal use trade, where its flesh is cooked and eaten for the treatment of general weakness used as aphrodisiac, and its liver is cooked and eaten to treat infertility. In addition, it is sold for Animal zoos.

Threats: Hunting is a major threat. Porcupines are considered agricultural pests by locals who trap and use them for food (Qumsiyeh, 1996; Aloufi and Eid, 2016). A study performed by Eid and Handal (2018) observed 32 carcasses posted on Facebook in 2015.

Conservation actions: This species is protected in situ in Dibeen, Yarmouk and Ajloun Forest Reserves, as well as Dana Biosphere Reserve. In addition, it is Listed in Appendix II for wildlife protection of the Agricultural Law Number 13 for the year 2015 based on regulation Number 43 for the year 2008.

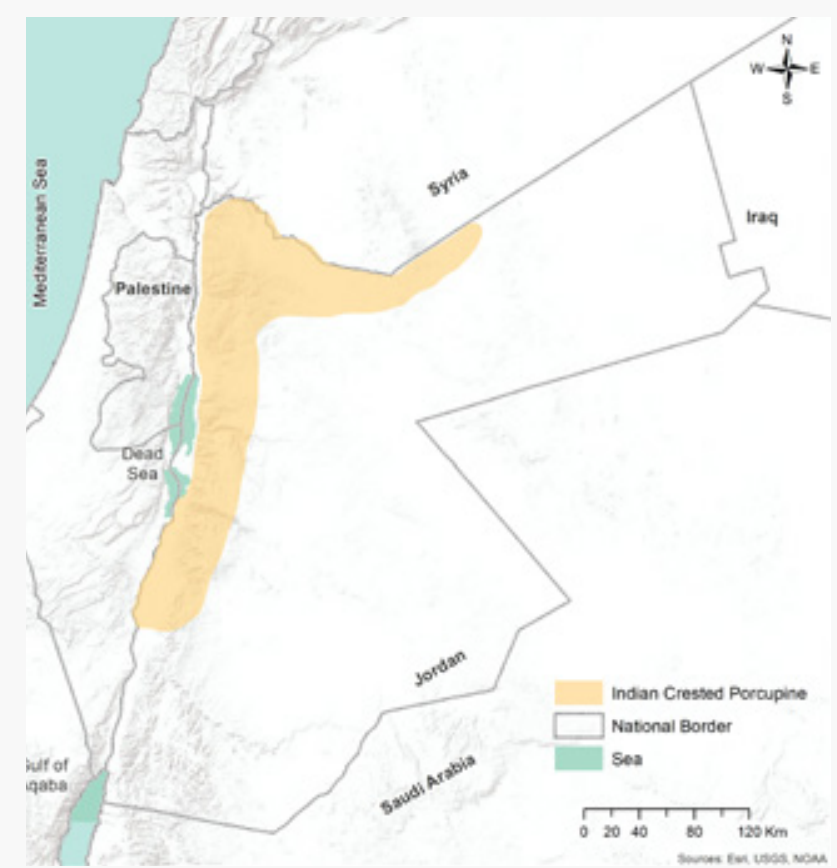

Map 54: Distribution of Hystrix indica in Jordan.

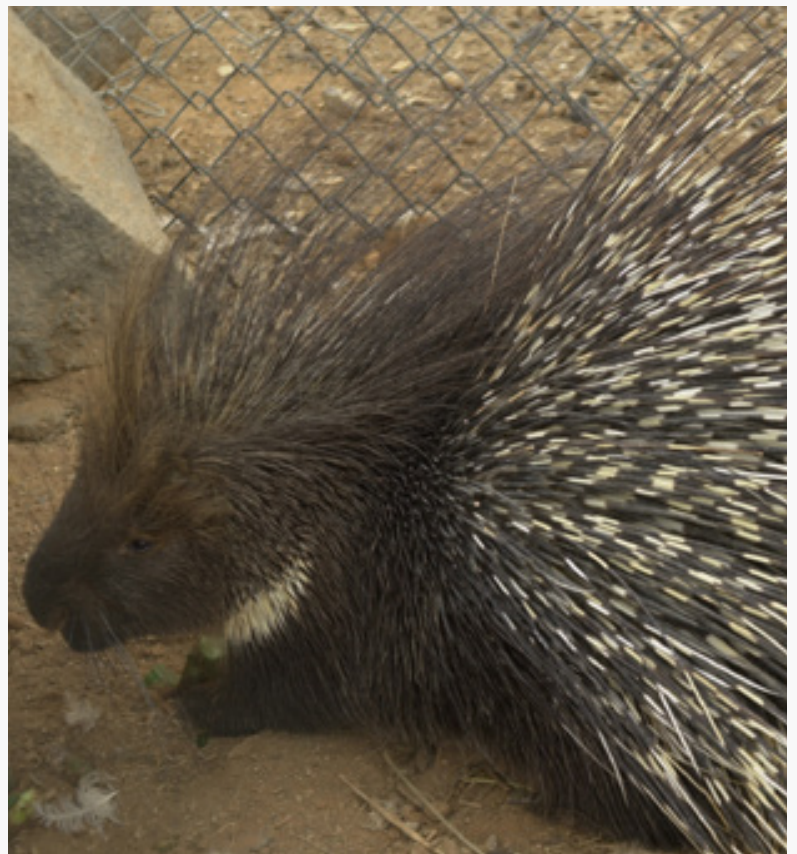

Figure 57: Hystrix indica (C) Ehab Eid) 


\section{Spalax ehrenbergi (Nordmann, 1840)}

Animalia - Chordata- Mammalia- Rodentia- Spalacidae

Common name(s): Palestine mole rat, Middle East blind mole rat.

Red List status: Least Concern.

Justification: Common and widespread and no serious threats are affecting this species.

Geographical range: This species is found in isolated pockets of appropriate habitat in coastal north-east Libya and central coastal Egypt. It is widespread in the eastern Mediterranean and ranges north into Turkey. In Jordan, it is recorded from Ash Shawbak, Aqraba, Busayra, Ibbin, Between Jarash and Suf, Jubeiha, Ramtha, Dana Biosphere Reserve, 10 km NW Amman Mountains, At Tafila, Dhiban, Irbid, Jizah, Karak, NW Madaba, Mazar, Moab, Mount Nebo, Salt Mountains, Naur, 10 km N Wadi Hassa, 5 km N Wadi Mujib, Wadi Musa, Zarqa, Marj Al Hammam, Fuhis, Iraq al Wahaj, Wadi Zarqa Ma'in, Al Hashemeyeh, Ajlune, Jarash, Petra, Ras Al Naqab, and Um Al Quttain (Amr et al., 2018).

Population: It is a widespread, relatively common species that is considered a pest in some areas.

\section{Area of occupancy}

\section{Extent of occurrence}

13203

Biogeographical realms: Palearctic.

General use and trade information: No trade or use information was reported.

Threats: There are no major threats to this species. Regular ploughing of fields disturbs the burrows of this species and may have a negative impact on local populations.

Conservation actions: This species is protected in situ in Dibeen, Yarmouk and Ajloun Forest Reserves, Dana and Mujib Biosphere Reserves.

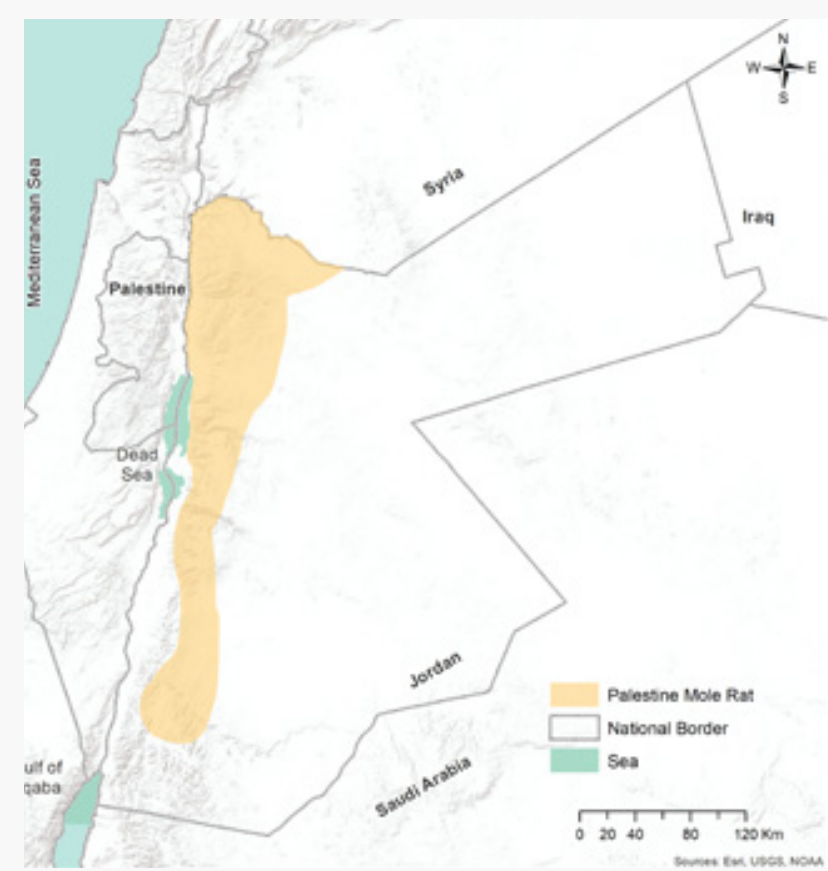

Map 55: Distribution of Spalax ehrenbergi in Jordan.

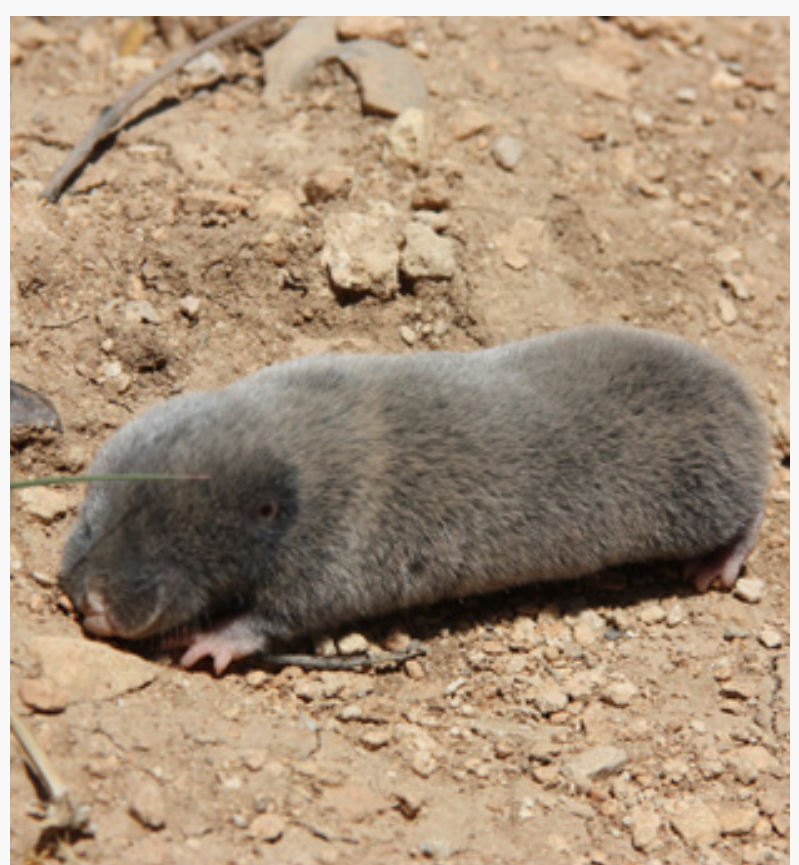

Figure 58: Spalax ehrenbergi (@ Zuhair Amr) 



\subsection{Carnivora}

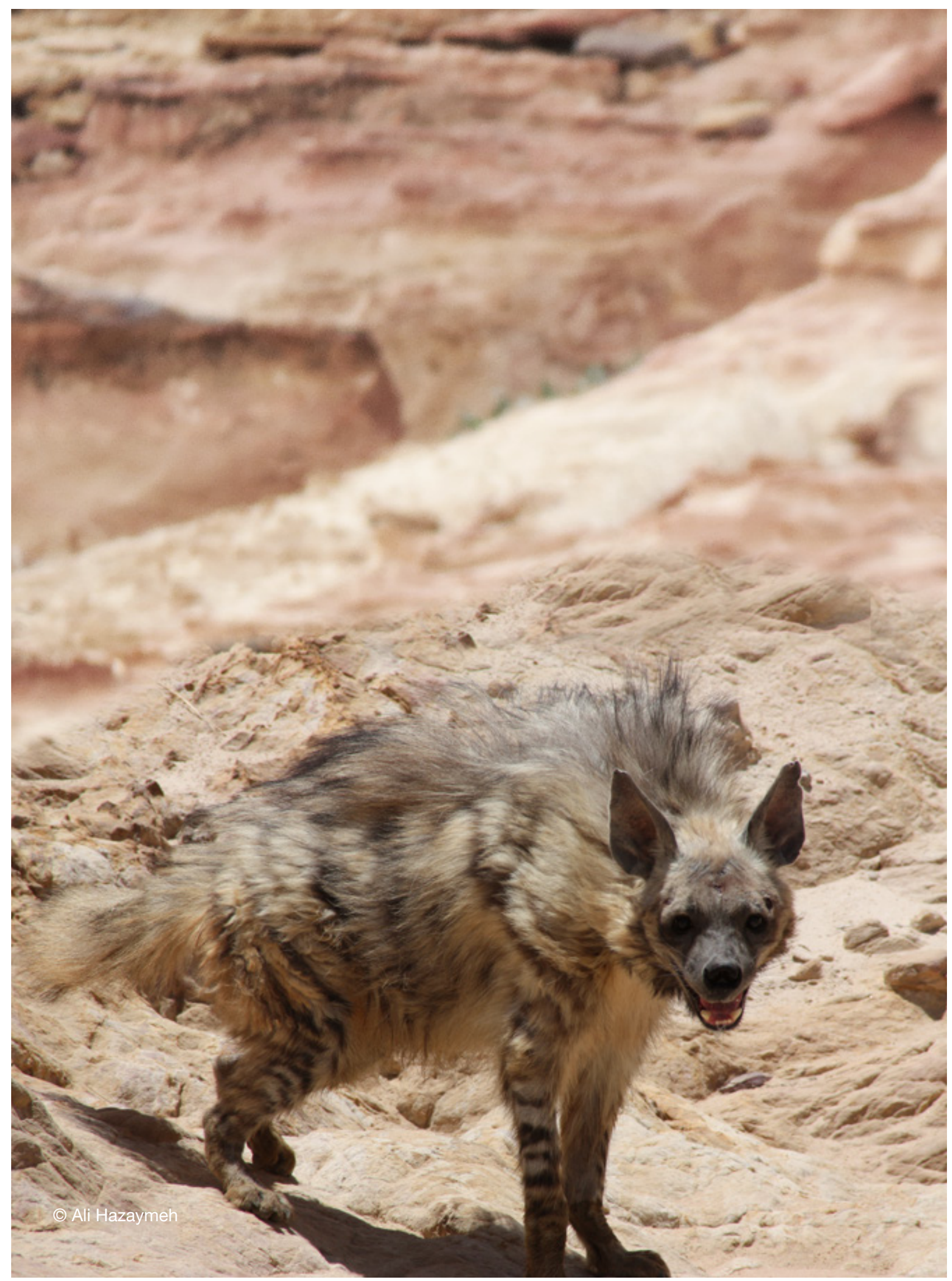




\section{Canis aureus (Linnaeus, 1758)}

Animalia - Chordata - Mammalia - Carnivora - Canidae

Common name(s): Golden jackal, Asiatic jackal, common jackal.

Red List status: Least Concern.

Justification: The Golden jackal is a widespread species in Jordan and common in some localities within its range of distribution. In addition, they are tolerant of dry habitats and their omnivorous diet, supports their survival in a wide variety of habitats.

Geographical range: The Golden jackal is widespread in North and north-east Africa, occurring from Senegal on the west coast of Africa to Egypt in the east, in a range that includes Morocco, Algeria and Libya in the north to Nigeria, Chad and Tanzania in the south. They also occur in the Arabian Peninsula and have expanded their range into Europe, where they have a patchy distribution, being resident in the Balkans and, since recent times, in Hungary and south-western Ukraine. It is regularly found as a vagrant in Austria, Slovakia, Slovenia and north-eastern Italy. Eastwards they range into Turkey, Syria, Jordan, Iraq, Iran, Central Asia, the entire Indian subcontinent, then east and south to Sri Lanka, Myanmar, Thailand and parts of Indo-China. In Jordan, this species is recorded from Azraq Nature Reserve, Wadi Rum, Lubban, Al Hazim, Inbeh, Wadi Alal, Al Baqourah, Ash Shawbak, Jabal Masuda Protected Area, Qatar Protected Area, and Yarmouk Protected Area.

Population: The Golden Jackal is locally common within its range. It is found in stable populations in suitable areas such as Ajloun and Azraq, and they are common along the Yarmouk Valley especially in military areas (Amr, 2012).

\section{Area of occupancy}

\section{Extent of occurrence}

5962

Biogeographical realms: Palearctic, Afrotropical, Oriental

General use and trade information: This species was recorded in trade as mounted specimens (Eid, Pers. Comm.)

Threats: Jackal population is stable if not increasing in Jordan. However, poisoning and hunting might be considered as threats to this species (Qumsiyeh et al., 1993). Eid and Handal, (2018) stated three killed Jackals specimens based on Facebook photos collected in 2015.

Conservation actions: This species is protected in situ in Ajloun Forest Reserve, Dana Biosphere Reserve, Wadi Rum World Heritage Area, Azraq Wetland Reserve, Shaumari Wildlife Reserve, Yarmouk Protected Area, Fifa Protected Area, Shubak and Burqu' Protected Area. In addition, it is Listed on Appendix I for wildlife protection of the Agricultural Law Number 13 for the year 2015 based on regulation Number 43 for the year 2008.

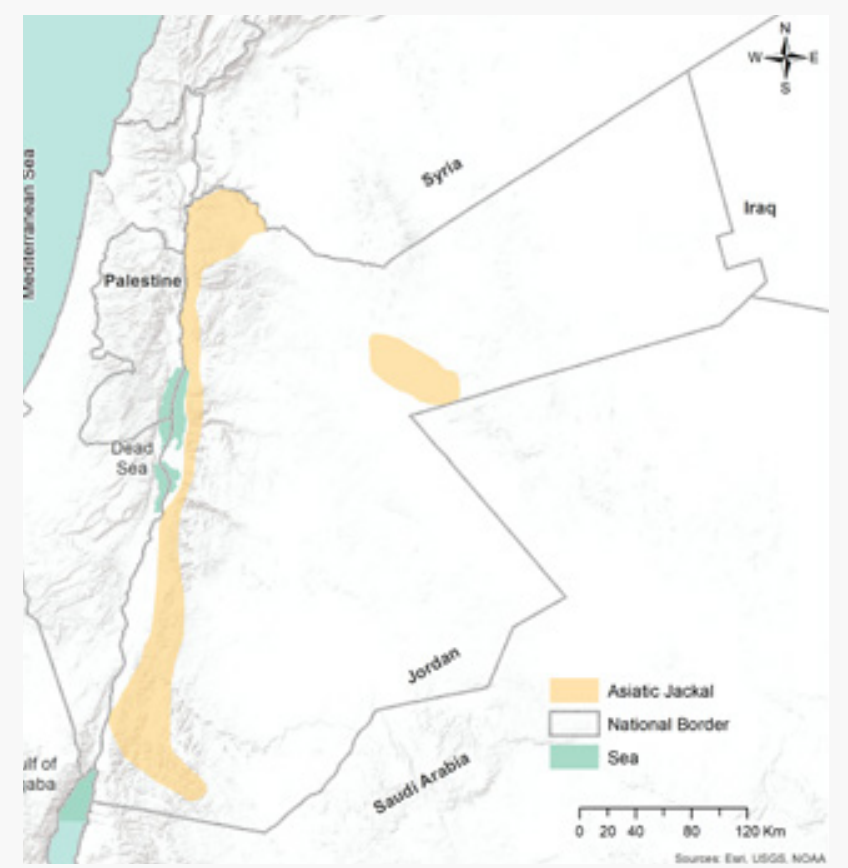

Map 56: Distribution of Canis aureus in Jordan.

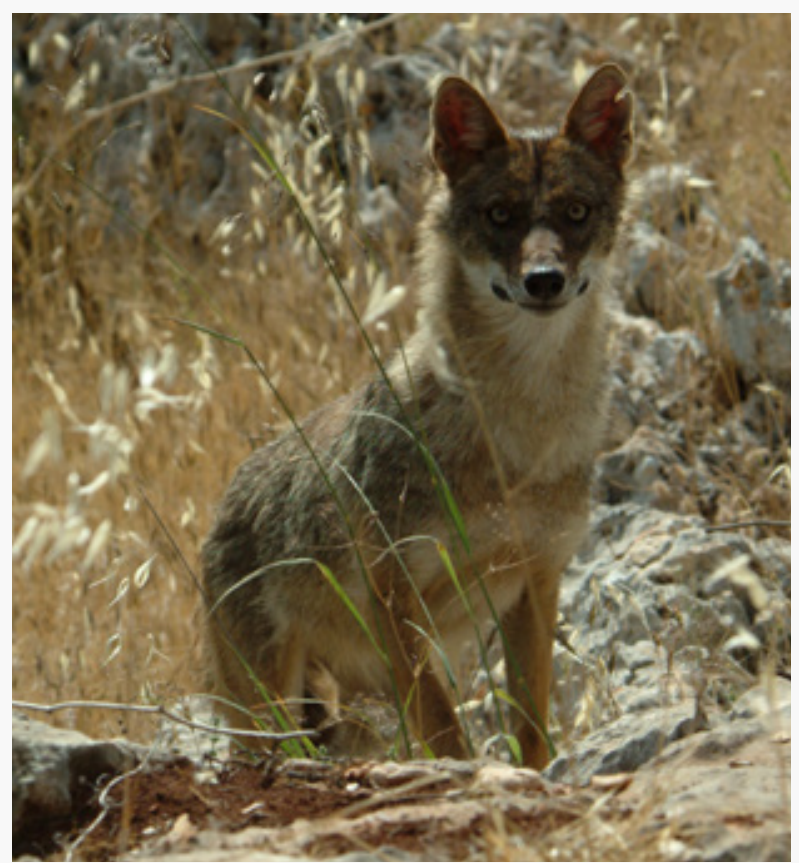

Figure 59: Canis aureus (@ Kita Nashimora) 


\section{Canis lupus (Linnaeus, 1758)}

Animalia - Chordata- Mammalia- Carnivora- Canidae

Common name(s): Arabian wolf, wolf.

Red List status: Endangered A2acd.

Justification: A decline of more than $50 \%$ was observed for the wolf population in Jordan over the last ten years.

Geographical range: The world's most widely distributed mammal, living throughout the northern hemisphere north of $15^{\circ} \mathrm{N}$ latitude in North America and $12^{\circ} \mathrm{N}$ in India. It is found in North America south to Mexico, Europe, Asia, including the Arabian Peninsula. In Jordan, this species is recorded from Aqaba, Um Al Quttain, Wadi Araba, Abu Anseer, Ma'an, Reishah, Wadi Finan, Wadi Rum, Ajlun, Azraq, Marab Swaia'ad, Ash Shawbak, Fifa Protected Area, Humrat Ma'in Special Conservation Area, Jabal Masuda Protected Area, Qatar Protected Area, Wadi Al Mujib, and Yarmouk Protected Area (Qumsiyeh et al., 1993).

Population: Wolf populations are declining in Jordan.

\section{Area of occupancy}

88

\section{Extent of occurrence}

62046

Biogeographical realms: Palearctic, Oriental.

General use and trade information: Mounted specimens of this species were found in some shops in Amman, and it is captured for zoo exhibitions. A study performed by Aloufi and Eid stated that parts of the wolf are used for traditional medicine, where blood is used as ointment to treat rheumatic pain, (2016) flesh is cooked and eaten to treat exhaustion and joints and muscle pain, canines are crushed and eaten to treat infertility, and pharynx is dried and placed on the patient's neck to treat pulmonary diseases especially whooping cough.

Threats: This species is under severe threats in Jordan including land-use changes, rural human population expansion, prey content decline, competition with humans for livestock and game species, exaggerated concern by the public regarding the threat and danger of wolves and fragmentation of habitat, with resulting areas becoming too small for populations. Eid and Handal, (2018) reported a single killed specimen based on Facebook photos posted in 2015.

Conservation actions: This species is protected in situ in Yarmouk and Ajloun Forest Reserves, Dana Biosphere Reserve, Azraq Wetland Reserve, Fifa Protected Area, Wadi Rum World Heritage Area, Shubak Proposed Protected Area and Burqu' Protected Area. In addition, this species is Listed on Appendix I for wildlife protection of the Agricultural Law Number 13 for the year 2015 based on regulation Number 43 for the year 2008.

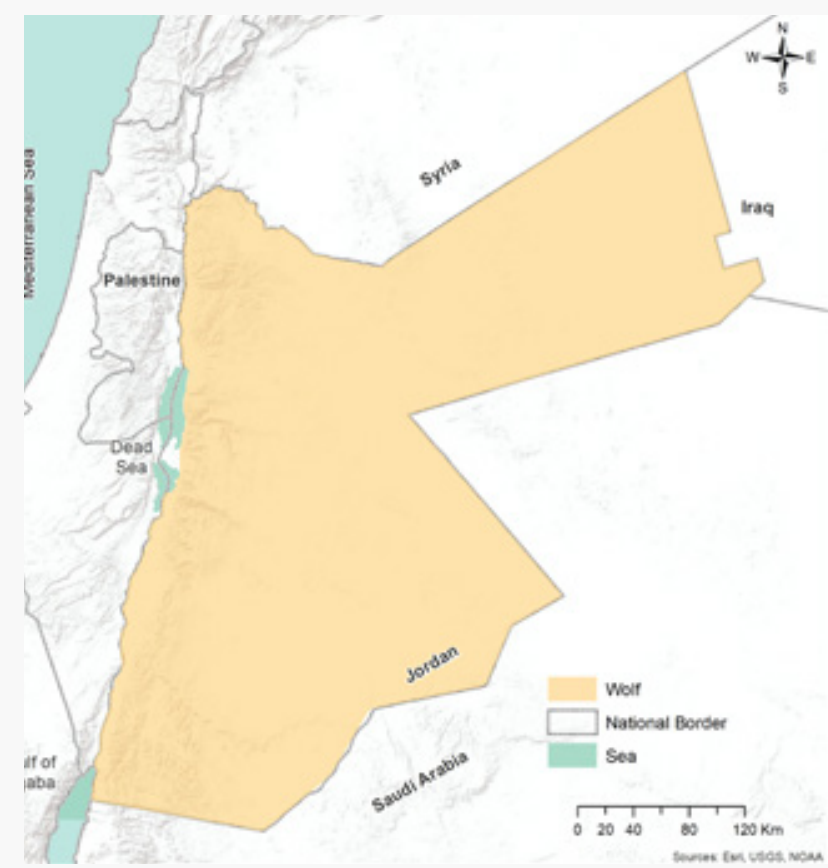

Map 57: Distribution of Canis lupus in Jordan

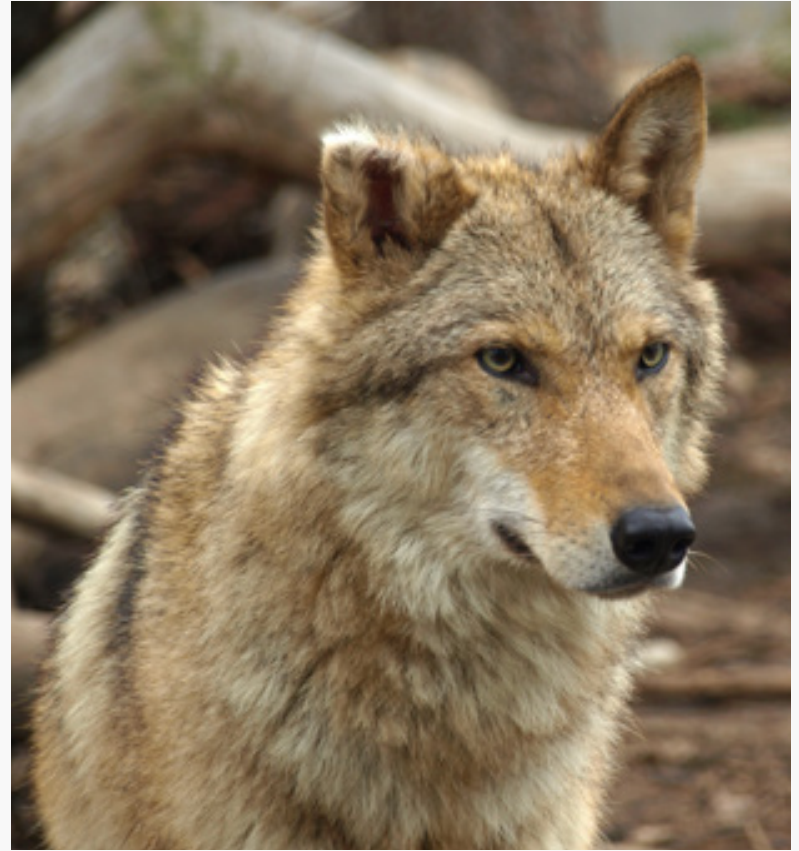

Figure 60: Canis lupus (๑ Shutterstock) 


\section{Vulpes cana (Blanford, 1877)}

Animalia - Chordata- Mammalia- Carnivora- Canidae

Common name(s): Blanford's fox, steppe fox, Afghan fox.

Red List status: Endangered B1B2ab (ii, iii).

Justification: This species has a restricted range of distribution in the mountainous regions of Jordan. These areas are under continuous threats of habitats degradation and deterioration due to human expansion, and drought. A localized decline in its populations is expected, especially with the limited specimens reported in relation to the extensive surveying efforts.

Geographical range: Palestine, Jordan, Saudi Arabia, Oman, United Arab Emirates, Turkmenistan, Afghanistan, NE Iran, Pakistan. In Jordan, it is recorded from Dana Biosphere Reserve, Petra, Mujib Biosphere Reserve, Wadi Rum, Ash Shawbak, and Jabal Masuda Proposed Protected Area.

Population: Density identified as 8.5 individuals per $\mathrm{km}^{2}$ from Jabal Masuda proposed protected area (Eid et al., 2013).

\section{Area of occupancy}

32

\section{Extent of occurrence}

2867

Biogeographical realms: Oriental.

General use and trade information: No trade or use information was reported for this species in Jordan.

Threats: Habitat loss, due mainly to expanding settlement and tourism development and human persecution are considered major threats to this species (Abu-Baker et al., 2004; Eid et al., 2013; Eid et al., 2014).

Conservation actions: This species is protected in situ in Mujib and Dana Biosphere Reserves, Wadi Rum World Heritage Area and Jabal Masuda Proposed Protected Area. It is Listed in Appendix II for wildlife protection of the Agricultural Law Number 13 for the year 2015 based on regulation Number 43 for the year 2008.

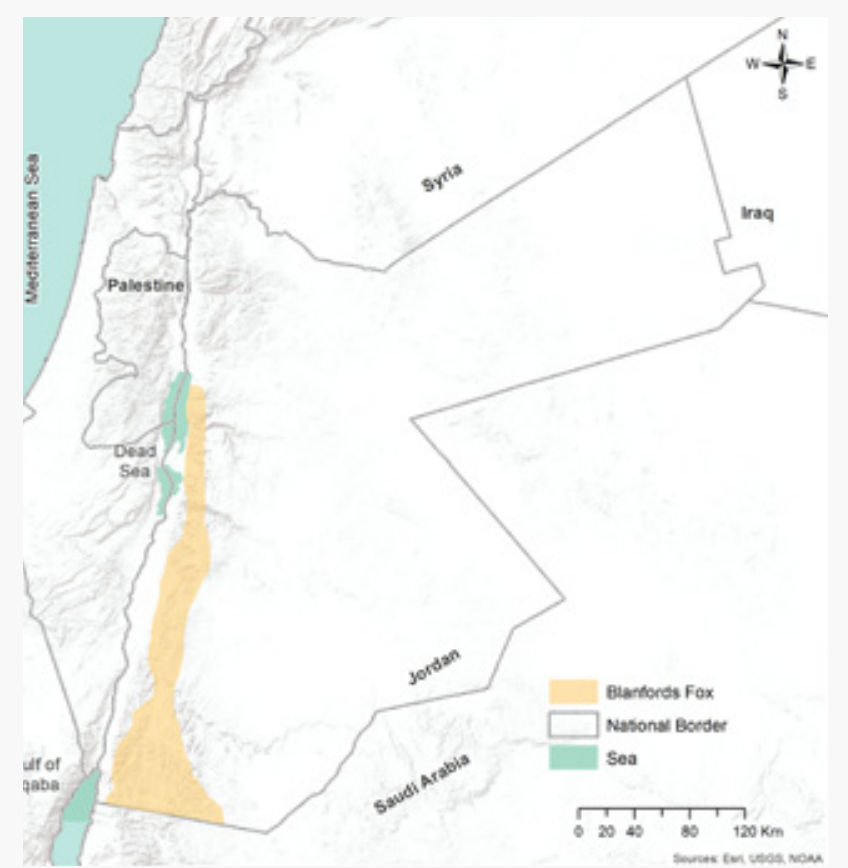

Map 58: Distribution of Vulpes cana in Jordan.

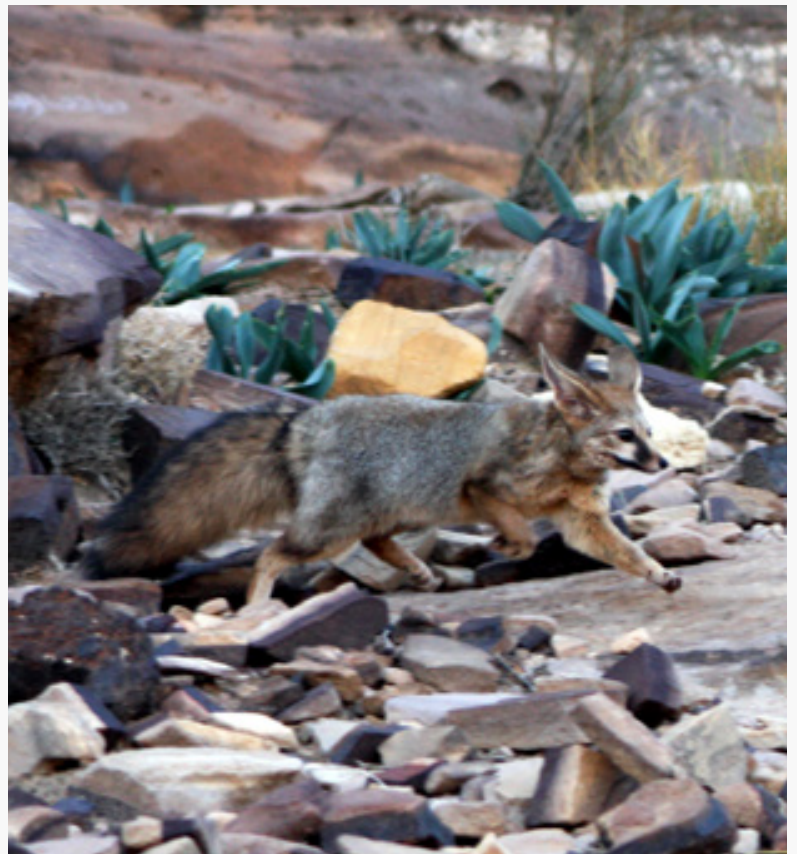

Figure 61: Vulpes cana (C Ehab Eid) 


\section{Vulpes rueppelli (Schinz, 1825)}

Animalia - Chordata- Mammalia- Carnivora- Canidae

Common name(s): Rüppell's fox, sand fox, Rüppell's sand fox, Rüeppell's fox.

Red List status: Near Threatened.

Justification: Limited information is available on the distribution and population of this species. However details on the degradation of its habitat is available which may if continued threaten this species.

Geographical range: Arid areas of N Africa from Morocco to Somalia; Egypt; Sinai; Arabia; Iran; parts of Pakistan and Afghanistan. In Jordan, it is recorded in Mushash Hodraj, Al Shawmari Wildlife Reserve, Wadi Araba, 2 Km SE Aqaba, Al Dahik, Al Hazim, Qasr Burqu' and the western part of Jabal Masuda proposed Protected Area.

Population: There is no estimate of total population size.

\section{Area of occupancy}

36

\section{Extent of occurrence}

20461

Biogeographical realms: Afrotropical.

General use and trade information: No trade or use information was reported for this species.

Threats: Threats include habitat degradation, as well as the indiscriminate use of poisons.

Conservation actions: This species was recorded in situ in Burqu' Protected Area. In addition, it was Listed in Appendix I for wildlife protection of the Agricultural Law Number 13 for the year 2015 based on regulation Number 43 for the year 2008 .

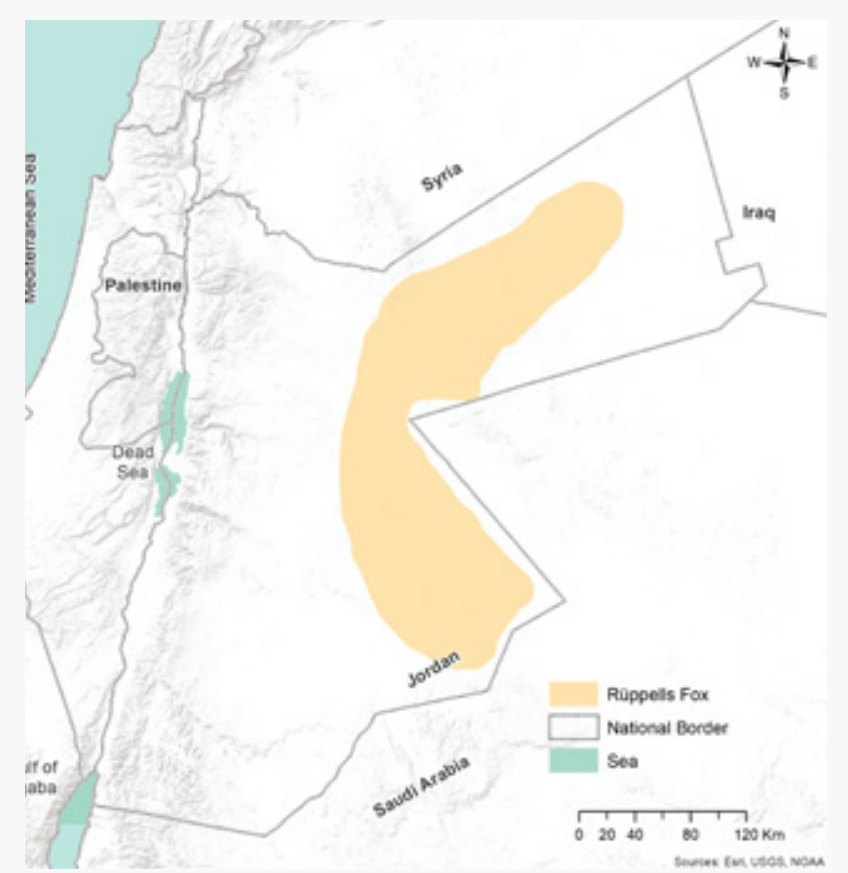

Map 59: Distribution of Vulpes rueppelli in Jordan.

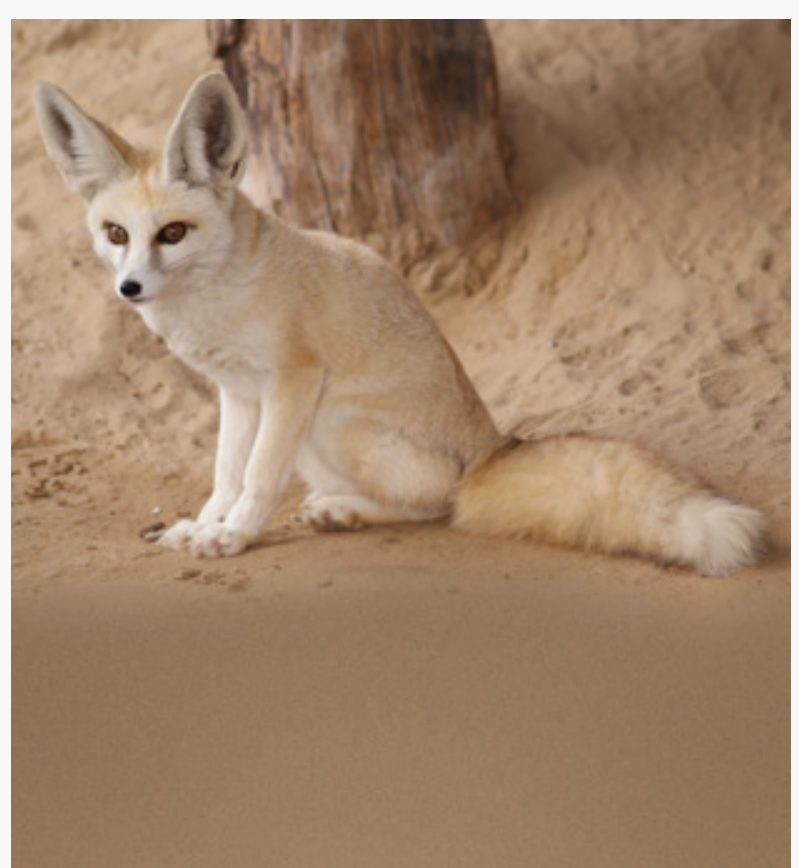

Figure 62: Vulpes rueppelli (@ Wolfgang Dreier) 


\section{Vulpes vulpes (Linnaeus, 1758)}

Animalia - Chordata- Mammalia- Carnivora- Canidae

Common name(s): Red fox, silver fox, cross fox.

Red List status: Least Concern.

Justification: The Red Fox has the widest geographical range of any member of the order Carnivora, being distributed across the entire area of Jordan.

Geographical range: Distributed across Europe and continental Asia except the tundra; N India and peninsular Indochina; Japan; Palearctic Africa; N America as far south as Texas and New Mexico (USA), but absent in part of the Central Plains and the Arctic. Introduced to Australia. In Jordan, it is recorded in Azraq, Al Jafr, between Ma'an and Wadi Al Hassa, Aqraba, Jawa, Al Inab, Ash Shawbak, Azraq, Irbid, Karak, Madaba, Zarqa, Dana Biosphere Reserve, Deir Al Kahf, Al Areteen, Al Dahek, Al Hazim, Al Buqawiyah, Jawa, Al Hashad, Ghawr es Safi, Jabal Masuda proposed Protected Area, Qasr Burqu', Qatar, Safawi, and Wadi Al Mujib Biosphere Reserve.

Population: Common and found throughout Jordan.

\section{Area of occupancy} 168

\section{Extent of occurrence}

87802

Biogeographical realms: Palearctic, Oriental.

General use and trade information: Aloufi and Eid, 2016 stated that the red fox is hunted and used in folk medicine.

Threats: No major threats were reported, but habitat degradation, loss, and fragmentation, exploitation, and direct and indirect persecution could represent threats on the species. However, the red fox's versatility and eclectic diet are likely to ensure their persistence despite changes in landscape and prey base. A study performed by Eid and Handal, (2018) showed 18 foxes killed by hunters based on Facebook photos posted in 2015.

Conservation actions: This species is well-protected in situ where it is found in all protected areas established in Jordan.

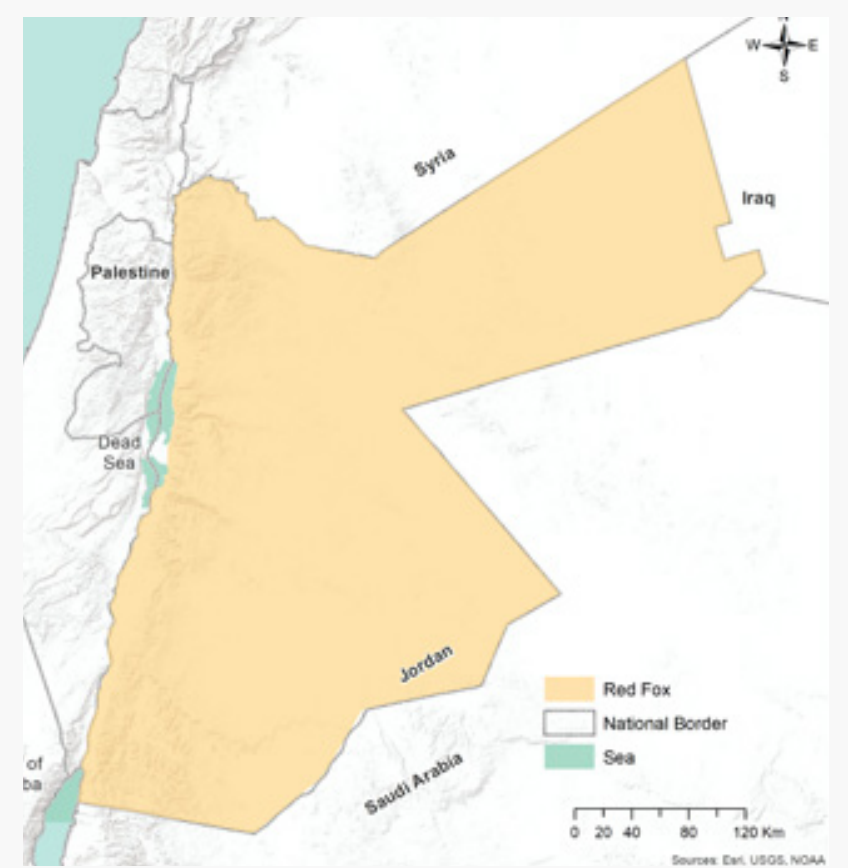

Map 60: Distribution of Vulpes vulpes in Jordan.

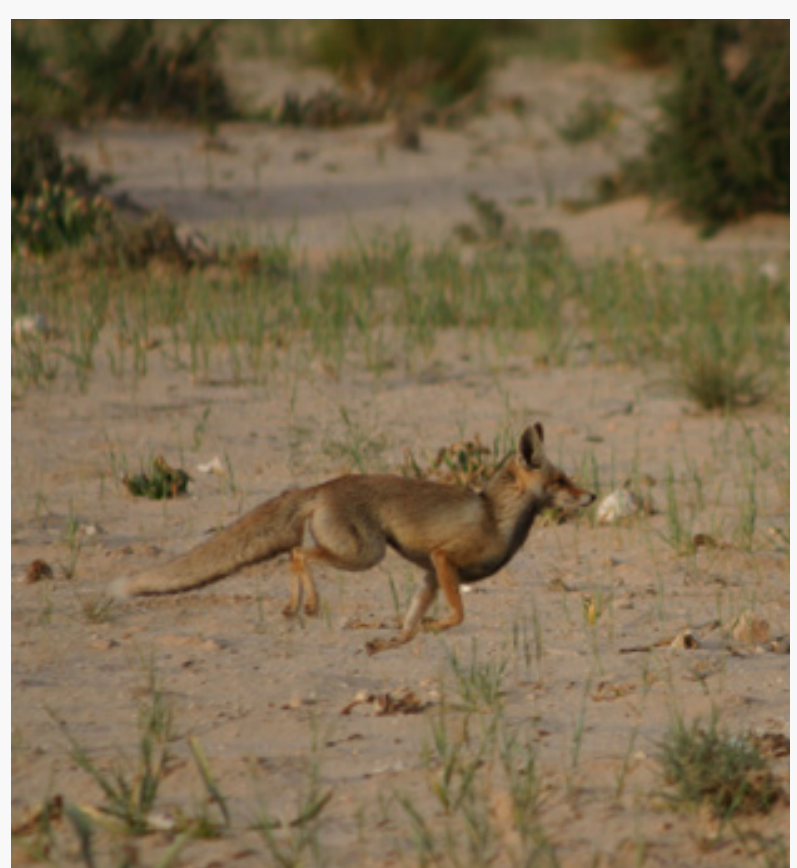

Figure 63: Vulpes vulpes (๑ Ehab Eid) 


\section{Caracal caracal (Schreber, 1776)}

Animalia - Chordata- Mammalia- Carnivora- Felidae

Common name(s): Caracal.

Red List status: Critically Endangered B1ab (i, ii, iii).

Justification: Very rare species, with a limited area of occupancy, which is presumed to be confined to Dana and Mujib Biosphere Reserve and some patches in the Eastern Desert. Despite its existence at protected areas, the population is very small which might affect its survival rates in the future

Geographical range: Aden, Afghanistan, Algeria, Angola, Arabia, Botswana, Egypt, Ethiopia, Gabon, India, Iran, Iraq, Palestine, Kenya, Kuwait, Libya, Malawi, Mauritania, Morocco, Mozambique, Namibia, Niger, Pakistan, Senegal, Somalia, South Africa, Sudan, Syria, Tanzania, Turkey, Turkmenistan, Uganda, Zaire, Zambia, Zimbabwe. In Jordan, this species is recorded fron Al Hazim, Al Shawmari Wildlife Reserve, Dana Biosphere Reserve, Al Dahik and Qaser Burqu' (Amr, 2012).

Population: Population is declining sharply in Jordan, with some records showing only five individuals exist at Dana Biosphere Reserve (E. Eid. personal communication).

\section{Area of occupancy}

\section{Extent of occurrence}

3830

Biogeographical realms: Afrotropical.

General use and trade information: This species was not recorded in trade from Jordan, but a study performed by Aloufi and Eid, (2016) stated that the liver of this species is cooked and eaten to treat diabetes mellitus and liver cirrhosis.

Threats: Persecution is a major threat since caracals are capable of taking small domestic livestock. In addition, severity of depredation appears to be dependent on the availability of wild prey. Habitat destruction (agriculture and desertification) is a significant threat where caracals are naturally sparsely distributed. A study performed by Eid and Handal, (2018) showed a single caracal killed by hunters and posted on Facebook in 2015.

Conservation actions: This species is protected in situ in Dana and Mujib Biosphere Reserves, Shaumari Wildlife Reserve, in addition to Burqu Protected Area. In addition, it is listed in Appendix I for wildlife protection of the Agricultural Law Number 13 for the year 2015 based on regulation Number 43 for the year 2008.

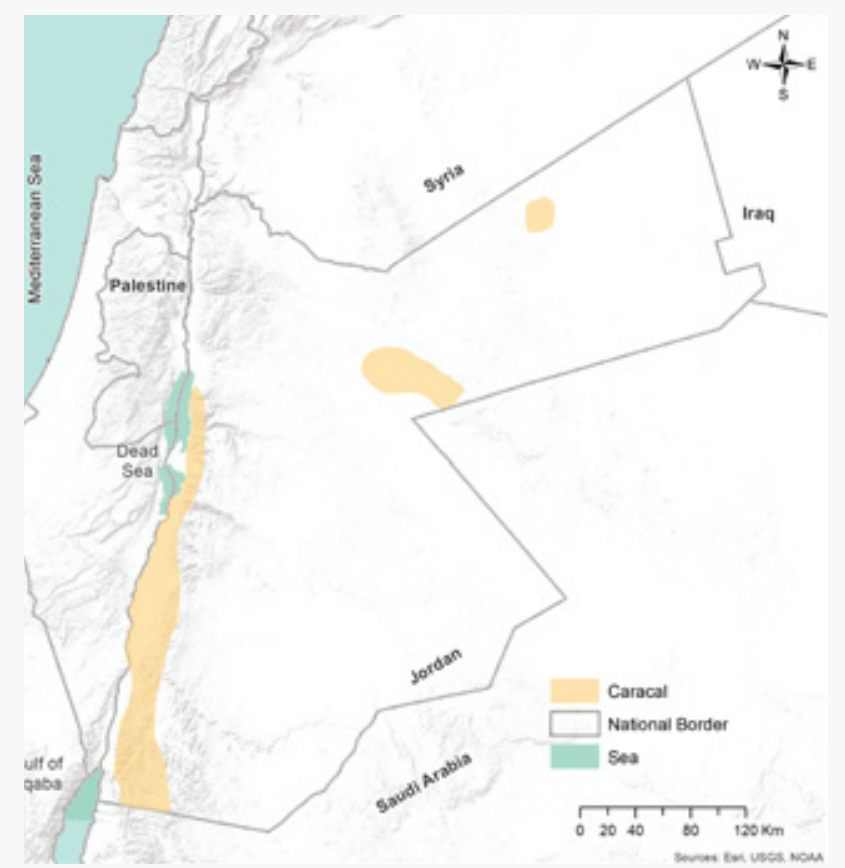

Map 61: Distribution of Caracal caracal in Jordan.

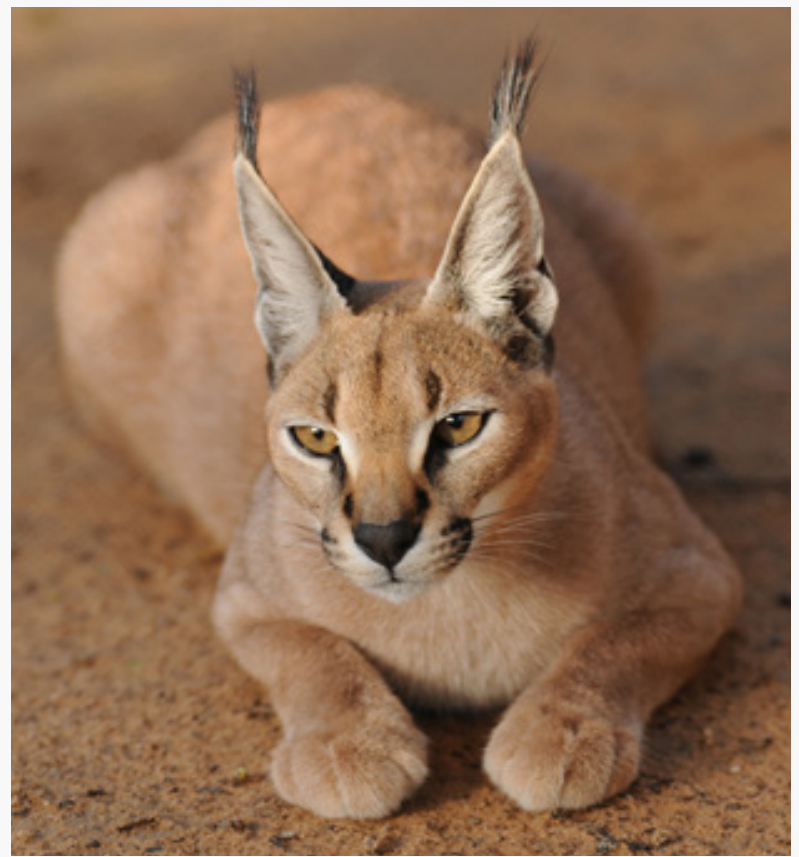

Figure 64: Caracal caracal (๑ Kevin \& Jane Budd) 


\section{Felis chaus (Schreber, 1777)}

Animalia - Chordata- Mammalia- Carnivora- Felidae

Common name(s): Jungle cat, reed cat, swamp cat.

Red List status: Critically Endangered B1, B2ab (i, ii, iii).

Justification: Rare species with a very limited range of distribution, restricted to the most northwestern part of Jordan. Its presence was confirmed in only two localities: Damyeh and Al-Baqurah (Abu Baker et al., 2003). The two localities are under serious threats of habitat degradation, and agricultural expansion.

Geographical range: Afghanistan, Algeria, Arabia, Benin, Burma, China, Egypt, India, Iran, Iraq, Palestine, Kenya, Malawi, Morocco, Mozambique, Nepal, Pakistan, Sri Lanka, Syria, Thailand, republics of the former USSR, Vietnam, Yemen, Zambia, Zimbabwe. In Jordan, this species is recorded from Damyeh Bridge, and Al-Baqurah in Yarmouk protected area (Kock et al., 1993; Abu Baker et al., 2003).

Population: Population is small due to the limited area of occupancy, and is thought to be declining in Jordan.

\section{Area of occupancy}

28

\section{Extent of occurrence}

463

Biogeographical realms: Oriental.

General use and trade information: This species was recorded in private ownerships farms, through origin is not confirmed but most probably from Syria.

Threats: The expansion of agricultural areas around the river beds of Yarmouk and Jordan rivers are considered a major threat. Habitat destruction and human persecution are also affecting the species population densities (Abu Baker et al., 2003; Amr, 2012).

Conservation actions: This species is protected in situ in Yarmouk Forest Reserve. In addition, it is listed in Appendix I for wildlife protection of the Agricultural Law Number 13 for the year 2015 based on regulation Number 43 for the year 2008 .

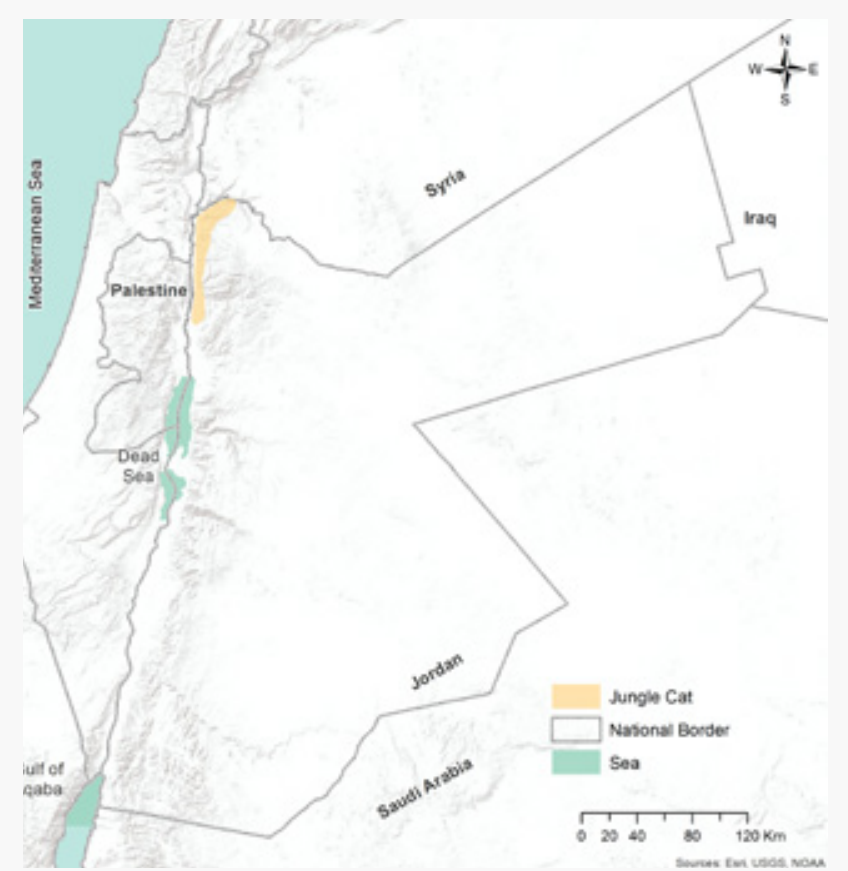

Map 62: Distribution of Felis chaus in Jordan.

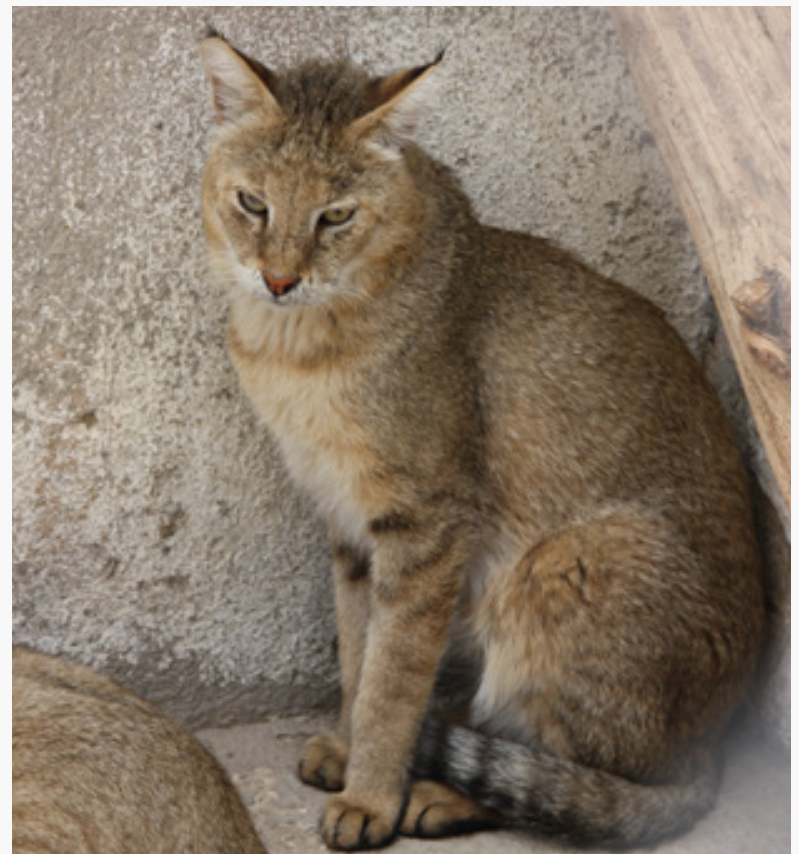

Figure 65: Felis chaus (C Zuhair Amr) 


\section{Felis margarita (Loche, 1858)}

Animalia - Chordata - Mammalia - Carnivora - Felidae

Common name(s): Sand cat, sand dune cat.

Red List status: Critically Endangered B1, B2ab (i, ii, iii).

Justification: The Sand Cat occurs at low densities and is considered a rare species in Jordan. In addition, serious threats are affecting its range of occurrence in Jordan.

Geographical range: Deserts in Algeria, Egypt, Iran, Libya, Morocco, Niger, Oman, Pakistan, Qatar, Saudi Arabia, Sudan, Tunisia, Turkmenistan, Uzbekistan, Yemen. In Jordan, this species is recorded from Wadi Rum, Qasr Burqu and 5km NW Mansheyat Al-Ghiath.

Population: There are relatively few records of Sand Cats from Jordan, and it is often reported as a rare species (Amr, 2012).

Area of occupancy

8

\section{Extent of occurrence}

Biogeographical realms: Afrotropical.

General use and trade information: This species was not recorded in trade or use from Jordan.

Threats: Habitat degradation is the major threat to the sand cat. In addition, this species is extremely sensitive to human disturbance, habitat encroachment and competition from larger predators. Other threats include poisoning and baiting.

Conservation actions: This species is expected to survive at Wadi Rum World Heritage Area, after two records confirmed by Mountfort (1965), and Hemmer (1978), who reported a skull. It is protected in situ in Burqu protected area (Hamidan and Al-Geyyath, 2017). In addition, it is Listed in Appendix I for wildlife protection of the Agricultural Law Number 13 for the year 2015 based on regulation Number 43 for the year 2008.

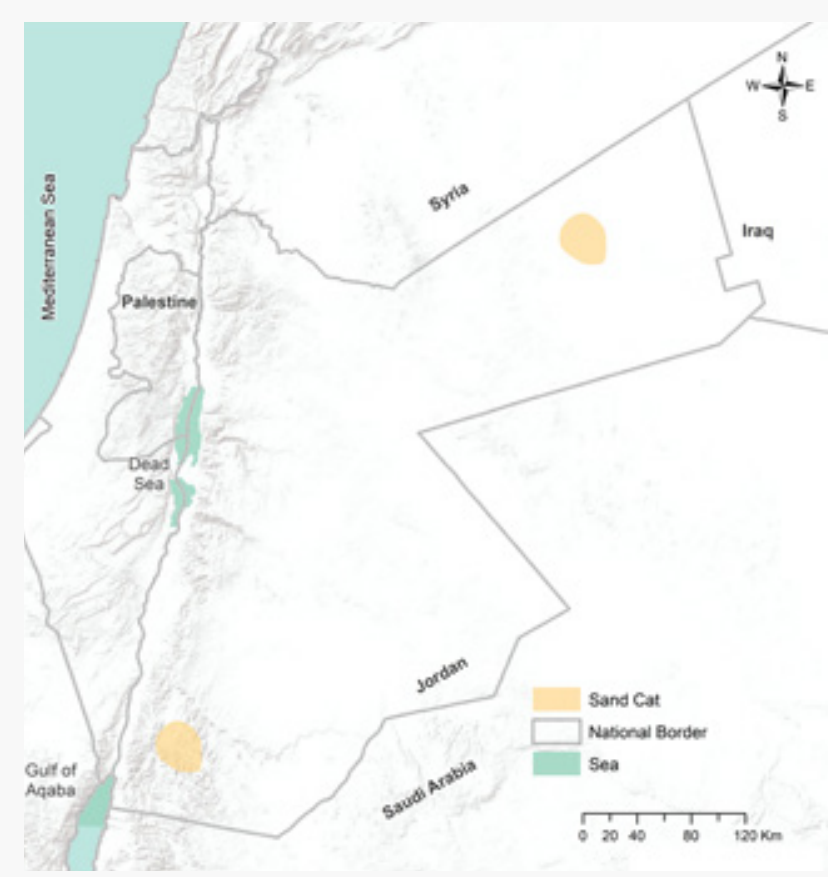

Map 63: Distribution of Felis margarita in Jordan.

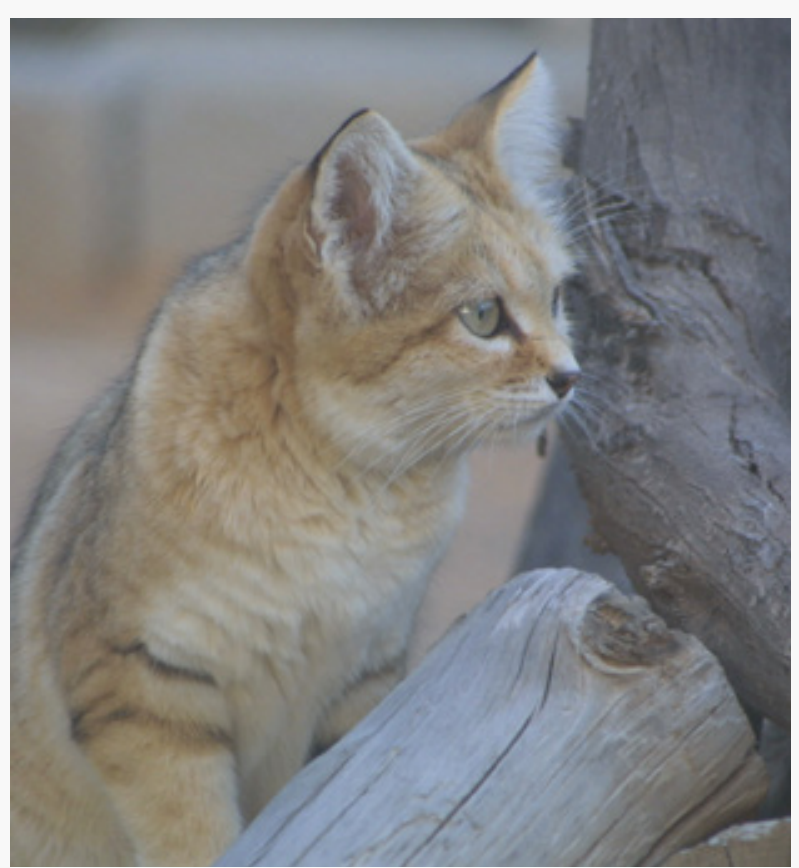

Figure 66: Felis margarita ( Zuhair Amr) 


\section{Felis silvestris (Schreber, 1775)}

Animalia - Chordata - Mammalia - Carnivora - Felidae

Common name(s): Wild cat, wildcat.

Red List status: Least Concern.

Justification: The Wild Cat is the most common and widely distributed wild felid species in Jordan, and thus Listed as Least Concern.

Geographical range: Afghanistan, Algeria, Angola, Arabia, Botswana, Chad, China, Egypt, Ethiopia, France, Germany, Guinea, India, Iran, Iraq, Palestine, Italy, Kazakhstan, Libya, Malawi, Mali, Mauritania, Morocco, Mozambique, Namibia, Pakistan, Poland, Senegal, South Africa, Spain, Sudan, Syria, Tanzania, Tunisia, Turkistan, United Kingdom, Zambia, Zimbabwe. Introduced to: Australia, Brazil, Canada, and Madagascar. In Jordan, this species is recorded from Azraq ash Shishan, Ghawr Seisaban, Mu'ab area, Dana Biosphere Reserve, Kufr Som, Fifa Proposed Protected Area, Jabal Masuda proposed Portected Area, Humrat Mae'n Special Conservation Area, Qatar Protected Area, Shawmari Wildlife Reserve and Yarmouk Protected Area.

Population: It is considered common species and widely distributed.

\section{Area of occupancy}

72

\section{Extent of occurrence}

30915

Biogeographical realms: Palearctic, Oriental, Afrotropical.

General use and trade information: No trade or use information were reported from Jordan.

Threats: No threats were reported on this species, though it is still surviving in remote areas away from human settlements. However, future research on hybridization levels is needed.

Conservation actions: This species is protected in situ in Dibeen and Ajloun Forest Reserves, Mujib and Dana Biosphere Reserves, Fifa Protected Area, and Wadi Rum World Heritage Area. In addition, it is Listed in Appendix III for wildlife protection of the Agricultural Law Number 13 for the year 2015 based on regulation Number 43 for the year 2008 .

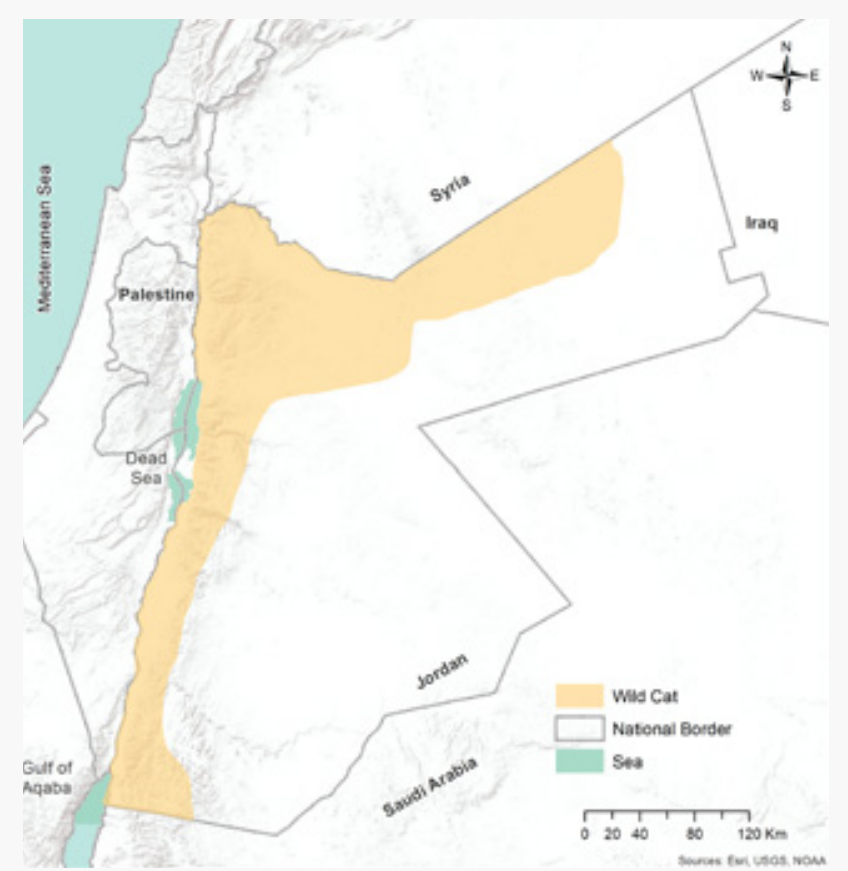

Map 64: Distribution of Felis silvestris in Jordan.

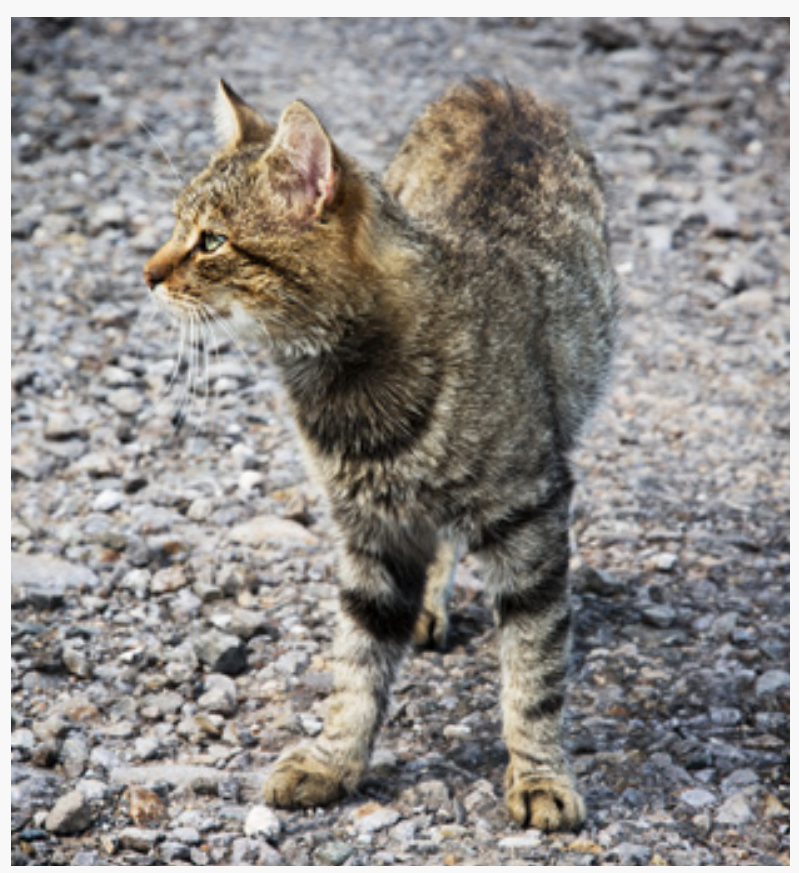

Figure 67: Felis silvestris (@ Shutterstock) 


\section{Herpestes ichneumon (Linnaeus, 1758)}

Animalia - Chordata- Mammalia- Carnivora- Herpestidae

Common name(s): Egyptian mongoose, large gray mongoose.

Red List status: Endangered B1, B2ab (iii).

Rational: Number of locations reported are less than five. In addition, quality of habitat is declining due to continuous development activities.

Geographical range: This species is found mainly in sub-Saharan Africa, from Senegal and Gambia to East Africa, then southwards in Angola, Zambia, Malawi and Mozambique. In addition, it was recorded from north-east Namibia, northern Botswana, northern and eastern Zimbabwe and all along the South African coastline. In North Africa, ranges in a narrow coastal strip from Western Sahara to Tunisia, and also from northern and eastern Egypt southwards to Ethiopia. This species is also found from the Sinai Peninsula to the south of Turkey, and on the Iberian Peninsula in southern and central Portugal and south-western Spain. In Jordan, this species is recorded from Aqraba, Maqarin Dam, North Shounah, Jordan Valley, Ain Ghazal, Kuraimah, Kufr Som, Turabah, Al Mujib Biosphere Reserve, and Yarmouk Protected Area.

Population: Population thought to be declining from Jordan.

\section{Area of occupancy}

\section{Extent of occurrence}

1391

\section{Biogeographical realms: Afrotropica}

General use and trade information: Trapping of this animal for trade purposes was confirmed from Jordan (Z. Amr. personal communication). In addition, stuffed specimens were confirmed in Amman pet markets (E. Eid. personal communication).

Threats: Habitat degradation is a serious threat, which is affecting this species population and distribution. In addition, trapping, and poisoning are considered threats a study performed by Eid and Handal, (2018) showed a single mongoose killed by hunters and published on Facebook photos in 2015.

Conservation actions: This species is protected in situ in Mujib Biosphere Reserve, and Yarmouk Forest Reserve. In addition, it is listed in Appendix II for wildlife protection based on Agricultural Law Number 13 for the year 2015 based on regulation Number 43 for the year 2008.

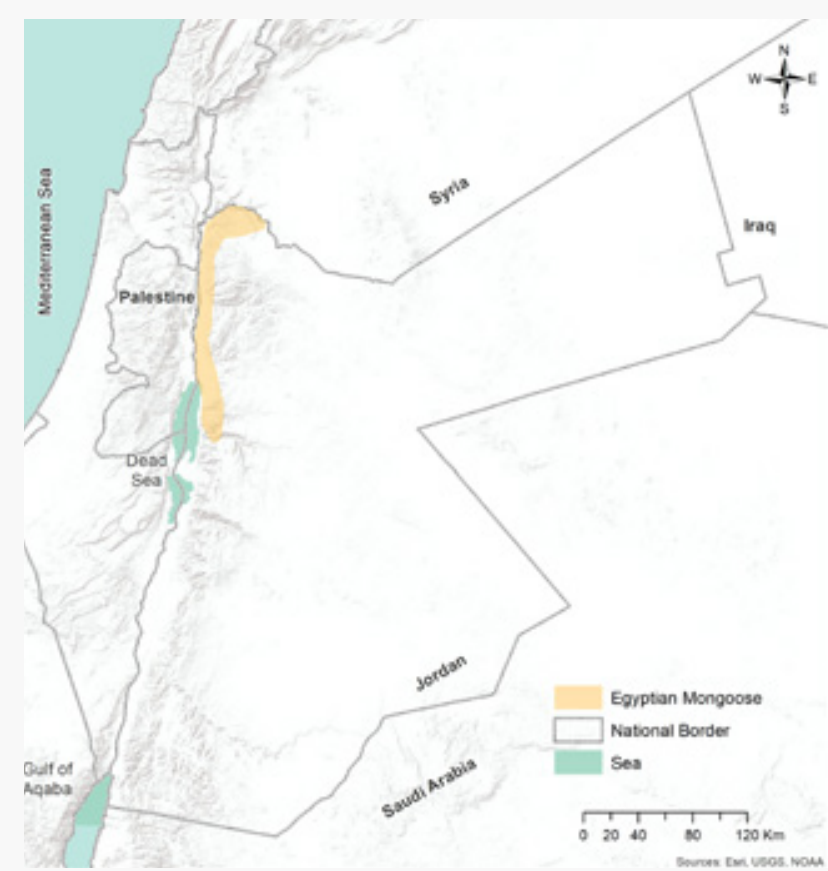

Map 65: Distribution of Herpestes ichneumon in Jordan.

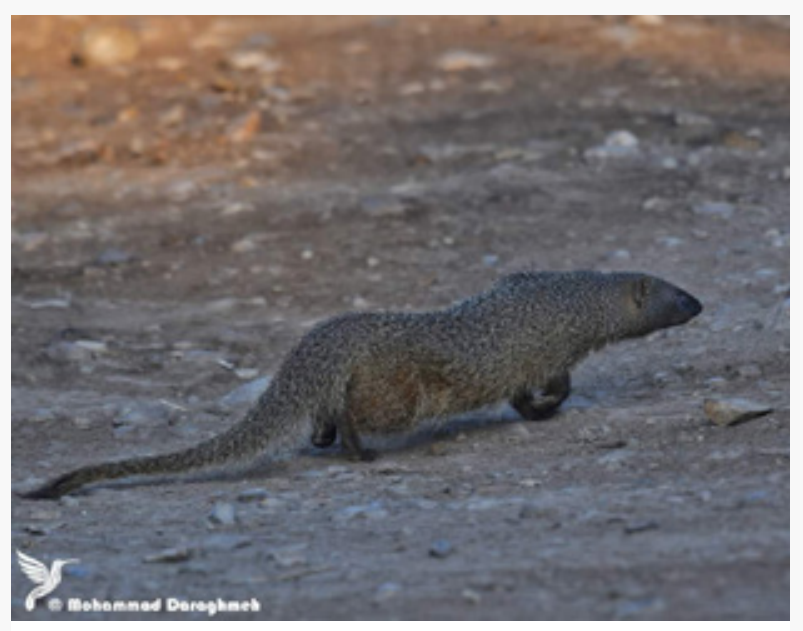

Figure 68: Herpestes ichneumon ( Mohammad Daraghmeh) 


\section{Hyaena hyaena (Linnaeus, 1758)}

Animalia - Chordata- Mammalia- Carnivora- Hyaenidae

Common name(s): Striped hyaena.

Red List status: Endangered A2acd.

Justification: Despite its wide distribution range in Jordan, it suffers severe decline in its population size, and inferred with more than 50\%. It is experiencing ongoing deliberate and incidental persecution coupled with a decrease in its food sources.

Geographical range: The Striped Hyaena has a very large, albeit now patchy distribution, extending from Africa, north of and including the Sahel, and including much of east and northeast Africa south to about central Tanzania, through the Middle East and Arabian Peninsula, Turkey, the Caucasus, Central Asia, and the Indian subcontinent, though not reaching Assam, Bhutan or Myanmar. They may have recently expanded into Nepal. In Jordan, this species is recorded between Ma'an and Al Hassa, Bayir, Burqu', Jabal Masuda, Rajil, Zubiya, Jawa, Al Jubyha, Al Kastal, Náur, Suweilih, Wadi Finan, Abu Enssair, Al-Aal, Al Dahek, Al Nwattif, Ash Shawmari, At Tafila, Dana Biosphere Reserve, Deir Al Kahf, Ezmal, Faydat al Dahikiyah, Ibbin, Ishtafayna, Jebel el Aritein, Jawa, Madaba, Qatranah, Safawi, Tall al Ashqef, Tall Humaylan, Wadi Araba, Wadi al Uwaynid, Abu Al-Kursi, Al-Ameed Cave, Al-Badia Cave, Al-Fahda Cave, Al-Hayya Cave, Al-Howa, Al-Ra'ye Cave, Azzam Cave, Beer Al-Wisad, Dahdal Cave, Dabié Cave, Hashemite University Cave, Al Mujib Nature Reserve, Ajloun Forest Reserve (Amr et al., 1996).

Population: The only available knowledge on hyaena's population derived from Attum et al., (2018) where they found nine animals in 2010 and ten in 2012 at the artificial waterholes in Dana Biosphere Reserve. However, it is found in very low densities.

\section{Area of occupancy}

220

\section{Extent of occurrence}

\section{0}

\section{Biogeographical realms: Oriental, Afrotropical}

General use and trade information: This species is collected from the wild for exhibition purposes in the Jordanian zoos (E. Eid. personal communication). In addition, it is sold as a stuffed animal in markets (Qarqaz et al., 2004). Aloufi and Eid, (2016) stated that the Hyaena flesh is cooked and eaten to treat neurological failure and infertility.

Threats: The major reasons for the apparent decline include persecution (especially poisoning), decreasing natural and domestic sources of carrion and changes in livestock practices (Amr, 2012). Humans are consistently indicated as the major source of mortality, largely because the hyaena is loathed as a grave robber, is associated with several superstitions (Amr, 2012). A study performed by Eid and Handal (2018) showed 27 killed Hyenas and posted by hunters on Facebook in 2015.

Conservation actions: This species is protected in situ in Dibeen and Ajloun Forest Reserves, Dana and Mujib Biosphere Reserves, Wadi Rum World Heritage Area, Fifa Protected Area, and Qatar Protected Area. In addition, it is listed in Appendix I for wildlife protection of the Agricultural Law Number 13 for the year 2015 based on regulation Number 43 for the year 2008.

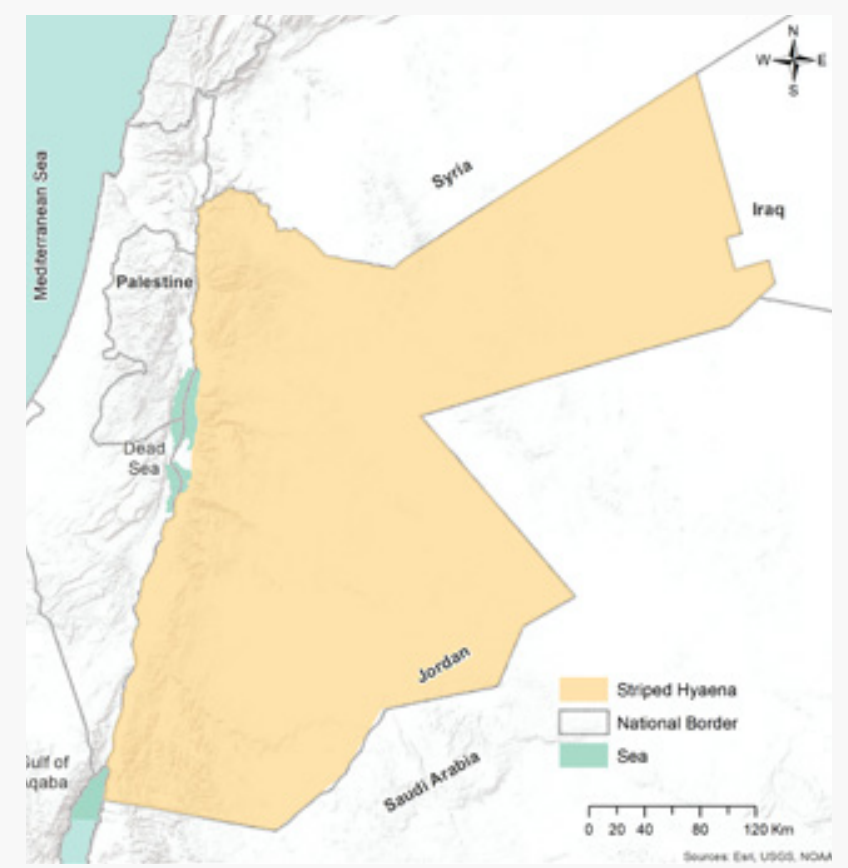

Map 66: Distribution of Hyaena hyaena in Jordan.

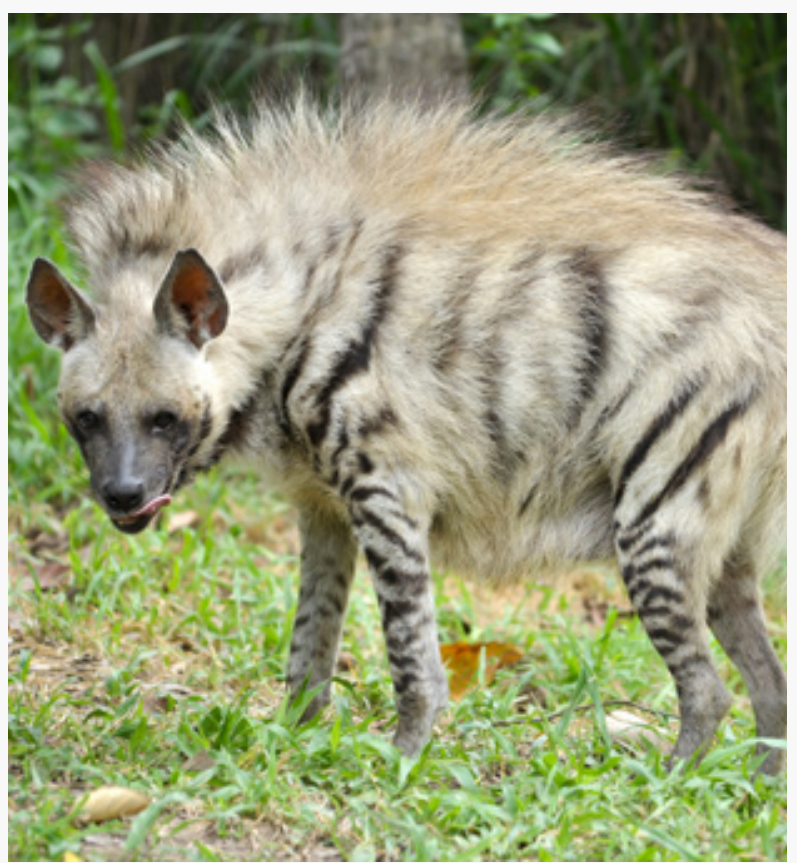

Figure 69: Hyaena hyaena (@ Shutterstock) 


\section{Lutra lutra (Linnaeus, 1758)}

Animalia - Chordata- Mammalia- Carnivora- Mustelidae

Common name(s): Eurasian otter, European otter, European river otter, old World otter, common otter.

Red List status: Critically Endangered B1ab (i, ii, iii).

Justification: As an isolated population at the southern distribution limit (Reuther et al., 2001), the Eurasian Otter is considered to be Critically Endangered due to an ongoing and severe population decline due to habitat degradation, loss of water resources, minimum food source and competition with invasive alien species; Myocastor coypus.

Geographical range: Eurasia (excl. tundra and desert): Afghanistan, Albania, Algeria, Austria, Bangladesh, Belgium, Bulgaria, China, Czechoslovakia, Denmark, England, Estonia, Finland, France, Germany, Greece, Hungary, India, Indonesia, Iraq, Ireland, Palestine, Italy, Japan, Jordan, Korea, Laos, Lithuania, Malaysia, Mongolia, Morocco, Norway, Pakistan, Poland, Portugal, Scotland, Spain, Sri Lanka, Sweden, Switzerland, Taiwan, Tunisia, Turkey, republics of the former USSR, Vietnam, and the former Yugoslavia. In Jordan, this species was recorded in the upper reaches of Yarmouk River, along the Jordan River.

Population: The isolated population of otter in Jordan is declining sharply and thought to be extinct from the Yarmouk area.

\section{Area of occupancy}

8

\section{Extent of occurrence}

Biogeographical realms: Palearctic.

General use and trade information: No trade or use for this species was recorded from Jordan.

Threats: The aquatic habitats of otters are extremely vulnerable to man-made changes. Removal of bank side vegetation, dam construction, and associated man-made impacts on aquatic systems are all unfavorable to otter populations. Pollution is a major threat, in addition to the high competition with the invasive species Myocastor coypus.

Conservation actions: This species is protected in situ in Yarmouk Forest Reserve. In addition, it is listed in Appendix I for wildlife protection of the Agricultural Law Number 13 for the year 2015 based on regulation Number 43 for the year 2008.

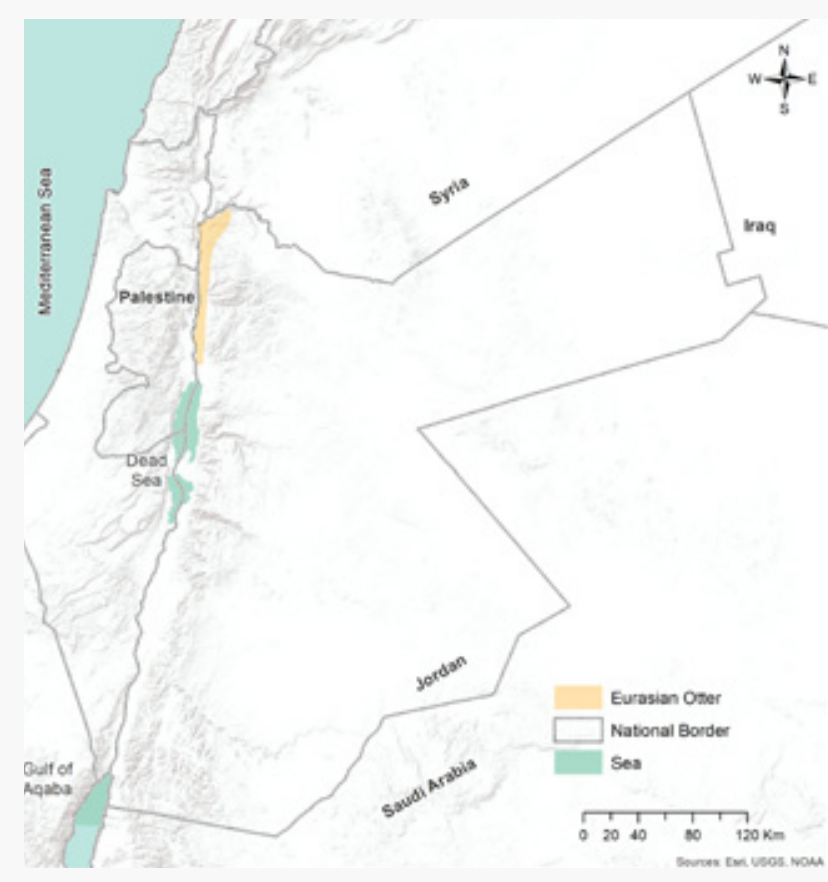

Map 67: Distribution of Lutra lutra in Jordan.

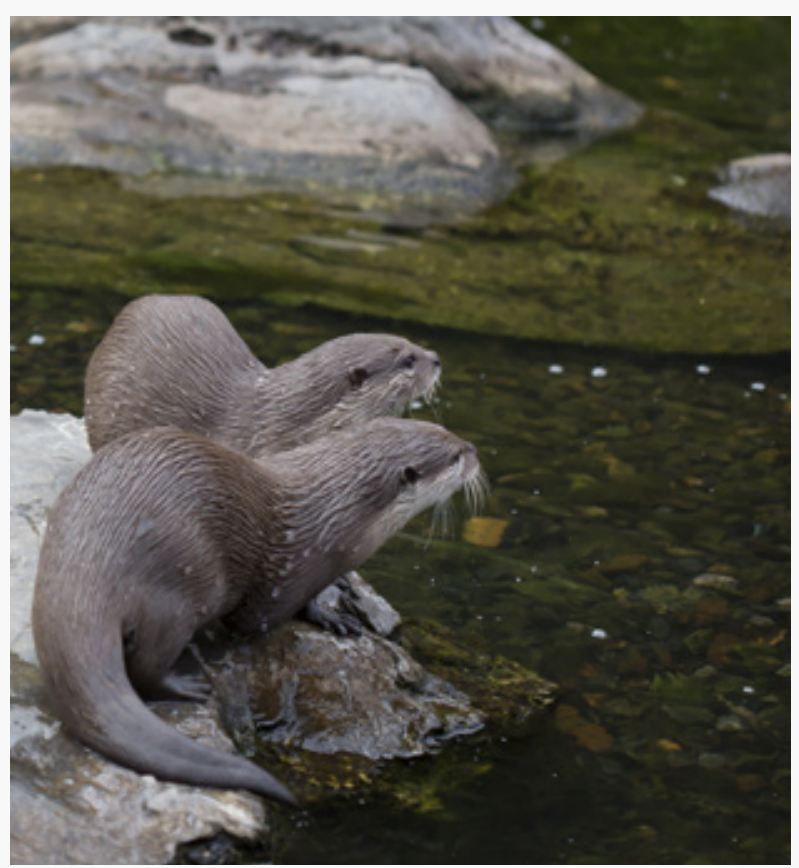

Figure 70: Lutra lutra (@ Shutterstock) 


\section{Martes foina (Erxleben, 1777)}

Animalia - Chordata- Mammalia- Carnivora- Mustelidae

Common name(s): Beech marten, stone marten.

Red List status: Endangered B1, B2ab (i, ii, iii).

Justification: This species is Listed as Endangered in view of its restricted distribution, which is confined to forested areas that represents less than 1\% of the total area of Jordan. In addition, this species has a small population size, and is under severe threats.

Geographical range: Europe, Asia Minor, Iran and extends into northern India to China and Mongolia. In Jordan, this species is recorded from Wadi As Sir, Al Mazar, Jarash-Amman road, Thaghrat Asfour, Wadi Aqraba, Dayr Abu Said-Beit Yafa road, Al-Mazar, Ajlune, Kufr Kefia, Johfiya, Dibeen Forest Reserve, Jarash, Salt, Wadi al Kafrayn, and Yarmouk Protected Area (Al-Shafee et al., 1997).

Population: Population is under severe decline in Jordan (Eid and Alatoom, 2016). Six specimens were captured in a survey performed in Dibeen Forest Reserve in 2006 (Eid and Alatoom, 2016).

\section{Area of occupancy}

48

\section{Extent of occurrence}

2085

Biogeographical realms: Palearctic.

General use and trade information: No trade or use information was recorded from Jordan.

Threats: This species is a forest dwelling species, which is affected by the continuous habitat degradation, agricultural expansion, woodcutting and urban developments. In addition, road killing, poisoning, trapping, shooting, and poisoning are considered major threats. A study performed by Eid and Handal (2018) showed a single specimen killed by hunters posted on Facebook in 2015.

Conservation actions: This species is protected in situ in Dibeen, Yarmouk and Ajloun Forest Reserves. In addition, it is listed in Appendix II for wildlife protection based on Agricultural Law Number 13 for the year 2015 based on regulation Number 43 for the year 2008.

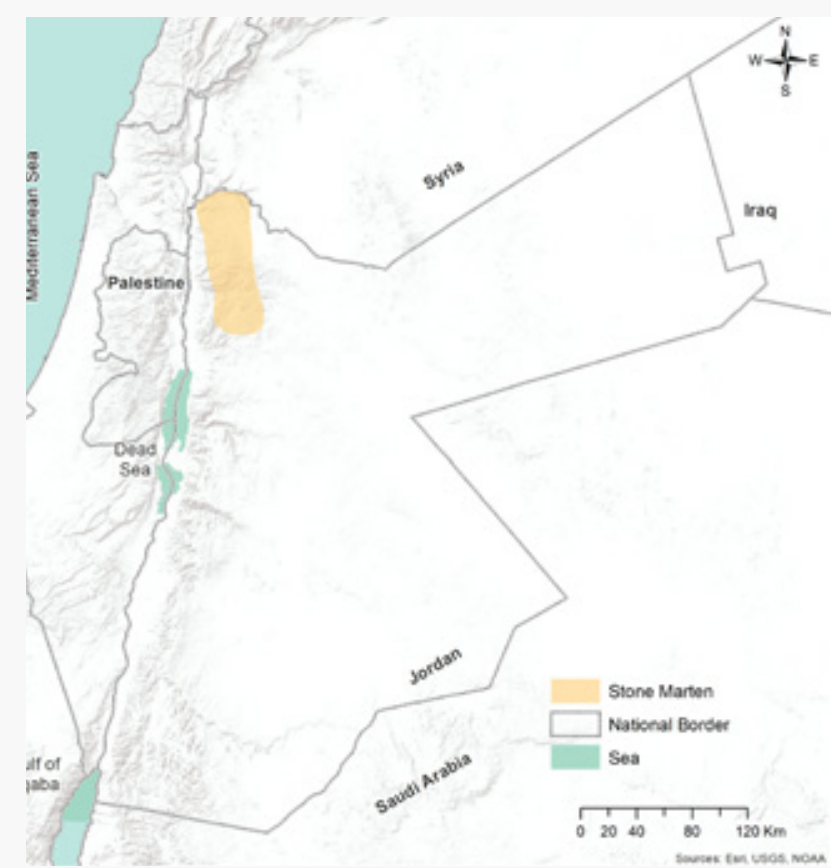

Map 68: Distribution of Martes foina in Jordan.

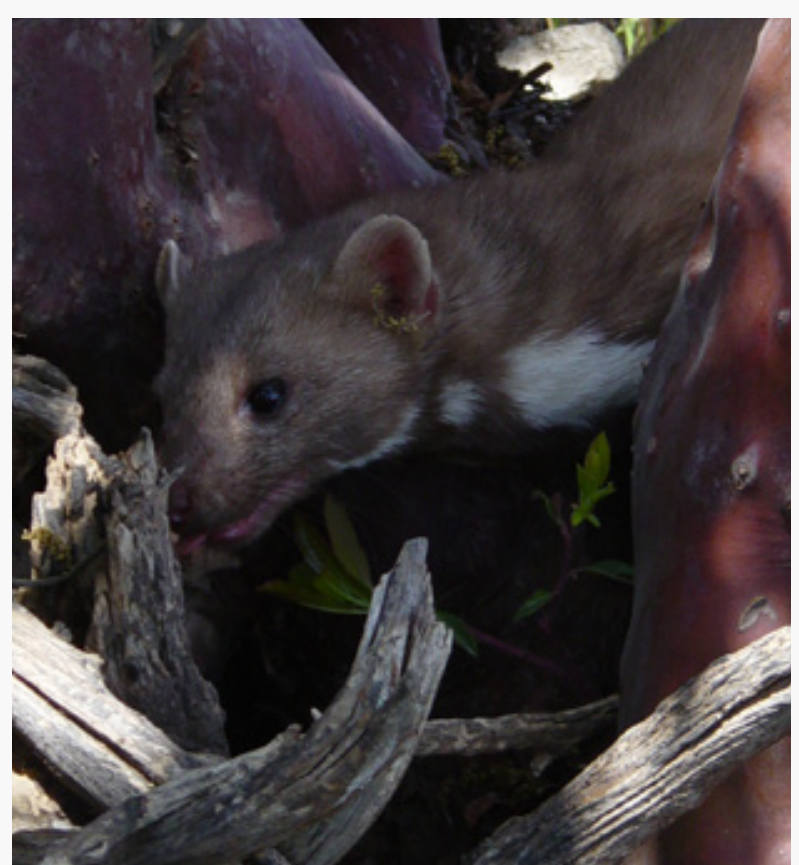

Figure 71: Martes foina (@ Mayas Qarqaz) 


\section{Meles meles (Linnaeus, 1758)}

Animalia - Chordata - Mammalia - Carnivora - Mustelidae

Common name(s): Eurasian badger, European badger, badger.

Red List status: Vulnerable B1ab (i, ii, iii).

Justification: Despite that it is widely distributed in Jordan, this species is under severe threat of habitat degradation which has led to severe fragmentation.

Geographical range: Scandinavia to S Siberia, south to Palestine; Iraq; China, Korea, and Japan; and on Ireland, Britain, Crete, and Rhodes. In Jordan, this species is recorded in Suwaylih area, Aqraba, Hartha, Irbid, Marw Agricultural Station, Adasiyah, near Na'ur, Kharja, An Nu'ayyimah, Marw, Mars'a, Thaghret Asfour, Al Munaysah, Jarash, Mansura, Al Jubayha, Dana Biosphere Reserve, Jarash, Malka, Um el Jimal, and Al Mujib Biosphere Reserve.

Population: The population is declining in Jordan.

\section{Area of occupancy}

96

\section{Extent of occurrence}

10578

Biogeographical realms: Palearctic.

General use and trade information: This species is consumed in Petra and Irbid areas and basically used for medical purposes (Abu Baker and Amr, 2002; Amr, 2012). A study performed by Aloufi and Eid, (2016) stated that the flesh of badger is used as a sexual tonic and joints and muscle pain and when cooked, its yielded soup can be used to treat rheumatic pain and neurological for failure.

Threats: Loss and destruction of suitable habitats due to forest degradation and expansion of urban areas as well as direct persecution represent the main threats that affect the presence and population densities of badgers in Jordan. In addition, poisoning is considered a major threat. A study performed by Eid and Handal, (2018) showed 30 killed specimens by hunters posted on Facebook in 2015.

Conservation actions: This species is protected in situ in Dibeen, Yarmouk and Ajloun Forest Reserves, Dana and Mujib Biosphere Reserves, and Shubak proposed protected area. In addition, it is listed in Appendix II for wildlife protection of the Agricultural Law Number 13 for the year 2015 based on regulation Number 43 for the year 2008.

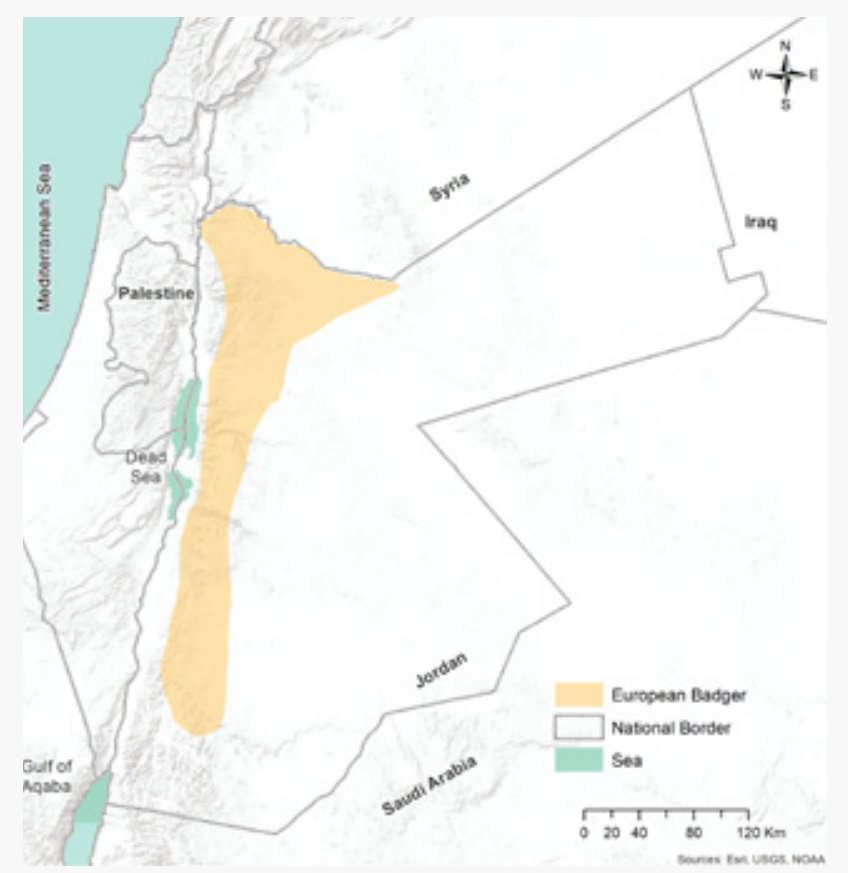

Map 69: Distribution of Meles meles in Jordan.

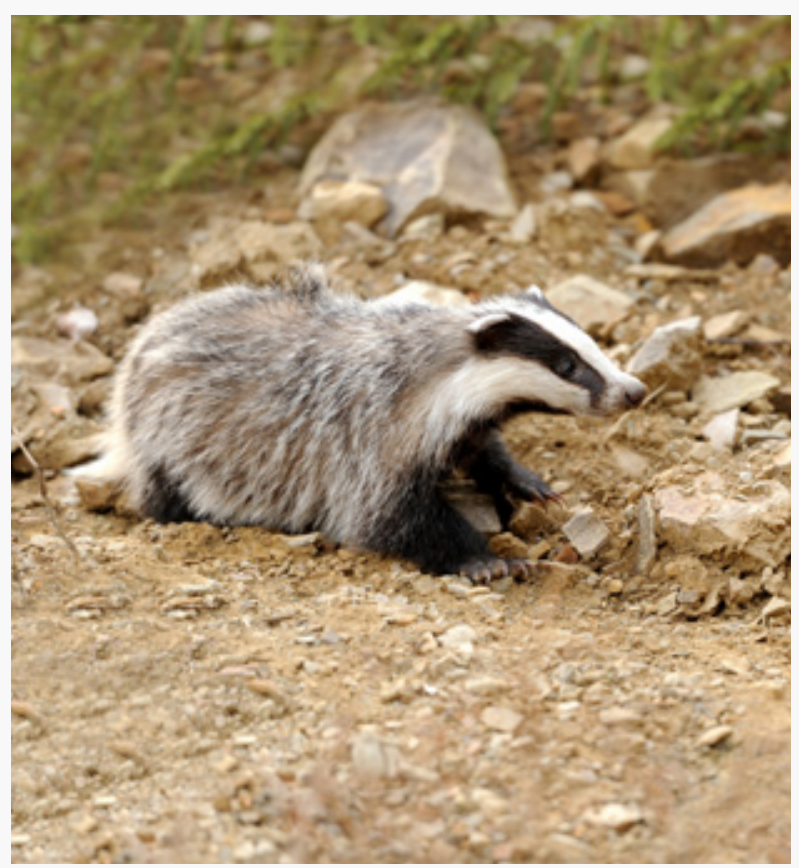

Figure 72: Meles meles (๑ Shutterstock) 


\section{Mellivora capensis (Schreber, 1776)}

Animalia - Chordata - Mammalia - Carnivora - Mustelidae

Common name(s): Honey badger, ratel.

Red List status: Data Deficient.

Justification: This species is rarely seen in Jordan with no known information on the threats on its habitats and population.

Geographical range: Savanna and steppe from Nepal, E India and Turkmenistan west to Lebanon, south of the Mediterranean to South Africa. In Jordan, this species is recorded in Azraq, Al-Lujoon, near the southern part of Jordan River, Jordan Valley and Mursa'.

Population: Honey Badger are considered a very rare species, and is expected to exist at a very low density in Jordan.

Area of occupancy

4

\section{Extent of occurrence}

189

Biogeographical realms: Afrotropical, Oriental.

General use and trade information: No trade or use information was reported of this species.

Threats: Ratels are directly persecuted if seen as Bedouins believe it is a dangerous animal that digs graves and drags the dead bodies (Amr, 2012).

Conservation actions: This species was listed in Appendix II for wildlife protection of the Agricultural Law Number 13 for the year 2015 based on regulation Number 43 for the year 2008.

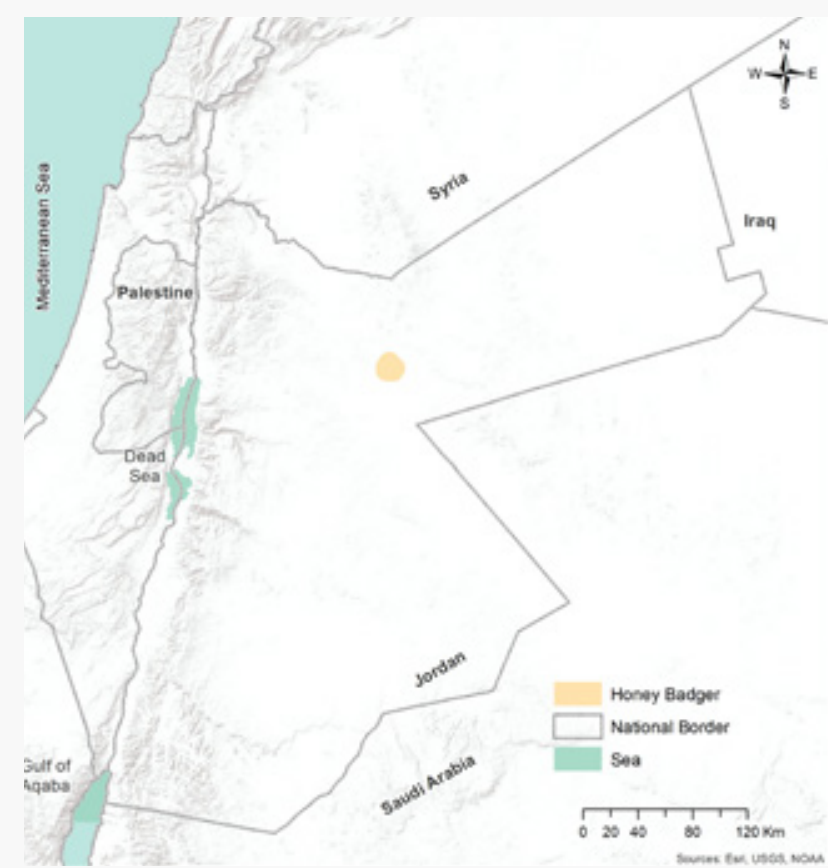

Map 70: Distribution of Mellivora capensis in Jordan.

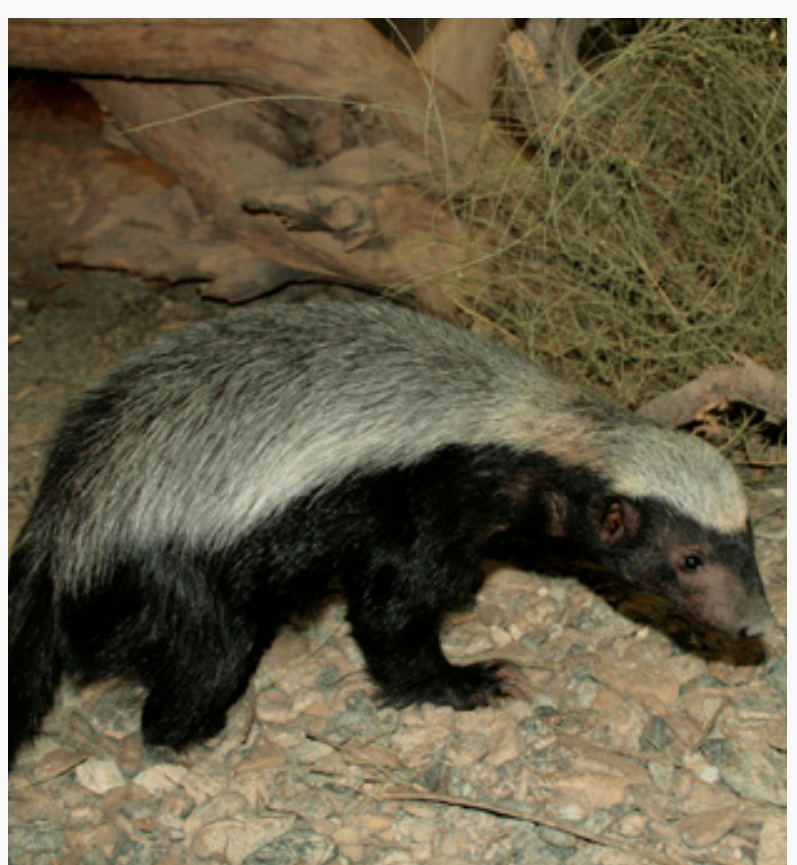

Figure 73: Mellivora capensis (C Zuhair Amr) 


\section{Vormela peregusna (Güldenstädt, 1770)}

Animalia - Chordata- Mammalia- Carnivora- Mustelidae

Common name(s): Marbled polecat, European marbled polecat.

Red List status: Least Concern.

Rational: Population is presumed stable in Jordan. Amr (2012) stated that farmers implement measures to control this species, but its distribution is expanding to new habitats.

Geographical range: The distribution extends from southeast Europe, through Asia Minor, the Caucasus, and Central Asia, northern China and Mongolia to the Middle East, where it is known to be widespread. In Jordan, this species is recorded in Wadi As-Sir, Um Al-Hiran, Amman, Eidun, Fo'ara, El-Barha, Al-Mazar El-Shamali, Kufr Khall, Kufr Jayez, At-Tayyibah, Ar-Ramtha, Harima, Irbid, Sal, Waqqas, Samma, Qastal, Azraq, Umm Al-Jimmal, Mutah, Baqa'a, Malka and Salt (Rifai et al., 1999).

Population: Population is stable in Jordan.

Area of occupancy

108

\section{Extent of occurrence}

7206

Biogeographical realms: Palearctic.

General use and trade information: No trade or use information were reported for this species.

Threats: This species is captured frequently by locals in the northern parts of Jordan and probably killed. Road killing and poisoning is another threat, thought to be very limited. A study performed by Eid and Handal, (2018) showed two specimens killed by hunters posted on Facebook in 2015.

Conservation actions: This species is protected in situ in Yarmouk Forest Reserve, and Mujib Biosphere Reserve. In addition, this species is listed in Appendix II for wildlife protection of the Agricultural Law Number 13 for the year 2015 based on regulation Number 43 for the year 2008.

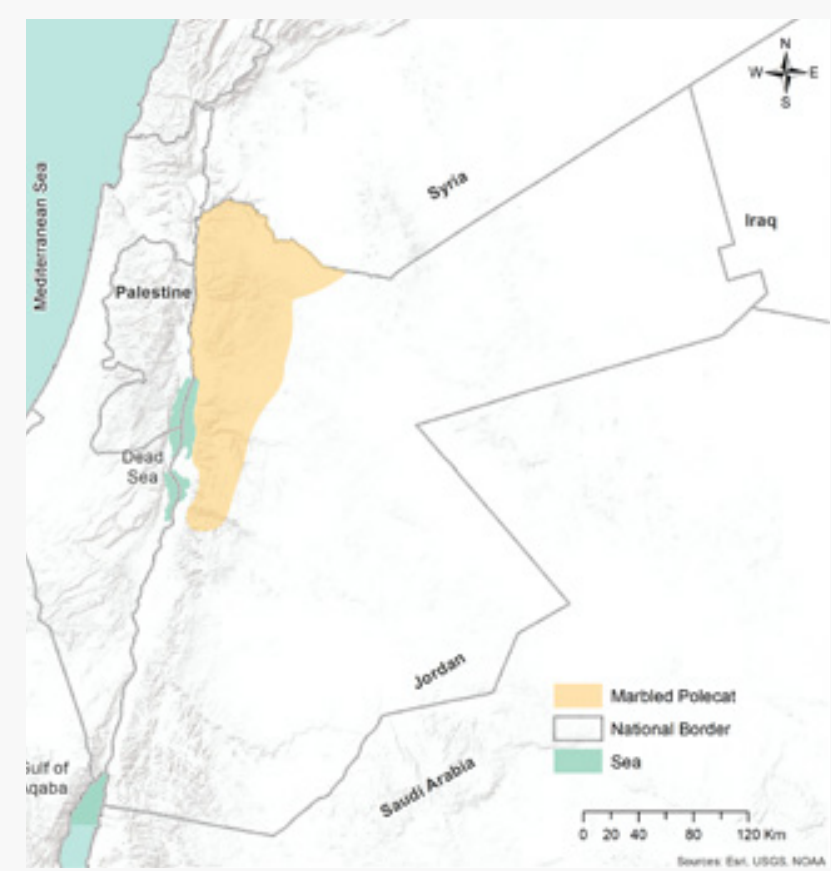

Map 71: Distribution of Vormela peregusna in Jordan.

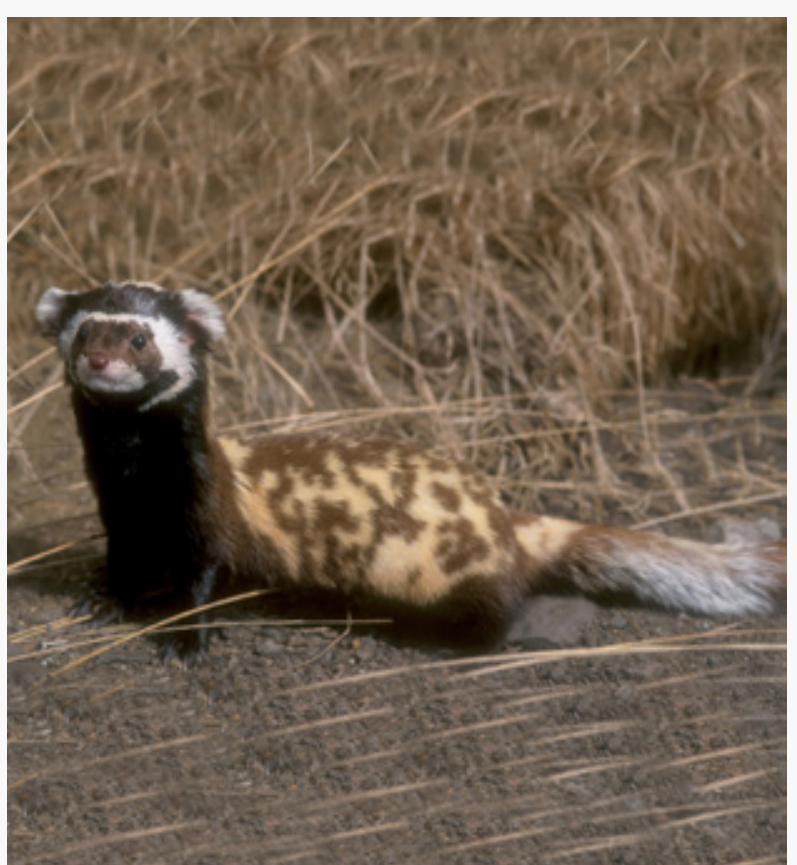

Figure 74: Vormela peregusna (@ Savci - Tchorík skvrnitý) 



\subsection{Lagomorpha}

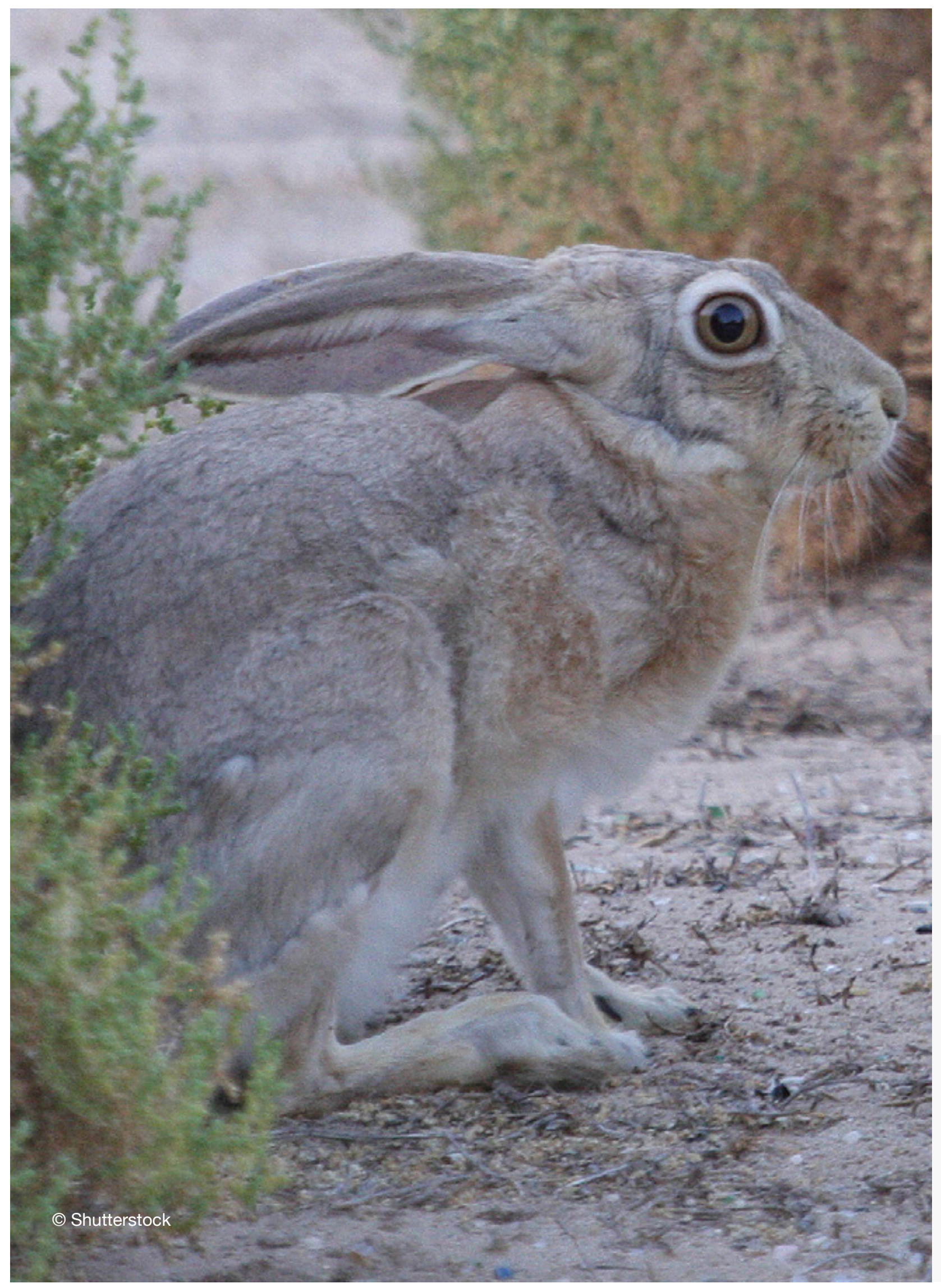




\section{Lepus capensis (Linnaeus, 1758)}

Animalia - Chordata- Mammalia- Lagomorpha- Leporidae

Common name(s): Cape hare, desert hare, Arabian hare, brown hare.

Red List status: Endangered A2acd.

Justification: Despite having widespread distribution there has been a sharp decline in its population and its habitats are under continuous threats.

Geographical range: The geographic range includes Africa in two separate, non-forested areas: South Africa, Namibia, Botswana, Zimbabwe, S Angola, Mozambique; and to the north, Tanzania, Kenya, Somalia, Ethiopia, countries of the Sahel and Sahara, and N Africa; then eastward through the Sinai to the Arabian Peninsula, Jordan, S Syria, S Palestine and $W$ and S Iraq, west of the Euphrates River. In Jordan, this species is recorded from Al Jafr, between Azraq ash Shishan and Qasr Amrah, Jabal Aseikhem, Jawa, Aqaba, Ghawr es Safi, Ma'an, Al Mafraq, Wadi Fidan, Qatrana, Ramtha, Al Shawmari, Burqu', Safawi, Wadi Araba, Wadi Rum, Yarmouk Protected Area, Dana Biosphere Reserve, Jabal Masuda proposed Protected Area, Jarash, and Qatar Proposed Protected Area (Amr, 2012).

Population: The population is under severe threats, which have caused a sharp decline in its population.

Area of occupancy

84
Extent of occurrence

42910

\section{Biogeographical realms: Afrotropical.}

General use and trade information: Aloufi and Eid (2016) stated that the flesh is used to treat bronchial asthma.

Threats: Include hunting which is a major threat; in addition to loss of habitat and habitat fragmentation, road kills, livestock competition, pesticides and poisoning. A study performed by Eid and Handal, (2018) showed 438 specimens killed specimens by hunters posted on Facebook in 2015.

Conservation actions: This species is protected in situ in Yarmouk Forest Reserve, Fifa Protected Area, Qatar Protected Area, Dana Biosphere Reserve, Wadi Rum World Heritage Area and Burqu' Protected Area. In addition, it is listed in Appendix III for wildlife protection of the Agricultural Law Number 13 for the year 2015 based on regulation Number 43 for the year 2008.

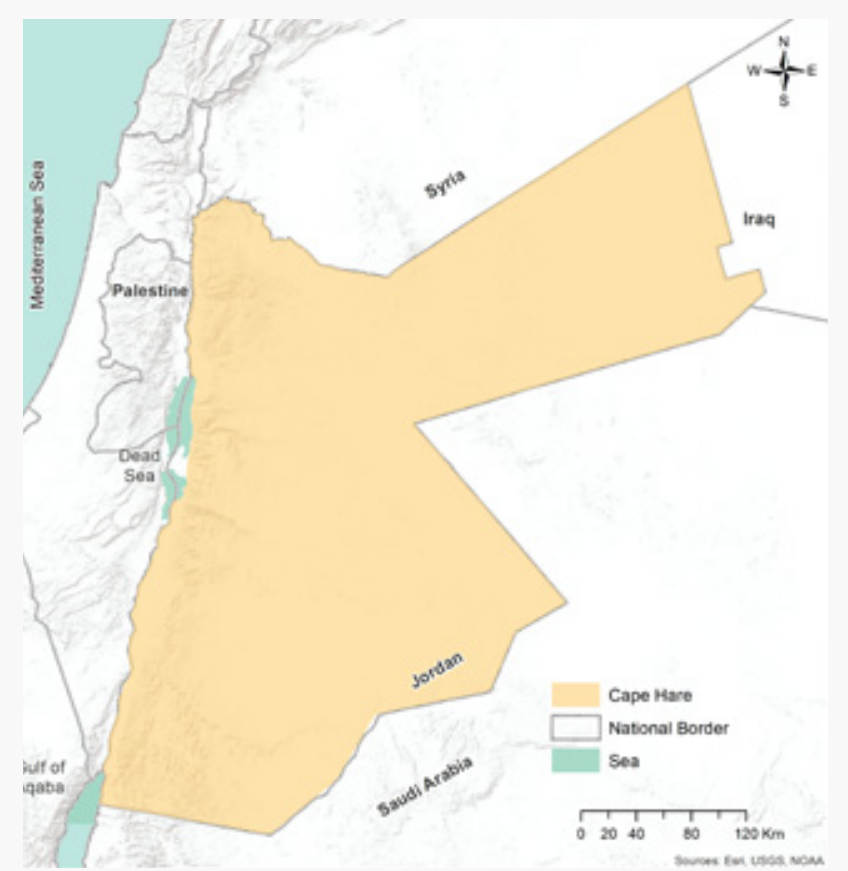

Map 72: Distribution of Lepus capensis in Jordan.

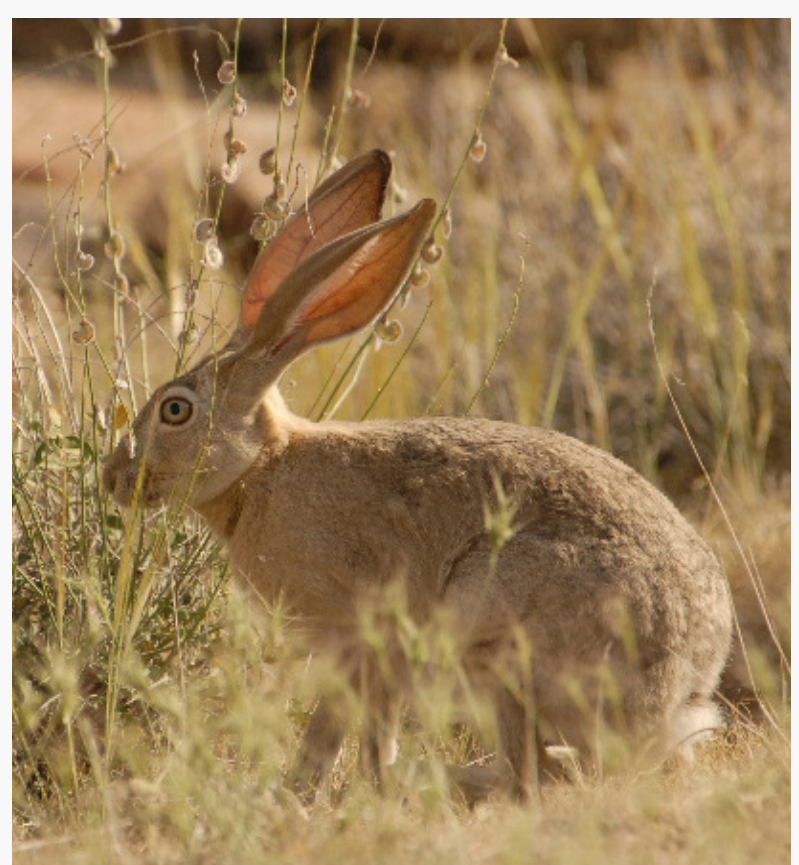

Figure 75: Lepus capensis (@ Shah Jahan) 


\subsection{Hyracoida}

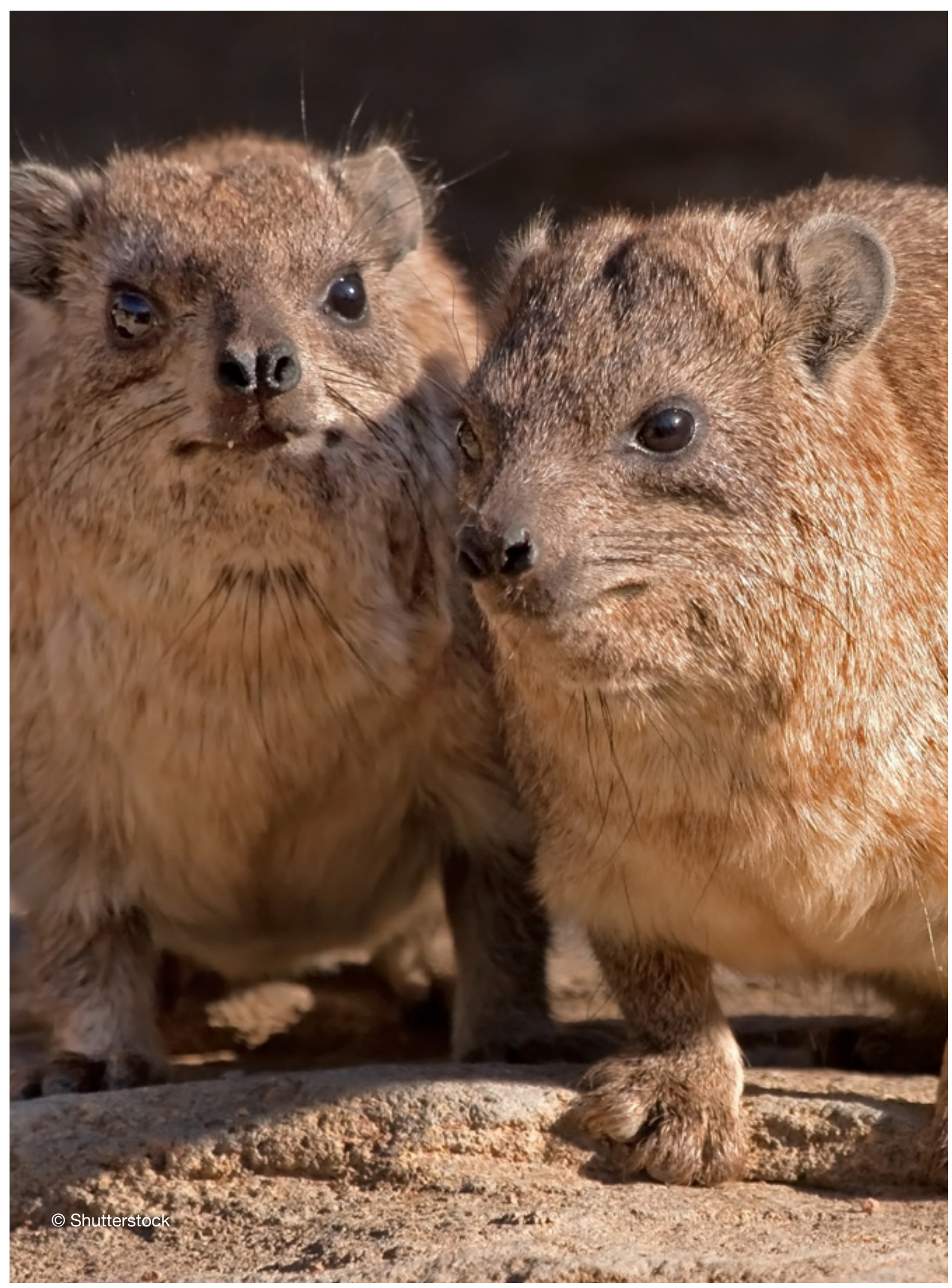




\section{Procavia capensis (Pallas, 1766)}

Animalia - Chordata- Mammalia- Hyracoidea- Procaviidae

Common name(s): Rock hyrax, rock dassie.

Red List status: Endangered B1, B2ab (i, ii, iii).

Justification: It has a restricted distribution to steep Rocky Mountains along the Jordan Rift Valley, presumed small populations. The population is under continues threats of hunting, habitat destruction and fragmentation.

Geographical range: The species is found throughout sub-Saharan Africa and northeast Africa, being discontinuously distributed from Senegal through southern Algeria (isolated population), Libya and Egypt (east of the Nile River) to central and southern Africa (excluding the Congo Basin forests). Procavia capensis extends to the Arabian Peninsula, mainly in the west, and to Lebanon, Jordan, and Palestine. In Jordan, this species is recorded from Mu'ab mountains, Dead Sea area, Mujib Biosphere Reserve, Wadi Rum, Petra, Ghawr es Safi, Wadi Araba, Al 'Adasiyah, Al Hammeh, At Tafila mountains, Wadi Zarqa' Main, Dana Biosphere reserve, Yarmouk Protected Area, and Jabal Masuda proposed Protected Area.

Population: Widespread, but number of individuals is very limited (Rifai et al., 2000).

\section{Area of occupancy}

64

\section{Extent of occurrence}

4165

\section{Biogeographical realms: Afrotropical}

General use and trade information: This species is consumed by locals and hunters. Aloufi and Eid, (2016) stated that the flesh is used to treat neurological failure, diabetes mellitus and also as a sexual tonic.

Threats: It is hunted locally, and may have been extirpated in some smaller localities. In addition, habitat degradation and fragmentation are also a major threat. A study performed by Eid and Handal, (2018) showed 37 specimens killed by hunters posted on Facebook in 2015.

Conservation actions: This species is protected in situ in Yarmouk Forest Reserve, Dana and Mujib Biosphere Reserves, and Wadi Rum World Heritage Area. In addition, it is listed in Appendix II for wildlife protection of the Agricultural Law Number 13 for the year 2015 based on regulation Number 43 for the year 2008.

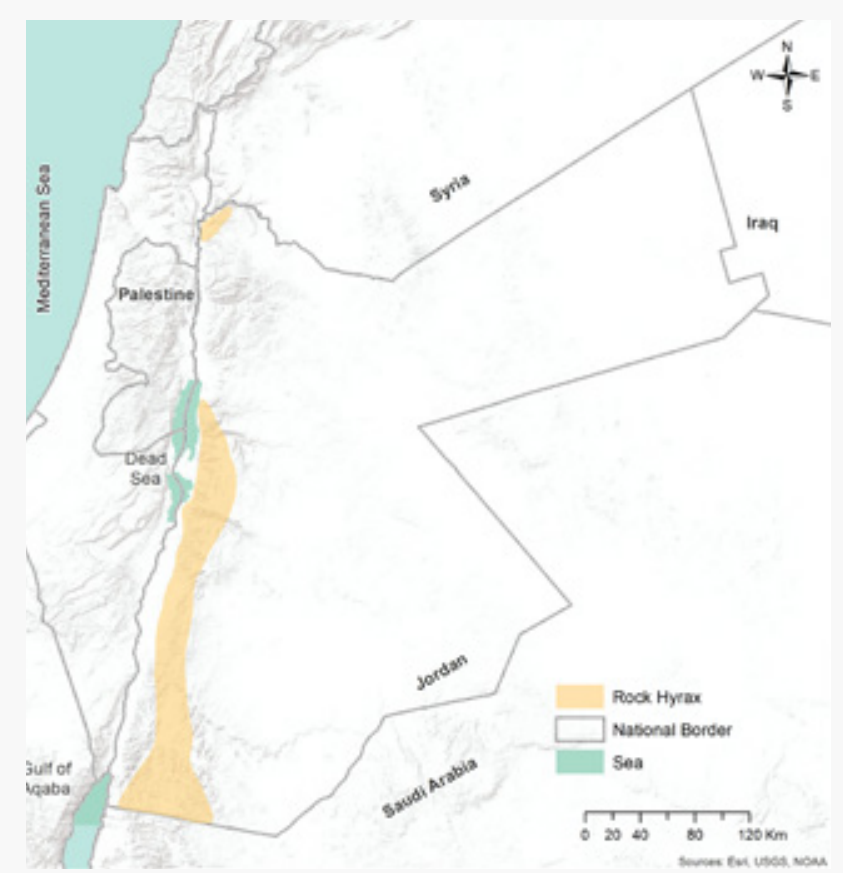

Map 73: Distribution of Procavia capensis in Jordan.

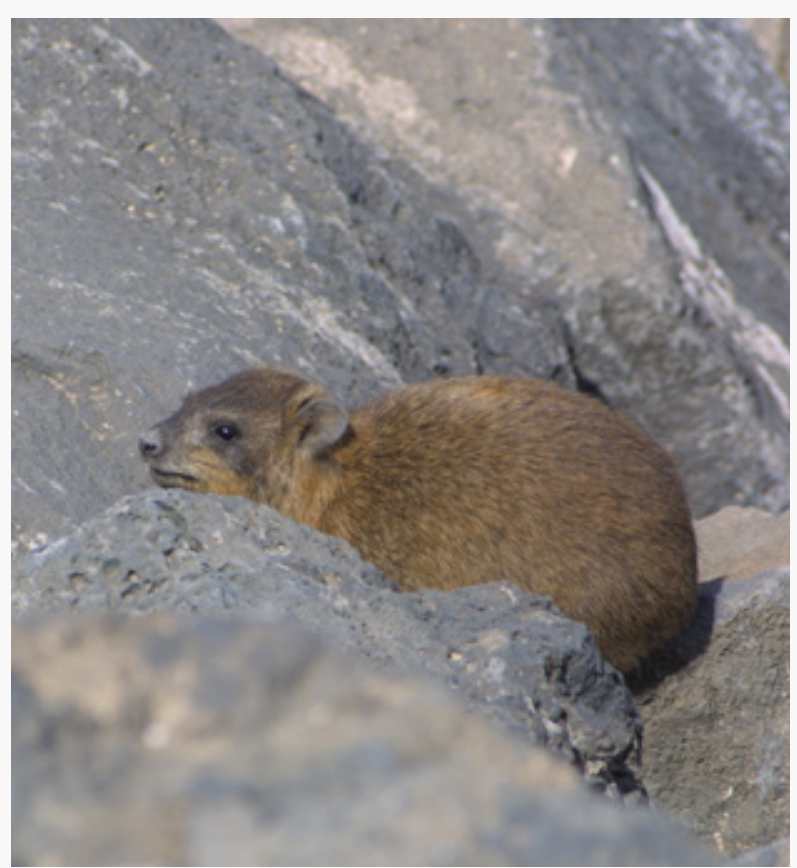

Figure 76: Procavia capensis (C Zuhair Amr) 


\subsection{Artiodactyla}

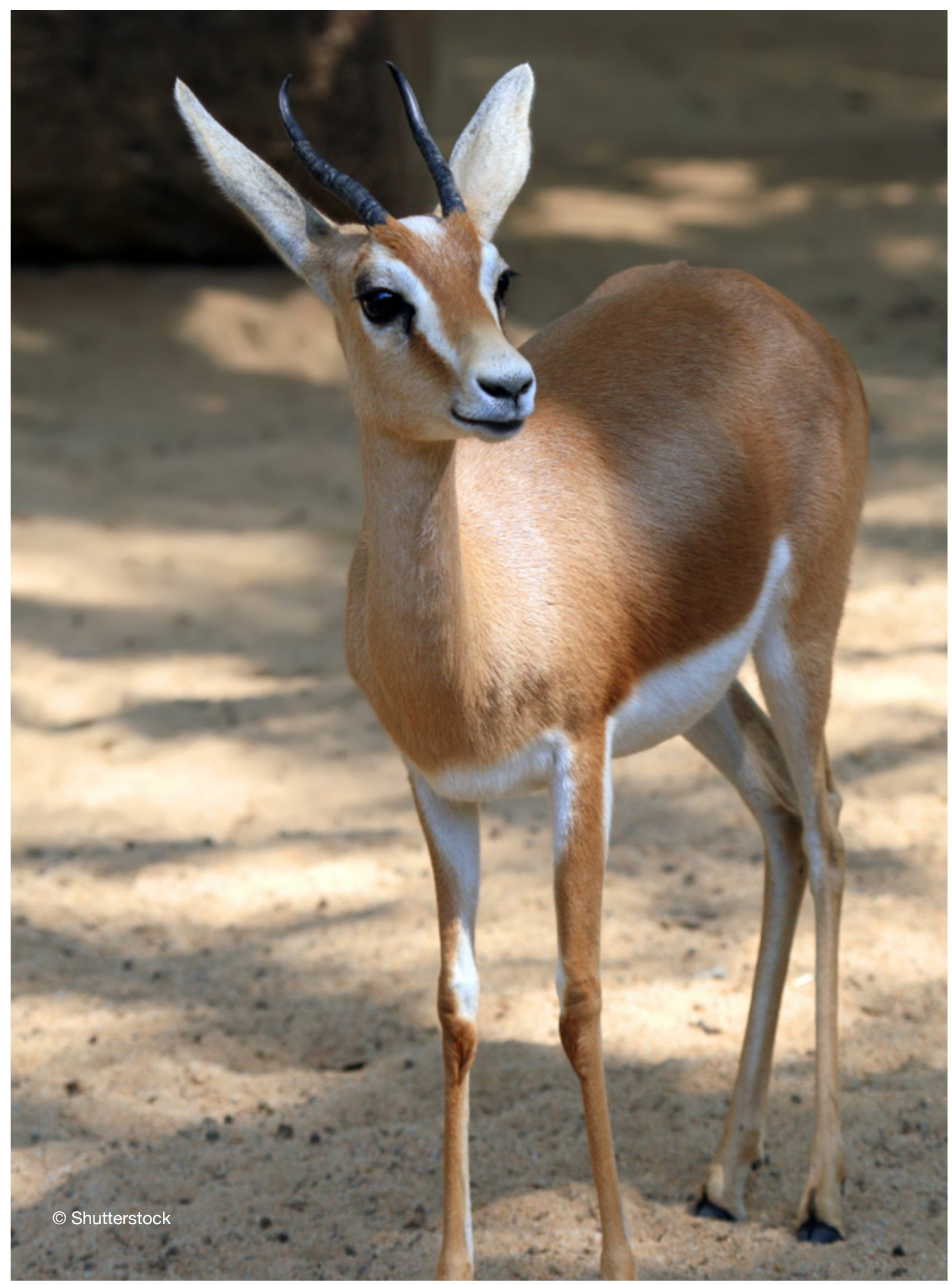




\section{Sus scrofa (Linnaeus, 1758)}

Animalia - Chordata- Mammalia- Artiodactyla- Suidae

Common name(s): Wild boar, Eurasian wild pig.

Red List status: Least Concern.

Justification: Listed as Least Concern due to its wide distribution, abundance, tolerance to habitat disturbance and its presence in many protected areas.

Geographical range: The Wild Boar occurs throughout the steppe and broadleaved forest regions of the Palaearctic, from Western Europe to the Russian Far East, extending southwards as far North Africa, the Mediterranean Basin and the Middle East, through India, Indo-China, Japan, Taiwan and the Greater Sunda Islands of South-east Asia. Populations east of Bali are probably all introduced. In Jordan, this species is recorded from Ghawr Safi, Azraq, Baoon, Dair Abi Said, Jordan Valley, North Shounah, Yarmouk river, and Dibeen Forest Reserve.

Population: This species is abundant and its population is probably increasing.

\section{Area of occupancy} 56

\section{Extent of occurrence}

2766

Biogeographical realms: Palearctic.

General use and trade information: This species is consumed in Jordan, but to a very limited extent (Qumsiyeh et al., 1996).

Threats: Hunting might be considered the major threat, but it does not affect the species population due to its reproduction cycle, presence in protected zones and presence in protected areas. This species is considered a pest by farmers. A study performed by Eid and Handal, (2018) showed 40 specimens killed by hunters through Facebook photos posted in 2015.

Conservation actions: This species is very well-protected in situ in Dibeen, Yarmouk and Ajloun Forest Reserves, as well as Fifa protected area. In addition, it inhabits the boundary areas extending from the northern parts to the eastern boundaries of the Dead Sea which is well-protected by the Jordanian army.

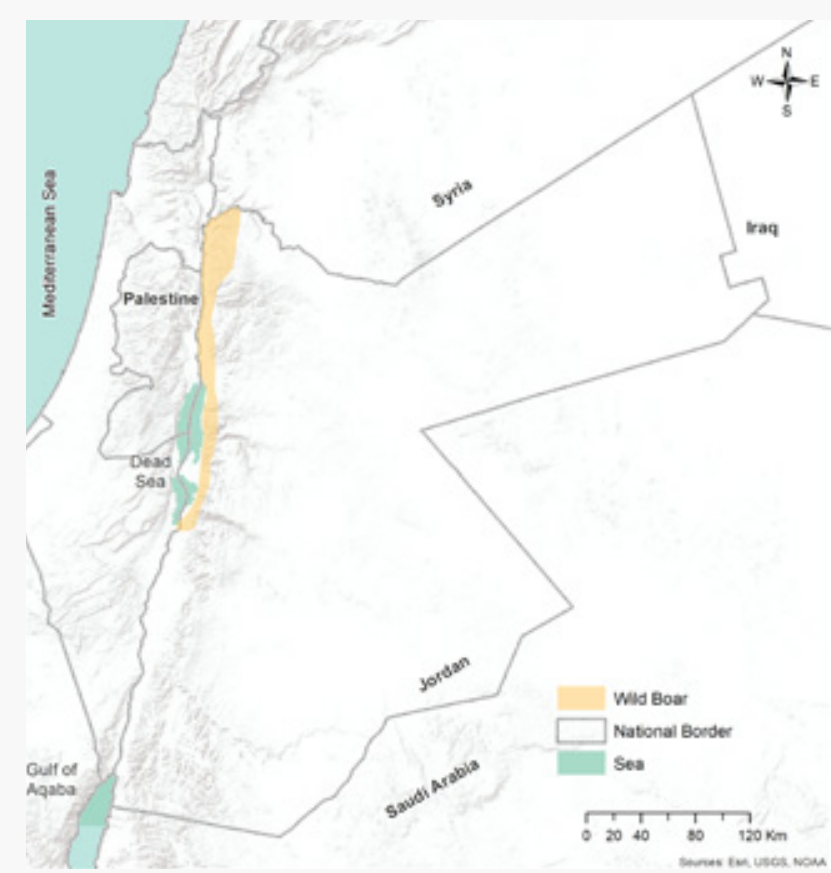

Map 74: Distribution of Sus scrofa in Jordan.

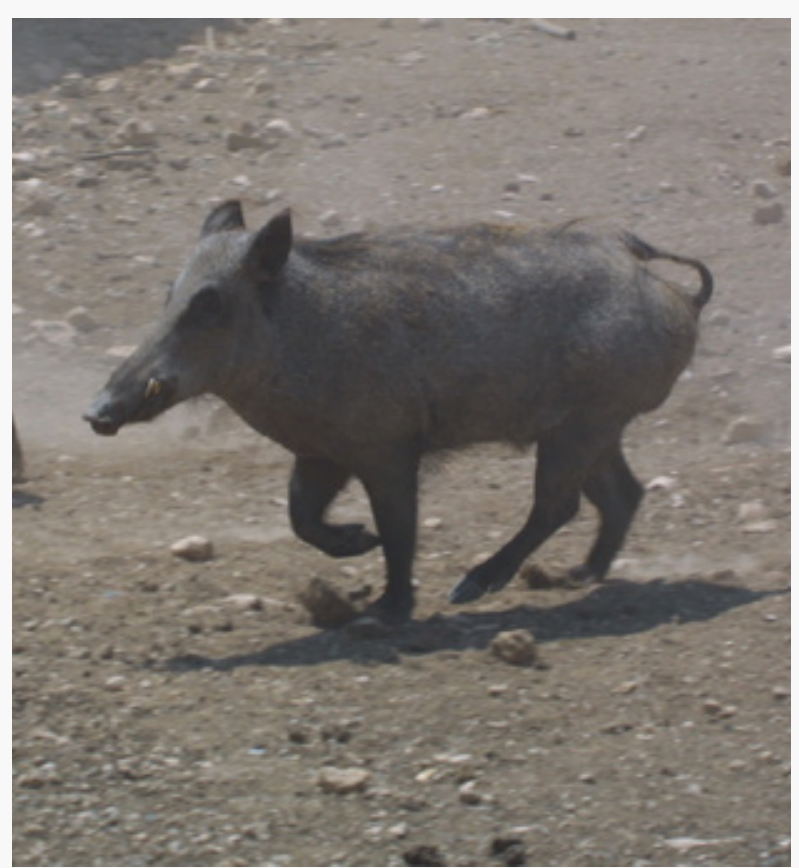

Figure 77: Sus scrofa (C Zuhair Amr) 


\section{Oryx leucoryx (Pallas, 1777)}

Animalia - Chordata - Mammalia - Artiodactyla - Bovidae

Common name(s): Arabian oryx, white oryx.

Red List status: Regionally Extinct.

Justification: This species was assessed as Regionally Extinct since the only surviving populations are held in enclosures with continuous fodder and water supplements. Thus, it can't be considered as self-sustaining wild populations.

Geographical range: The Arabian Oryx formerly occurred through most of the Arabian Peninsula, north to Kuwait and Iraq. Before 1920, Oryx distribution was separated into areas over 1,000 km apart: a northern population in and around the Nafud, and a larger southern population in the Rub Al Khali and the plains of central-southern Oman. Oryx disappeared from the north in the 1950s and by 1960, Oryx were restricted to parts of central and southern Oman. The last wild individuals were probably shot in 1972 on the Jiddat al Harasis. In Jordan, two re-introduced populations exist in Shumari Wildlife Reserve and Wadi Rum World Heritage area.

Arabian Oryx have been reintroduced to Oman (Arabian Oryx Sanctuary, from 1982); Saudi Arabia (Mahazat as-Sayd Reserve, 2,244 km² from 1990; Uruq Bani Ma'arid Reserve, 12,000 km² from 1995), Palestine (three sites in the Northern Arava and Negev Desert, from 1997); United Arab Emirates (Arabian Oryx Reserve, Abu Dhabi, from 2007); and Jordan (Shaumari in 1978 and Wadi Rum, beginning 2009).

Population: Current total population is estimated at approximately 80 individuals in Wadi Rum World Heritage Area in addition to about 70 individuals in Shaumari Wildlife Reserve.

\section{Area of occupancy}

\section{8}

\section{Extent of occurrence}

Biogeographical realms: Afrotropical

General use and trade information: This species was hunted for its meat, in addition to poaching activities. Currently this species is well protected (Qumsiyeh et al., 1996).

Threats: Illegal live capture for sale to private collections was reported from Wadi Rum (E. Eid. personal communication).

Conservation actions: This species is well-protected in situ at Wadi Rum World Heritage Area and Shaumari Wildlife Reserve. In addition, it is listed in Appendix I for wildlife protection of the Agricultural Law Number 13 for the year 2015 based on regulation Number 43 for the year 2008.

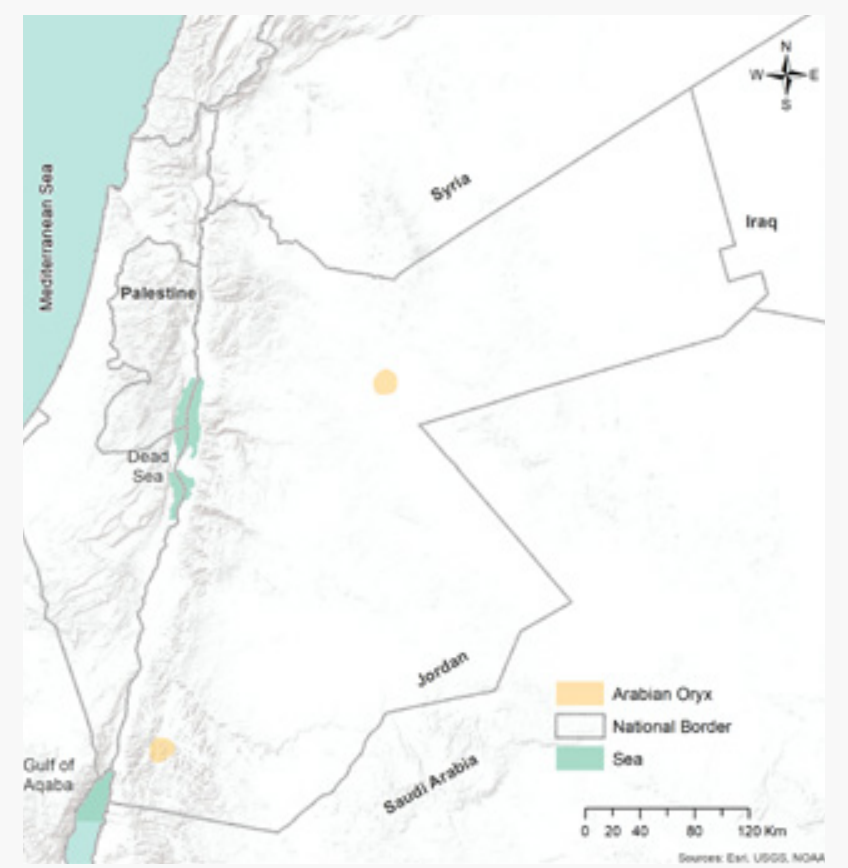

Map 75: Distribution of Oryx leucoryx in Jordan

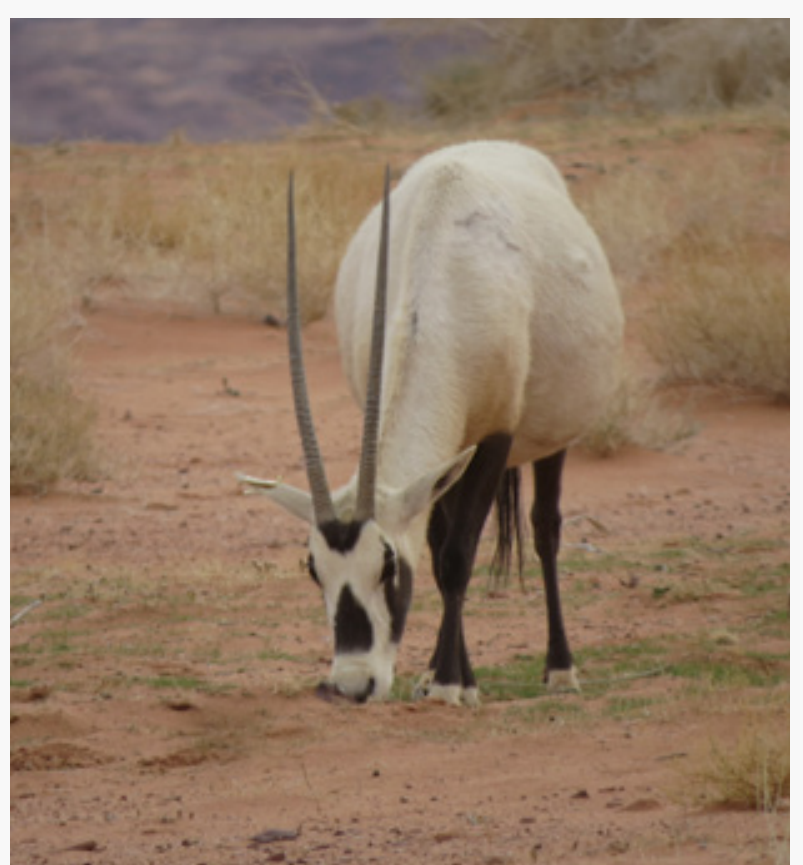

Figure 78: Oryx leucoryx (@ Ehab Eid) 


\section{Capra nubiana (F. Cuvier, 1825)}

Animalia - Chordata- Mammalia- Artiodactyla- Bovidae

Common name(s): Nubian ibex.

Red List status: Endangered A2acd; C1.

Justification: The wild population is less than 1,000 mature individuals. In the past a $50 \%$ reduction of the population was observed and its status is still under threat.

Geographical Range: This species was recorded from eastern Nile in Egypt, north-east Sudan, northern Ethiopia and western Eritrea, Palestine, West Jordan, scattered locations in western and central Saudi Arabia, scattered locations in Yemen, and in southern Oman (Grubb, 2005). It is extinct from Lebanon and Syria. In Jordan it is recorded from Aqaba, Wadi Zarqa Ma'in, Al Mazar Al Janobi, Mazraa'h, Karak, Wadi Rum, Al Qadeseyeh, Dana and Mujib Biosphere Reserves, and Wadi ibn Hammad (Qumsiyeh et al., 1996).

Population: An estimate from Dana showed that it holds a population of less than 250 individuals (E. Eid. personal communication). In addition, a captive breeding programme was started in 1989 to enlarge the small population in Mujib Biosphere Reserve, where the animals were released beginning of 1998, and the programme was terminated in 2006 when the wild population was estimated at approximately 200 (L. Harding. personal communication). A second captive breeding programme was initiated at Wadi Rum World Heritage Area where 100 individuals were brought from the United Arab Emirates. In October 2015, a total of 60 individuals were released to the wilderness (E. Eid. personal communication).

Area of occupancy

56

\section{Extent of occurrence}

5187

\section{Biogeographical realms: Afrotropical}

General use and trade information: This species is consumed by locals in Jordan (Aloufi and Eid, 2016). In addition, meat is sold locally in certain towns (Z. Amr. personal communication).

Threats: Hunting is considered the major threat, which has led to the sharp decline in its population in Jordan. Poaching also occurs in Jordan, although this threat has decreased recently (Hays and Bandak, 1997). The availability and distribution of waterholes is likely to be a major factor in the condition of populations, and both may fluctuate from year to year (Amr, 1997), along with habitat degradation by contamination of water sources, are major potential threats. High levels of tourists at watering, feeding and birthing sites also threatened the population. Habitat loss and degradation threatens the species particularly through the extension of roads, livestock encroachment and other development pressures in and around its remaining refuges (Habibi and Tatwany, 1997). A recent study by Eid and Handal, (2018) showed 115 killed specimens of the Nubian Ibex on Facebook posted by hunters in 2015 . 
Conservation actions: This species is protected in situ in Dana and Mujib Biosphere Reserves, as well as Wadi Rum World Heritage Area. Until 1978, the ibex was legally hunted in Jordan but since then it has received full protection and a total ban on hunting this species was put into effect indefinitely where the species was Listed on Appendix I for wildlife protection of the Agricultural Law Number 13 for the year 2015 based on regulation Number 43 for the year 2008.

Captive breeding programmes at the Mujib Biosphere Reserve have also contributed to the conservation efforts. A total of 22 young ibex were received from the San Diego Wild Animal Park in July 1989. These animals were housed in a $0.25-0.4 \mathrm{~km}^{2}$ enclosure on the slopes of Wadi Mujib. By 1992, a total of 34 individuals were found and increased to 68 adults in 1995. The Royal Society for the Conservation of Nature (RSCN) began releasing extra animals into the wild in 1998 and continued until 2006 when the programme was terminated (L. Harding. personal communication). Recently, a new captive breeding programme was initiated in Wadi Rum World Heritage Area with 60 individuals released to the wilderness in 2015.

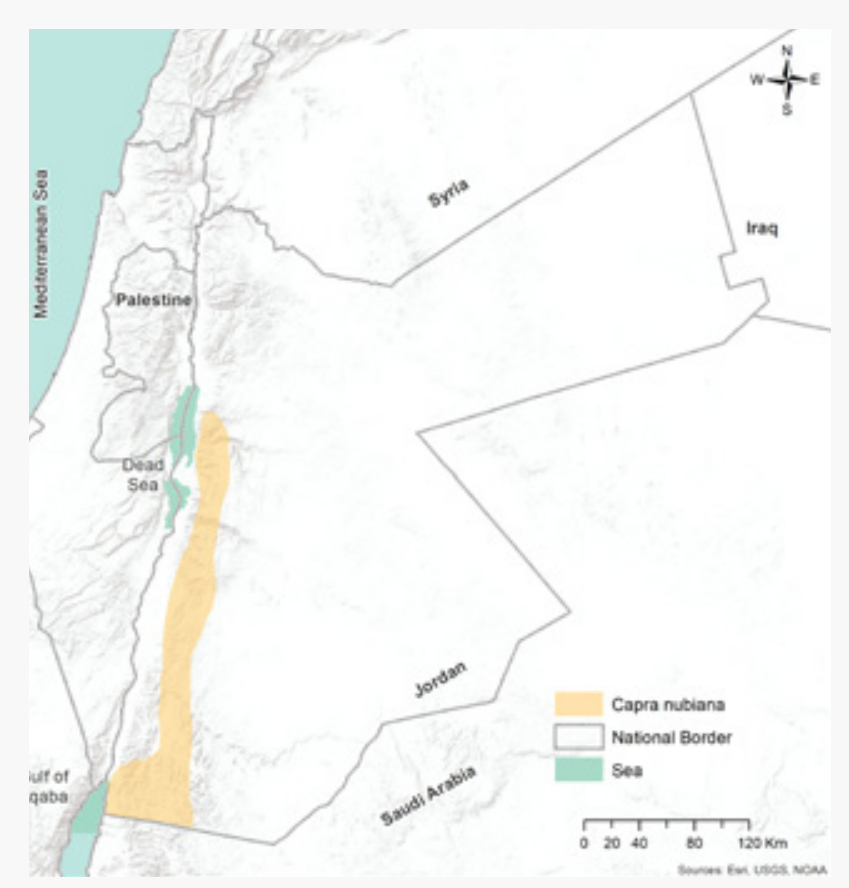

Map 76: Distribution of Capra nubiana in Jordan.

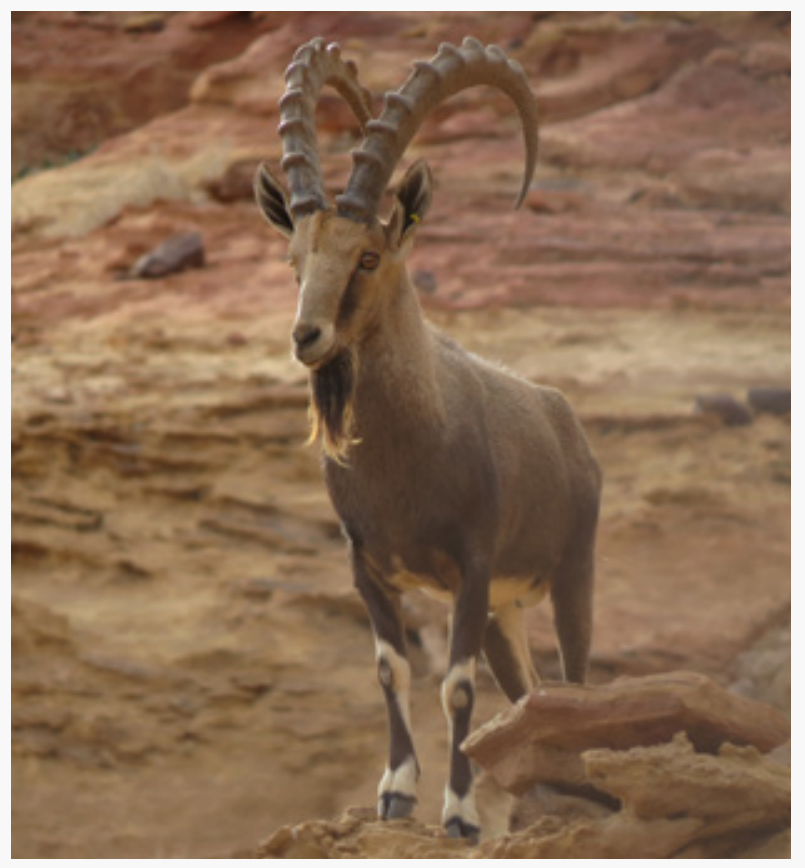

Figure 79: Capra nubiana (○ Ehab Eid) 


\section{Gazella dorcas (Linnaeus, 1758)}

Animalia - Chordata- Mammalia- Artiodactyla- Bovidae

Common name(s): Dorcas gazelle.

Red List status: Critically Endangered A2a, c; C1.

Justification: Numbers have declined sharply in Jordan, and populations are restricted in some localities to only a few individuals.

Geographical range: Morocco south to Mauritania (and formerly to Senegal) east to S Palestine and Egypt and from there south to Sudan, NE Ethiopia and N Somalia. In Jordan, this species is recorded from Wadi Fidan, Bir Madhkur, Risha, Rahma and Aqaba. Historical records were obtained from Amman (Anon, 1946).

Population: The population have witnessed a sharp decline in Jordan. An estimate was performed by Kiwan et al. (2001) showed a population estimated at only 180-200 individuals.

\section{Area of occupancy}

48

\section{Extent of occurrence}

2075

\section{Biogeographical realms: Afrotropical}

General use and trade information: This species is consumed by locals in Jordan. In addition, it is hunted for trophy collection.

Threats: it is considered one of Jordan's most threatened species. Continuous hunting and land encroachment are the main threats affecting the remaining population of this species (Kiwan et al., 2001). A study performed by Eid and Handal, (2018) showed two specimens killed by hunters and posted on Facebook in 2015.

Conservation actions: This species has a potential habitat at the western parts of Dana Biosphere Reserves and Rahma Special Conservation Area. In addition it is Listed in Appendix I for wildlife protection of the Agricultural Law Number 13 for the year 2015 based on regulation Number 43 for the year 2008.

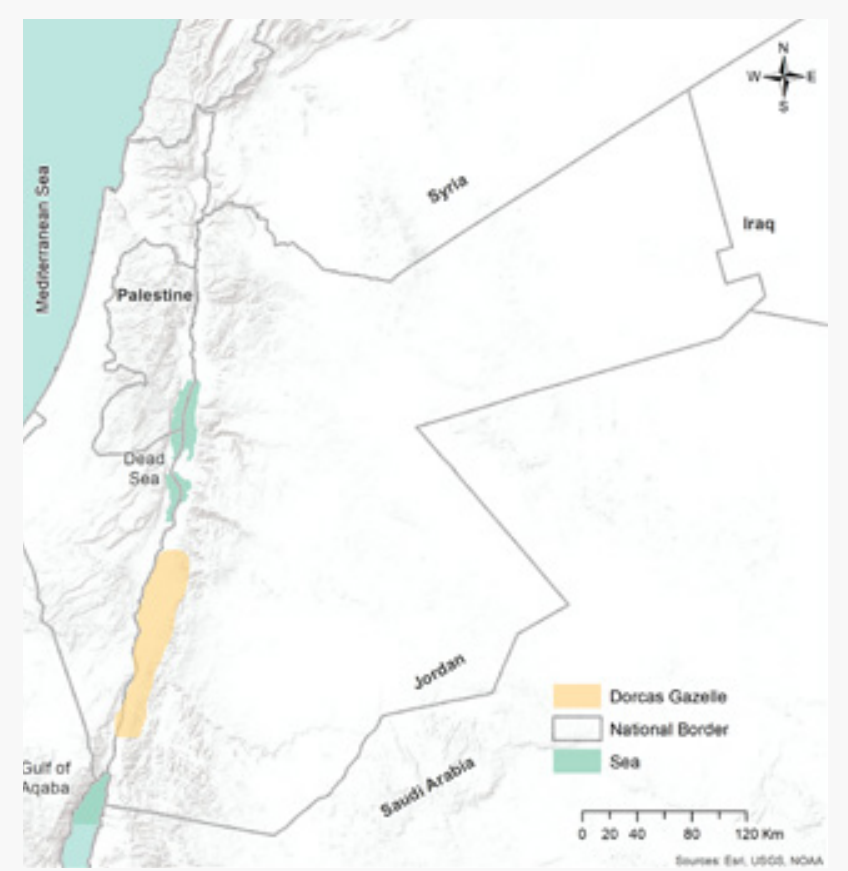

Map 77: Distribution of Gazella dorcas in Jordan.

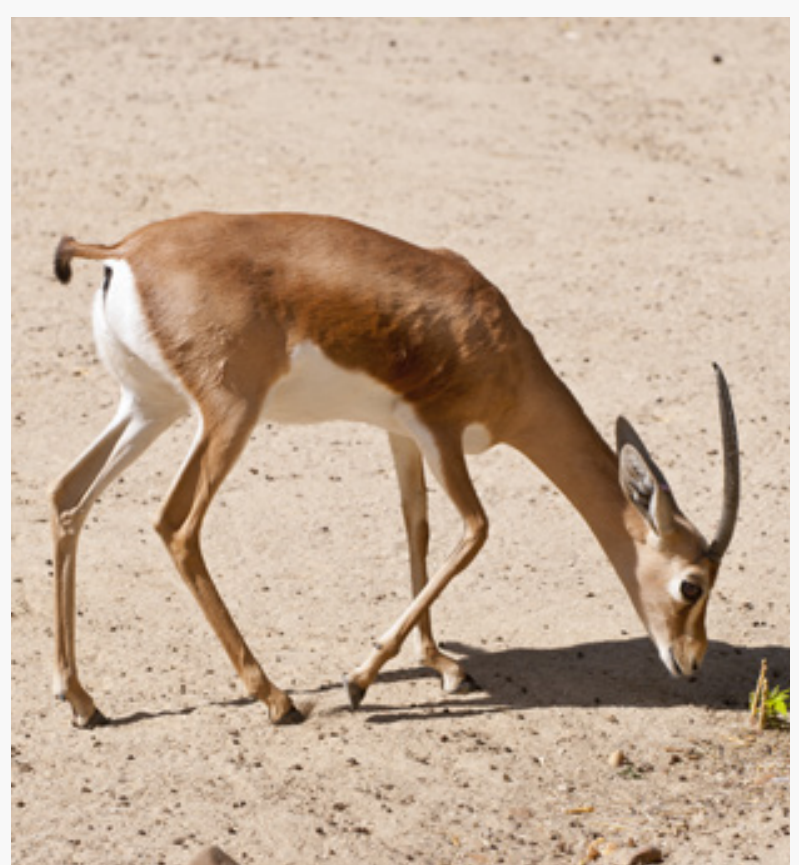

Figure 80: Gazella dorcas (○ Shutterstock) 


\section{Gazella gazella (Pallas, 1766)}

Animalia - Chordata- Mammalia- Artiodactyla- Bovidae

Common name(s): Mountain gazelle, idmi.

Red List status: Critically Endangered ${ }^{\circ}$ A2ac; B1, B2ab (i, ii, iii); C1.

Justification: There has been a continuing decline from Jordan, with a severely fragmented and restricted population. Although possibly extinct, the status was downlisted to CR as population from Palestine could rescue the regional population.

Geographical range: Syria, Palestine, Lebanon, Arabian Peninsula. In Jordan, this species tend to inhabit Aqraba and Salt Mountains (Qumsiyeh et al., 1996).

Population: Population has been declining sharply since 2001 and now is considered very rare.

\section{Area of occupancy}

4

\section{Extent of occurrence}

16

Biogeographical realms: Oriental.

\section{General use and trade information: This species is hunted for its meat in Jordan.}

Threats: The major threats are illegal hunting for meat. Habitat loss and deterioration through agricultural development, fencing pasture for cattle, construction of roads and settlement is also a major threat. A study performed by Eid and Handal, (2018) showed a single specimen killed by hunters and posted on Facebook in 2015.

Conservation actions: This species has a potential habitat in Yarmouk Forest Reserve. In addition it is Listed in Appendix I for wildlife protection of the Agricultural Law Number 13 for the year 2015 based on regulation Number 43 for the year 2008.

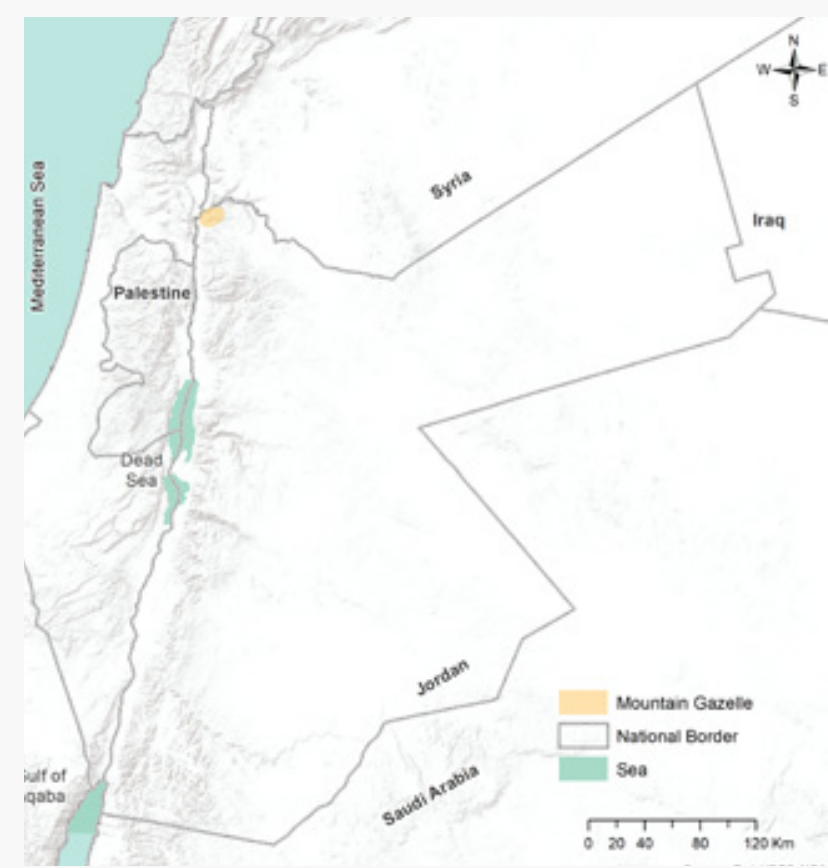

Map 78: Distribution of Gazella gazella in Jordan.

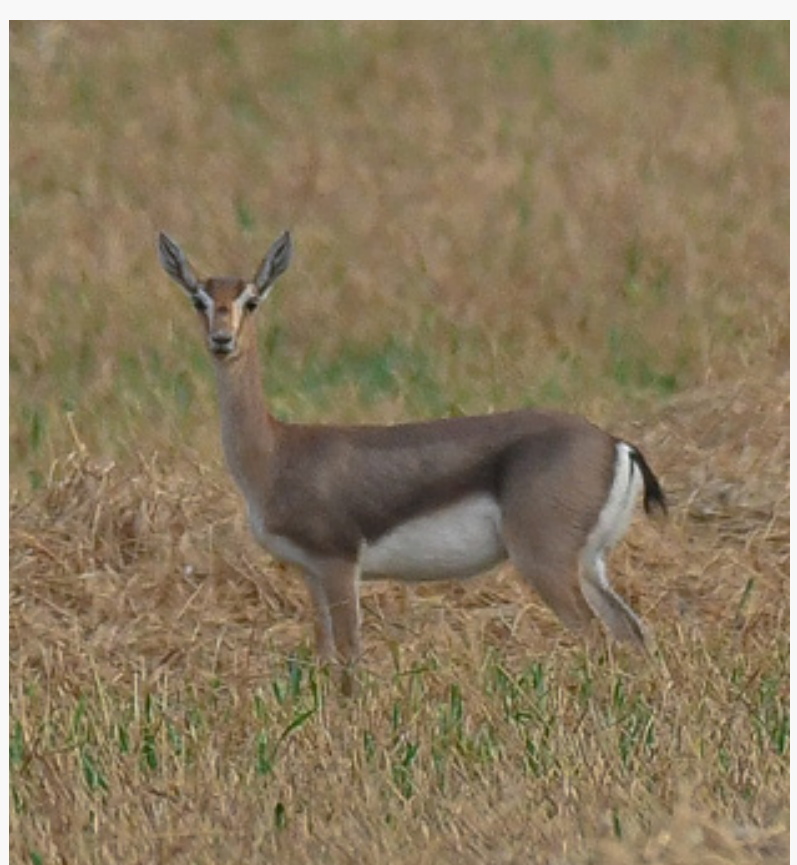

Figure 81: Gazella gazella (@Mohammad Daraghmeh) 


\section{Gazella marica (Güldenstaedt, 1780)}

Animalia - Chordata- Mammalia- Artiodactyla- Bovidae

Common name(s): Goitered gazelle.

Red List status: Critically Endangered A2a, c; C1.

Justification: The population witnessed a sharp decline in Jordan, and the taxon has a very limited distribution across Jordan.

Geographical range: Palestine; Jordan, C Arabia and E Caucasus through Iran; Afghanistan; WC Pakistan; Kazakhstan; Turkmenistan; Uzbekistan; Mongolia; W China. In Jordan, this species is recorded in Al Qatraneh, Safawi, Qa'a Dhuwelia, Burq'a and Al Hadalat (Qumsiyeh et al., 1996).

Population: Rare species, with a very sharp decline it its population and is still a victim of continuing illegal hunting and habitat loss. Kiwan (2001) stated a population of less than 100 individuals mostly concentrated in the eastern desert and in Wadi Araba. A captive-breeding herd is present in the fenced Shaumari Wildlife Reserve but breeding has not been very successful to date. The herd numbered 22 in 1990-91 and 14 in 1994.

\section{Area of occupancy}

28

\section{Extent of occurrence}

Biogeographical realms: Oriental.

General use and trade information: this species is hunted for its meat in Jordan.

Threats: The main threat is illegal hunting (for meat and to a lesser extent for trophies) and habitat loss (due to economic development, conversion to agriculture, increasing numbers of domestic livestock). Some records showed that specimens are live-caught for private collections (E. Eid. personal communication). A study performed by Eid and Handal, (2018) showed 23 specimens killed by hunters and posted on Facebook in 2015.

Conservation actions: This species has a potential habitat at Burqu Protected Area, where the captive breeding population at Shumari reserve can be used for a re-introduction programme. In addition, it is Listed in Appendix I for wildlife protection of the Agricultural Law Number 13 for the year 2015 based on regulation Number 43 for the year 2008.

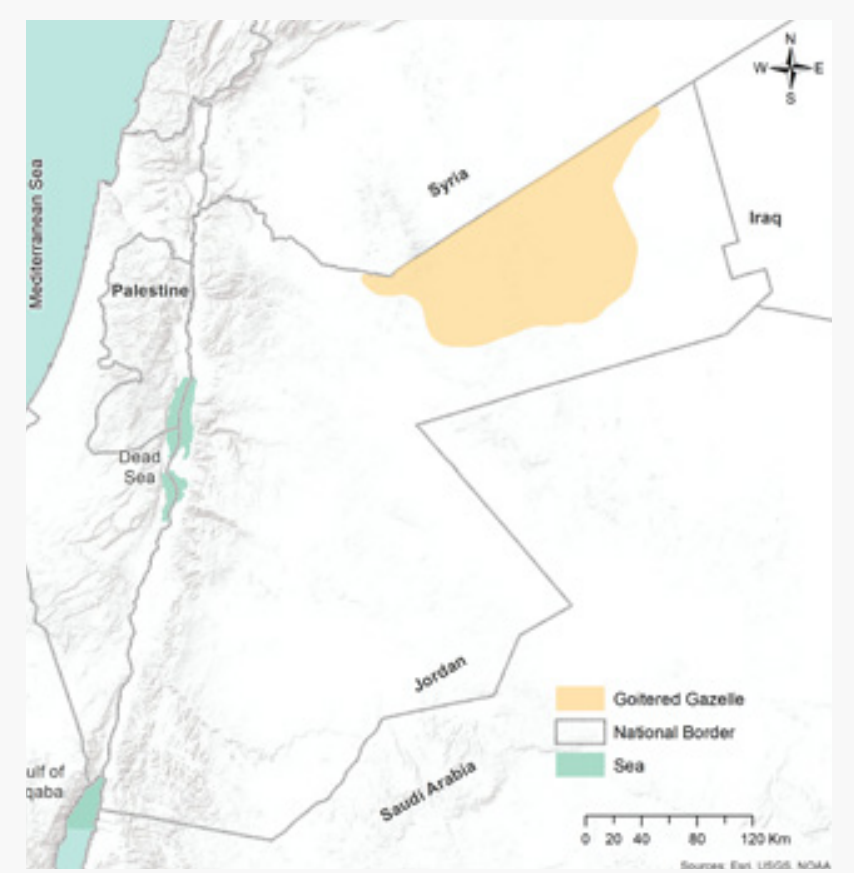

Map 79: Distribution of Gazella subgutturosa in Jordan.

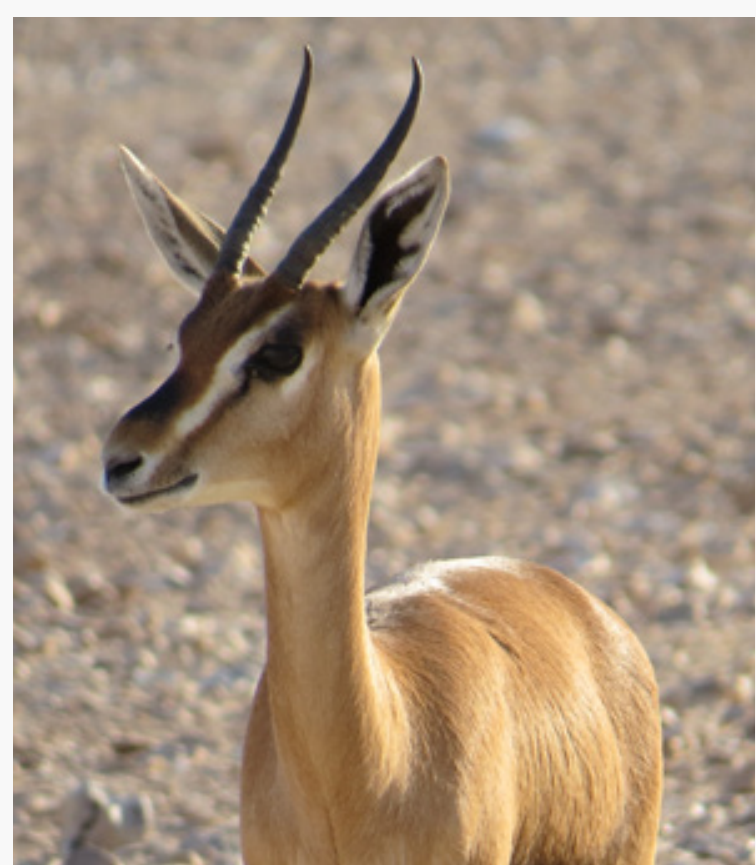

Figure 82: Gazella subgutturosa (○ Ehab Eid) 


\section{Capreolus capreolus (Linnaeus, 1758)}

Animalia - Chordata- Mammalia- Artiodactyla- Bovidae

Common name(s): European roe deer.

Red List status: Critically Endangered A2ac; B1, B2ab (i, ii, iii); C1.

Justification: Rare species with very restricted range of distribution and the population do not exceeds 25 individuals. In Jordan, this species is found in Ajloun Forest Reserve.

Geographical range: It is found through most of Europe (with the exception of Ireland, Cyprus, Corsica, Sardinia, Sicily, and most of the smaller islands), including western Russia (Stubbe, 1999). Outside Europe, it occurs in Turkey, northern Syria, northern Iraq, northern Iran, and the Caucasus (Wilson and Reeder, 2005). It is extinct in Palestine, Jordan and Lebanon (Wilson and Reeder, 2005) (though a re-introduction programme has started in Jordan (Eid and Ananbeh, 2009).

Population: It is declining sharply and restricted to Ajloun area.

\section{Area of occupancy}

4

\section{Extent of occurrence}

12

\section{Biogeographical realms: Palaearctic.}

General use and trade information: This species was not recorded in use or trade from Jordan.

Threats: The main threat is represented by hunting and habitat degradation (Eid and Ananbeh, 2009).

Conservation actions: This species is protected in situ in Ajloun Forest Reserve, after a captive breeding programme ended with releasing 26 individuals at Ajloun reserve (Eid and Ananbeh, 2009).

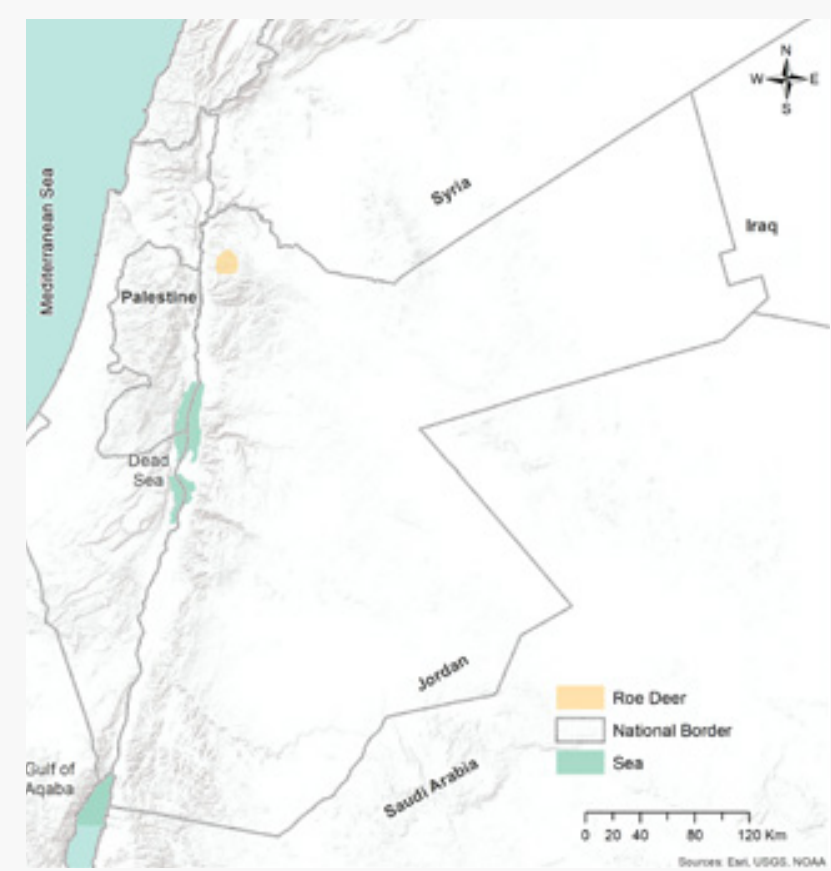

Map 80: Distribution of Capreolus capreolus in Jordan.

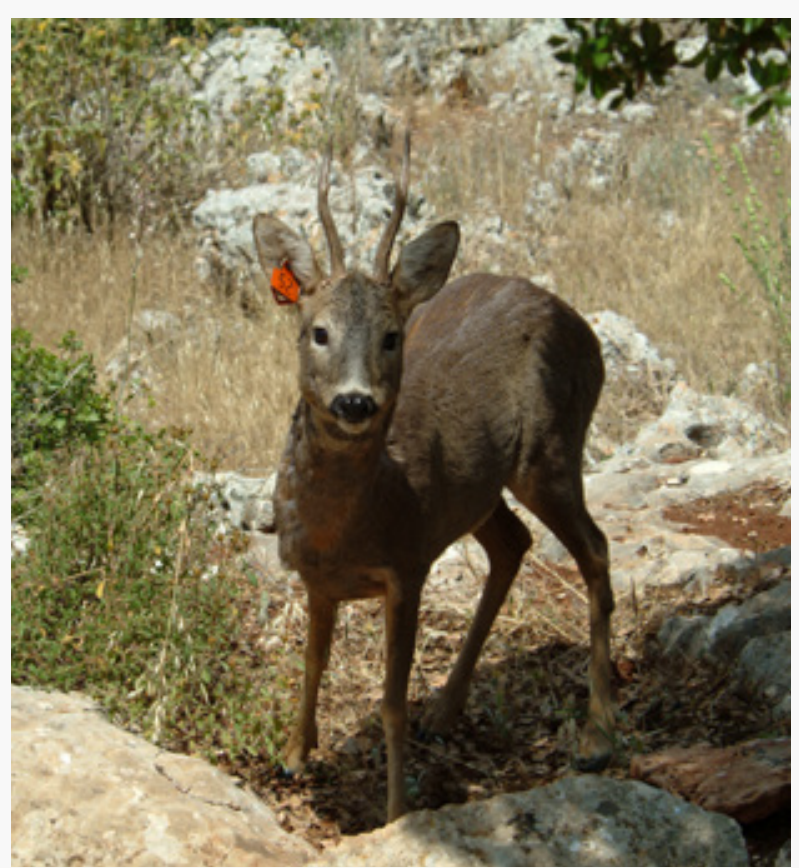

Figure 83: Capreolus capreolus (๑ Khalid Masri) 



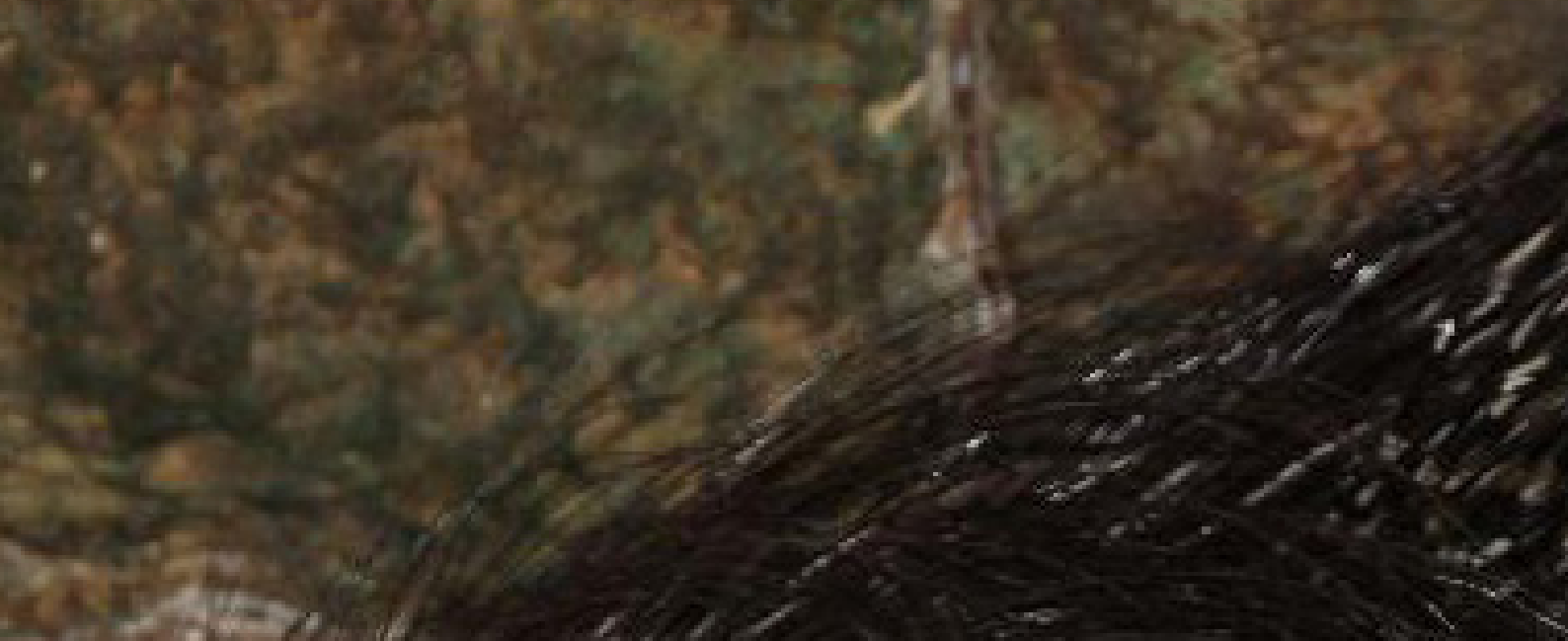

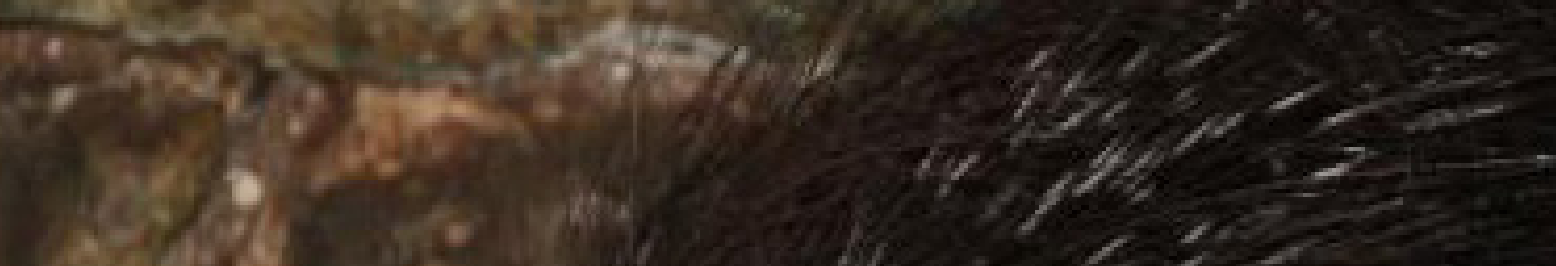

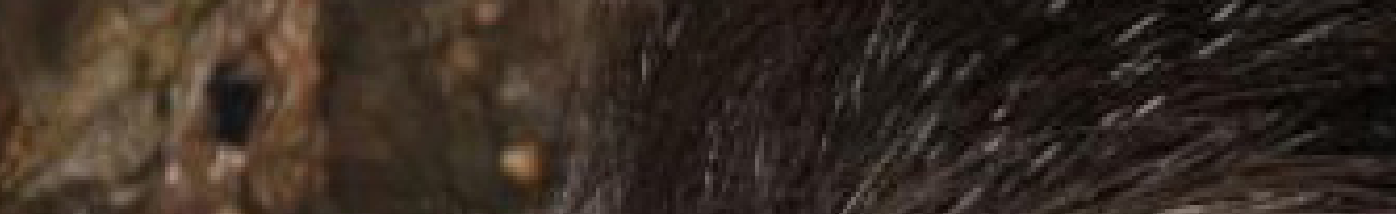

in

ताin

$102^{2}-2$

?

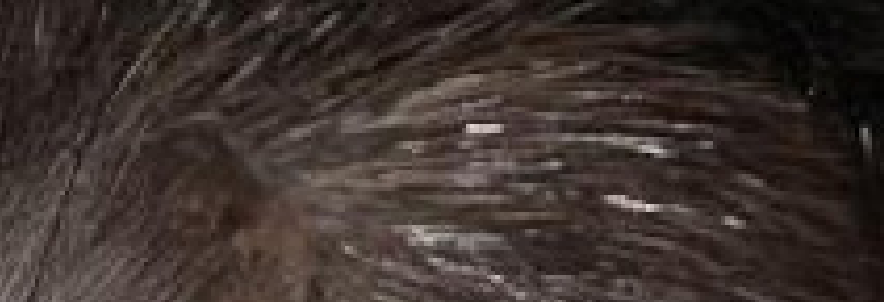

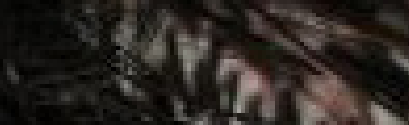

if.

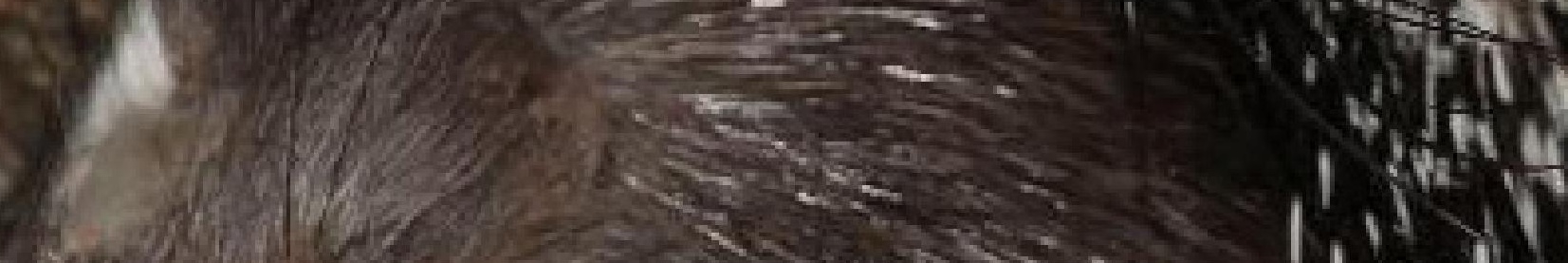

1.1

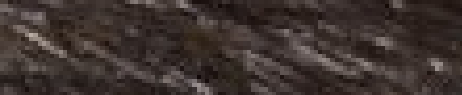

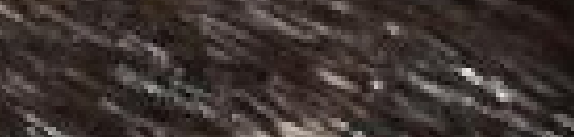

a.

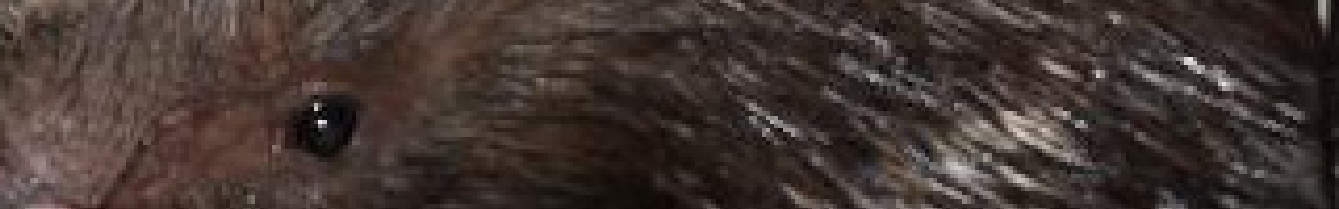

10

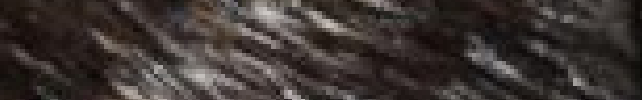

(5.2. himlin $=$

(2) $x^{20}$

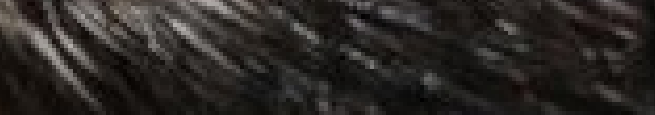

1 12

(c) Elias N. Handal

$8,7=$

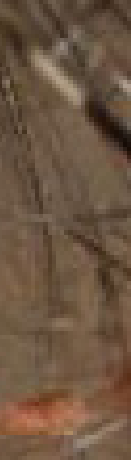

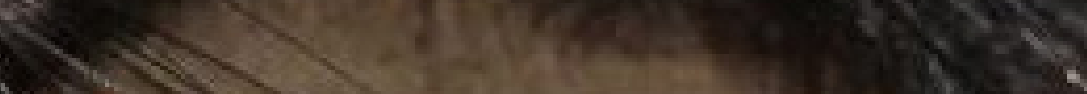

$x=1$
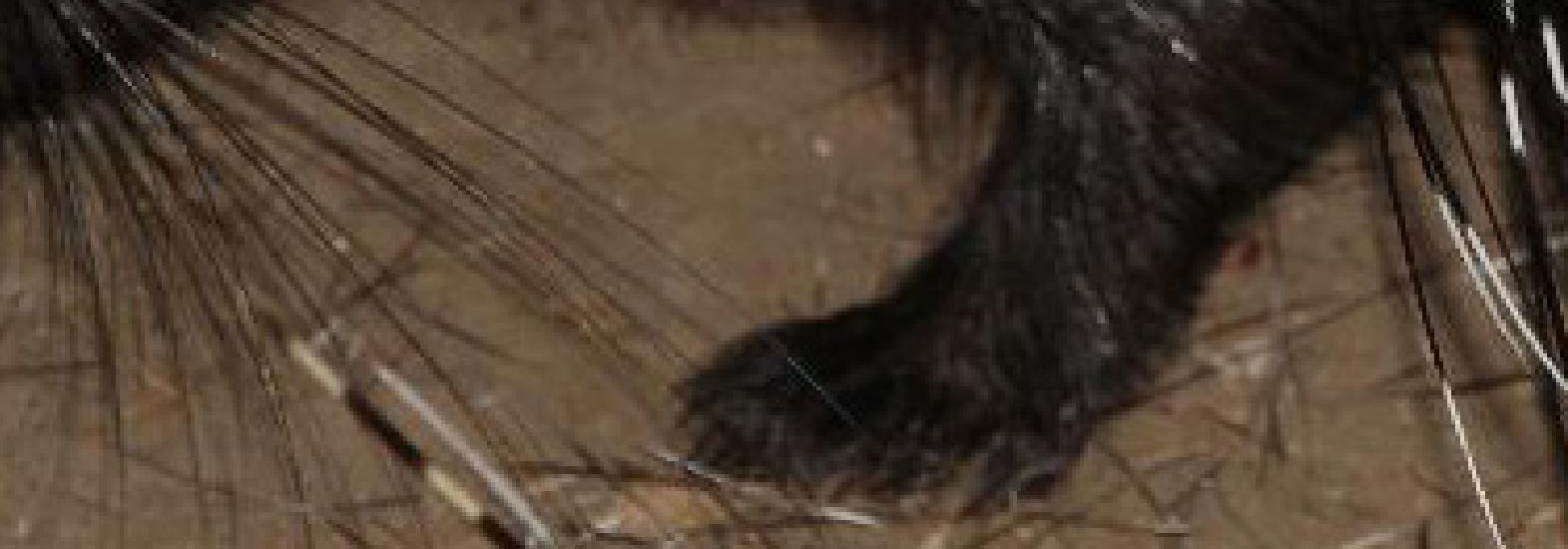

The main threats to mammals identified during the assessment process were illegal hunting, persecution, habitat loss and degradation. Other threats include disturbance through tourism and recreational activities. The following provide a tentative description on each major threat identified. Table 2 below illustrates the collective threats, which are affecting the diversity and population of mammals in Jordan.

\subsection{Illegal hunting and persecution}

Illegal hunting is considered the main cause of the severe decline in the population of large mammalian species especially those which belong to Artiodactyla and Carnivora groups. The populations of other groups such as Lagomorpha and Hyracoidea have been also affected. The main drivers were the introduction of machine guns and four-wheal vehicles in the beginning of nineteenth century. Gazelles, Nubian ibex, striped hyaena, jackal, and the Arabian wolf are among the species that have witnessed a drastic decline in their populations.

Eid and Handal, (2018), provided a detailed study on the magnitude of illegal hunting. Their study showed the hunting of large mammal's especially Nubian ibex and gazelles, with already depleted populations. Overall, the survey indicates an alarming picture of overhunting of threatened species and ineffective enforcement of hunting laws, despite the efforts of key government and non-governmental agencies. The study recommends urgent actions to address the causes of the problem and to improve the management of hunting through better collaboration, mobilization of resources and the raising of awareness.

Mammals also suffer from the illegal perceptions and roomers, which lead to an extensive persecution through shooting (Amr, 2012).

\subsection{Habitat loss and degradation}

Habitat loss and degradation is probably the most detrimental problem facing the biodiversity of Jordan. Agriculture, urbanization, and development took its toll at the expense of wildlife habitats throughout Jordan. Woodcutting in the form of fire wood collection and/or removal of trees to be replaced by agricultural fields has direct and indirect impacts on the natural habitats and the mammalian diversity. Due to the continued logging and forest clearing, many species are now found in fragmented populations separated by roads, farms and houses with limited viable biological corridors between the forest patches. This makes smaller forested areas unsuitable to sustain viable populations of the larger species while at the same time increasing the probabilities of road killing, hunting and other disturbances. Private ownerships, illegal infringements, and forest fires are major factors that have contributed greatly to the loss of habitats and the fragmentation of the forested areas.

Overgrazing or uncontrolled grazing is the main cause of habitat degradation and have negative impacts on mammals and the biodiversity in general due to the direct loss of vegetation and soil erosion. It causes a general decline in the quality of a habitat and affects trophic levels in the ecosystem. In heavily grazed areas of the highland, the loss of ground vegetation contributes to localized landslides, the toppling of trees and in turn the desertification. This will affect the habitats that are used by animals as shelter, feeding and breeding areas, which in consequence will affect negatively the species population and diversity.

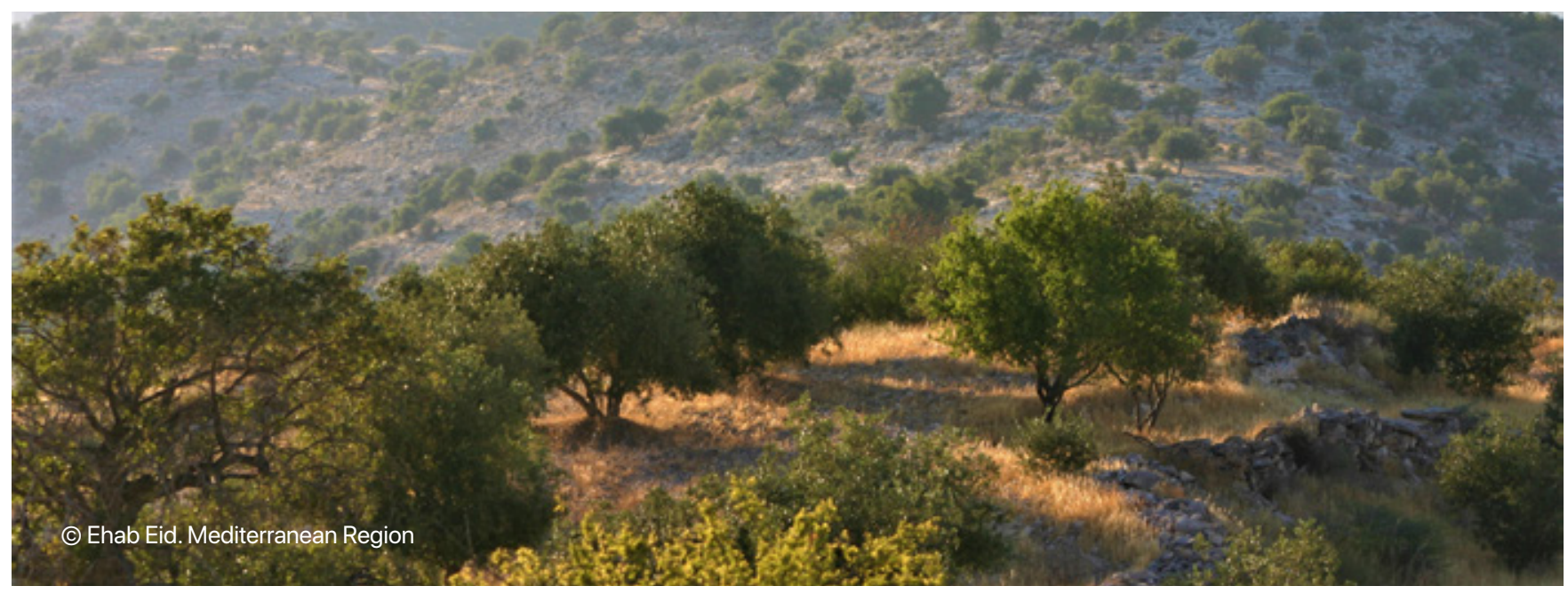




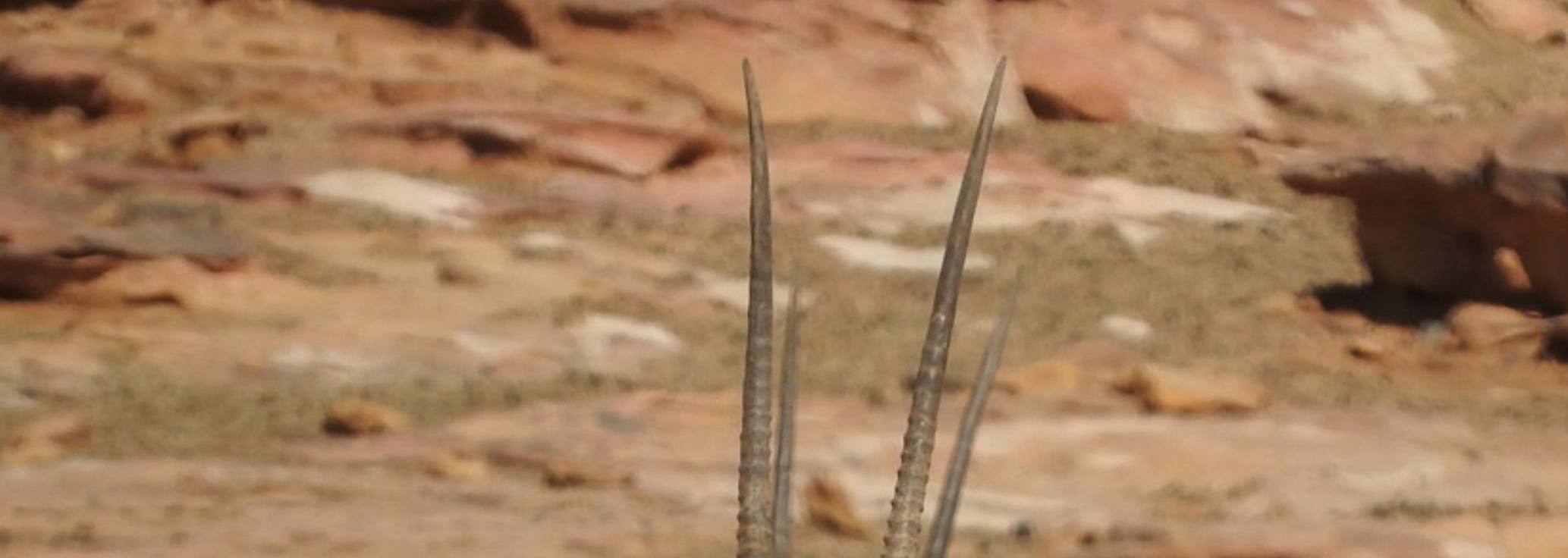

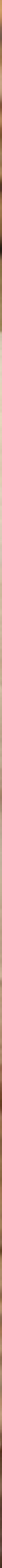
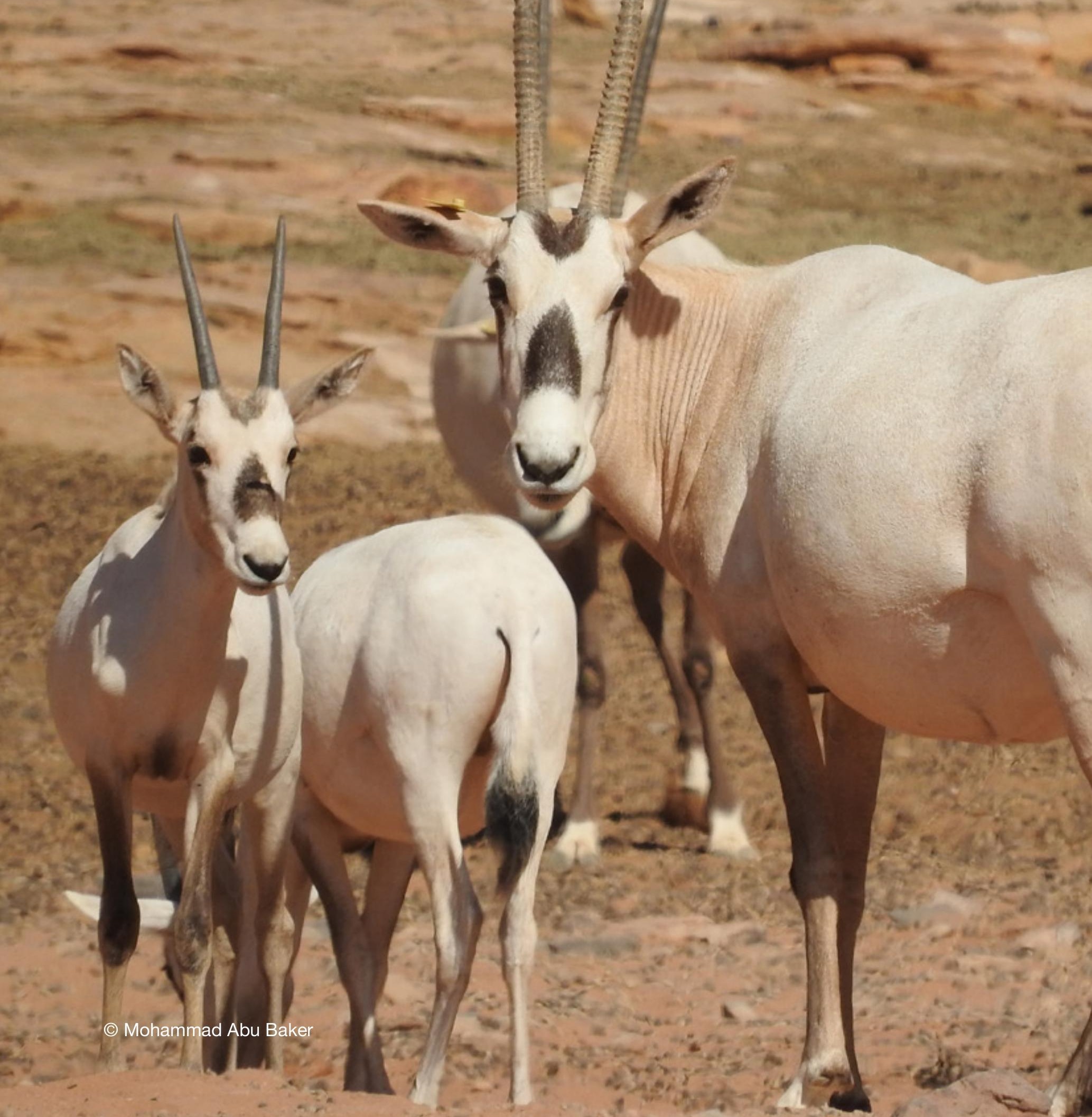

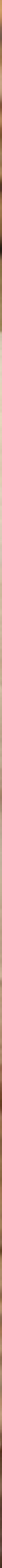

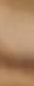
. 


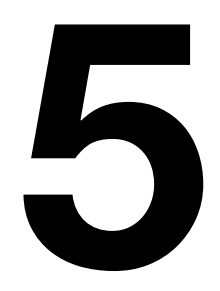

\section{Conservation measures}


Several conservation measures have been established in Jordan aiming to conserve species, habitats and eco-systems either at in situ or ex situ levels. The following provide some of these measures including tentative descriptions for each.

\subsection{In situ conservation measures}

\subsubsection{Legal framework}

Al Tawaha et al, (2019) provided the main legal frameworks, which was developed by the government of Jordan to protect mammals and their habitats. The main three laws are represented by the Environment Protection Law No. 6 for the year 2017, the Agricultural law No. 13 for the year 2015 and the Aqaba Special Economic Zone Law No. 32 for the year 2000 and its amendments. In addition, regulation No. Z/34 for the year 2003 regulates wildlife protection, hunting and trade. This bylaw was issued in accordance to article No. 57, paragraph (A) of the Provisional Agriculture Law No (44) for the year 2002. Bylaw No. 43 for the year 2008 categorized mammals and other wildlife banned from hunting according to its level of protection (Tables ). This bylaw was issued in accordance to article No. 57, paragraph $(H)$ of the Provisional Agriculture Law No (44) for the year 2002. In addition, Regulation No (Z/2) for the year 2009 includes instructions of regulating the International Trade in Endangered Species of Wild Fauna and Flora by virtue of Article (57)

Table 1: Mammals Listed in Appendix I, II and III of bylaw No. 43 for the year 2008 (Amr, 2012)

\begin{tabular}{ll} 
Common name & Scientific name \\
\hline Appendix I & \\
\hline Asiatic jackal & Canis aureus \\
\hline Wolf & Canis lupus \\
\hline Sand fox & Vulpes rueppelli \\
\hline Caracal & Caracal caracal \\
\hline Jungle cat & Felis chaus \\
\hline Sand cat & Felis margarita \\
\hline European otter & Lutra lutra \\
\hline Honey badger & Mellivora capensis \\
\hline Nubian ibex & Capra nubiana \\
\hline Dorcas gazelle & Gazella Dorcas \\
\hline Goitered gazelle & Gazella subgutturosa \\
\hline Arabian oryx & Oryx leucoryx \\
\hline Arabian leopard & Panthera pardus \\
\hline Appendix II & \\
\hline Blanford's fox & Vulpes cana \\
\hline Wild cat & Felis silvestris \\
\hline Egyptian mongoose & Herpestes ichneumon \\
\hline Striped hyena & Hyaena hyaena \\
\hline Stone marten & Martes foina \\
\hline Eurasian badger & Meles meles \\
\hline Marbled polecat & Vormela peregusna \\
\hline Rock hyrax & Procavia capensis \\
\hline Indian crested porcupine indica \\
\hline
\end{tabular}




\begin{tabular}{ll}
\hline Appendix III & \\
\hline East European hedgehog & Erinaceus concolor \\
\hline Long-eared hedgehog & Hemiechinus auritus \\
\hline Desert hedgehog & Paraechinus aethiopicus \\
\hline Lesser white-toothed shrew & Crocidura suaveolens \\
\hline Savi's pigmy shrew & Suncus etruscus \\
\hline Egyptian fruit bat & Rousettus aegyptiacus \\
\hline Long-fingered bat & Myotis capaccini \\
\hline Natterer's bat & Myotis nattereri \\
\hline Cape hare & Lepus capensis \\
\hline Asian garden mouse & Eliomys melanurus \\
\hline Persian squirrel & Sciurus anomalus
\end{tabular}

In addition, Jordan has ratified the CBD, and became a party in 1994. The Directorate of Nature Conservation at the Ministry of Environment acts as the focal point for this convention (Al Tawaha, 2019). The government of Jordan has ratified the CITES convention which came into force in Jordan in 1979. The management authority is shared between three national entities, which are: i) the Ministry of Agriculture, ii) the Royal Society for the Conservation of Nature and iii) Al Mawa for Wildlife and Nature.

\subsubsection{Protected areas}

Protected areas in Jordan are managed by the Royal Society for the Conservation of Nature (RSCN); a nongovernmental organization, mandated by the Ministry of Environment (legal governmental framework body that embraces all environmental issues in Jordan), except for Wadi Rum Protected Area (1997; 742Km²), which is managed by the Aqaba Special Economic Zone Authority (ASEZA). The RSCN has established and managed 12 protected areas to the date of writing this book which are; Shumari Wildlife Reserve (1975; $\left.21 \mathrm{Km}^{2}\right)$, Azraq Wetlands Reserve (1978; 74Km²), Mujib Biosphere Reserve (1985; 212Km²), Ajloun Forest Reserve (1987; 12Km²), Dana Biosphere Reserve (1989; 292 $\left.\mathrm{Km}^{2}\right)$, Dibeen Forest Reserve (2004; 8Km²), Yarmouk Forest Reserve (2010; 21 Km²), Fifa Nature Reserve (2011; $\left.25 \mathrm{Km}^{2}\right)$, Burqu Nature Reserve (2018; 2146 Km²), and Dahek Nature Reserve (2019; $\left.265 \mathrm{Km}^{2}\right)$. These areas represent representative areas of all habitats, and vegetation types in Jordan and harbors some of the remaining populations of threatened large Carnivora and Artiodactyla species.

\subsubsection{Special conservation areas}

So far, seven special conservation areas (SCA) have been established in Jordan, which are Yarmouk SCA, Tal ALArbaeen SCA, AL-Khayouf SCA, Wadi Ibn Hammad SCA, Rahmah SCA, and Aqaba Bird Observatory. Within these areas, management units where set up to work with local partners to recognize and protect the biodiversity significance of these areas. The only managed SCA under the management of RSCN -to the date of writing this document- are Yarmouk, and Aqaba Bird Observatory.

The Royal Botanic Garden was established in Tell Al Rumman and declared as an SCA in Jordan. The site perform tremendous efforts to conserve the floral species and it provide refuge for several mammalian species. Moreover, Al Mawa for Wildlife and Conservation was established in Jerash, under the Princess Alia Foundation to provide a sancturary for rescued animals. The site is hosting several species of mammals and it occupies both in-situ and ex-situ conservation dimensions. 


\subsection{Ex situ conservation measures}

\subsubsection{Al Mawa for Nature and Wildlife}

The Princess Alia Foundation in collaboration with Four Paws established Al Ma'wa for Nature and Wildlife in 2011 to provide a regional solution for rescued wildlife. For that, two entities were established, which are the New Hope Centre, and Al Ma'wa Wildlife Reserve in Jerash. The New Hope Centre serves as the main veterinary clinic; quarantine and rehabilitation facility for all confiscated and rescued wildlife. Animals admitted to the New Hope Centre receive immediate medical care and undergo a rehabilitation programme. Native animals are released back into the wilderness, while either others are returned to their country of origin or they find a permanent home in $\mathrm{Al}$ Ma'wa for Nature and Wildlife, which has a space of 70 hectares.

\subsubsection{Captive breeding and re-introduction programmes}

Several captive breeding programmes were established in Jordan, in order to re-introduce species to the wilderness. The first programme was initiated in 1978 by the RSCN to reintroduce the Arabian Oryx in Shumari Wildlife Reserve (Amr, 2012). This programme was followed by a second programme to reintroduce the Syrian onager; Equus hemionus hemippus in Shumari in 1983 (Boef, 1997). The two programmes are still running until now but no release programme has been conducted. The Nubian ibex was also reintroduced to Mujib Biosphere Reserve in 1989 where the herd was relased to the wilderness in 1997. The last reintroduction programme was conducted in Ajloun Forest Reserve were a herd of 26 roe deers; Capreolus capreolus were released into the wilderness in 2006 (Eid and Ananbeh, 2009).

In addition, ASEZA has initiated two reintroduction programmes, for the Arabian oryx in 2002, and a second programme for the Nubian ibex in 2013, where 60 individuals were released to the wilderness in 2015 . These efforts however remain hindered by the need for the rehabilitation of rangelands and regional cooperation with the reintroduction programmes of migratory species such as the oryx and ibex species (Amr, 2012).

\subsection{Public awareness}

Public awareness of the importance of conservation is a high priority issue in Jordan. NGOs provide awareness programmes to the public and in schools to address wildlife conservation and the importance of biodiversity in Jordan to encourage students to become more involved in conservation. These efforts are needed to change the attitude toward animals in general and reduce unlawful persecution and violations on natural habitats. Several NGOs such as the Royal Society for the Conservation of Nature (RSCN), Al Mawa for Nature and Conservation and the Royal Botanic Garden (RBG) volunteers have participated in these actions through public campaigns and activities advocating for environmental protection. An active Facebook page (@WildlifeofJordan) has been published in order to promote knowledge and awareness toward species diversity in Jordan, and to encourage people to protect those species and their habitats. Training and capacity building programmes have been implemented throughout Jordan targeting environmental practitioners, land use planners, and other institutions to share expertise and to mainstream biodiversity into other sectors such as tourism.

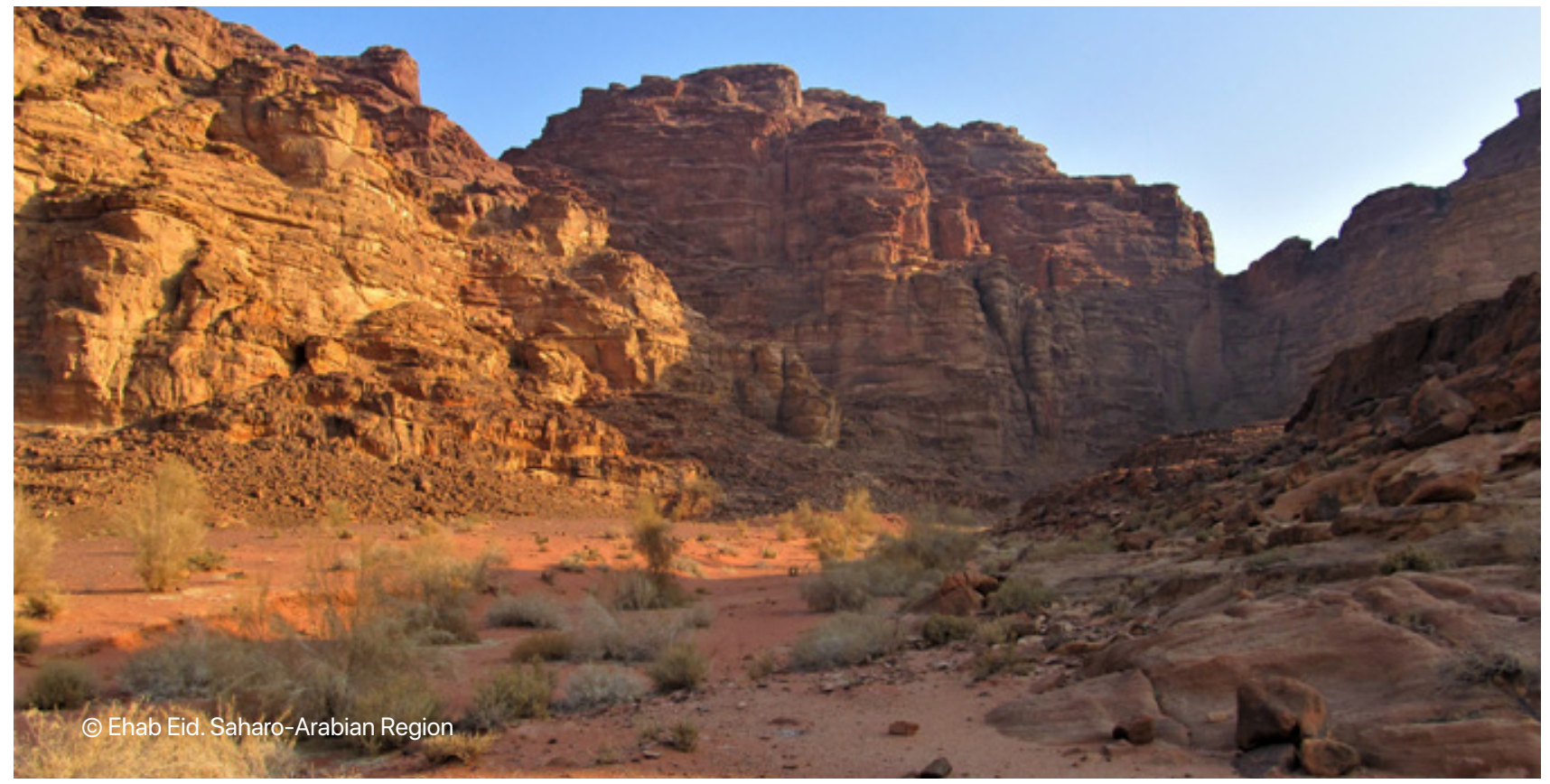





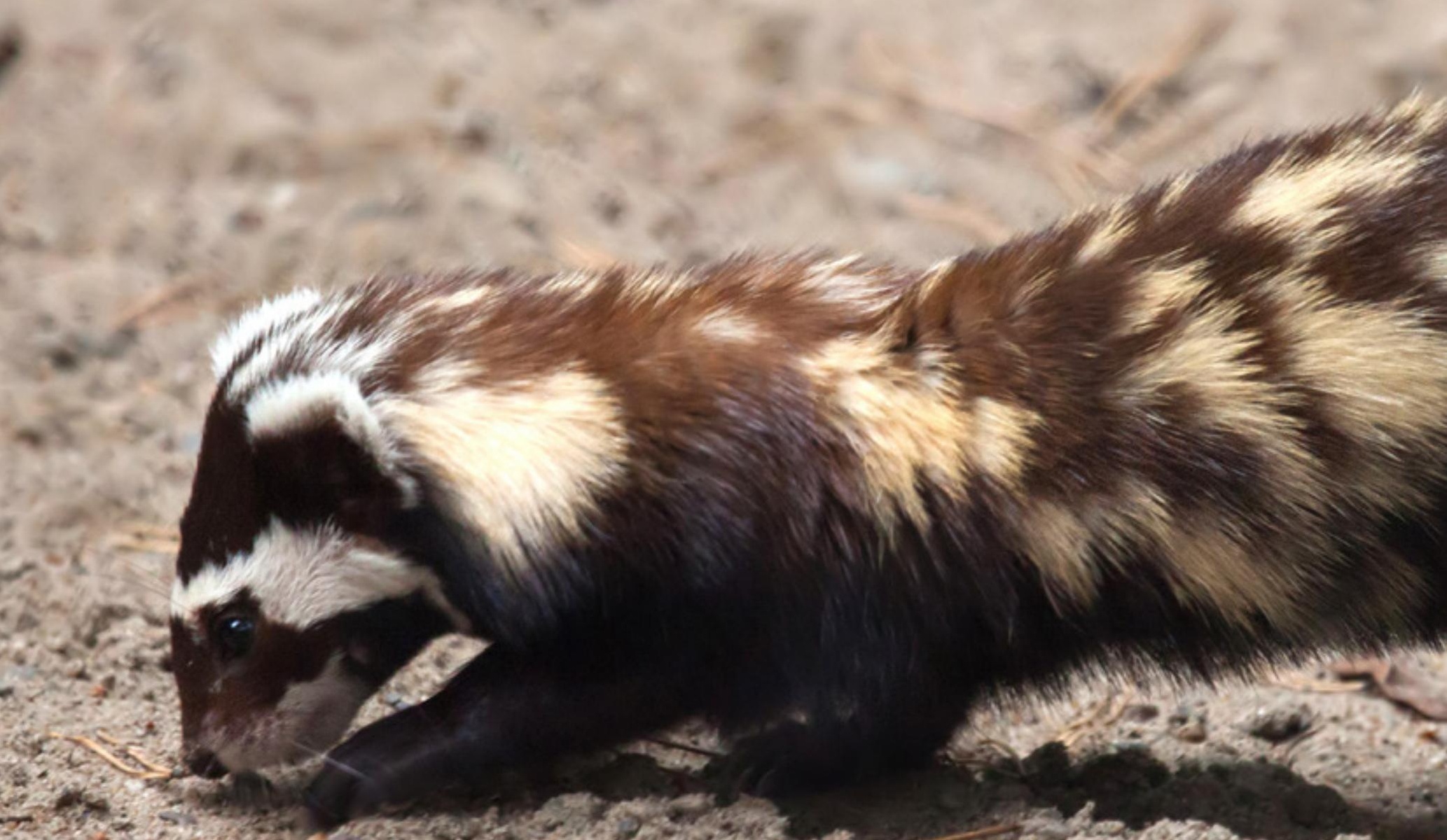

20.52 .

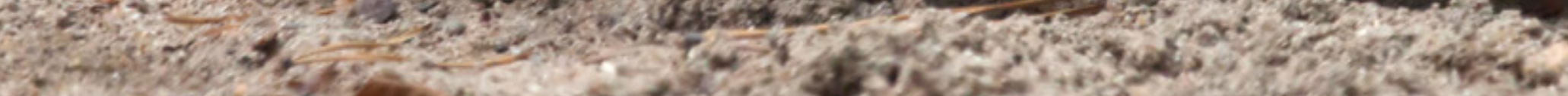

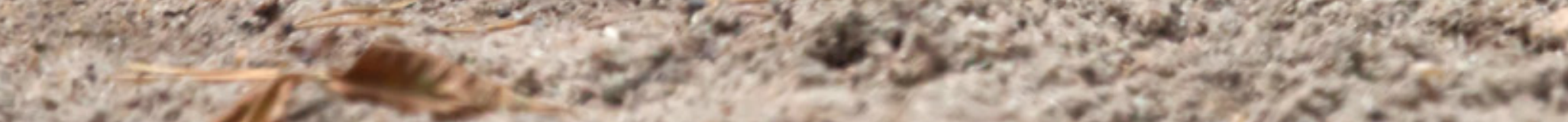

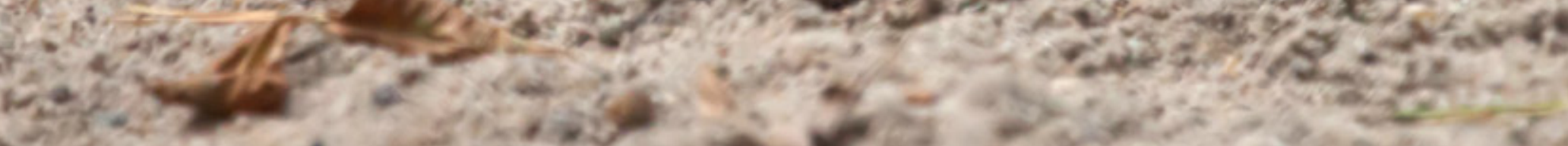

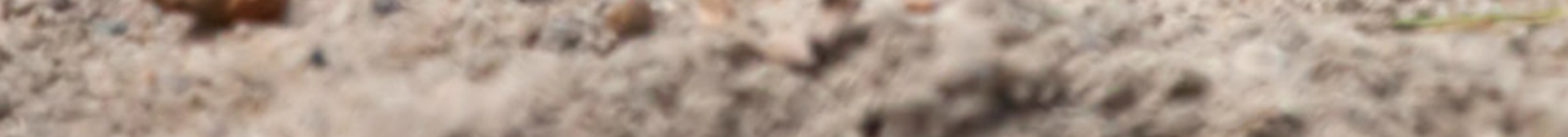

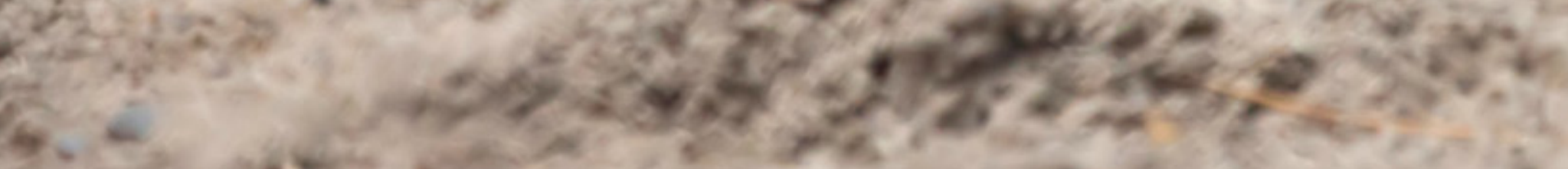

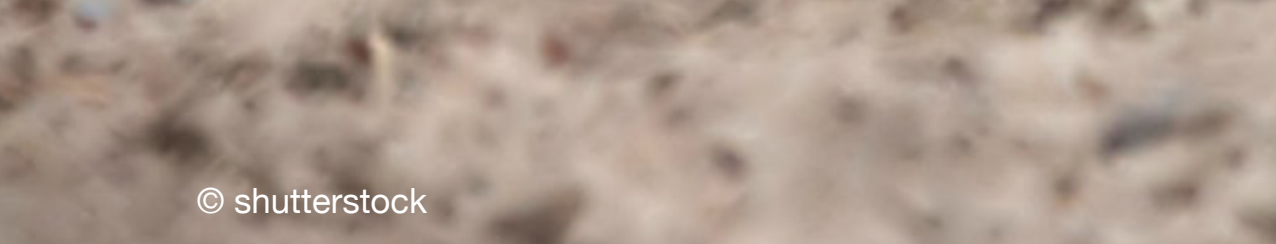




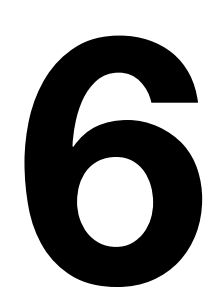

\section{Recommendations}


Currently, active research on the conservation of some species of mammals (e.g. bats, squirrel) in Jordan is in progress. However, further studies on the ecology and conservation of the mammals of Jordan that focus on conservation action plans to preserve the remaining diversity are needed and should be encouraged. Gaps in geographical coverage, data on population size, density and trends should be identified.

Urbanization due to population expansion, agricultural and industrial development remain a threat to biodiversity and mammals in particular. For example, renewable energy projects (wind and solar energy) have boomed in the last few years encroaching into the habitats and wilderness areas and posing a threat to species such as bats. To this end strict policies on the impact assessment of development on the conservation of mammals should be implemented.

Establishing a natural history museum and a zoological garden should be encouraged to enhance the cooperation and documentation of records, as well as increase the public awareness should be a priority. The museum would also implement training programmes in survey methodology and basic ecological research.

Protected areas and special conservation areas are considered the final safeguard areas of wildlife species including mammals. Therefore, it is necessary to invest in conserved areas, and provide them with more support at all levels including technical, and financial. In addition, coordination between entities and experts working in the field of nature conservation is needed for better conservation and management.

The tremendous role provided by the Royal Department for Environmental Protection (Rangers), RSCN, AI Mawa for Nature and other entities have to be strengthened and increased through manpower and training of officers. Therefore more support is urgently needed.

Coordinated campaigns across the country between the relevant NGOs and the media highlighting the ecological importance of mammals should be implemented and the importance of data shared.

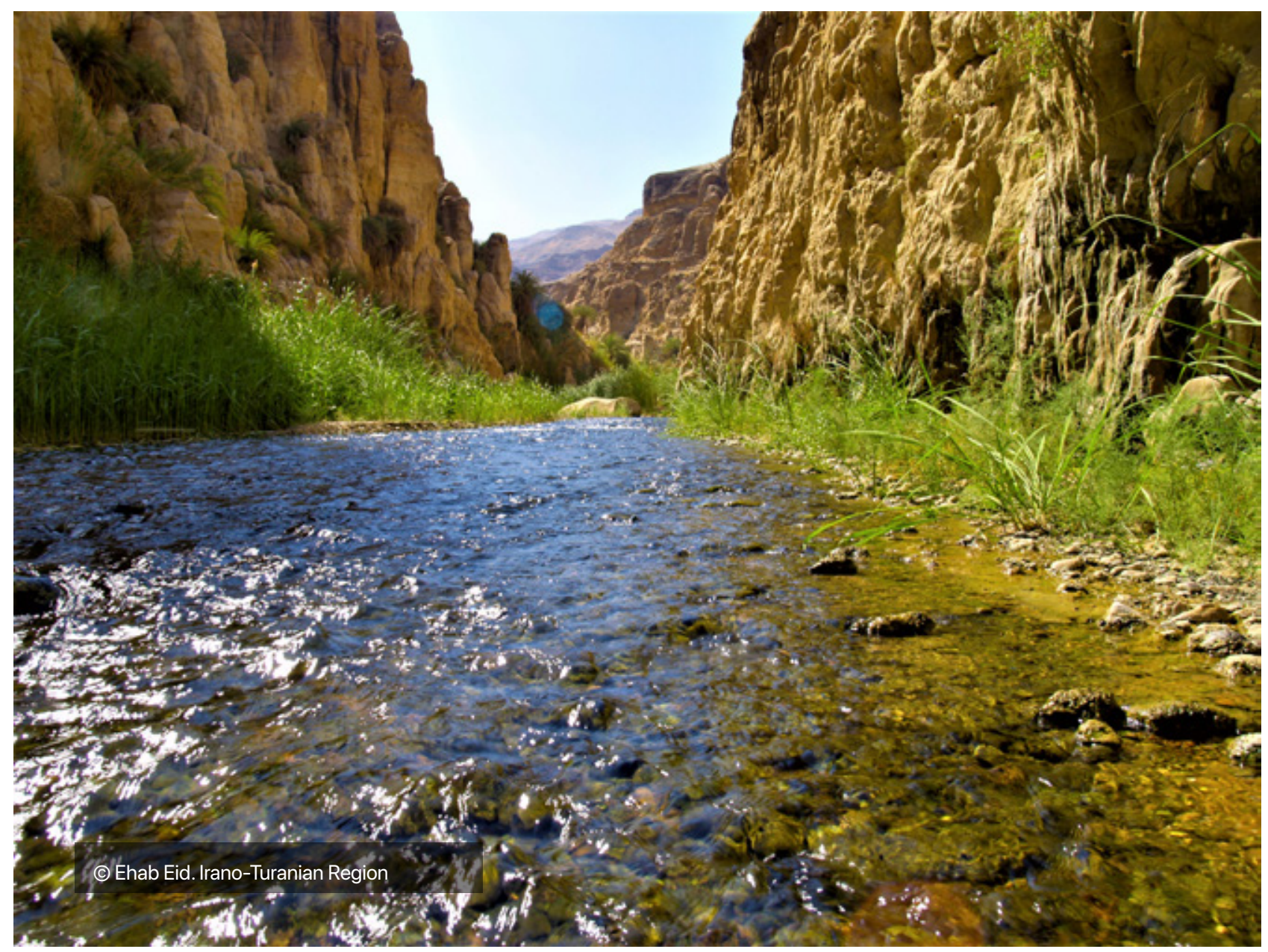




\section{References}

- $\quad$ Abi-Said, M., Outa, N.T., Makhlouf, H., Amr, Z.S., and Eid, E. (2018). 'lllegal Trade in Wildlife Species in Beirut, Lebanon'. Vertebrate Zoology 68(1): 1-4.

- $\quad$ Abu Baker, M. and Amr, Z. (2002). 'Status of the Eurasian Badger, Meles meles, in Jordan (Carnivora: Mustilidae)'. Zoology in the Middle East 27:13-20. https://doi.org/10.1080/09397140.2002.10637936.

- $\quad$ Abu Baker, M. and Amr, Z. (2008). 'Mice of the Genus Apodemus in Jordan'. Vertebrate Zoology 58 (1):127135.

- $\quad$ Abu Baker, M., Al Omari, K., Qarqaz, M., Khaled, Y., Ahmad, Q., and Amr, Z. (2004). 'On the Current Status and Distribution of Blanford's Fox, Vulpes cana Blanford, 1877, in Jordan (Mammalia: Carnivora: Canidae)'. Turkish Journal of Zoology 28:1-6.

- $\quad$ Abu Baker, M., Nassar, K., Rifai, L., Qarqaz, M., Al-Melhim, W. and Amr, Z. (2003). 'On the Current Status and Distribution of the Jungle Cat Felis chaus Güldenstäedt, 1776 in Jordan. (Mammalia: Carnivora: Felidae)'. Zoology in the Middle East 30:5-10. https://doi.org/10.1080/09397140.2003.10637982.

- $\quad$ Al Tawaha, M., Benzoni, F., Eid, E and Abu Awali, A. (2019). 'The Hard Corals of Jordan; a Field Guide'. The Royal Marine Conservation Society of Jordan. Amman, Jordan. ISBN: 978-9957-8740-4-9. 400pp.

- $\quad$ Aloufi, A and Eid, E. (2014). 'Conservation Perspectives of Illegal Animal Trade at Markets in Tabuk, Saudi Arabia'. TRAFFIC Bulletin 26(2): 77-80.

- Aloufi, A., and Eid, E. (2016). 'Zootherapy: A study from the Northwestern region of the Kingdom of Saudi Arabia and the Hashemite Kingdom of Jordan'. Indian journal of traditional knowledge 15(4):561-569.

- $\quad$ Aloufi, A., and Eid, E. (2019). 'Distribution and Morphometric Measurements of Blandford's fox Vulpes cana (Mammalia: Carnivora: Canidae) of the kingdom of Saudi Arabia'. Journal of Threatened Taxa 11(5): 1355713562. https://doi.org/10.11609/jott.4297.11.5.13557-13562.

- $\quad$ Al-Shafee, D. M., Yuosef, M., Al-Melhim, W. N. and Amr, Z. S. (1997). 'The Status of the Stone Marten, Martes foina syriaca (Nehring, 1902), in Jordan'. Zoology in the Middle East 15:5-8. https://doi.org/10.1080/09397 140.1997.10637730.

- $\quad$ Amr Z.S., Hamidan N. and Quatrameez, M. (2004). 'Nature Conservation in Jordan'. Denisia 14: 467-477.

- $\quad$ Amr, Z. (2012). 'Mammals of Jordan'. 2nd Edition. Al Rai Press. Amman, 308 pp.

- $\quad$ Amr, Z. S. (2000). 'Mammals of Jordan'. United Nations Environment Programme. Amman. 116 pp.

- $\quad$ Amr, Z. S., Kalishaw, G., Yosef, M., Chilcot, B, J. and Al-Budari, A. (1996). 'Carnivores of Dana Nature Reserve (Carnivora: Canidae, Hyaenidae and Felidae), Jordan'. Zoology in the Middle East 13:5-16. https:// doi.org/10.1080/09397140.1996.10637701.

- $\quad$ Amr, Z., Abu Baker, M. and Qumsiyeh M. (2006a). 'Bat Diversity and Conservation in Jordan'. Turkish Journal of Zoology 30:235-244.

- Amr, Z., Eid, E., Qarqaz, M. A. and Abu Baker, M. (2006b). 'The Status and Distribution of the Persian Squirrel, Sciurus anomalus, in Dibbeen Nature Reserve'. Zoologische Abhandlungen (Dresden) 55:9-17.

- Amr, Z.S., Abu Baker, M.A., Qumsiyeh, M. and Eid, E. (2018). 'Systematics, Distribution and Ecological Analysis of Rodents in Jordan'. Zootaxa 4397:1-94. https://doi.org/10.11646/zootaxa.4397.1.1.

- $\quad$ Attum, O., Rosenbarger, D., Al Awaji, M., Kramer, A. and Eid, E. (2016). 'Population Size and Artificial Waterhole Use by Striped Hyenas in the Dana Biosphere Reserve, Jordan'. Mammalia. ISSN 1864-1547. https://doi. org/10.1515/mammalia-2015-0155. 
- Benda, P., Lucan, R., Obuch, J., Reiter, A., Andreas, M., Backor, P., Bohnenstengel, T., Eid, K, E., Sevcik, M., Vallo, P and Amr, S, Z. (2010). 'Bats (Mammalia: Chiroptera) of the Eastern Mediterranean and Middle. East. Part 8. Bats of Jordan: Fauna, Ecology, Echolocation, Ectoparasites'. Acta Societatis Zoologicae Bohemicae 74: 185-353.

- Edwards, S., Al Awaji, M., Eid, E., and Attum, O. (2017). 'Mammalian Activity at Artificial Water Sources in Dana Biosphere Reserve, Southern Jordan'. Journal of Arid Environments 02: 141. https://doi.org/10.1016/j. jaridenv.2017.01.015.

- $\quad$ Eid, E. Kh. Ananbeh., Y. (2009). 'Assessment of the Release Program of the European Roe Deer; Capreolus Capreolus (Cetariodactyla: Cervidae) at Ajloun Nature Reserve- Jordan'. Journal of threatened Taxa 1(6): $323-$ 326. https://doi.org/10.11609/JoTT.02103.323-6.

- $\quad$ Eid, E., Al Hasani, I., Al Share, T., Abed, O., Amr. Z. (2010). 'Animal Trade in Amman Local Market, Jordan'. Jordan Journal of Biological Science 4 (2): 101-108.

- $\quad$ Eid, E., Al Share, T., and Aabed, O. (2015). 'Additional Knowledge on the Blanford's Fox Vulpes cana from Jordan'. Canids News 1478-2677.

- Eid, E., and Alatoom. M., (2016). 'The Stone Marten, Martes foina, in Dibeen Forest Reserve, Jordan'. Jordan Journal of Natural History 02: 66.

- $\quad$ Eid, E., and Ananbeh, Y., (2010). ‘Roe Deer in Ajloun Nature Reserve, Jordan'. In: P.S. Soorae (ed.) Global Re-introduction Perspectives: 2010. Additional case-studies from around the Globe, pp.265-268. Abu Dhabi, UAE: IUCN SSC Re-introduction Specialist Group. xii + 352 pp. Available at: https://portals.iucn.org/library/ node/9774.

- $\quad$ Eid, E., and Handal, R. (2018). 'Illegal hunting in Jordan: Using Social Media to Assess Impacts on Wildlife'. Oryx, 52(4). https://doi.org/10.1017/S0030605316001629.

- $\quad$ Eid, E; Boulad, B; Al Share, T; Abed, O; and Hageer, Y. (2013). 'Population density of the Blanford's Fox; Vulpes cana in Jordan'. Vertebrate Zoology. 63 (2): $241-245$.

- Khoury, F., Amr, Z., Hamidan, N., Al Hassani, I., Mir, S., Eid, E and Boulad N. (2011). 'Some Introduced Vertebrate Species to the Hashemite Kingdome of Jordan'. Vertebrate Zoology 62 (3): 435-451.

- Kock, D., Shafie, D. M. and Amr, Z. S. (1993). 'The Jungle Cat, Felis chaus Güldenstaedt, 1776, in Jordan'. Zeitschrift Für Säugetierkunde 58:313-315.

- Qarqaz, M., Abu Baker, M. and Amr, Z. S. (2004). 'Status and Ecology of the Striped Hyaena, Hyaena hyaena, in Jordan'. Zoology in the Middle East 33:87-92. https://doi.org/10.1080/09397140.2004.10638067.

- Qumsiyeh, M. B., Amr, Z. S. and Budairi, A. M. (1996). 'Status and Conservation of Artiodactylia (Mammalia) in Jordan'. Mammalia 60(3):417-430. https://doi.org/10.1515/mamm-1996-0307.

- Qumsiyeh, M. B., Amr, Z. S. and Shafei, D. (1993). 'The Status and Conservation of Carnivores in Jordan'. Mammalia 57(1):55-62. https://doi.org/10.1515/mamm.1993.57.1.55.

- $\quad$ Reuther, C., Rifai, L., Qarcas, M., Abu Baker, M. and Amr, Z. (2001). 'Results of an Initial Field Survey for Otters (Lutra lutra) in Jordan'. IUCN Otter Specialist Group Bulletin 17(2):75-79.

- Rifai, L., Abu Baker, M. and Amr, Z. (2000). 'Ecology, Distribution and Status of the Rock Hyrax, Procavia capensis syriaca (Schreber, 1784), in Jordan'. Zoology in the Middle East 21:19-26. https://doi.org/10.1080 /09397140.2000.10637829.

- $\quad$ Rifai, L., Al-Shafee, D., Al-Melhim, W. and Amr, Z. S. (1999). 'Status of the Marbled Polecat, Vormela peregusna (Güldenstaedt, 1770), in Jordan'. Zoology in the Middle East 17:5-8. https://doi.org/10.1080/093 97140.1999 .10637764$.

- $\quad$ The Encyclopedia of Mammals. Oxford University Press, Oxford. 


\section{IUCN}

INTERNATIONAL UNION FOR CONSERVATION OF NATURE Regional Office for West Asia (ROWA) Abdel Latif Salah street, bldg. 29

P.O.Box 942230 Amman 11194, Jordan Tel: +962 6 5546912/3/4

Fax: +962 65546915

E-mail: westasia@iucn.org www.iucn.org

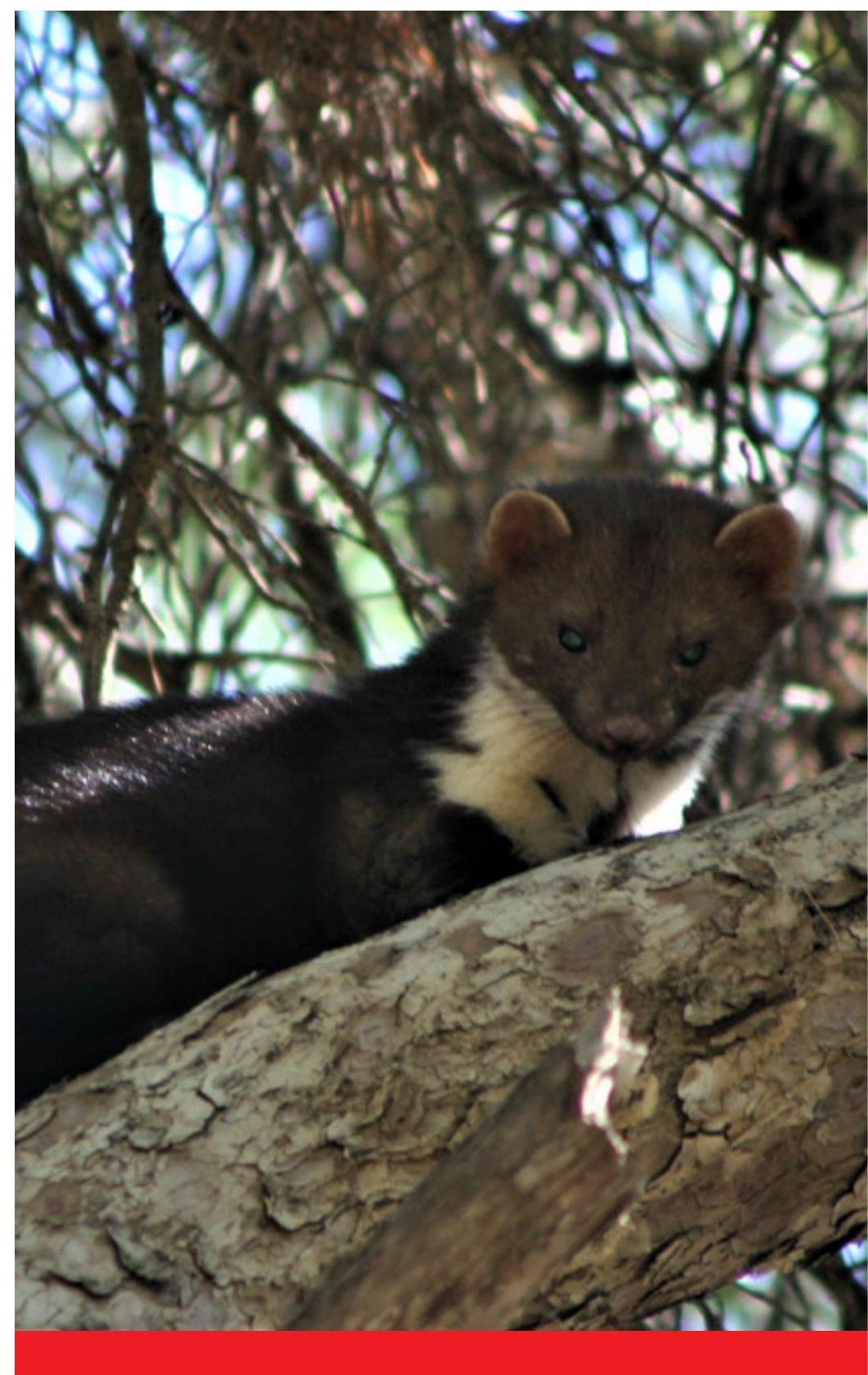

